FINAL REPORT

\title{
Superconducting Open-Gradient Magnetic Separation for the Pretreatment of Radioactive or Mixed Waste Vitrification Feeds:
}

\author{
by \\ L. Nunez ${ }^{1}$, M.D. Kaminsky ${ }^{1}$, R.D. Doctor ${ }^{2}$, \\ C. Crawford*, J.A. Ritter** \\ ${ }^{1}$ Chemical Technology Section \\ ${ }^{2}$ Energy Systems Division \\ for \\ Environmental Management Science Program (EMSP)-96
}

December 1999

The submitted manuscript has been created by
the University of Chicago as Operator of
Argonne National Laboratory ("Argonne") under
Contract No. W-31-109-Eng-38 with the U.S.
Department of Energy. The U.S. Government
retains for itself, and others acting on behalf, a
paid-up, nonexclusive, irrevocable worldwide
license and said article to reproduce, prepare
derivative works, distribute copies to the public,
and perform publicly and display publicly, by or
on behalf of the Government.




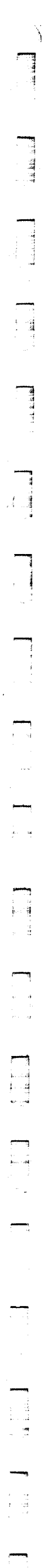


Superconducting Open-Gradient Magnetic Separation for the Pretreatment of Radioactive or Mixed Waste Vitrification Feeds:

Progress Report

\author{
L. Nuñez, M. D. Kaminski, R. Doctor, C. Crawford*, J. A. Ritter** \\ Energy Systems and Chemical Technology Divisions \\ Argonne National Laboratory \\ Argonne, Illinois
}

Vitrification has been selected as a final waste form technology in the U.S. for long-term storage of high-level radioactive wastes (HLW). However, a foreseeable problem during vitrification in some waste feed streams lies in the presence of elements (e.g., transition metals) in the HLW that may cause instabilities in the final glass product. The formation of spinel compounds, such as $\mathrm{Fe}_{3} \mathrm{O}_{4}$ and $\mathrm{FeCrO}_{4}$, results in glass phase separation and reduces vitrifier lifetime and the durability of the final waste form. A superconducting open gradient magnetic separation (OGMS) system may be suitable for the removal of the deleterious transition elements (e.g. Fe, Cr, $\mathrm{Co}$, and $\mathrm{Ni}$ ) and other elements (lanthanides) from vitrification feed streams due to their ferromagnetic or paramagnetic nature. The OGMS systems are designed to deflect and collect paramagnetic minerals as they interact with a magnetic field gradient. This system has the potential to reduce the volume of HLW for vitrification and ensure a stable product. In order to design efficient OGMS and high gradient magnetic separation (HGMS) processes, a fundamental understanding of the physical and chemical properties of the waste feed streams is required. Various simulant waste streams (solid-solid and solid-liquid) from the Savannah River Technology Center, Hanford, and Rocky Flats sites were physically and chemically characterized. These waste streams were evaluated by using breakthrough curves to describe processing characteristics in an HGMS separator. The effluents will be used as a feed into an OGMS system. Computer trajectory models were also developed to predict the separation capability for a superconducting OGMS system. Sorption studies were used to determine the partitioning of the hazardous or radioactive elements. These sorption studies provided the optimal $\mathrm{pH}$ for separation of various spinel phases $\left(\mathrm{Fe}_{3} \mathrm{O}_{4}, \mathrm{MgFe}_{2} \mathrm{O}_{4}, \mathrm{NiFe}_{2} \mathrm{O}_{4}\right)$ and the maximum partitioning of the metals onto a solid mineral phases. Furthermore, the OGMS unit was outfitted with an HGMS prefilter and modified to handle both radioactive solids and slurry waste streams. An economic evaluation of the OGMS process is included.

\footnotetext{
*Westinghouse Savannah River Company

Savannah River Technology Center

Aiken, South Carolina

**Chemical Engineering Department

University of South Carolina

Columbia, South Carolina
} 


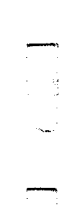




\section{TABLE OF CONTENTS}

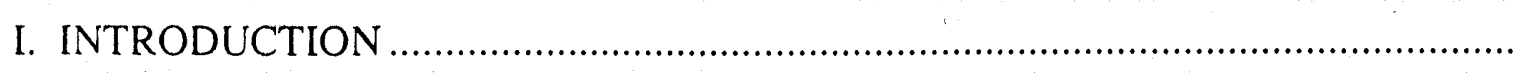

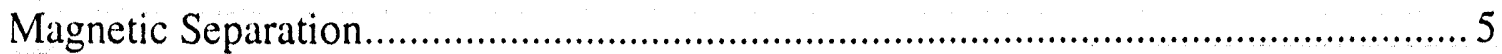

II. EXPERIMENTAL

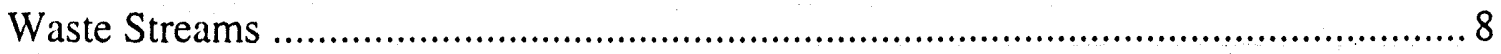

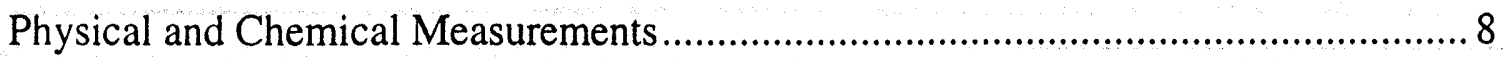

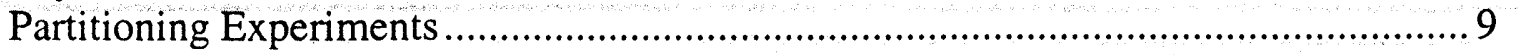

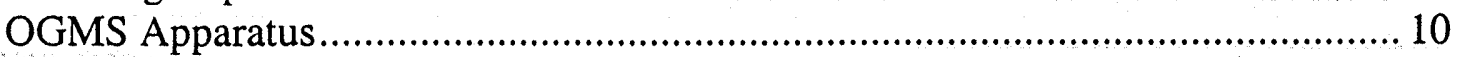

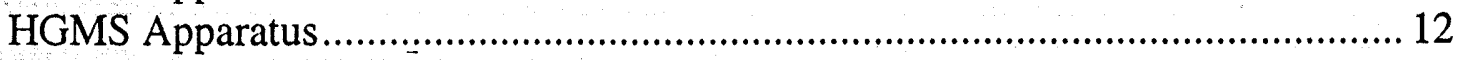

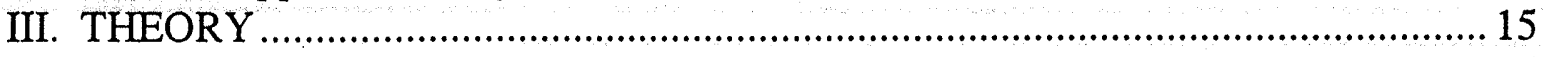

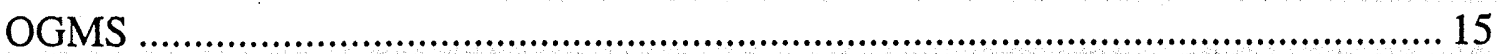

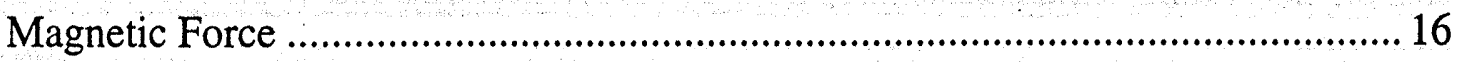

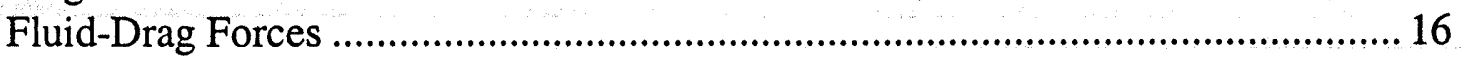

Gravitational and Buoyancy Forces ................................................................ 17

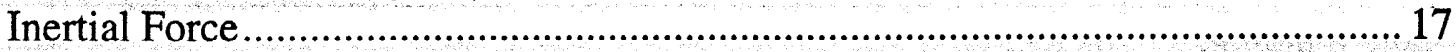

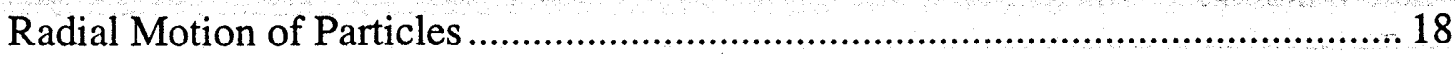

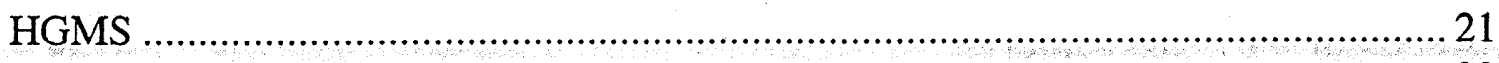

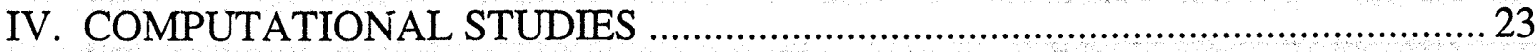

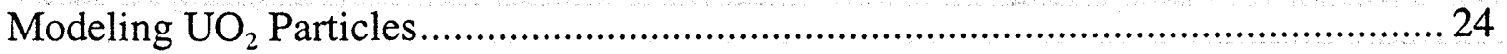

Modeling $\mathrm{PuO}_{2}$ Particles ................................................................................... 27

Modeling Other Components ………........................................................................ 30

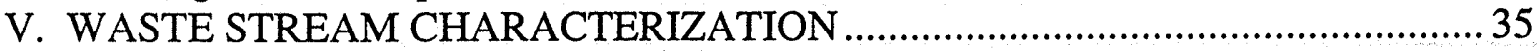

Hanford CIF Fly Ash and C-103 Sludge Simulants .................................................35

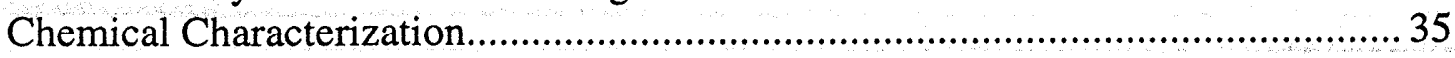

CIF Fly Ash Microstructure.......................................................................... 37

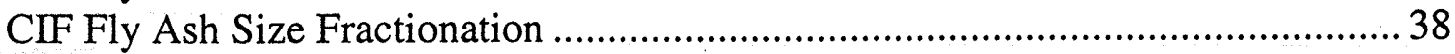

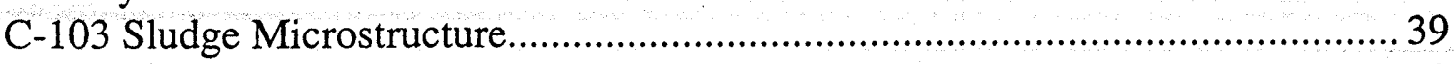

CIF and Hanford Tank C-103 Magnetic Characterization ...................................... 39

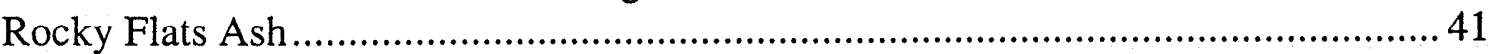

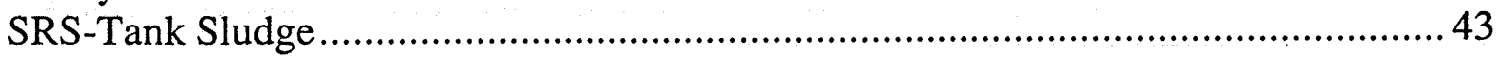

Chemical Characterization..................................................................................4 43

Microstructural Characterizations.................................................................... 45

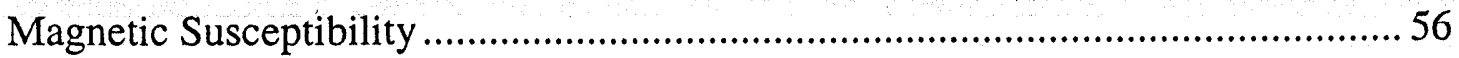

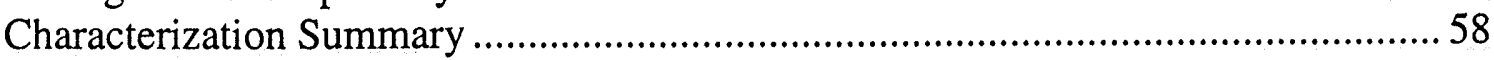

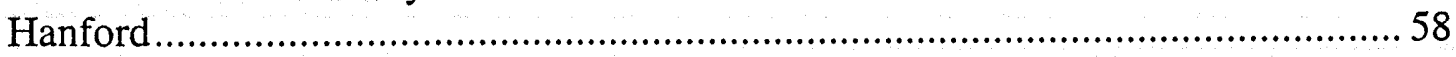

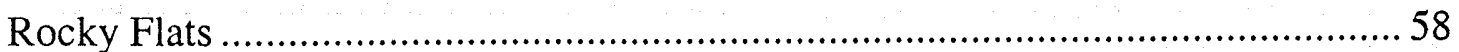

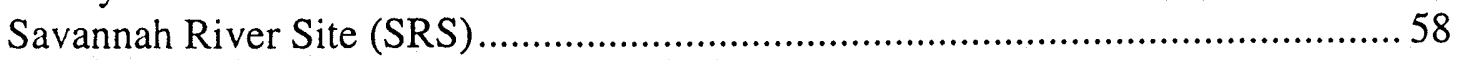

VI. RADIONUCLIDE SORPTION ON SPINEL PHASES ....................................... 59

Sorption Theory for Oxide Surfaces ..............................................................60

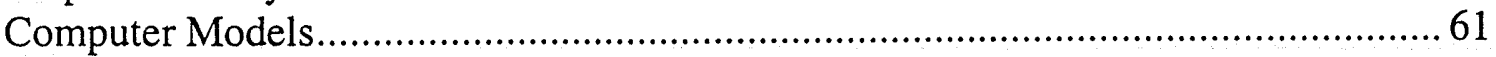

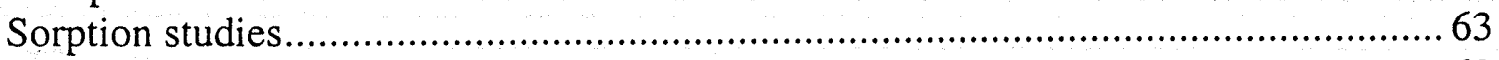

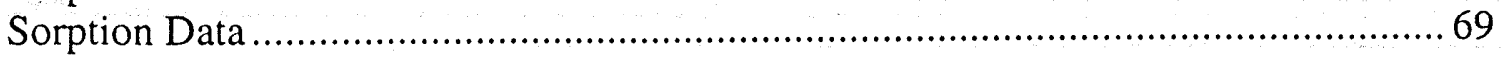

Suggested Experimental Studies ..................................................................... 71

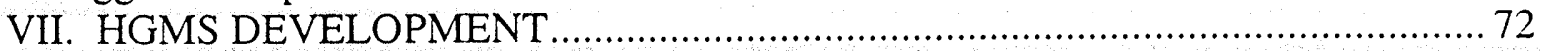

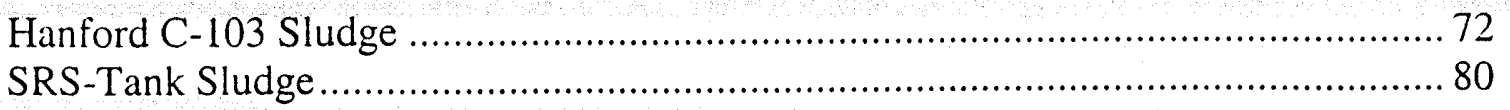


VIII. ENGINEERING HGMS/OGMS APPARATUS ….......................................... 82

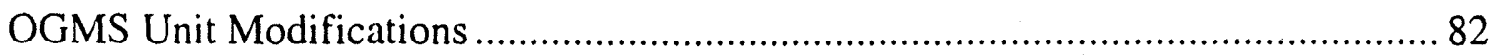

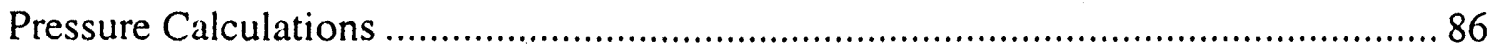

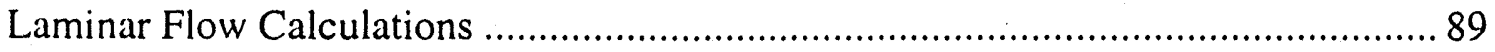

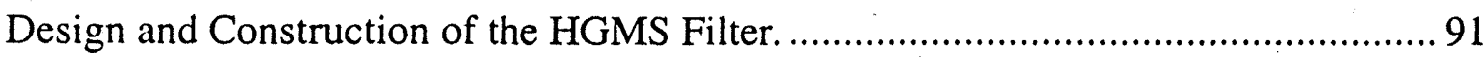

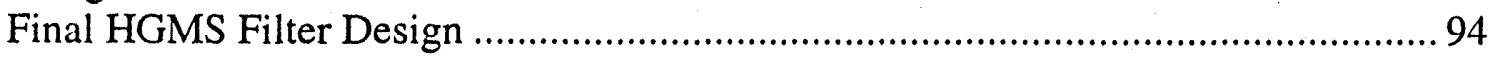

Magnetic Field Profile Model........................................................................ 96

IX. OPEN-GRADIENT MAGNETIC SEPARATION: COSTS ………...................... 102

Open-Gradient Magnetic Separation-Overview for Field Application.......................102

Commercial Development of Magnetic Separation................................................... 103

Soil Remediation Using a Segmented-Gate System - Rocky Flats Application ....... 103

Soils: Open-Gradient Magnetic Separation Linked to the Segmented Gate ...............104

Tank Sludge: Open-Gradient Magnetic Separation Linked to the Segmented Gate..105

Open-Gradient Magnetic Separation Conceptual Scheme .......................................... 105

Superconducting Quadrupole Magnet Annualized Costs ......................................... 107

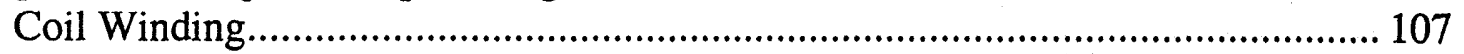

Ancillary Equipment ............................................................................... 108

Suspect Soil Throughput Rates.........................................................................109

Annualized Operating Costs ................................................................... 110

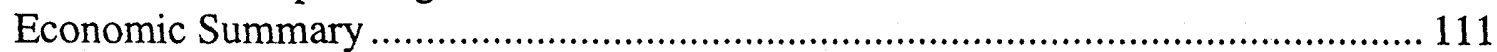

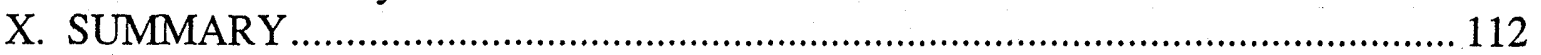

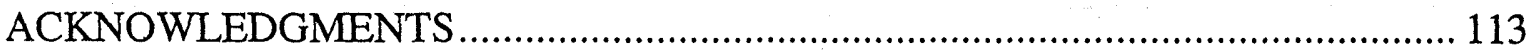

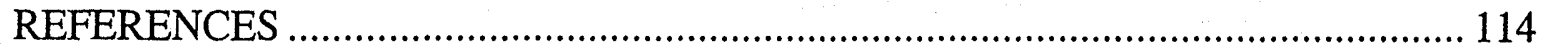

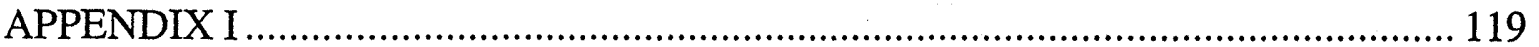

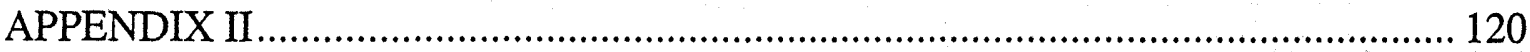

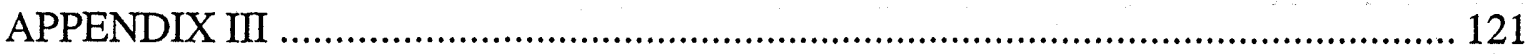

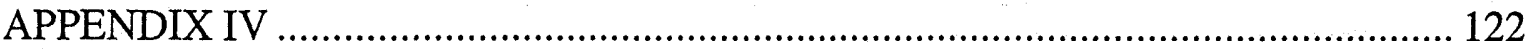

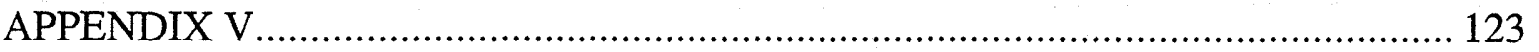




\section{INTRODUCTION}

An open-gradient magnetic separation (OGMS) process is being considered to separate deleterious elements from radioactive and mixed waste streams prior to vitrification or stabilization. By physically segregating solid wastes and slurries based on the magnetic properties of the solid constituents, this potentially low-cost process may serve the U.S. Department of Energy (DOE) by reducing the large quantities of glass produced from defense-related high-level waste (HLW). Furthermore, the separation of deleterious elements from low-level waste (LLW) also can reduce the total quantity of waste produced in LLW immobilization activities.

Many HLW and LLW waste streams at both Hanford and the Savannah River Site (SRS) include constituents deleterious to the durability of borosilicate glass and the melter many of the constituents also possess paramagnetism. For example, $\mathrm{Fe}, \mathrm{Cr}, \mathrm{Ni}$, and other transition metals may limit the waste loading and affect the durability of the glass by forming spinel phases at the high operating temperature used in vitrification. Some magnetic spinel phases observed in glass formation are magnetite $\left(\mathrm{Fe}_{3} \mathrm{O}_{4}\right)$, chromite $\left(\mathrm{FeCrO}_{4}\right)$, and others $\left[(\mathrm{Fe}, \mathrm{Ni}, \mathrm{Mg}, \mathrm{Zn}, \mathrm{Mn})(\mathrm{Al}, \mathrm{Fe}, \mathrm{Ti}, \mathrm{Cr}) \mathrm{O}_{4}\right]$ as described elsewhere [Bates-1994, Wronkiewicz-1994] Stable spinel phases can cause segregation between the glass and the crystalline phases. As a consequence of the difference in density, the spinel phases tend to accumulate at the bottom of the glass melter, which decreases the conductivity and melter lifetime [Sproull-1993].

Crystallization also can affect glass durability [Jantzen-1985, Turcotte1979, Buechele-1990] by changing the chemical composition of the matrix glass surrounding the crystals or causing stress at the glass/crystal interface. These are some of the effects that can increase leaching [Jantzen-1985]. A SRS glass that was partially crystallized to contain $10 \%$ vol. crystals composed of spinels, nepheline, and acmite phases showed minimal changes in short term leachability [Jantzen-1985, Hench-1982]. However, Jantzen et al. found that leaching increased preferentially at grain boundary interfaces [Jantzen-1985]. For a SRL 165 glass crystallized up to $30 \%$ vol., leachability 
measured by normalized boron release increased by a factor of three compared to the uncrystallized glass [Kelly-1975, Plodinec-1979]. In general, the magnitude of the crystallization effect depends highly on glass composition and cooling rate. The current SRS HLW sludge ${ }^{11 \cdot 12}$ varies in $\mathrm{Fe}_{2} \mathrm{O}_{3}$ content from 4.5-46.9\% wt. and the composition of other transition metals $(\mathrm{Ni}, \mathrm{Cr}$ ) from $0.4-8 \%$ wt. Other waste streams can benefit from OGMS processing, such as the low-level mixed waste from Oak Ridge, particularly, the Central Neutralization Facility (CNF) sludge containing up to $26 \%$ wt. iron which presents a challenge for vitrification at SRS.

The development of OGMS is intended to reduce processing costs and maximize melter lifetime. Optimization of an OGMS system involves identifying the heterogeneous mineral phases present in the waste and the sorption behavior of target radionuclides onto the mineral phases. The program discussed in this report addresses feasibility and optimization of an OGMS system for separating paramagnetic constituents (transition metals and actinide minerals) from DOE waste streams targeted for vitrification. We have investigated; (1) the mineral composition and physical and chemical properties of the constituents in a host of waste materials, (2) separation characteristics based on a particle trajectory model and the OGMS test facility, (3) the use of a high-gradient magnetic separator (HGMS) to increase separation efficiency and function as a prefilter to the OGMS for highly magnetic waste streams, (4) the disposition of radionuclides reversibly bound to magnetic minerals typically found in the wastes, and (6) the engineering of an integrated HGMS/OGMS test unit for the treatment of radioactive slurries and solids.

\section{Magnetic Separation}

OGMS is based on a particle's behavior in a magnetic field (see Figure I-1). Paramagnetic particles (e.g., U, Pu, ferrite, pyrite) are deflected when free falling in an applied magnetic field and attracted toward the outer bore wall of the magnet. Diamagnetic particles (e.g., clay, alkali and Al salts) are repelled from the magnetic field toward the center of the bore. With the advent of superconducting magnets, spatial separations of different fractions are achieved in a short distance. For example, coal fly ash with a size 
distribution between 50 and $150 \mu \mathrm{m}$ has been used to demonstrate the OGMS separation of pyrite $\left(\mathrm{FeS}_{2}\right)$ from the remaining coal components. Argonne National Laboratory (ANL) currently houses a $0.7-\mathrm{m}$ long, 3.6-T superconducting quadrupole magnet with a highly uniform gradient of 60 $\mathrm{T} / \mathrm{m}$. Previous studies using OGMS systems to separate plutonium and uranium waste streams were limited to magnetic fields up to $2 \mathrm{~T}$ and proportionally less separation efficiency.

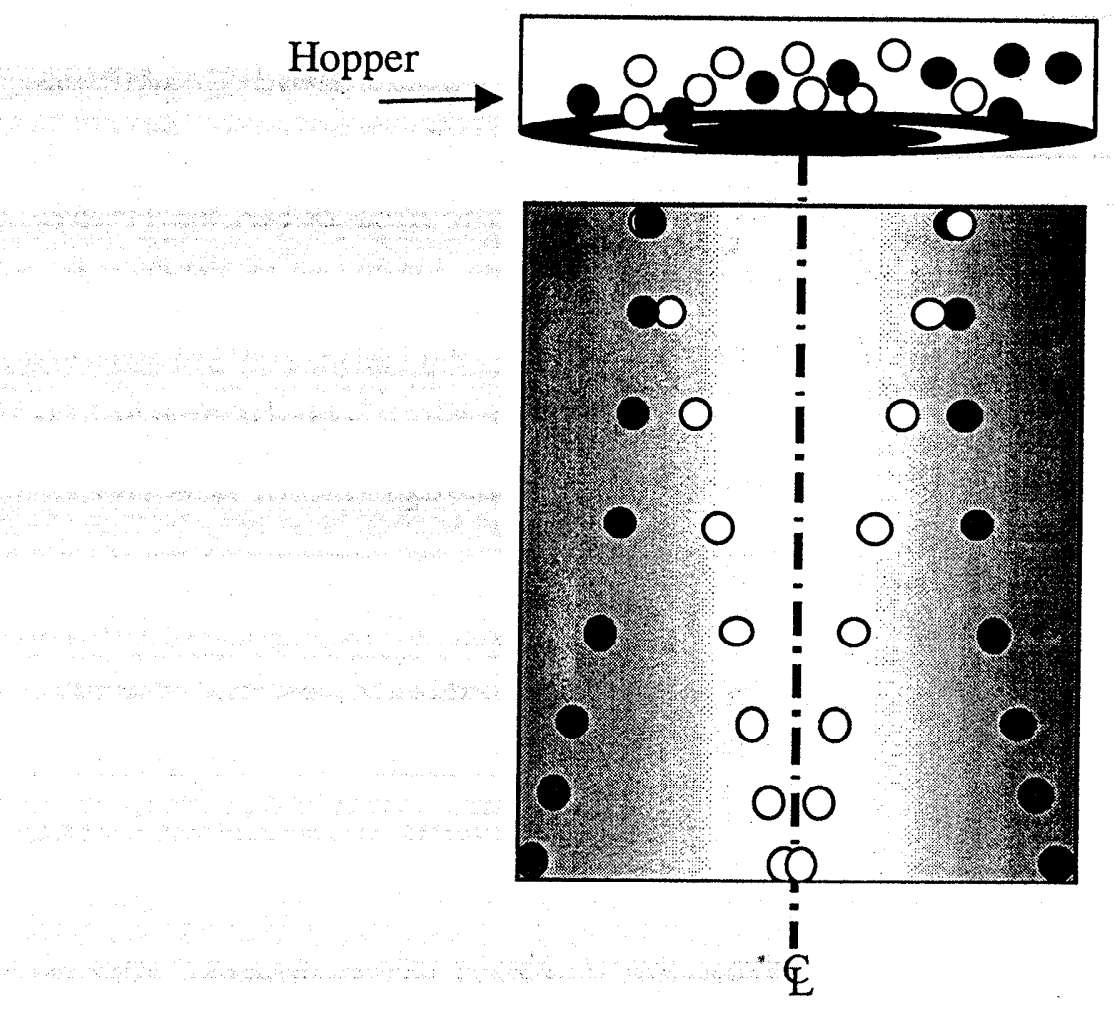

Figure I-1. Simplified drawing of the trajectory of free-falling particles in a vertical cylinder immersed in a magnetic field set up by a quadrupole magnet. A conceptual vibrating hopper feeds magnetic particles (black) and diamagnetic particles (white) at a fixed radius into the OGMS. The darker shading corresponds to a stronger magnetic field. Thus, the magnetic particles will deflect toward the wall while diamagnetic particles will deflect toward the low field at the centerline.

The ANL OGMS system [Doctor-1987] has several advantages over physical and chemical separation techniques when applied to radioactive and hazardous waste streams: (1) no mechanical parts, (2) minimal, if any, chemical additives, (3) effective separation with solid or slurry wastes, (4) continuous processing, (5) much higher magnetic fields and gradients than 
for separators limited to the saturation properties of iron $\left(\mathrm{B}_{0} \sim 2 \mathrm{~T}\right),(6)$ highfeed throughput, and (7) low power consumption (about on-fifth the cost of conventional separators).

A HGMS process is designed to remove materials with ferromagnetic or highly paramagnetic properties and small size from a feed. The HGMS process consists of a fine ferromagnetic wire matrix (e.g., stainless steel mesh) inserted in the bore of the magnet, which is then energized by an externally applied magnetic field. The fine ferromagnetic wires strongly distort the local magnetic field creating large magnetic field gradients, thereby producing enough force to capture and improve the removal efficiency of relatively small magnetic particles. The major difference between HGMS and OGMS is that HGMS is designed to capture particles while OGMS is designed for deflecting the trajectory of particles. In this program, the HGMS would function as a prefilter to remove the highly magnetic components from the waste feed and maintain the throughput of the OGMS unit.

HGMS has been used extensively since the early 1970's by the kaolin clay industry to remove iron and other magnetic impurities from the raw clay feed [see Ebner-1999 for a brief review]. Also, HGMS has proven applications in mineral benefaction, waste reclamation and recycling, and ultrapurification of chemical refractories and powders. Other applications of HGMS are under development, including environmental remediation and nuclear waste treatment. Novel applications of HGMS include biomagnetic separation, where enzymes, viruses, and cells are removed by coating them with magnetic oxides. 


\section{EXPERIMENTAL}

The experimental section of this report describes a wide range of activities. The microstructural, chemical and magnetic characterization, the radionuclide sorption experiments, and tests performed with the HGMS process. All the developing and engineering with the OGMS is described in a separate chapter.

\section{Waste Streams}

A number of simulant and actual wastes were obtained from DOE laboratories for characterization and feasibility testing in this program. The Hanford C-103 tank sludge simulant was selected due to the availability of the sludge and the typically high concentration of $\mathrm{Fe}$ in the waste stream. Iron coprecipitation had been used to concentrate the transuranics in some DOE tank waste streams. Approximately 200-L of the C-103 Hanford sludge simulant ( $8 \%$ by weight of solids) was prepared at Pacific Northwest National Laboratory (PNNL) and sent to ANL. From Rocky Flats, we received an actual $\mathrm{Pu}$ fly ash that contains mainly refractory metals and $\mathrm{PuO}_{2}$, which makes the waste stream a candidate for actinide separation [Kelly-1975]. Savannah River Site sent a few different types of waste simulants. We studied the Consolidated Incineration Facility (CIF) simulant fly ash from the standpoint of reducing hazardous components and the volume of LLW that need to be processed. Although this particular fly ash waste stream has been targeted for cementation, separations are needed to reduce the volume of Resource Conservation and Recovery Act (RCRA) metals in the vault space. In addition SRS sent four sludge simulants that contain appreciable amounts of iron compounds. The components of SRS tank sludge are described in detail in Appendix I. Specific details of the composition of the other wastes tested were obtained from the DOE sites.

\section{Physical and Chemical Measurements}

Samples were examined in an ATOPON ABT-60 scanning electron microscope $(\mathrm{SEM})$ at $13-20 \mathrm{kV}$. Samples that were suitable for electron 
dispersive spectroscopic (EDS) and backscattering analyses were performed in tandem using a NORAN ultrathin window system in the horizontal port of the ABT-60. Furthermore, particle size distributions were obtained using the National Institute of Health image program with SEM micrographs. Waste particle samples were prepared for electron microscopy by drying, embedding them in epoxy, and sectioning with an ultramicrotome. Sections produced were approximately 500 and $1000 \AA$ thick. Samples were then examined in a JEOL 2000FXII transmission electron microscope (TEM) at 200kV. A Siemen powder diffractometer was used to determine the chemical structure of various mineral phases. The cations and anions chemical analysis of the sludge and fly ash were determined using inductively coupled plasma-atomic absorption spectroscopy (ICP-AES) following digestion of the solid waste. The magnetic properties of the materials were characterized with a Superconducting QUantum Interference Device (SQUID) magnetometer. The powder X-ray diffraction (XRD) was performed using a Model 2005+ Rigaku Co. vertical goniometer.

\section{Partitioning Experiments}

The spinel phases were studied for sorption of hazardous metals or radionuclides. The non-radioactive metals were obtained from Aldrich Chemicals as $99.9 \%$ pure. The radioisotopes were obtained from the laboratory supply and were $>99 \%$ purity as measured by gamma spectroscopy. The experiments were done in test tubes or in flasks at a solution volume-to-powder mass ratio of $25 \mathrm{~mL}$ per one gram. For radioactive tests, test tubes were preferred to minimize waste generation. The spinel phase was contacted with the appropriate amount of the stock solution and vigorously mixed. Equilibrium times were determined by withdrawing aliquots at various times and observing constant metal concentration or radioactivity in solution. The $\mathrm{pH}$ was adjusted using microliter quantities of either $0.1 \underline{\mathrm{M}} \mathrm{HNO}_{3}$ or $\mathrm{NaOH}$ and monitored with an Accumet $\mathrm{pH}$ meter. For non-radioactive tests, the solution metal concentration was determined by thermal neutron activation analysis (University of Texas-Austin) and a high 
purity germanium detector (EG\&G Ortec). For radioactive tracer experiments, the activity was measured with a 3 inch $\mathrm{NaI}(\mathrm{Tl})$ scintillator.

\section{Open Gradient Magnetic Separation/High-Gradient Magnetic Separation} Experimental Description

In this section the magnetic separator units that were tested and modified for testing of the waste streams are described. In an OGMS system, it is recognized that there are some limitations/precautions when processing feeds that contain a large concentration of ferromagnetic and highly paramagnetic materials such as magnetite, native iron, and hematite. Under these conditions the strong fields of the OGMS will be sufficient to deflect and capture the magnetic particles on the wall of the cylinder. This can lead to reduced throughputs, trajectory interference, and eventual clogging of the system. In this separation program we have combined OGMS and HGMS prefilter in order to take advantage of their strengths and overcome their limitations for solid-liquid or solid-solid separation of radioactive waste streams. The following section describes the general background and OGMS and HGMS apparatus.

\section{OGMS Apparatus}

Figure II-1 shows a schematic of the OGMS apparatus at ANL. In the apparatus, the magnetic field axis ( $\mathrm{z}$ ) is vertical, the gradient is constant in the radial direction $(r$ ) from the bore center to the wall, and the magnetic field is isotropic in the angular $(\theta)$ axis. In a cylindrical bore, a uniform magnetic field gradient can be produced with a quadrupole superconducting magnet (in this study, length $=0.68 \mathrm{~m}$ and diameter $=0.064 \mathrm{~m}$ ). The magnet operates at liquid $\mathrm{He}$ temperatures and generates intense magnetic field gradients of $60 \mathrm{~T} / \mathrm{m}$. For solid waste streams like soils and ashes, the waste is metered into the system through an AccuRate screw feeder capable of feeding solid waste at $0-20 \mathrm{~kg} / \mathrm{h}$. Waste continuously spills into a vertical pipe that permits $1.83 \mathrm{~m}$ of free falling space before the waste passes through an annulus of 3.18 to $4.13 \mathrm{~cm}$ and enters the magnetic field zone. The magnetic field gradient in the center bore is characterized by a high field at 
the bore wall and a zero field at the center. For processing of wet waste streams, PVC plumbing was installed (see Section VIII of this report) to mix waste slurries and pump the contents to a diffuser at the top of the unit (the diffuser replaced the screw feeder assembly). Therefore, with simple disconnects, this design can be used for both dry and wet processing.

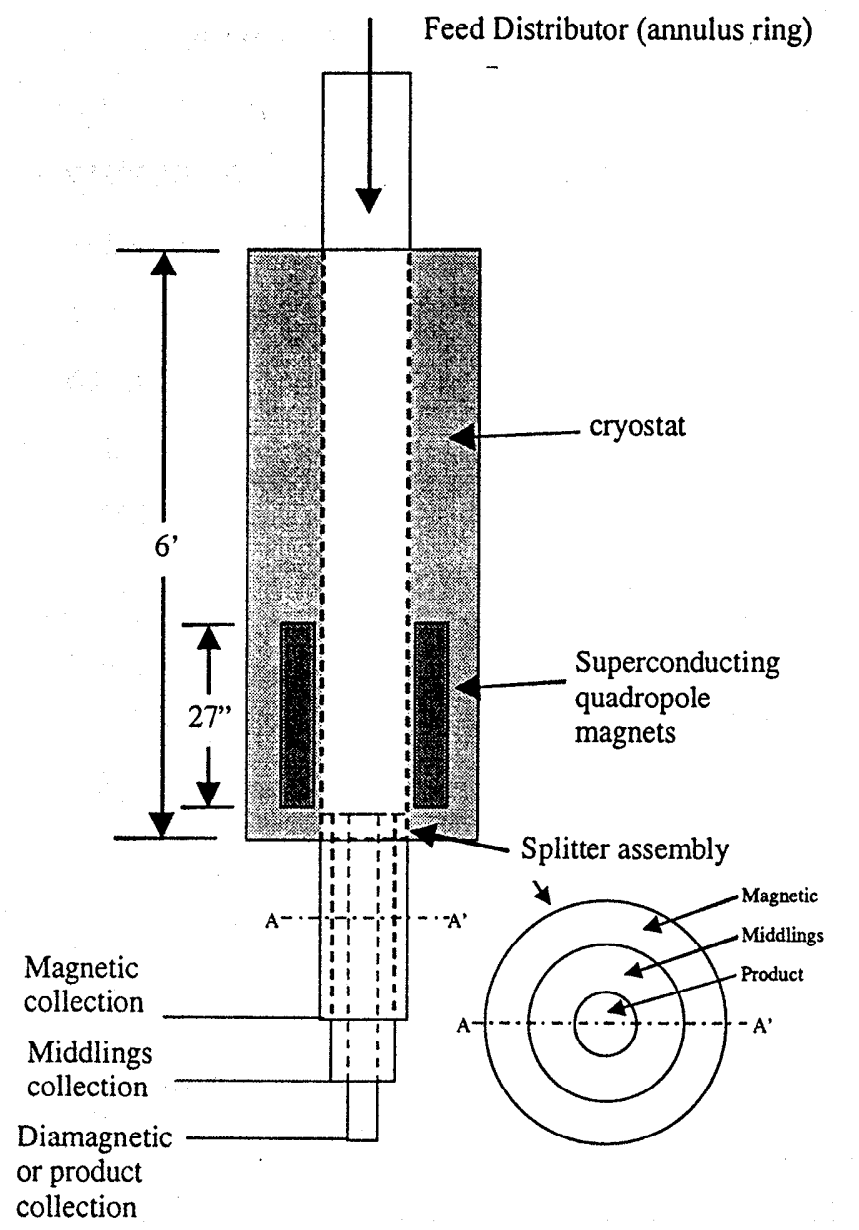

Figure II-1. Schematic of the superconducting open-gradient magnetic separator (OGMS) at ANL. The radiuses of the splitter assembly annuli are: product $0.50 "(12.7 \mathrm{~mm})$, middlings $0.94 "(23.8 \mathrm{~mm})$, and wall $1.19 "(30.2 \mathrm{~mm})$.

Extensive experimental and theoretical work has been performed on OGMS and high-gradient magnetic separation (HGMS) systems for coal benefaction and other mineral separations [Doctor-1988]. The OGMS and HGMS techniques have advantages and disadvantages for specific waste streams. Superconducting magnetic separation is used commercially to remove $\mathrm{Fe}_{2} \mathrm{O}_{3}$ and $\mathrm{TiO}_{2}$ impurities from kaolin clay in the paper industry [Liu-1979]. Magnetic separation of uranium from $\mathrm{MgF}_{2}$ has shown potential 
in wet and dry systems [Hoegler-1987, -1989]. An OGMS system was used by Avens et al. to separate $\mathrm{Pu}$ from graphite, bomb reduction materials, sand, slag, and crucible into Pu-rich and -lean fractions [Avens-1990]. If the lean fraction meets the LLW release requirements, the process can be used for direct waste reduction. Other Pu-containing waste streams, such as electrorefined pyrochemical salts and direct oxide reduction salts, were less suitable for nonsuperconducting OGMS systems due to the high concentration of $\mathrm{Pu}$ obtained in the lean fraction, essentially creating two waste streams. The high-gradient fields possible with the ANL superconducting OGMS system may increase separation efficiency and potentially reduce the $\mathrm{Pu}$ in the lean fraction to LLW levels. The OGMS technique was unable to separate the $\mathrm{Pu}$ for the Rocky Flat incinerator ashes studied by Avens et al. [Avens-1990]. However, a good separation was obtained by Avens et al. for one particular $\mathrm{Pu}$ ash waste stream with the magnetic field of the OGMS at 2T. These previous investigations were not conclusive and its possible that the performance of these OGMS can be improved by increasing the field gradient and modeling the magnetic separation on the basis of the chemical and physical characterization of the waste streams.

\section{HGMS Apparatus}

An HGMS system from Advanced Environmental System, Inc. (located at the University of South Carolina -Chemical Engineering Department) was used in this study; a schematic is shown in Figure II-2. This 0.3 T HGMS system (A) has a magnetic bore that is $12.1-\mathrm{cm}$ long and $6.45 \mathrm{~cm}$ diameter with a filter canister (B) area of $40 \mathrm{~cm}^{2}$. The filter canister includes magnetic pole piece that serves to evenly distribute the magnetic field over the matrix area. The matrix consists of graded expanded metal discs, about 30 grams of steel wool, stacked within the canister to a maximum height of $12.1 \mathrm{~cm}$. The element size of the steel wool discs varies between 200 and $500 \mu \mathrm{m}$. The packing density was $6 \%$ by volume. This HGMS system has been field tested by the manufacturer, where they claim at least $99 \%$ of the iron, cobalt, magnetite, and other spinel and ferrites, at least $50 \%$ of the hematite, and at 
least $30 \%$ of the hydrated irons $\left(\mathrm{FeO}^{*} \mathrm{OH}\right.$ species), all of particle sizes greater than $0.1 \mu \mathrm{m}$ can be removed from aqueous streams [Ebner-1999].

In the tests carried out in this study, the simulant waste stream was passed upward through the canister to ensure complete flooding; and the effluent was collected in a 1-L bottle (D) (see Figure II-2). The feed solution was continuously stirred with a magnetic stirrer (E) and transported at a flow rate at $150 \mathrm{~mL} / \mathrm{min}$ with a peristaltic pump (F) placed just before the separation unit. Initially, the magnet was turned on and 1-L of the waste stream was passed through the magnet. All the effluent was collected and denoted as the head. Then, with the magnet still turned on, $\mathrm{pH} 10$ distilled water was passed upward through the magnet to remove the loosely attached and least magnetic particles from the stainless steel matrix and to retain the presence of a magnetically retained fraction within the stainless steel mesh. This effluent solution, denoted as the drain, was collected until it became noticeably dilute. Then, while still continuously passing $\mathrm{pH} 10$ distilled water, the magnetic field was turned off to remove and collect the magnetically retained fraction. The colored effluent was collected until it became noticeably dilute. Finally, with the field turned off, the magnet was flushed with distilled water to prepare it for the start of a new stage. This stage was initiated by passing the head solution collected from the previous stage through the HGMS system, and so went the cycle from stage to stage. All the fractions were stirred and sampled for subsequent analysis. Three different analyses were carried out on the three separate fractions from each stage and on initial sample. Initially, three aliquots were taken from each of the fractions of the first four stages to determine the volume particle size distributions (VPSDs) and mean particle sizes, in triplicate, using a Nicomp ${ }^{\mathrm{TM}}$ 370 Submicron Particle Sizer. Then all of the samples (i.e., the initial sample and all of the fractions from each of the stages) were completely vacuum filtered using Gelman Sciences $0.45 \mu \mathrm{m}$ Tuffryn ${ }^{\circledR}$ membrane filters. Subsequently, the samples were dried overnight under vacuum ( $0.6 \mathrm{~atm})$ and at room temperature to maintain the particle size distribution. The dried initial sample and samples from the first stage were analyzed in a Hitachi $2500 \triangle$ SEM integrated with EDS. Finally, $0.5 \mathrm{~g}$ of each sample was 
digested for $2 \mathrm{hr}$ at $100^{\circ} \mathrm{C}$ in $6 \mathrm{~mL}$ of nitric acid (50 wt\%) in sealed $30-\mathrm{mL}$ Teflon tubes. The resulting liquid and solid phases were denoted as digestible and nondigestible phases, respectively. The phases were separated using vacuum filtering and Gelman Sciences $0.45 \mu \mathrm{m}$ Tuffryn ${ }^{\circledR}$ membrane filters and then the liquid phase was adequately diluted prior to analyzing its metal content ( $\mathrm{Fe}, \mathrm{Al}, \mathrm{Ca}$, and $\mathrm{Si}$ ) using a Perkin Elmer 3300 Flame Atomic Absorption (AA) Spectrometer. The nondigestible phase was a very fine white powder as opposed to the typical brownish color of the sludge, it was assume to be $\mathrm{SiO}_{2}$.

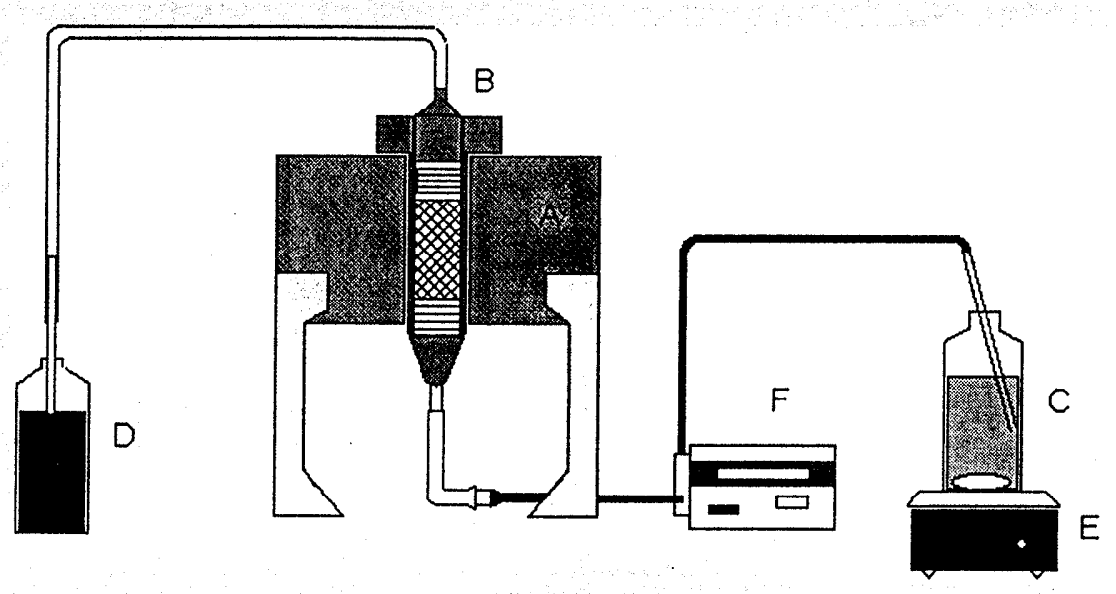

Schematic of the 0.3-T HGMS unit: (A) 0.3-T magnet; (B) filter canister

(C) feed solution; (D) effluent solution; ( $E$ ) magnetic stirrer; $(F)$ peristaltic pump

Figure II-2. High-gradient magnetic separator (HGMS) apparatus. 


\section{THEORY}

The application of both Open Gradient Magnetic Separation and HighGradient Magnetic Separation processes for environmental remediation requires the development of flowsheet models that can predict the limitation of the separation process. The following section describes the general theory for both OGMS and HGMS.

\section{$\underline{\text { OGMS }}$}

The major forces acting on the particles in the open-gradient magnetic separator, assuming no particle-particle or particle-wall interactions, are magnetic, fluid drag, gravitational, and buoyancy forces (see Figure III-1 for a free body diagram). Theoretical modeling must take these forces into consideration and include the method used to introduce the waste into the separator.
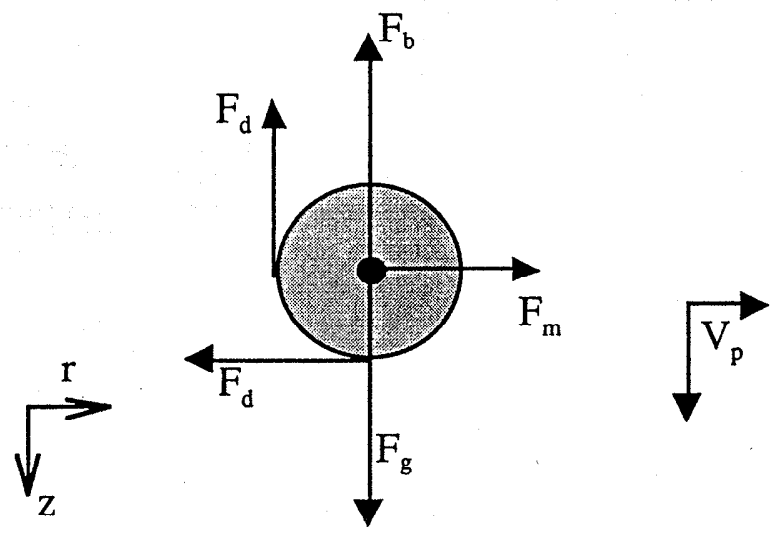

Figure III-1. Free body diagram of magnetic sphere falling with velocity $\mathrm{V}_{\mathrm{p}}$ in a fluid contained in a magnetic field. $F_{m}$ is the magnetic force, $F_{d}$ is fluid friction drag, $F_{g}$ is the force due to gravity, and $F_{b}$ is the buoyancy force. Note, the fluid drag force will have components in the direction opposite of particle flow whether it be radial motion or motion in the z-direction. 


\section{Magnetic Force}

The magnetic force $\left(\mathrm{F}_{\mathrm{m}}\right)$ acting on a weakly magnetic particle is proportional to the magnetic field gradient $(\nabla \mathrm{B}$; in units of Tesla/meter or $\mathrm{T} / \mathrm{m})$, the particle diameter $\left(\mathrm{D}_{\mathrm{p}} ; \mathrm{m}\right)$, the particle magnetic susceptibility ( $\chi$, dimensionless in MKS units), and the magnetic permeability of the fluid medium $\left(\mu_{0}, T^{*} \mathrm{~m} / \mathrm{A}\right)$, as shown in Eqs. -1 and -2 .

$$
\mathrm{F}_{\mathrm{m}}=\frac{\pi}{6} \mathrm{D}_{\mathrm{P}}^{3} \chi \frac{\overrightarrow{\mathrm{B}}}{\mu_{\mathrm{o}}} \nabla \overrightarrow{\mathrm{B}}
$$

For angular motion, the field gradient for the quadrupole magnet is constant for a given $\theta$ value. For radial motion, this magnet has a constant gradient $\left(60 \mathrm{~T} / \mathrm{m}\right.$ ) at the field maximum, which leads to $\overrightarrow{\mathrm{B}}=\frac{\mathrm{dB}}{\mathrm{dr}} \mathrm{r}$, for the geometry of this magnet ${ }^{1}$ and resulting force relation of

$$
F_{m}=\frac{\pi}{6} D_{\mathrm{P}}^{3} \chi \frac{\vec{B}}{\mu_{\mathrm{o}}} \frac{\mathrm{dB}}{\mathrm{dr}}=\frac{\pi}{6} \mathrm{D}_{\mathrm{P}}^{3} \chi\left(\frac{\mathrm{dB}}{\mathrm{dr}}\right)^{2} \mathrm{r}
$$

\section{Fluid-Drag Forces}

The fluid-drag force $\left(\mathrm{F}_{\mathrm{d}}\right)$ acting on a particle will be determined by the relative motion of the waste particle with respect to the carrier fluid (e.g., air, water). A low Reynolds number $(\operatorname{Re}<0.3)$ is expected for the radial motion of the particle. Stokes' law can be used to calculate fluid-drag force (Eq. III-3), where $\eta\left(\mathrm{N} \cdot \mathrm{s} / \mathrm{m}^{2}\right)$ is the fluid viscosity, and $\mathrm{V}_{\mathrm{P}}$ and $\mathrm{V}_{\mathrm{f}}$ are the flow velocities of the particle and the fluid media, respectively.

$$
F_{d}=3 \pi \eta D_{P}\left(V_{f}-V_{p}\right)
$$

For those cases where the Reynolds number is greater than 0.3 but less than $1000, F_{d}$ (Eq. III-4) is defined as 


$$
F_{d}=\frac{\pi}{8} \rho_{f} C_{d} D_{P}^{2}\left(V_{P}-V_{f}\right)^{2}
$$

where $C_{d}$ is the empirical coefficient of drag. Newton's law for drag would apply for Reynolds numbers greater than 1000 .

\section{Gravitational and Buoyäncy Forces}

The particles will experience gravitational effects and buoyancy forces while travelling in the carrier fluid. Both forces are volume forces and can be conveniently expressed as a single quantity in terms of the densities of the particle and the fluid media, $\rho_{\mathrm{p}}\left(\mathrm{kg} / \mathrm{m}^{3}\right)$ and $\rho_{\mathrm{f}}$, respectively, as expressed below,

$$
F_{g}=g \frac{\pi}{6} D_{P}^{3}\left(\rho_{P}-\rho_{f}\right)
$$

Since the radial magnetic force is driving the magnetic separation and this magnetic force is less than the gravitational force, the magnet is arranged such that the two forces are orthogonal or the magnetic bore is parallel to the gravitational force.

\section{Inertial Force}

The total of the above forces results in the particle inertia, $F=$ ma. In differential form and in terms of particle diameter,

$$
F_{i, r}=\rho_{P} \frac{\pi D_{P}^{3}}{6} \frac{d^{2} r}{d t^{2}}
$$

for radial motion and

$$
F_{i, z}=\rho_{p} \frac{\pi D_{P}^{3}}{6} \frac{d^{2} z}{d t^{2}}
$$

\footnotetext{
${ }^{1} \mathrm{DB} / \mathrm{dr}=$ constant for the ANL open gradient magnetic separator because of its special design. Other open
} 
for motion in the z-direction.

Radial Motion of Particles

The force balance in the radial direction is

$$
F_{i}=F_{m}+F_{d}
$$

Initially, the fluid will have no inertial velocity component in the r-direction. The OGMS system's orientation where the magnet is vertical (radius is orthogonal to gravitational force) allows for the negation of the gravitational force term in Equation III-8.

For Stokes' law in the low-flow region ( $\mathrm{Re}<0.3)$, Equation III-7 becomes a second order homogeneous differential equation with constant coefficients:

$$
\rho_{P} \frac{\pi D_{P}^{3}}{6} \frac{d^{2} r}{d t^{2}}=\frac{\chi \pi D_{P}^{3}}{6 \mu_{o}}\left(\frac{d B}{d r}\right)^{2} r-3 \pi \eta D_{P} \frac{d r}{d t}
$$

or equivalently,

$$
\frac{d^{2} r}{d t^{2}}+\frac{18 \eta}{\rho_{P} D_{P}^{2}} \frac{d r}{d t}-\frac{\chi}{\rho_{P} \pi \mu_{o}}\left(\frac{d B}{d r}\right)^{2} r=0
$$

with the boundary conditions of

$$
\mathrm{r}(\mathrm{o})=\mathrm{r}_{\mathrm{o}} \text { and }\left.\frac{d r}{d t}\right|_{t=0}=0
$$

To simplify the analytical solution we write Eqn. III-10 in the following form,

$$
a r^{\prime \prime}+b r^{\prime}+c r=0
$$

where

$$
a=1
$$

gradient magnetic separators may not display similar isotropy. 


$$
\begin{aligned}
& \mathrm{b}=\frac{18 \eta}{\rho_{p} D_{p}^{2}} \\
& \mathrm{c}=-\frac{\chi}{\rho_{p} \pi \mu_{o}}\left(\frac{d B}{d r}\right)^{2}
\end{aligned}
$$

By assuming a solution of the form $\mathrm{e}^{\text {st }}$, the characteristic equation

$$
a s^{2}+b s+c=0
$$

is obtained. This quadratic equation has the characteristic roots

$$
s_{1,2}=\frac{-b \pm \sqrt{\left(b^{2}-4 a c\right)}}{2 a}=\frac{-b}{2 a} \pm \frac{\sqrt{\left(b^{2}-4 a c\right)}}{2 a}
$$

or to use the convention of the modeling program, $s_{1,2}=A_{1} \pm B_{1}$. There are three solutions to the above equation depending on the value of $B_{1}$.

1. If the roots are real and unequal (i.e., $b^{2}-4 a c>0$ ), then

$$
r(t)=\frac{r_{o}}{2 B_{1}}\left[s_{1} s^{s_{2} t}-s_{2} e^{s_{1} t}\right]
$$

2. If the square root term is zero then the methodology followed in solution 1) can be followed to find the first solution. The second solution is obtained through a reduction of variables, which leads to

$$
r(t)=r_{o}\left[e^{A_{1} t}-A_{1} t e^{A_{1} t}\right]
$$

3. If the roots are complex numbers then (i.e., $b^{2}-4 a c<0$ ), then imaginary roots are obtained. The imaginary solution can be avoided by using the trigonometric form of the general solution,

$$
r(t)=r_{\rho} e^{A_{1} t} \cos \left(B_{1} t\right)-\frac{A_{1}}{B_{1}} e^{A_{1} t} \sin \left(B_{1} t\right)
$$


For the vertical motion of a particle (in the z-direction), Equation III-19 is solved

$$
F_{z i}=F_{8}+F_{d}
$$

or, in the Stokes regime,

$$
m \frac{d^{2} z}{d t^{2}}=\left(\rho_{p}-\rho_{f}\right) \frac{\pi}{6} D_{p}^{3} g-3 \pi \eta D_{p} v
$$

and in the non-Stokes regime

$$
m \frac{d^{2} z}{d t^{2}}=\left(\rho_{p}-\rho_{f}\right) \frac{\pi}{6} D_{p}^{3} g-\frac{\pi}{8} C_{D} D_{p}^{2} \rho_{f} v^{2}
$$

where

$$
C_{D}=\frac{24}{\operatorname{Re}}\left(1+0.14 \mathrm{Re}^{0.7}\right)
$$

and results in Equation III-13, where $\mathrm{V}_{0}$ is the initial velocity

$$
z(t)=\frac{g D_{P}^{2} \rho_{P}}{18 \eta}\left[t+\left(\frac{D_{P}^{2} \rho_{P}}{18 \eta}-\frac{V_{o}}{g}\right)\left(e^{\frac{-18 \eta t}{D_{\rho}^{2} \rho_{p}}}-1\right)\right]
$$

This equation applies to systems in the low Reynolds number region.

The general solution for the regime intermediate to Stokes and Newton is found by direct integration,

$$
z(t)=\frac{g D_{P} \rho_{P}}{C_{D} \rho_{f}}\left[\ln \left(1+k_{1} e^{\frac{t}{\theta}}\right)-\ln \left(1+k_{1}\right)\right]-\gamma t
$$

where 


$$
\begin{aligned}
& k_{1}=\frac{\gamma+V_{v}}{\gamma-V_{o}} \\
& \vartheta=\left(\frac{3 C_{D} \rho_{f} g}{D_{P} \rho_{P}}\right)^{-\frac{1}{2}} \\
& \gamma=\left(\frac{4 D_{P} \rho_{P} g}{3 C_{D} \rho_{f}}\right)^{\frac{1}{2}}
\end{aligned}
$$

The solutions to Eqns. III-10 and III-24 will determine the r-position of particles at the exit position of the magnetic region and beginning of the splitter assemblies. This array determines the fraction collected into the product, middle, and magnetic regions of the OGMS collectors. Thus, the necessary parameters to determine the extent of separation are magnetic susceptibility, particle size distribution, and flow velocity for a given OGMS unit.

\section{$\underline{\text { HGMS }}$}

High gradient magnetic separation (HGMS) using superconducting magnet technology is the form of magnetic separation that generates the largest magnetic field gradients and is, therefore, the most appropriate form for application requiring the capture of ferromagnetic particles. HGMS separators typically consist of a high-field solenoid magnet, the bore of which contains a fine-structured, ferromagnetic matrix material. The matrix material locally distorts the magnetic field and creates large field gradients in the vicinity of the matrix elements. These elements then become trapping sites for ferromagnetic or paramagnetic particles and are the basis for the magnetic separation process.

If the particles are physically liberated from the host material and are not electrically charged, the principal forces governing their behavior are magnetic, viscous, and gravitational similar to OGMS. The performance of the magnetic separator is modeled using a force balance on an individual ferromagnetic or paramagnetic particle in the immediate vicinity of a matrix 
element, as shown in Figure III-2. The model assumes that if the magnetic capture forces are greater than the competing viscous drag and gravity forces, the particle is captured and removed from the flow stream. Rate models have been proposed for this process and depends on the separation coefficient, which is defined in terms of a capture cross section, and a potential function defined by the force balance on the particle. However, since the HGMS is only used as a prefilter for the OGMS these models were not further developed in this program.

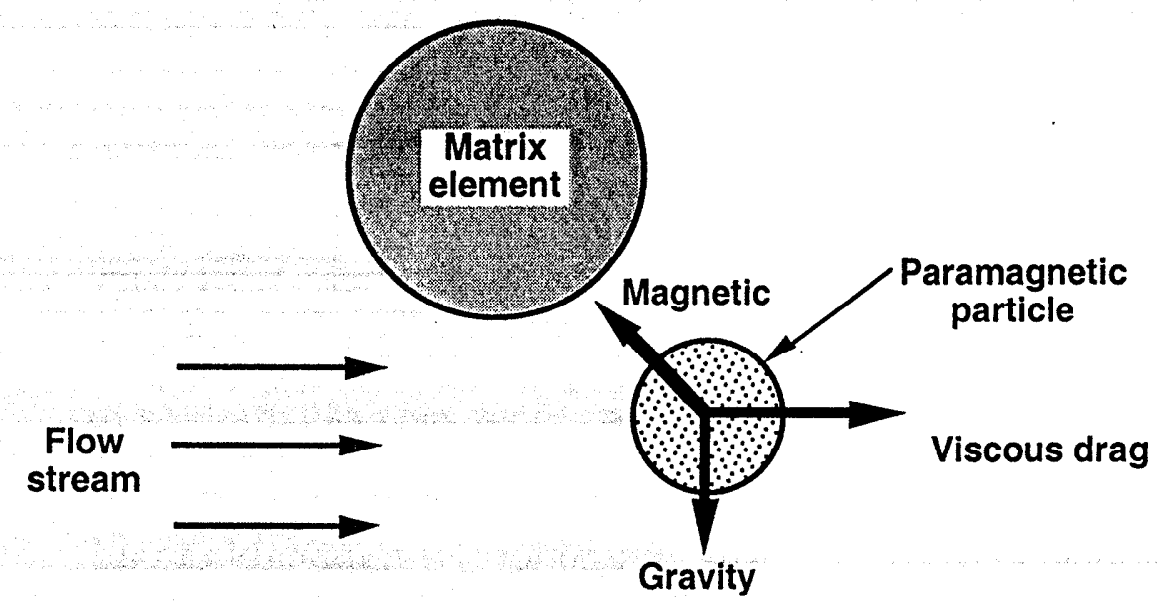

Figure III-2. Force balance on a paramagnetic particle in the vicinity of a matrix element.

The magnetic force on the particle is given by Eqn III-1. At applied field strengths below about $2 \mathrm{~T}$ the magnetic force is proportional to $\mathrm{B}^{2}$ and changes in magnetic field have a significant effect on magnetic force, however, at field strengths above $2 \mathrm{~T}$ the typical ferromagnetic matrix material saturates preventing further increase in the field gradient and reducing the field dependence to near linear. For this reason, operation near $2 \mathrm{~T}$ has become a somewhat accepted optimum for commercial magnetic separators. 


\section{COMPUTATIONAL STUDIES}

As part of the coal cleaning investigation [Doctor-1986,-1987], a computer model was developed to calculate the trajectories of individual particles falling through the bore of the quadrupole superconducting magnet. Doctor et al. developed the equations of motion for the particles and wrote the original Basic program to calculate trajectories for paramagnetic particles in the early 1980's based on the theory described in chapter III. In 1985, the program was translated to Fortran 77 and added several sign change tests such that the original formulation could be extended to solve diamagnetic particle trajectories.

With interest in OGMS being extended to radionuclide and hazardous waste remediation application, a second update to the particle trajectory model has been made. This update has been written in Fortran90 ("freeform" Fortran) and includes improvements in three areas. First, several changes to the governing equations and solutions have been made: additional equations for Stokes flow radial solutions make the program generally applicable to all particle susceptibilities, additions to all z-direction solutions make them applicable to working fluids for which buoyancy is not negligible, and changes in the expression for the coefficient of drag and the equation of motion used by the non-Stokes flow solution have been added to replace errors in the earlier work. Second, changes to the solution algorithm employed by the original program have been made in the revised edition to take advantage of the additional computational power not available in 1985 . These changes increase the accuracy of the program considerably. Third, minor conveniences, such as an option to calculate terminal particle velocities to be used as initial conditions and the formatting of output to be easily analyzed in spreadsheet software, have been included in the program update.

Changes in each of these areas - equations, algorithms, and other additions are all derived from the theoretical analysis shown in chapter III. The derivation of the exact solution of the equations is provided in Appendix II. Afterwards, the effect of these changes on the original coal cleaning results is presented (Appendix II). Attached to the end of the report, 
Appendix II contains errata found in the papers describing the original coal cleaning analysis and Appendix III contains a copy of the updated particle trajectory program and an informal users' guide.

The trajectory program described here provides vital information on deflection path and time required for a particle of a given composition and size to travel the OGMS magnet described in Chapter II and III. This section concentrates on trajectory for major components relevant to radionuclide and hazardous waste streams in this OGMS unit. The results of this computational analysis will aid the user to design magnetic separation flowsheets. In order to validate our computational efforts we will be required to test in the future with radionuclide components.

The plots that follow show the scenario by which the particles would have the longest path to follow to deflect to their desired splitter assembly. That is, the magnetic particles (both paramagnetic and ferromagnetic) are shown to begin their flight through the unit near the centerline for deflection to the outer wall. The diamagnetic particles are shown to begin their path near the wall for deflection toward the centerline. This provides a worse case scenario for particle deflection. In practice, a vibrating hopper will be used that will force the particles to be fed at a neutral radius position at $15-20 \mathrm{~mm}$ from the centerline. However, particle-particle interactions may cause deviation from this starting point.

\section{Modeling $\mathrm{UQ}_{2}$ Particles}

The cumulative effect of the trajectory model on the $\mathrm{UO}_{2}-\mathrm{SiO}_{2}$ mixture falling in air can be seen in Figures IV-1-3. The required travel times for $100 \% \mathrm{UO}_{2}$ particles (dependent on size) to reach the wall (from an initial centerline position) ranged from 0.59 to 0.67 seconds and for $\mathrm{SiO}_{2}$ particles to reach the magnet center (from an initial position at the bore wall) the time ranged between 1.8 to 4 seconds. Figure IV-1 shows the required magnet length for the $100 \% \mathrm{UO}_{2}$ particles to reach the wall as a function of particle size. In the range between 50 and $125 \mu \mathrm{m}$, the separation still occurs within the magnet length and all will be collected in the magnetic region of the collectors (see Figure IV-2). In addition, all the particles were determined to 
be in the non-Stoke region. The particle deflection increases with reduction in particle size.

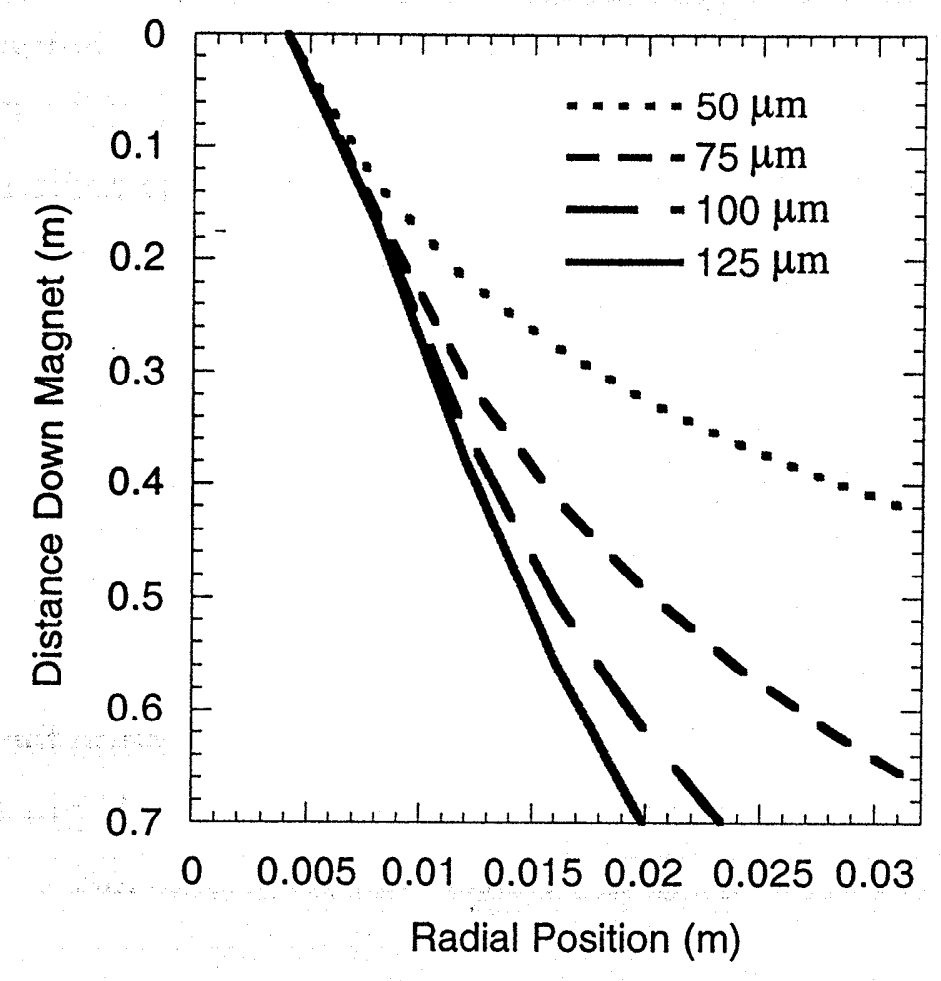

Figure IV-1. Trajectory of $100 \% \mathrm{UO}_{2}$ particles as a function of particle size.

Figure IV-2 shows that the paramagnetic deflection still occurs within the magnetic region of the OGMS unit even when the starting position is varied. 


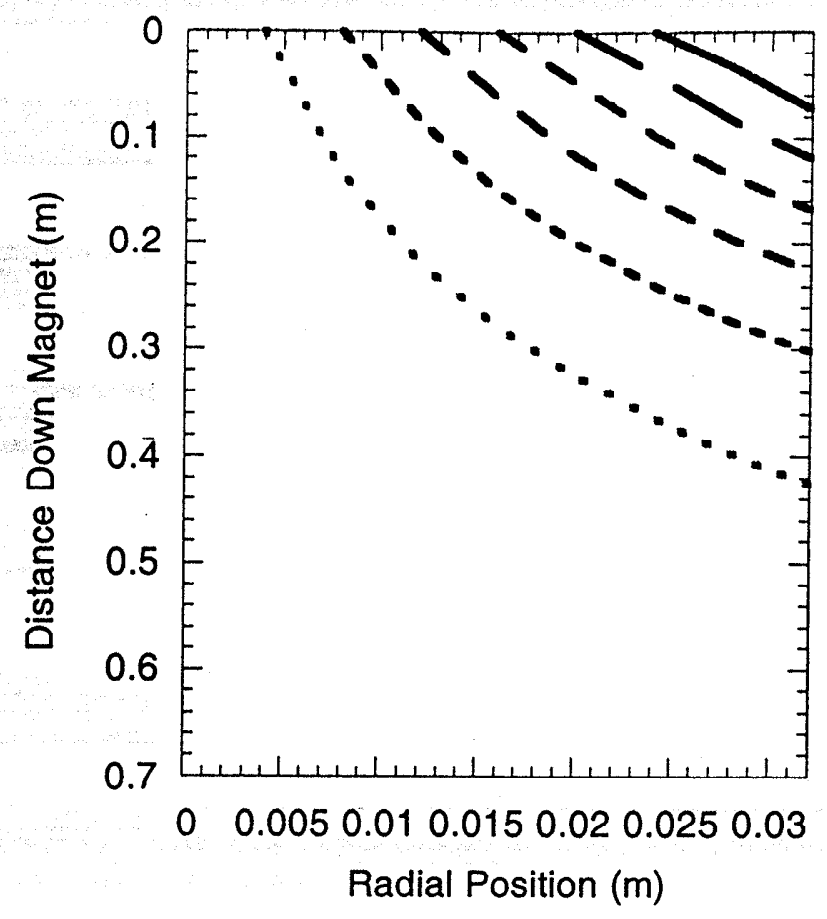

Figure IV-2. Trajectory of $50 \mu \mathrm{m}, 100 \% \mathrm{UO}_{2}$ particles as a function of radial starting position

Figure IV-3 shows the variation of the deflection trajectory when the $\mathrm{SiO}_{2}$ concentration is increased, thus increasing the diamagnetic contribution of the particle. The figure also shows that even with $20 \% \mathrm{UO}_{2}$ (with particle size ranging from 50 to $100 \mu \mathrm{m}$ ) the particles are paramagnetic and are directed toward the magnet wall. 


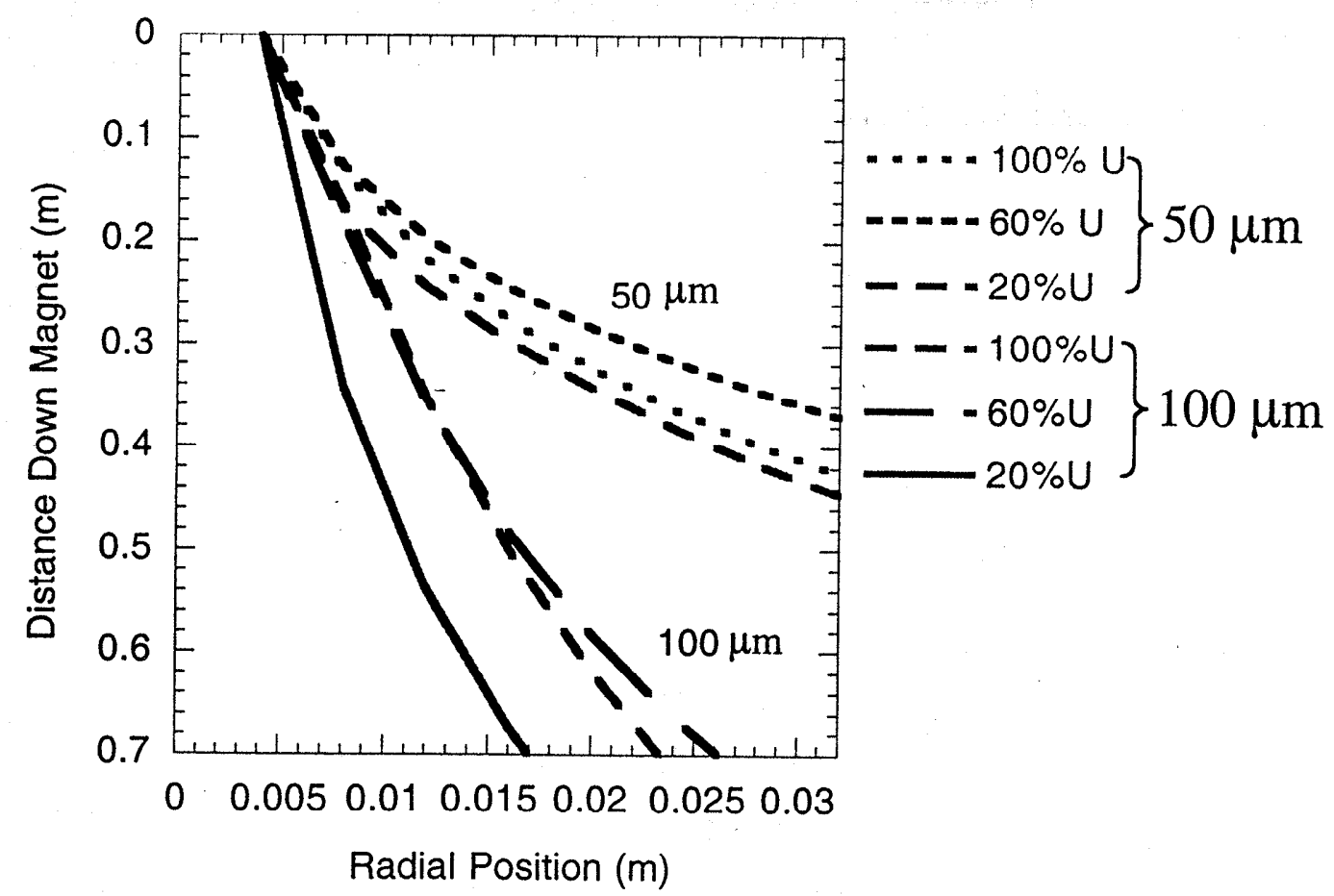

Figure IV-3. Trajectory as a function of $\mathrm{UO}_{2}$ composition and particle size.

In all of these cases (Figure IV-1-3), particle flight falls in the nonStokes flow regime, and the Reynolds numbers vary from 1 to 21 , depending on the particle type and size.

\section{Modeling $\mathrm{PuO}_{2}$ Particles}

The cumulative effect of the trajectory model on the $\mathrm{PuO}_{2}-\mathrm{SiO}_{2}$ mixture can be seen in Figures IV-4-6. The required travel times for $100 \% \mathrm{PuO}_{2}$ particles (dependent on size) to reach the wall range from 1.19 to 1.58 seconds. Thus, most of the $\mathrm{PuO}_{2}$ particles do not reach the magnet wall ( $>75$ microns) and fall within the middling (see Figure II-1) and product segregation region of the OGMS unit. Thus, the size distribution will be critical for the separation of the $\mathrm{PuO}_{2}$ particles. Figure IV-4 shows the required magnet length for the $100 \% \mathrm{PuO}_{2}$ particles to reach the wall as a function of particle size. In the range between 50 and $125 \mu \mathrm{m}$ the separation still occurs within the magnet length. In addition, all the particles were 
determined to be in the non-Stoke region. The $\mathrm{PuO}_{2}$ particle deflection increases with reduction in particle size.

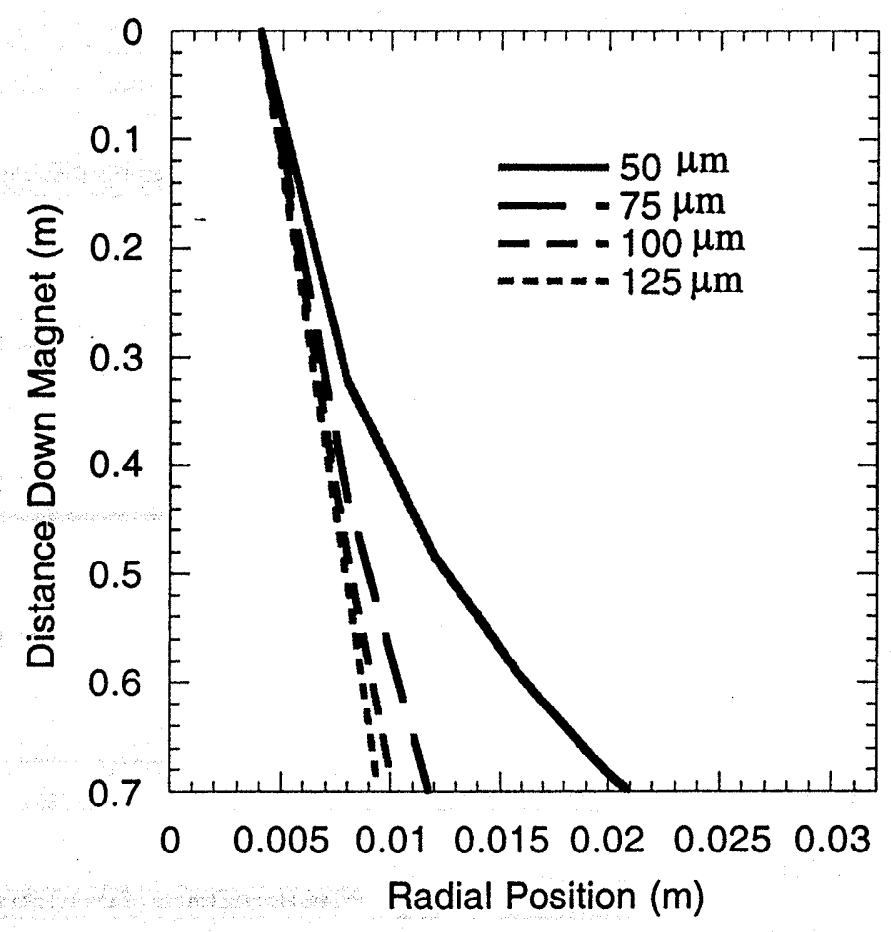

Figure IV-4. Trajectory of $100 \% \mathrm{PuO}_{2}$ particles as a function particle size.

Figure IV-5 shows that the paramagnetic deflection still occurs within the magnet length when the starting position is varied. 


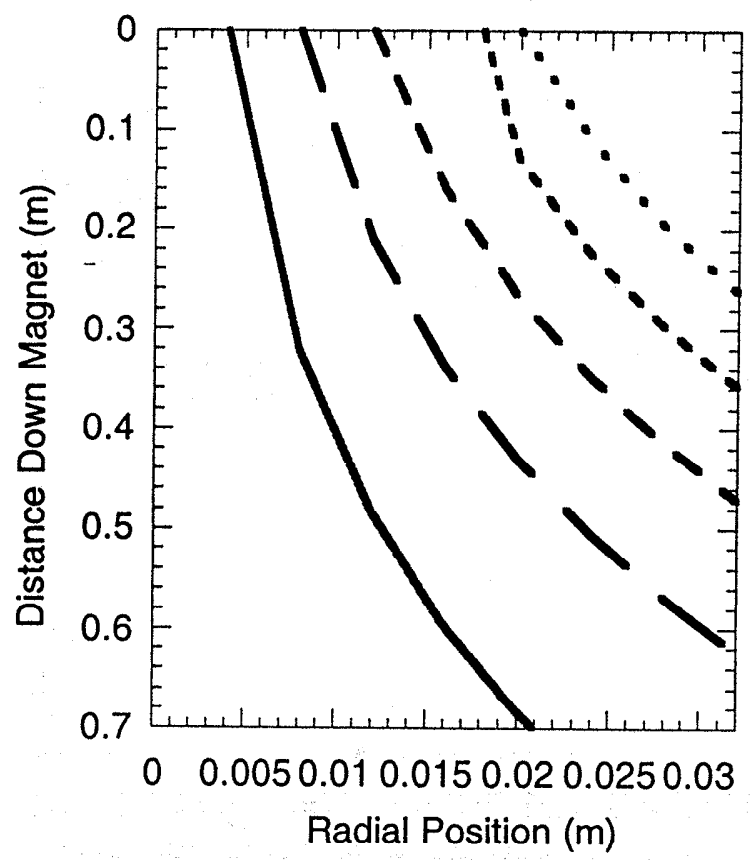

Figure IV-5. Trajectory of $50 \mu \mathrm{m}, 100 \% \mathrm{PuO}_{2}$ particles as a function of radial starting position.

Figure IV-6 shows the variation of the deflection trajectory when the $\mathrm{SiO}_{2}$ concentration is increased, thus increasing the diamagnetic contribution of the particle. The figure also shows that even with $20 \% \mathrm{PuO}_{2}$ the particles (with particle size ranging from 50 to $100 \mu \mathrm{m}$ ) trajectories are paramagnetic or toward the magnet wall and the middlings segregating region. 


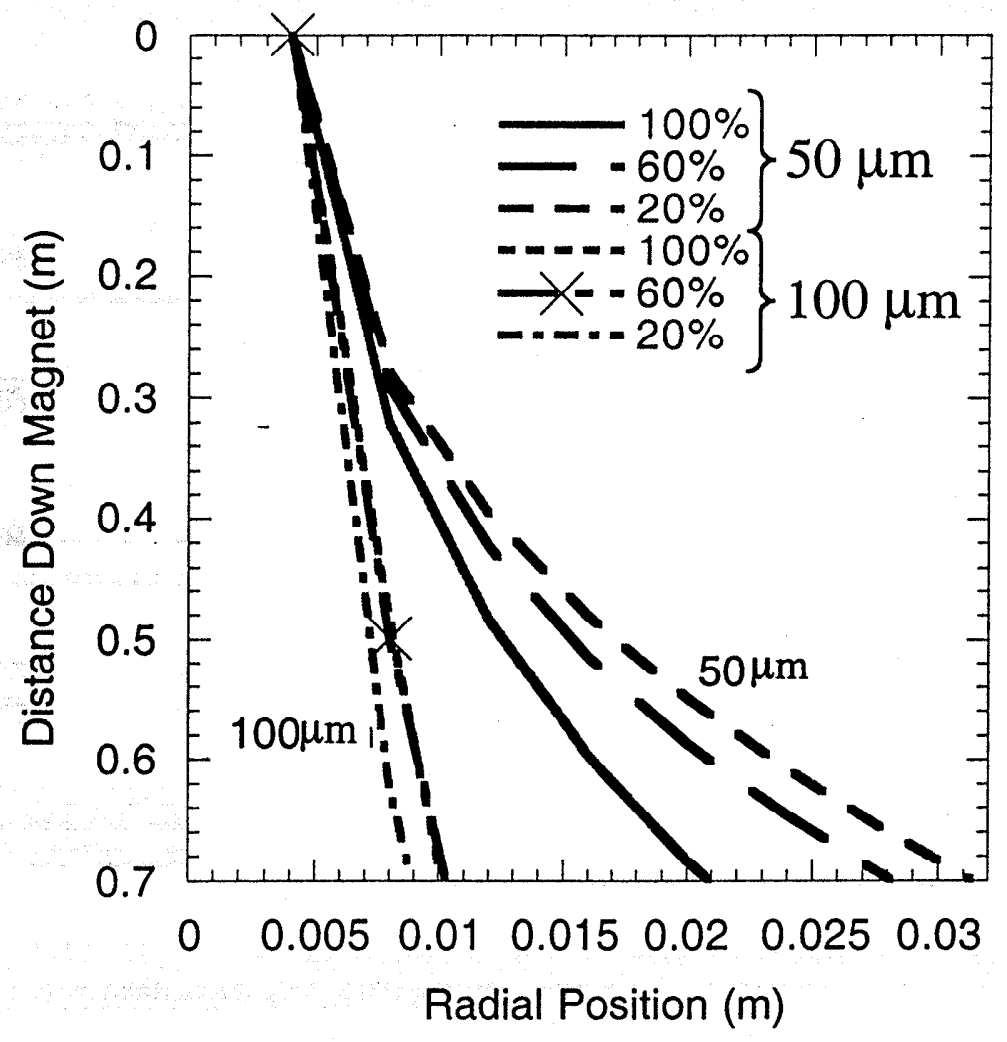

Figure IV-6. Trajectory as a function of $\mathrm{PuO}_{2}$ composition and particle size.

In all of these cases Figures IV-4-6, trajectory solutions fall in the nonStokes flow regime, and the Reynolds numbers vary from 1 to 22 , depending on the particle type and size.

\section{Modeling Other Components}

The cumulative effect of the trajectory models on the $\mathrm{Al}_{2} \mathrm{O}_{3}-\mathrm{SiO}_{2}$ mixtures, $\mathrm{Fe}_{2} \mathrm{O}_{3}$ (hematite) can be seen in Figures IV-7-8. In Figure IV-7 the diamagnetic behavior of the $\mathrm{Al}_{2} \mathrm{O}_{3}$ deflected the particles toward the product region (see Figure II-1) of the OGMS magnet and this is insignificantly changed with the particle size or increased $\mathrm{SiO}_{2}$ concentration. 


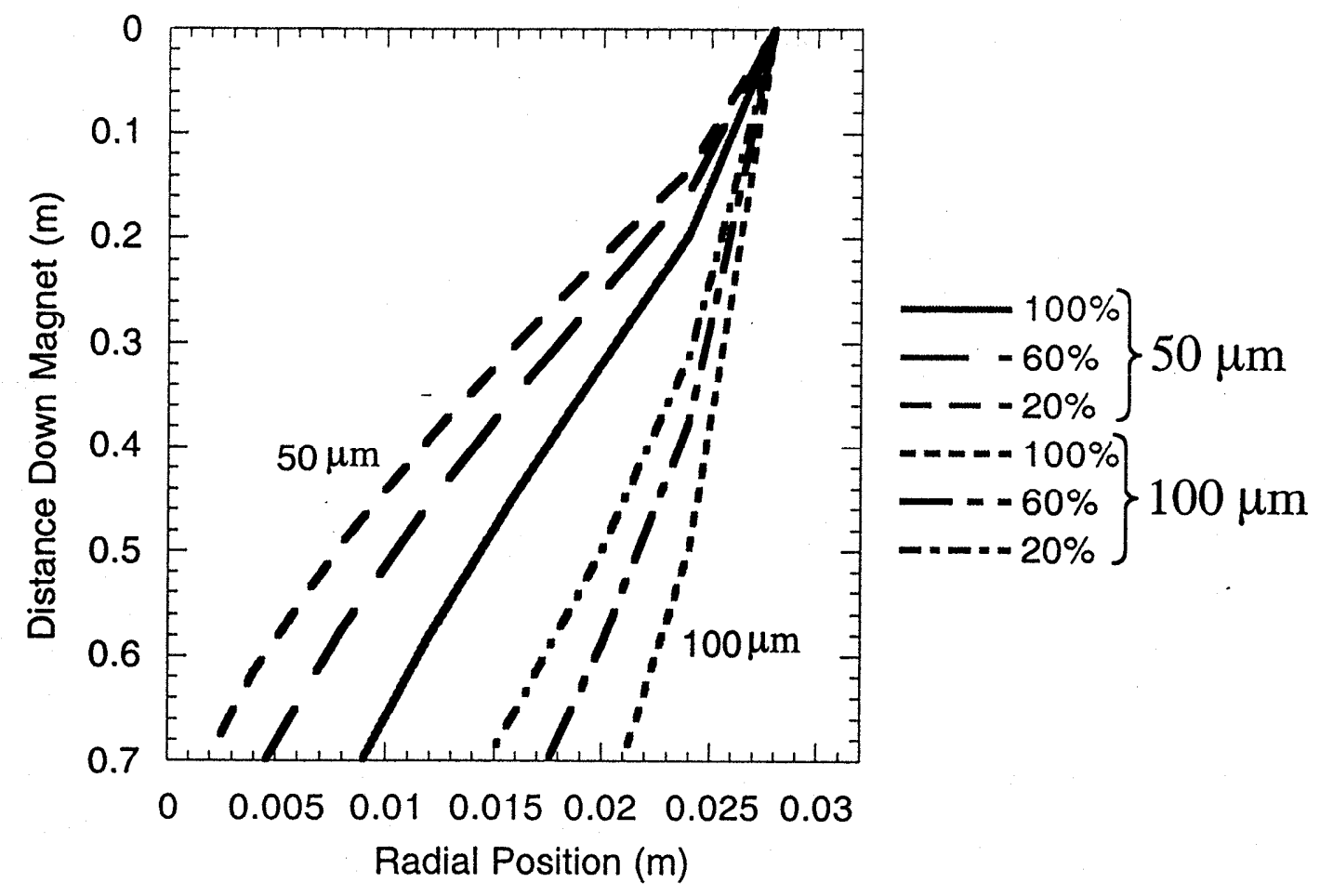

Figure IV-7. Trajectory model for $\mathrm{Al}_{2} \mathrm{O}_{3}-\mathrm{SiO}_{2}$ mixtures.

In addition, the hematite can eventually cause OGMS processing problems due to the strong paramagnetism observed in Figure IV-8 and this may require HGMS pretreatment. 


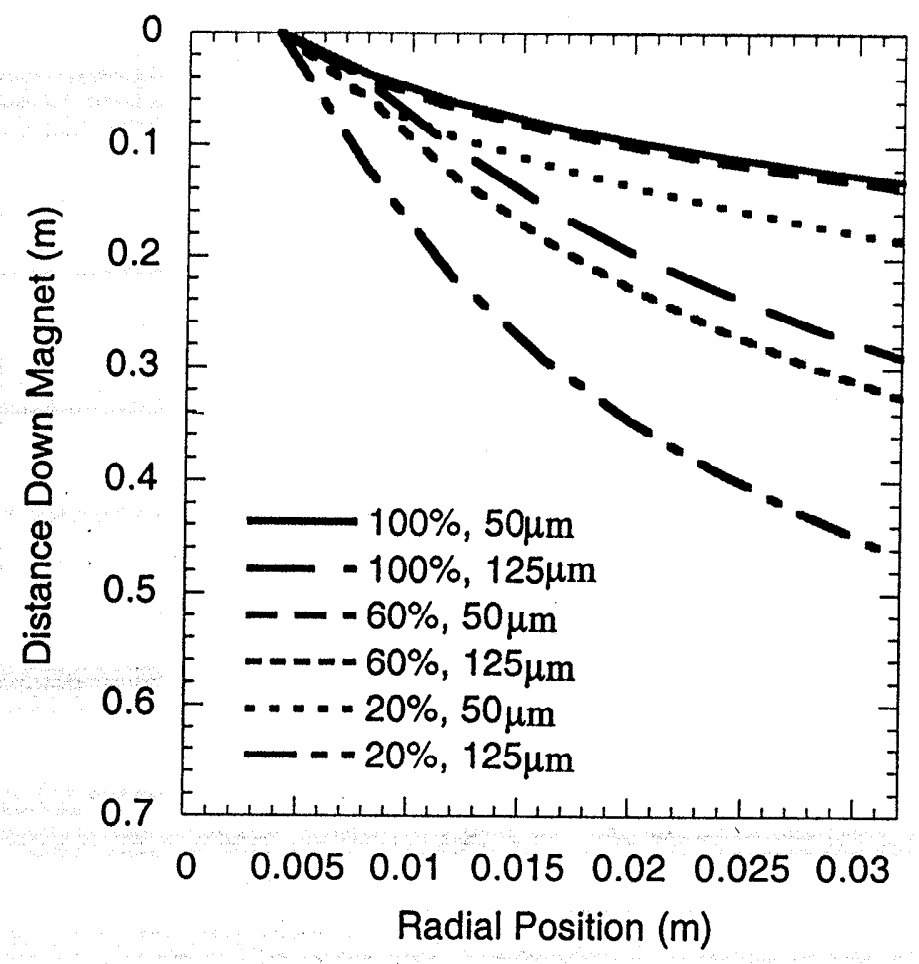

Figure IV-8. Trajectory model for hematite-SiO ${ }_{2}$ mixtures.

A summary of particle deflection or trajectories for a wide range of components is shown in Figure IV-9. 


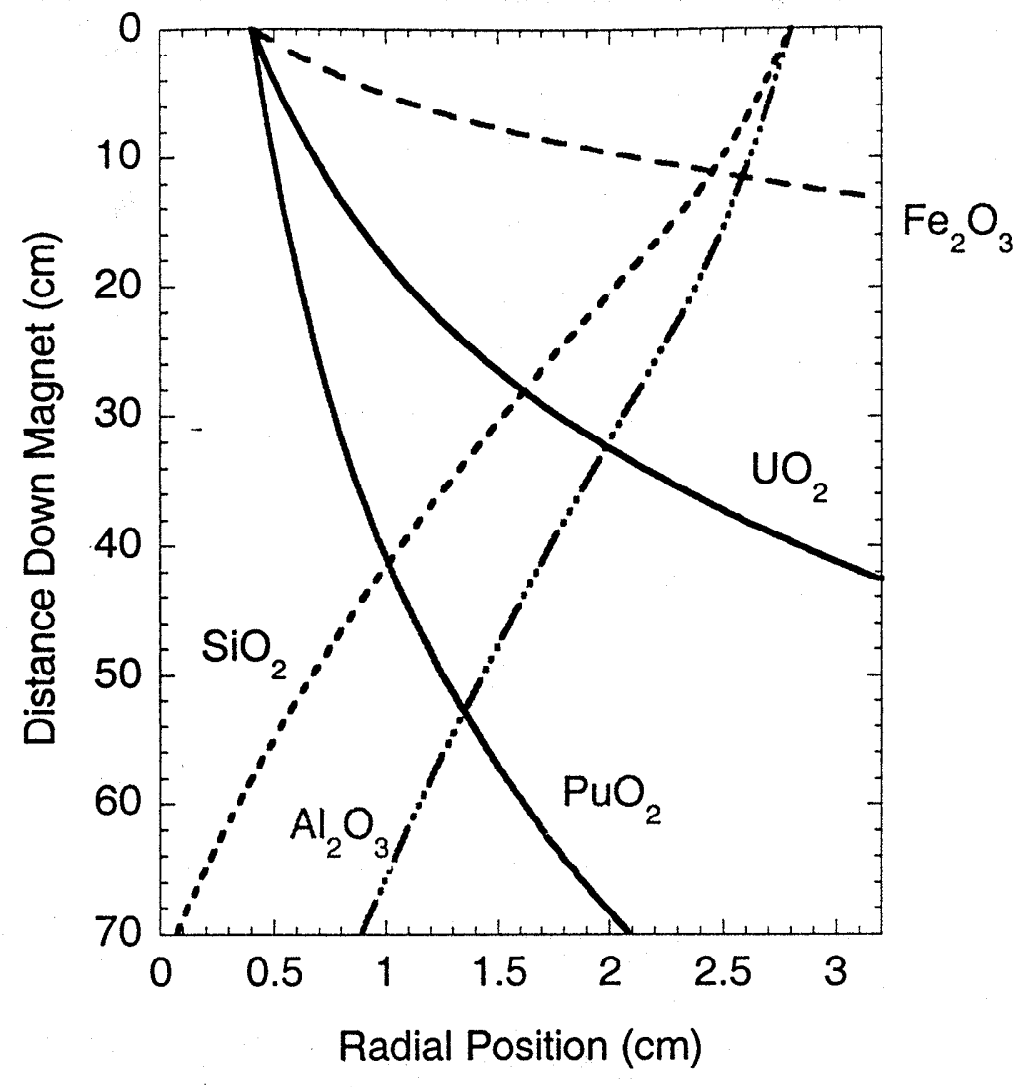

Figure IV-9. Summary of $50 \mu \mathrm{m}$ particles of various pure components.

In summary, computational trajectory simulations using the simple free fall trajectory model has shown that the radioactive solids such as $\mathrm{UO}_{2}$ and $\mathrm{PuO}_{2}$ can be concentrated by an OGMS system. The separation will be concentrated in the magnetic collector region of the OGMS for $\mathrm{UO}_{2}$ particles between 50 and 125 micron. On the other hand, the smaller $\mathrm{PuO}_{2}$ particles $(50 \mu \mathrm{m})$ will be concentrated in the magnetic collector region, the majority $(<75 \mu \mathrm{m})$ will be distributed in the middlings region of the OGMS unit, larger particles will pass to the product region which will require further treatment or longer magnet design. All the diamagnetic phases studied deflect toward the center of the magnet or the product region of the OGMS unit. For hematite, the large concentration and the paramagnetic properties justify a prefiltering using HGMS in order to avoid clogging during OGMS processing (more information is provided in chapter VIII). Both $\mathrm{UO}_{2}$ and $\mathrm{PuO}_{2}$ particles can be separated regardless of initial starting point and particle deflection is 
contained within the OGMS magnet length. Eulerian models have been developed to study various single particle distributions, see Appendix IV. Further work will concentrate on the development of multi-particle models. 


\section{WASTE STREAM CHARACTERIZATION}

The proper design of a magnetic separation process requires knowledge of the microstructure, particle size distribution, and magnetic and chemical properties of the waste stream components in order to determine proper candidacy for treatment. As well, these parameters are needed for input into the computer model to optimize separation and predict product compositions. Westinghouse Savannah River Site (WSRS) performed much of the elemental characterization of the waste streams highlighted in this section (see Appendix I for the WSRS summary.

\section{Hanford CIF Fly Ash and C-103 Sludge Simulants}

\section{Chemical Characterization}

The simulant CIF fly ash and the C-103 tank sludge chemical composition are listed in Table V-1. The CIF fly ash has a high concentration of $\mathrm{Ti}, \mathrm{Mg}, \mathrm{Al}$, and $\mathrm{Fe}$, and the sludge displays a high concentration of $\mathrm{Al}, \mathrm{Fe}$, and $\mathrm{Si}$. The high concentration of $\mathrm{Fe}$ in both the fly ash and sludge are indicative of the presence of various Fe phases that have high susceptibility and are favorable for magnetic separation. 
Table V-1. Elemental composition of simulant CIF waste streams and fractionated fly ash.

\begin{tabular}{|c|c|c|c|c|c|c|c|}
\hline \multicolumn{3}{|c|}{ Simulant Wastes } & \multicolumn{5}{|c|}{ CIF Fly Ash Fractions } \\
\hline Element & $\begin{array}{c}\text { CIF Fly } \\
\text { Ash } \\
(\mathrm{mg} / \mathrm{kg})\end{array}$ & $\begin{array}{l}\text { C-103 } \\
\text { Sludge } \\
\text { (mg/kg) }\end{array}$ & Element & $\begin{array}{c}75 \mu \mathrm{m} \\
11.35 \% \\
(\mathrm{mg} / \mathrm{kg})\end{array}$ & $\begin{array}{c}45 \mu \mathrm{m} \\
48.3 \% \\
(\mathrm{mg} / \mathrm{kg})\end{array}$ & $\begin{array}{c}38 \mu \mathrm{m} \\
7.12 \% \\
(\mathrm{mg} / \mathrm{kg})\end{array}$ & $\begin{array}{l}\text { Bottoms } \\
33.23 \% \\
(\mathrm{mg} / \mathrm{kg})\end{array}$ \\
\hline Cs & 114 & 41.5 & $\mathrm{Fe}$ & 16,990 & 26,390 & 29,790 & 33,590 \\
\hline $\mathrm{K}$ & 4,630 & $5.5-$ & $\mathrm{Ca}$ & 5,760 & 6,840 & 6,860 & 6,380 \\
\hline $\mathrm{Li}$ & 52.6 & $<1.0$ & $\mathrm{Na}$ & 417 & 585 & 629 & 845 \\
\hline $\mathrm{Ti}$ & 1,800 & 60 & $\mathrm{Zn}$ & 49 & 63 & 83 & 103 \\
\hline $\mathrm{Mn}$ & 77.2 & $<3.0$ & $\mathrm{Cr}$ & 40.5 & 54.7 & 55.3 & 73.1 \\
\hline Co & 20.1 & $<8.0$ & $\mathrm{Ba}$ & 364 & 488 & 404 & 536 \\
\hline $\mathrm{Ca}$ & 71 & $<3.0$ & $\mathrm{~Pb}$ & 32 & 44 & 28 & 72 \\
\hline $\mathrm{Mg}$ & 1,510 & 22.2 & $\mathrm{Ni}$ & 31.4 & 42.6 & 47.4 & 54.6 \\
\hline $\mathrm{Fe}$ & 2,630 & 12,500 & $\mathrm{Ag}$ & $<3.2$ & $<3.2$ & $<3.2$ & $<3.2$ \\
\hline $\mathrm{Hg}$ & $<1.0$ & $<0.1$ & $\mathrm{~K}$ & 3,148 & 4,260 & 4,824 & 6,616 \\
\hline $\mathrm{Cd}$ & 1.4 & $<1.2$ & $\mathrm{Li}$ & 36 & 45.2 & 49.6 & 66.4 \\
\hline $\mathrm{Al}$ & 32,900 & 2,475 & $\mathrm{Ti}$ & 1,121 & 1,517 & 1,603 & 1,861 \\
\hline $\mathrm{Sr}$ & 287 & $<5.0$ & $\mathrm{Mn}$ & 57.6 & 72.8 & 77.2 & 86.8 \\
\hline $\mathrm{Gd}$ & 20 & * & Co & 17.7 & 30.5 & 34.5 & 35.9 \\
\hline $\mathrm{Zr}$ & 20 & * & $\mathrm{Cu}$ & 47.5 & 61.7 & 70.3 & 91.9 \\
\hline B & 52 & * & $\mathrm{Mg}$ & 1,230 & 1,570 & 1,670 & 2,150 \\
\hline $\mathrm{Si}$ & 275 & 1400 & $\mathrm{Hg}$ & $<0.1$ & $<0.1$ & $<0.1$ & $<0.1$ \\
\hline $\mathrm{Nd}$ & 20 & $*$ & & & & & \\
\hline Pr & 25 & $*$ & & & & & \\
\hline
\end{tabular}


CIF Fly Ash Microstructure

Microscopy of the Consolidated Incinerator Facility (CIF) fly ash particles revealed a narrow particle size distribution (Figure V-1). Most particles are less than $25 \mu \mathrm{m}$ long, but some may be as long as $100 \mu \mathrm{m}$.

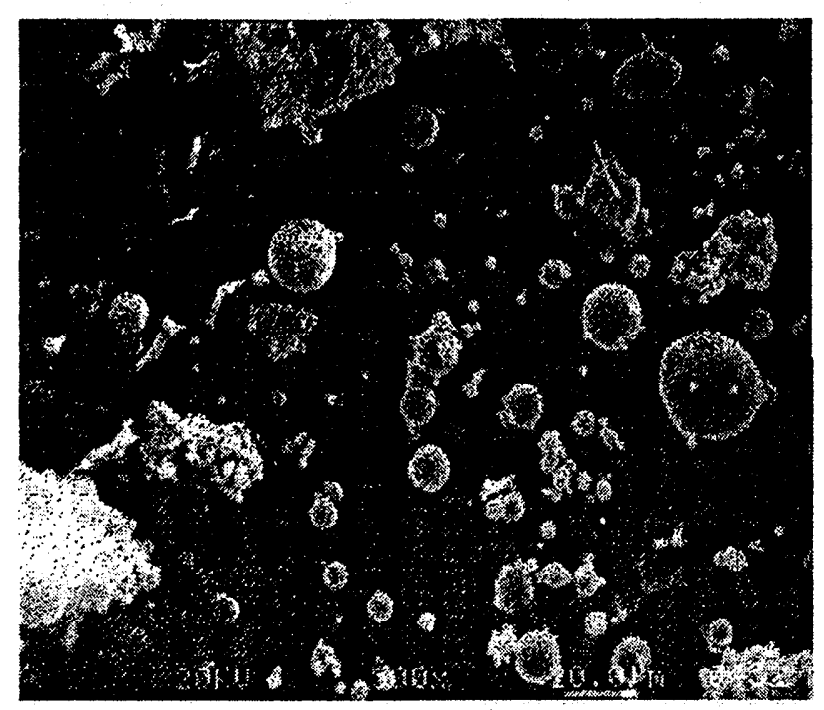

Figure V-1. SEM micrograph of CIF fly ash.

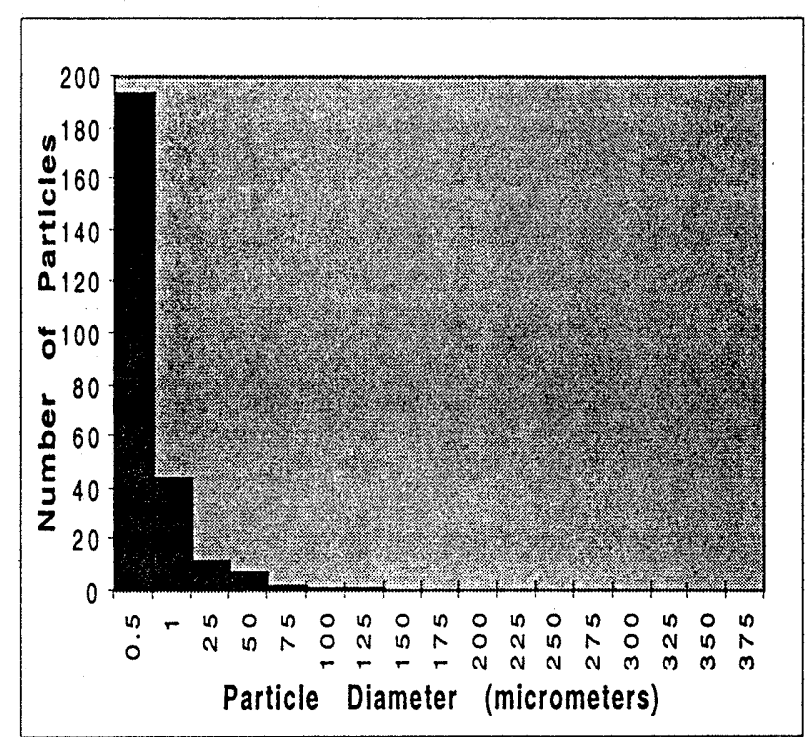

Figure V-2. Particle size distribution for CIF fly ash.

Several large non-spherical particles in Figure V-1 appear to be agglomerations of smaller particles. This information provides some necessary insight about the actual particle size distribution and agglomeration effects during the feeding of the waste stream into the OGMS unit. Various Al-Si-rich phases, 10-50 nm in size, embedded in the fly ash particles were identified with TEM and electron diffraction analyses. The EDS spectra for other spherical particle sizes show a high percentage of diamagnetic $\mathrm{Si}$ and $\mathrm{Al}$ present. However, other metals, such as $\mathrm{Fe}, \mathrm{K}, \mathrm{Ti}, \mathrm{Ca}$, and $\mathrm{Mg}$, are present at high concentrations. In the same sample, an EDS spectrum of a different particle size, which is also representative of the sample shows a different composition, containing $\mathrm{S}, \mathrm{Cl}$, and $\mathrm{Ca}$ at higher percentage's than in other particles. Figure V-2 shows the particle size distribution for CIF fly ash and excludes agglomerations greater than $50 \mu \mathrm{m}$. The high distribution of particles less than a micrometer in size $(>50 \%)$ will 
have a negative effect on the magnetic separation due to the competing forces (e.g., electrostatic, Brownian). However, the SEM analysis shows that distinct regions in particles consist of hazardous minerals of paramagnetic nature and can be liberated; therefore, magnetic separation could partition this LLW stream.

\section{CIF Fly Ash Size Fractionation}

The step fractionation of the simulant fly ash shows that over $33 \%$ was less than $38 \mu \mathrm{m}$ (defined as bottoms). The highest sample fraction was found in the 45-75 $\mu \mathrm{m}$ range and the lowest fraction in the $38-45 \mu \mathrm{m}$ range. These size fractions and high transition metal magnetic susceptibility are within the optimal range for OGMS (Tables V-1 and 2). In all four fractions, there are large concentrations of $\mathrm{Fe}, \mathrm{Ti}, \mathrm{Cr}, \mathrm{Ni}$, and other transition metals that are potential candidates for magnetic separation. In addition, the magnetic susceptibility is different for each size fraction and mineral phase. The bottoms are enriched in all elements except $\mathrm{Ca}$. The differences between the chemical analysis of the bulk and the fractionated CIF fly ash are attributed to sample inhomogeneity. Table V-1 also shows that the particle distribution determined by fractionation is larger than the distribution determined by the SEM micrograph analysis due to the exclusion of the agglomerated particles in the SEM analysis.

Table V-2. Magnetic Susceptibility* of Waste Components

\begin{tabular}{cc}
\hline Compound & Susceptibility $\left(\times 10^{6}\right)$ \\
\hline $\mathrm{Fe}\left(\mathrm{NO}_{3}\right)_{3} \bullet 9 \mathrm{H}_{2} \mathrm{O}$ & $15,200.0$ \\
$\mathrm{FeO}$ & $7,178.0$ \\
$\mathrm{Fe}_{2} \mathrm{O}_{3}$ & $3,586.0$ \\
$\mathrm{UO}_{2}$ & $1,760.0$ \\
$\mathrm{PuO}_{2}$ & 730.0 \\
$\mathrm{Fly} \mathrm{Ash}_{\mathrm{S}}$ & 3.465 \\
$\mathrm{Sludge}$ & 0.208 \\
$\mathrm{ZrO}_{2}$ & -13.8 \\
$\mathrm{Al}_{2} \mathrm{O}_{3}$ & -18.0 \\
$\mathrm{SiO}_{2}$ & -29.6 \\
\hline *diamagnetic (-) and paramagnetic (+)
\end{tabular}




\section{C-103 Sludge Microstructure}

The SEM micrographs obtained for Hanford C-103 tank sludge samples show a wide variety of particle shapes and sizes. The EDS spectrum (not shown) is consistent with the simulant composition and a large concentration of crystalline $\mathrm{NaCl}$. The majority of particles appear to have rough edges and lengths between 30 and $100 \mu \mathrm{m}$. Judging from the appearance of the particles and their morphology, an inhomogeneous composition and distribution is present. Asymmetrical particles are predominant, although other particles are long and narrow with a layered appearance. The average particle size is about $50-60 \mu \mathrm{m}$, with some approximately $100 \mu \mathrm{m}$ in size. Backscattering micrographs (not shown) illustrate regions of high electron density in the particles. An iron phase was identified in the large particles with backscatter analysis. The iron nitrate phase is one with the highest magnetic susceptibility and can be easily separated from the diamagnetic components. The disposition of the radionuclides in the actual sludge will be required to ascertain how effective the OGMS unit can segregate the waste stream. Magnetic separation of a $\mathrm{MgF}_{2}$ residue (75-100 $\mu \mathrm{m}$ size particles) containing $\sim 2 \%$ uranium resulted in a product that was $6 \%$ of the initial bulk residue and contained $95 \%$ of the uranium. The iron nitrate phase (Table V-2) has higher magnetic susceptibility than the uranium oxide; thus, stronger partitioning in the sludge waste is expected for the same particle size range.

\section{CIF and Hanford Tank C-103 Magnetic Characterization}

The magnetic susceptibility is a vital physical property for the magnetic separation of materials from the feed waste streams. For coal particles of up to $50 \mu \mathrm{m}$, ash and pyrite $\left(\chi=1.9 \times 10^{-5}\right)$ are liberated and separated effectively from the coal composite $\left(\chi=-3.1 \times 10^{-6}\right)$ with OGMS [Doctor-1986]. However, coal is not as chemically complex as the radionuclide and hazardous waste streams considered for magnetic separation. In order for magnetic separations to be effective, the susceptibilities for the major phases must be determined. The magnetic susceptibility of $\mathrm{PuO}_{2}$ is $7.3 \times 10^{-4}$; however, the variation in oxygen 
stoichiometry of the oxide in the ash waste causes the lowering of the pure oxide phase susceptibility. The particle size distribution and composition will determine the extent of constituent liberation for the magnetic separation. The Hanford C-103 tank sludge simulant contains various sized particles of colloidal $\mathrm{SiO}_{2}$, gibbsite $\mathrm{Al}(\mathrm{OH})_{3}$, boehmite $\mathrm{AlOOH}, \mathrm{Ca}_{10}(\mathrm{OH})_{2}\left(\mathrm{PO}_{4}\right)_{6}$, and $\mathrm{Fe}\left(\mathrm{NO}_{3}\right)_{3} \bullet 9 \mathrm{H}_{2} \mathrm{O}$ as initially prepared [Lummetta-1996]. After heat treatment and storage, these particle sizes are expected to vary significantly. Simulants of ash and other waste streams will have similar problems. Due to the high susceptibility of the transition metals and the micrometer-size particle range, these constituents can be separated with a HGMS or OGMS system. The optimal particle size range for HGMS systems is between 0.3 and $90 \mu \mathrm{m}$.

The magnetic susceptibility of the simulant Hanford C-103 sludge and CIF fly ash are shown in Figure V-3. The plot of reciprocal susceptibility vs. temperature for CIF fly ash shows a rapid increase as temperature increases. The plot assumes a more linear shape (Curie-Weiss law) for the sludge. The magnetic susceptibility value for the simulant fly ash was $3.47 \times 10^{-6}$ at $25^{\circ} \mathrm{C}$. The shape of the susceptibility curve can be due to the inhomogeneity of magnetic phases in the CIF fly ash (e.g., $\mathrm{FeO}, \mathrm{PuO}_{2}, \mathrm{PuO}_{2-\mathrm{x}}, \mathrm{Pu}_{4} \mathrm{O}_{7}$ ). The CIF fly ash magnetic susceptibility values are low in comparison with those for other iron-containing compounds in the waste stream (e.g., $\left.\mathrm{Fe}\left(\mathrm{NO}_{3}\right)_{3}\right)$. The bulk magnetic susceptibility for the simulant sludge was $2.08 \times 10^{-7}$ at $25^{\circ} \mathrm{C}$. The magnetic susceptibility as a function of size fraction shows the highest susceptibility for the $38-45 \mu \mathrm{m}$ fraction. Again the particles are in the optimal size distribution and magnetic susceptibility for OGMS applications. Table V-2 shows the diamagnetic and paramagnetic susceptibilities of the simulant materials, which are compared with pure mineral phase susceptibilities. The magnetic susceptibility values for the CIF ash are greater than the simulant sludge, agreeing with the chemical composition. Both waste streams show paramagnetic behavior and separation is expected in an OGMS unit. In addition, the ongoing studies to determine the radionuclide disposition would allow the final evaluation of OGMS as a pretreatment process for Rocky Flat ash and Hanford sludge waste streams. 


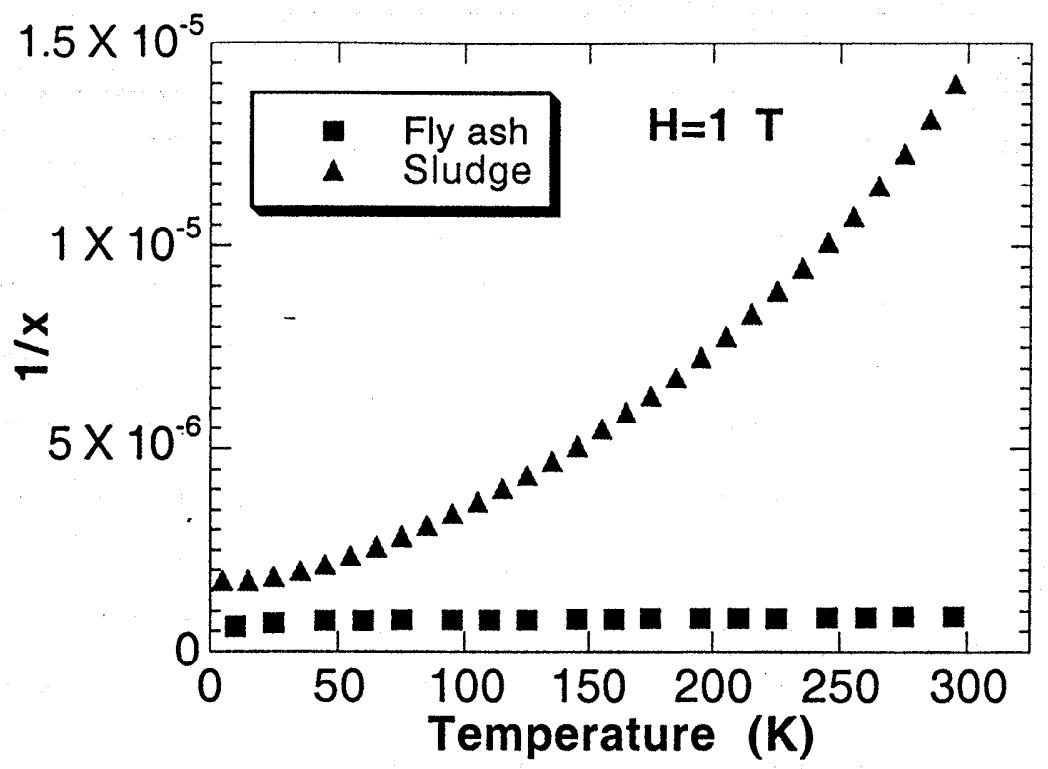

Figure V-3. Magnetic susceptibility as a function of temperature for waste stream.

\section{Rocky Flats Ash}

The evaluation of various radioactive fly ash samples from the Rocky Flats site shows that the percentage of transition metals can vary from 2 to 25 wt\% while the $\mathrm{PuO}_{2}$ content is 0.3-0.8\% [Behrens-1995]. Step fractionation of many of the fly ash waste streams result in $43-61 \mathrm{wt} \% \mathrm{PuO}_{2}$ in the $<350 \mu \mathrm{m}$ size and in the next highest fraction of $\mathrm{PuO}_{2}$ is $177-350 \mu \mathrm{m}$. The high weight fraction distribution $(>25 \%)$ of plutonium oxide for $<350 \mu \mathrm{m}$ particles and the magnetic susceptibility favors segregation with OGMS. Particles of $5 \mu \mathrm{m}$ were observed with SEM analysis with $\mathrm{Pu}$-rich and Pu-lean fractions (Figure V-4). The liberation of particles $>0.5 \mu \mathrm{m}$ favors increased separation between the phases, and future simulations will be performed to determine the particle's trajectory profile with the OGMS system. Nonmagnetic phases (Figure V-4) in the Rocky Flats ash were also observed, such as an aluminosilicate phase, $\mathrm{CaAlSiO}_{\mathrm{x}}$, possibly amorthite, $\mathrm{SiO}_{2}$-quartz, $\mathrm{CaMgSiO}_{\mathrm{x}}$, zirconia (artifact from grinding), and $\mathrm{SiTiO}_{\mathrm{x}}$. The magnetic 
susceptibilities for these phases are in the range of -1 to $-30 \times 10^{-65}$. The iron ferromagnetic phase can be easily separated from the paramagnetic $\mathrm{PuO}_{2}$ using HGMS as a prefilter for OGMS. This result would suggest that a Purich fraction can be obtained that is similar to what Avens et al. had shown in their magnetic separation study. Although magnetic susceptibility of Pu may potentially decrease due to the presence of $\mathrm{Pu}_{4} \mathrm{O}_{7}$ and $\mathrm{PuO}_{2-\mathrm{x}}$ phases in the ash, the decrease in plutonium magnetic susceptibility would be small. In Avens' study, OGMS was used to obtain fine particles of $45-90 \mu \mathrm{m}$, which concentrated $80-90 \%$ of the $\mathrm{Pu}$ in $15-30 \%$ of the initial bulk material. The plutonium concentration in the lean fraction was low enough to discard [Avens-1990] Figure V-4 shows Pu-rich and Pu-lean Rocky Flats fly ash particles illustrated by backscattering measurements. Figure V-5 shows the TEM micrograph that was used to identify various mineral phases in the $\mathrm{Pu}$ lean fly ash.
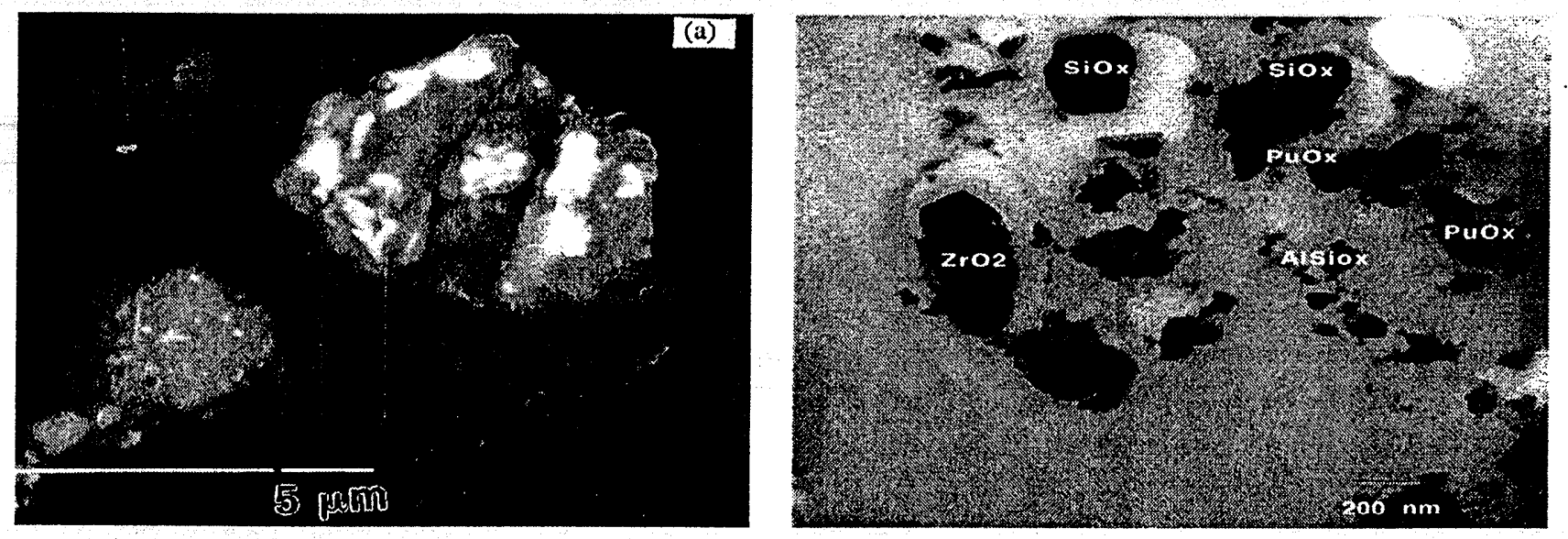

Figure V-4. Backscattering image of Rocky Flats Ash showing Pu-rich (bright spots) and Pu-lean particles.

Figure V-5. TEM of Rocky Flats Ash showing the various mineral phases. 


\section{SRS-Tank Sludge}

\section{Chemical Characterization}

The chemical composition of various drums is tabulated in Tables V-34. Drum 2 shows high metal concentrations of $\mathrm{Mn}, \mathrm{Al}$, and Fe. Drum 4 shows high concentration of $\mathrm{Mn}, \mathrm{Al}, \mathrm{Ca}, \mathrm{Ni}$, and $\mathrm{Fe}$. Drum 7 shows high concentration of $\mathrm{Fe}$ and Drum 9 displays a high concentration of $\mathrm{Al}, \mathrm{Fe}, \mathrm{Mn}$, $\mathrm{Ca}$, and $\mathrm{Ni}$. The high concentrations of paramagnetic $\mathrm{Fe}, \mathrm{Ni}$, and $\mathrm{Mn}$ species in the drum waste are indicative of various metal phases that have high susceptibility and are favorable for magnetic separation. Tables V-5 and-6 show the magnetic susceptibility of various oxide or minerals. 
Table V-3. Elemental Composition of Simulant Waste Streams (mg/kg)

\begin{tabular}{|c|c|c|c|c|}
\hline Element & Drum 2 & Drum 4 & Drum 7 & Drum 9 \\
\hline $\mathrm{K}$ & 16450 & 2065 & 2946 & 12000 \\
\hline $\mathrm{Li}$ & 1935 & 295 & 530 & 645 \\
\hline $\mathrm{Ti}$ & 1441 & 417 & 255 & 767 \\
\hline $\mathrm{Mn}$ & 14500 & 33300 & 5150 & 21200 \\
\hline Co & $<8.4$ & 32.5 & $<8.4$ & 24.8 \\
\hline $\mathrm{Cu}$ & 1690 & 1465 & 948 & 4405 \\
\hline $\mathrm{Mg}$ & 1255 & 390 & 408 & 1765 \\
\hline $\mathrm{Hg}$ & 574 & 2.4 & 105 & 1356 \\
\hline $\mathrm{Cd}$ & 26.8 & 2.4 & 1.1 & 1.8 \\
\hline $\mathrm{Al}$ & 29450 & 69000 & 3020 & 15650 \\
\hline $\mathrm{Fe}$ & 47000 & 188700 & 25325 & 166000 \\
\hline $\mathrm{Ca}$ & 4065 & 13825 & 1845 & 18985 \\
\hline $\mathrm{Na}$ & 30500 & 34500 & 6850 & 46850 \\
\hline $\mathrm{Zn}$ & 730 & 160 & 355 & 1135 \\
\hline $\mathrm{Cr}$ & 24.3 & 242 & 31.2 & 63.5 \\
\hline $\mathrm{Ba}$ & 487 & 78.8 & 290 & 1068 \\
\hline $\mathrm{Pb}$ & 599 & 31 & 430 & 1594 \\
\hline $\mathrm{Ni}$ & 2635 & 21175 & 2750 & 21245 \\
\hline $\mathrm{Ag}$ & 41.0 & 1.8 & 12.6 & 60.2 \\
\hline Cs & 935 & 160 & 27 & 220 \\
\hline B & 4550 & 300 & 890 & 10600 \\
\hline $\mathrm{Si}$ & 430 & 290 & 470 & 270 \\
\hline $\mathrm{Sr}$ & 1030 & 490 & 39 & 310 \\
\hline $\mathrm{Zr}$ & 630 & 42 & 32 & 41 \\
\hline $\mathrm{Ce}$ & 140 & 1700 & 32 & 390 \\
\hline $\operatorname{Pr}$ & 75 & 190 & 18 & 70 \\
\hline $\mathrm{Nd}$ & 3050 & 400 & 16 & 30 \\
\hline $\mathrm{Sm}$ & $<10$ & 60 & $<10$ & $<10$ \\
\hline $\mathrm{Gd}$ & $<20$ & 30 & $<20$ & $<20$ \\
\hline $\mathrm{Sb}$ & 10 & 32 & $<10$ & $<10$ \\
\hline
\end{tabular}

Table V-4 shows the anion composition for the four simulant sludges.

For all drums, chlorides and nitrates are found in the highest concentration. 
Table V-4. Anion Composition of Simulant Waste Streams.

\begin{tabular}{ccccc}
\hline Anion & Drum 2 & Drum 4 & Drum 7 & Drum 9 \\
\hline $\mathrm{Cl}$ & 1100 & 4000 & 306 & 1300 \\
$\mathrm{NO}_{3}{ }^{-}$ & 12300 & 8000 & 2550 & 9200 \\
$\mathrm{PO}_{4}{ }^{3-}$ & $<25$ & $<25$ & $<25$ & $<25$ \\
$\mathrm{SO}_{4}{ }^{2-}$ & 460 & 631 & 101 & 349 \\
\hline
\end{tabular}

\section{Microstructural Characterizations}

\section{Tank Sludge Drum 2}

The X-ray diffraction measurements of tank sludge Drum 2 were able to identify phases that were in concentrations larger than $10 \% \mathrm{wt}$ and are shown in Table V-5. All of the major phases identified by X-ray are diamagnetic, thus a large fraction of the minerals would be deflected towards the center of the OGMS magnetic separator.

Table V-5. SRS Tank Sludge Drum 2 Mineral Phases Identified by X-Ray Diffaction.

\begin{tabular}{ll}
\hline Mineral & Compound \\
\hline soda Niter & $\mathrm{NaNO}_{3}$ \\
Gibbsite & $\mathrm{Al}(\mathrm{OH})_{3}$ \\
Quartz & $\mathrm{SiO}_{2}$ \\
Niter & $\mathrm{KNO}_{3}$ \\
\hline
\end{tabular}

Drum 2 SRS is composed of $15.3 \%$ insoluble solids of which $\mathrm{Fe}$ (98.8 $\mathrm{mg} / \mathrm{g}), \mathrm{Al}(59.8 \mathrm{mg} / \mathrm{g})$, and $\mathrm{Mn}(29.6 \mathrm{mg} / \mathrm{g})$ comprise the bulk of the digestible fraction. Similar to Drum 9 sludge, Drum 2 sludge is composed mostly of non-digestible phases $(560 \mathrm{mg} / \mathrm{g})$. This sludge is brown in color. From optical microscopy five particle morphologies could be distinguished in the fractions $>44 \mu \mathrm{m}-1$ ) colorless shards, 2) tan/yellow spheres, 3) white shards, and 4) a very small amount of black particles. The bottoms fraction contained the minute-sized brown particles with scattered tan/yellow spheres and black particles. From XRD analysis the major crystalline phases were determined 
to be gibbsite $\left(\mathrm{Al}(\mathrm{OH})_{3}\right)$, quartz $\left(\mathrm{SiO}_{2}\right)$, and niter $\left(\mathrm{KNO}_{3}\right)$. An insignificant number of particles were larger than $125 \mu \mathrm{m}$ with the bulk (>99\%) at $<44 \mu \mathrm{m}$.

Table V-6. Relative masses of Drum 2 sludge as a function of mesh size.

\begin{tabular}{ccc} 
& Sieve \# (in $\mu \mathrm{m})$ & \% mass \\
\hline $18(1000)$ & $<0.1$ \\
$120(125)$ & $<0.1$ \\
& $170(88)$ & 0.38 \\
& $230(63)$ & 0.58 \\
& $325(44)$ & 0.54 \\
& Bottom $(<44)$ & 98.5 \\
\hline
\end{tabular}

Using SEM/EDS, it was evident that this sludge was much different than the other three. There was relatively little iron in the sample in any of the size fractions isolated. Figure V-5a-c shows the wide view of the $\# 230$ retained fraction (Table V-6) while Figure V-6 illustrate the bottom fraction. Irregular shaped shards dominate the composition as in the other sludges. Silicon, $\mathrm{Al}$, and $\mathrm{O}$ dominated the EDS scans.

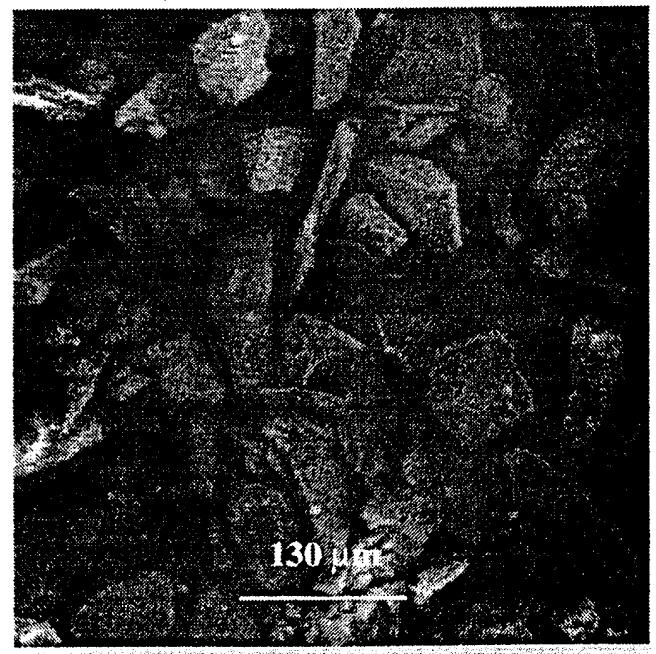

Figure V-5a. Wide field view of Drum 2 \# 230 mesh particles.

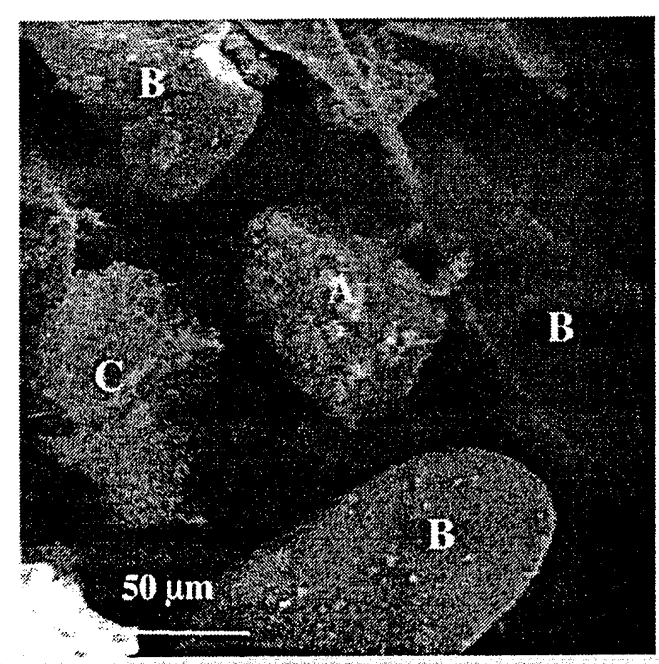

Figure V-5b. Three types of particles are shown here in Drum 2 \# 230 mesh. A). Si-Fe-O rich particle with significant quantities of $\mathrm{Al}, \mathrm{Mn}, \mathrm{Ca}, \mathrm{K}$, and $\mathrm{Ni}$. B) Si-O rich shards. C) $\mathrm{Si}-\mathrm{Ca}-\mathrm{O}$ rich particle with significant quantities of $\mathrm{Al}, \mathrm{Na}, \mathrm{Fe}$, and $\mathrm{Mn}$. 


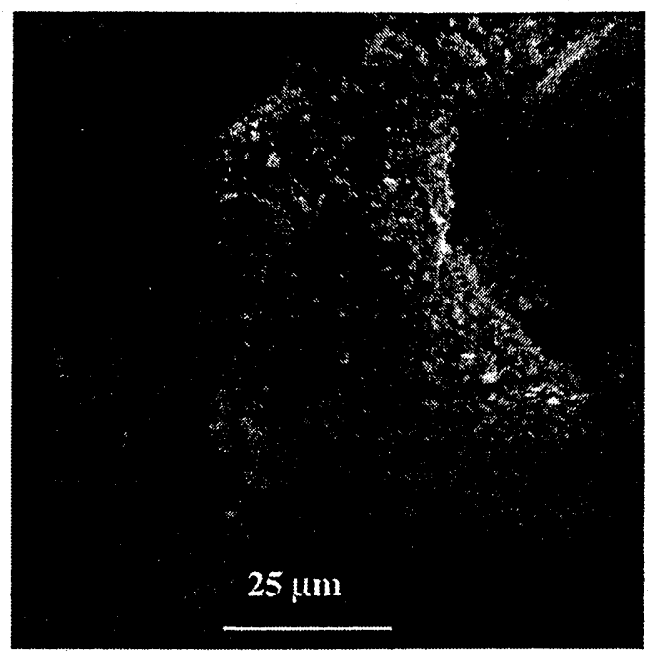

Figure V-5c. Close-up of Ca, O, $\mathrm{Na}, \mathrm{Si}$ rich particle riding on a $\mathrm{Si}$ rich shard in Drum 2 \#230 mesh.

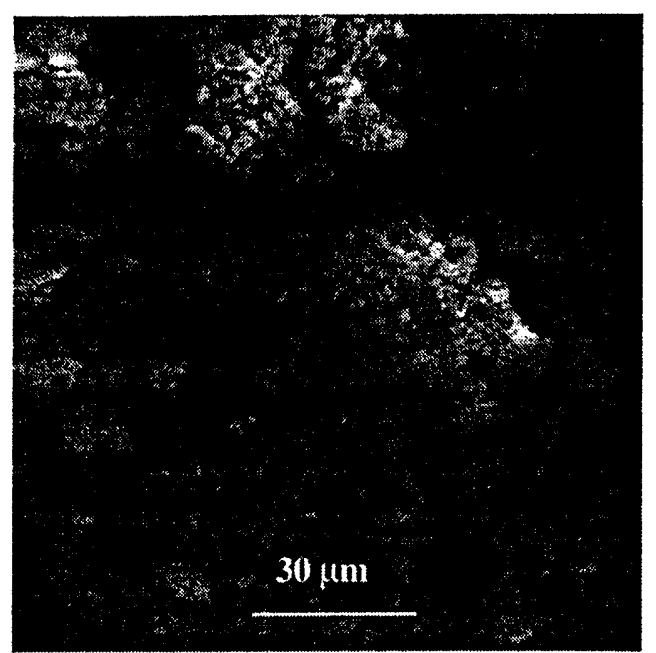

Figure V-6. Drum 2 bottoms fraction contains $\ll 40 \mu \mathrm{m}$ sized particles containing mostly $\mathrm{Si}, \mathrm{O}$, $\mathrm{Al}$, and Na. Significant quantities of $\mathrm{K}, \mathrm{Fe}, \mathrm{Ca}$, and $\mathrm{Mn}$ were also detected.

Tank Sludge Drum 4

Drum 4 SRS is composed of $9.93 \%$ insoluble solids of which Fe (315 $\mathrm{mg} / \mathrm{g}$ ) and, to a lesser extent, $\mathrm{Al}(50 \mathrm{mg} / \mathrm{g})$ comprised the digestible fraction and $180 \mathrm{mg} / \mathrm{g}$ is in the non-digestible fraction. This sludge is brown in color. From optical microscopy three particle morphologies could be distinguished in the fractions $>44 \mu \mathrm{m}-1$ ) colorless shards, 2) tan/yellow particles, and 3) $\mathrm{red} / \mathrm{brown}$ shards in abundance. Also evident are filamentous material, turquoise shards and white shards. The filamentous material did not appear in the \#325 and bottoms sieves. The bottom fraction contained the small brown particles almost exclusively. From XRD analysis the major crystalline phases were determined to be gibbsite $\left(\mathrm{Al}(\mathrm{OH})_{3}\right)$, quartz $\left(\mathrm{SiO}_{2}\right)$, and goethite $(\mathrm{FeOOH})$. An insignificant number of particles were larger than $1 \mathrm{~mm}$ with the bulk ( $>99 \%)$ at $<44 \mu \mathrm{m}$.

Using SEM/EDS, Figure V-7a-d shows the wide view of the \#230 retained fraction. Irregular shaped shards dominate the composition as in 
the other sludges. Iron rich particles typically contain $\mathrm{O}, \mathrm{Al}, \mathrm{Si}, \mathrm{Pb}$ and $\mathrm{Ni}$. Pure Si particles are also abundant.

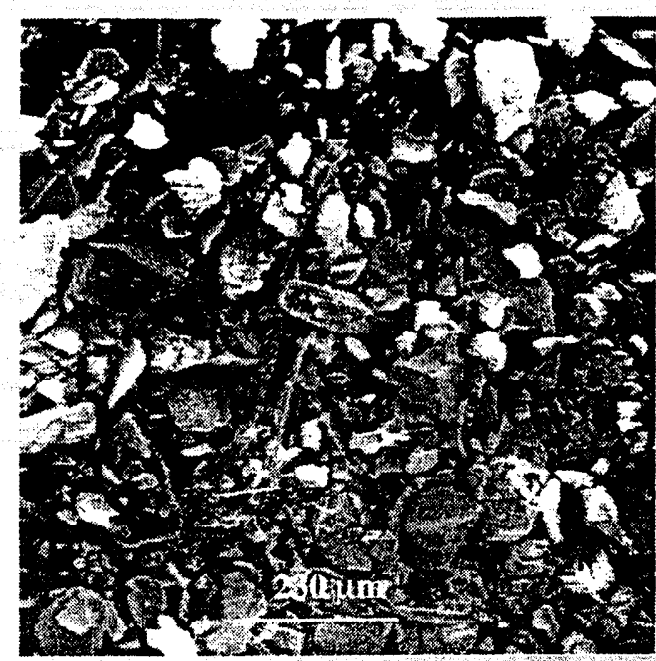

Figure V-7a. Wide view of Drum 4 \# 230 mesh.

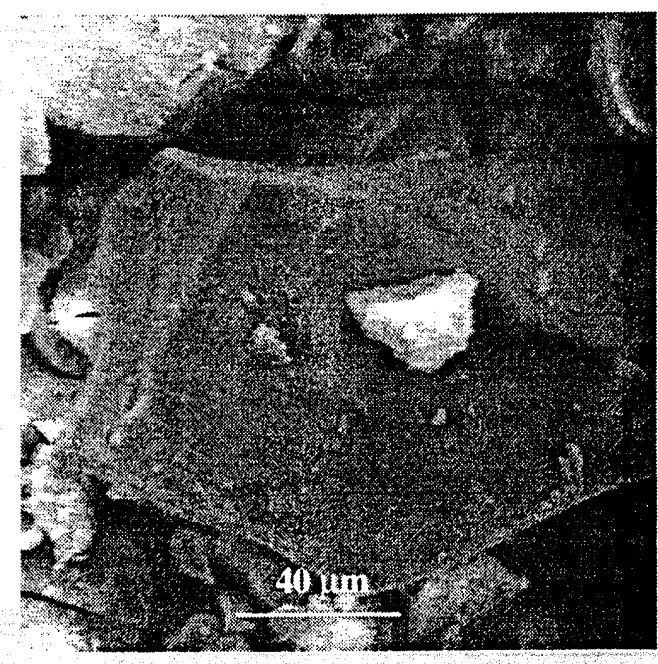

Figure V-7c. Si rich particle from Drum 4 \#230 mesh.

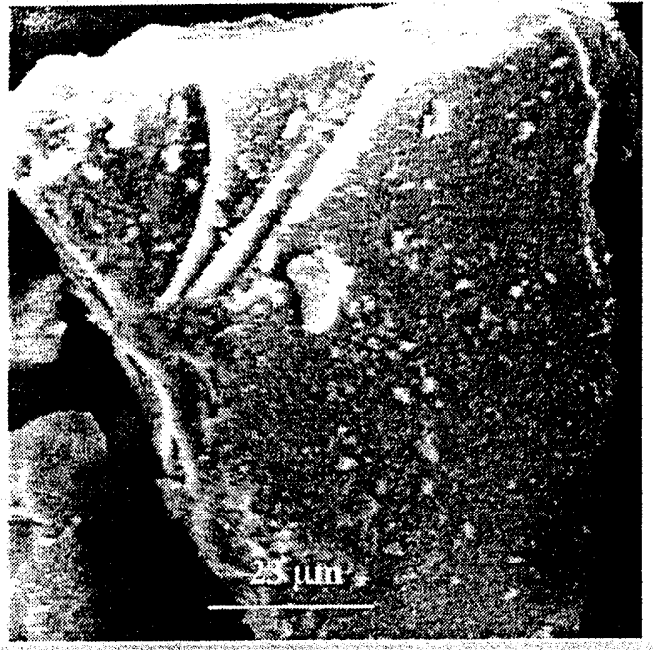

Figure V-7b. Close-up view of silicate containing detectable quantities of $\mathrm{Fe}, \mathrm{O}$, and $\mathrm{Al}$ from Drum 4 \#230 mesh.

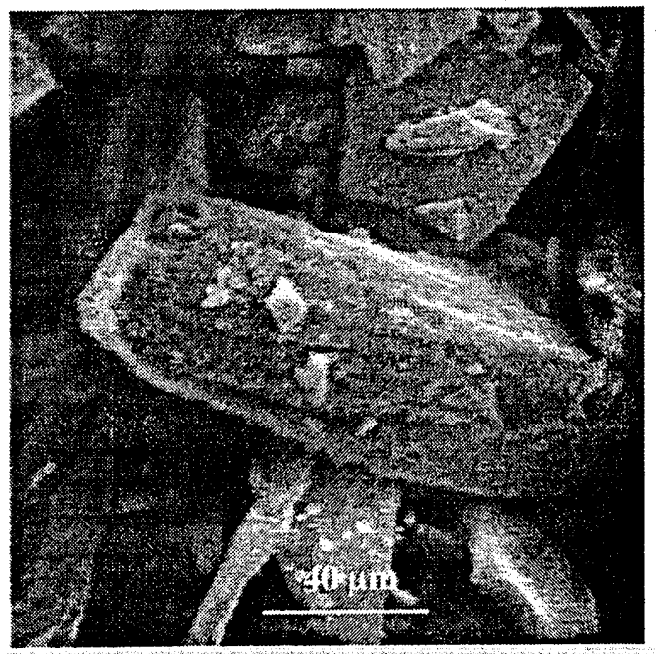

Figure V-7d. Close-up view of silica rich particle in an field of $\mathrm{Fe}$ rich particles in Drum $4 \# 230$ mesh. The filamentous material below the silica shard is composed of $\mathrm{C}$ and detectable quantities of $\mathrm{Fe}, \mathrm{Si}, \mathrm{O}$, and $\mathrm{Al}$. 
Figure V-8 shows the particles of the bottoms fraction. EDS of individual particles showed a complex make-up of predominantly $\mathrm{Fe}$ and $\mathrm{O}$ with significant quantities of $\mathrm{Al}$ and $\mathrm{Si}$, and detectable quantities of $\mathrm{Ca}, \mathrm{Na}$, $\mathrm{Ni}$, and Mn. Particle sizes ranged to the sub-micron level.

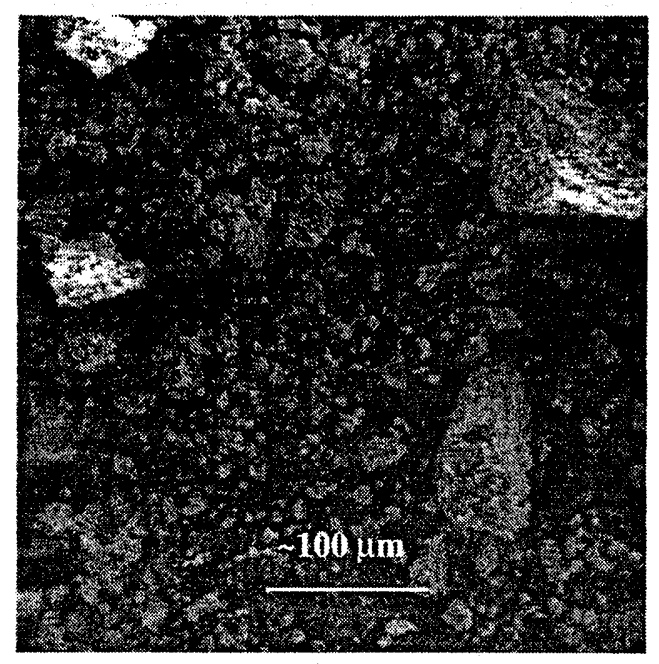

Figure V-8. Wide field image of Drum 4 bottoms fraction. Individual particle sizes are $<<44 \mu \mathrm{m}$ but drying this sludge during sample preparation caused conglomerate to form.

The phases identified by X-ray diffaction measurements are shown in Table V-7. All of the major phases identified by X-ray diffraction are diamagnetic, except the goethite which is paramagnetic and predicted to segregate with the prefiltering HGMS or OGMS.

Table V-7. Drum 4 Mineral Phases Identified by X-Ray Diffaction.

\begin{tabular}{cc}
\hline Mineral & Compound \\
\hline soda Niter & $\mathrm{NaNO}_{3}$ \\
gibbsite & $\mathrm{Al}(\mathrm{OH})_{3}$ \\
quartz & $\mathrm{SiO}_{2}$ \\
goethite & $\mathrm{FeO}(\mathrm{OH})$ \\
\hline
\end{tabular}

Tank Sludge Drum 7

Drum 7 SRS is composed of $2.7 \%$ insoluble solids of which $\mathrm{Fe}$ (345 $\mathrm{mg} / \mathrm{g})$ and, to a lesser extent, $\mathrm{Mn}(70.7 \mathrm{mg} / \mathrm{g})$ comprises the digestible fraction 
and $180 \mathrm{mg} / \mathrm{g}$ is in the non-digestible fraction. This sludge is brown in color. From optical microscopy three particle morphologies could be distinguished 1) very small yellow spheres, 2) irregular shaped brown/black particles, and 3) translucent shards. From previous XRD analysis the major crystalline phases were determined to be gibbsite $\left(\mathrm{Al}(\mathrm{OH})_{3}\right)$, quartz $\left(\mathrm{SiO}_{2}\right)$, and niter $\left(\mathrm{KNO}_{3}\right)$. An insignificant number of particles were larger than $1 \mathrm{~mm}$ with the bulk appearing in diameters of between $88 \mu \mathrm{m}$ and $125 \mu \mathrm{m}$. Table V-8 displays the relative size fractions.

Table V-8. Relative masses of Drum 7 sludge as a function of mesh size

\begin{tabular}{cc}
\hline Sieve \# (in $\mu \mathrm{m})$ & $\%$ mass \\
\hline $18(1000)$ & 0 \\
$120(125)$ & 42.6 \\
$170(88)$ & 24.1 \\
$230(63)$ & 11.0 \\
$325(44)$ & 5.9 \\
Bottom $(<44)$ & 16.4 \\
\hline
\end{tabular}

Using SEM/EDS, Figure V-9a-c shows the wide view of the \#230 retained fraction while the bottom fraction is shown in Figure V-10a-b. Irregular shaped shards dominate the composition as in the other sludges. A higher magnification reveals the presence of silica shards around an Al-rich conglomerate of similar structure as found in Drum 9 analysis. Other shards are rich in (a) $\mathrm{O}, \mathrm{Si}, \mathrm{Al}, \mathrm{Fe}$, and (b) $\mathrm{Si}, \mathrm{Fe}, \mathrm{O}, \mathrm{Al}, \mathrm{Mn}, \mathrm{Ni}$. 


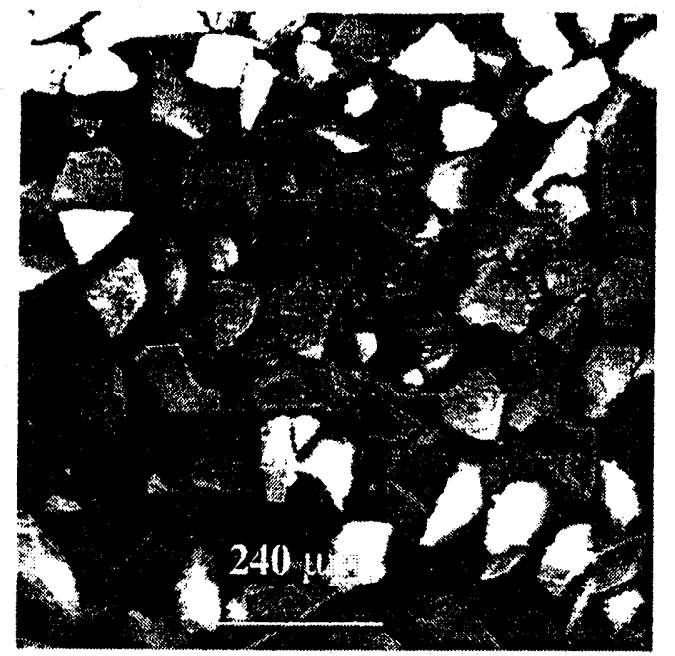

Figure V-9a. Drum 7 \#230 retained fraction. Particles of $\mathrm{Si}$, $\mathrm{Fe}$, and $\mathrm{Al}$ dominate.

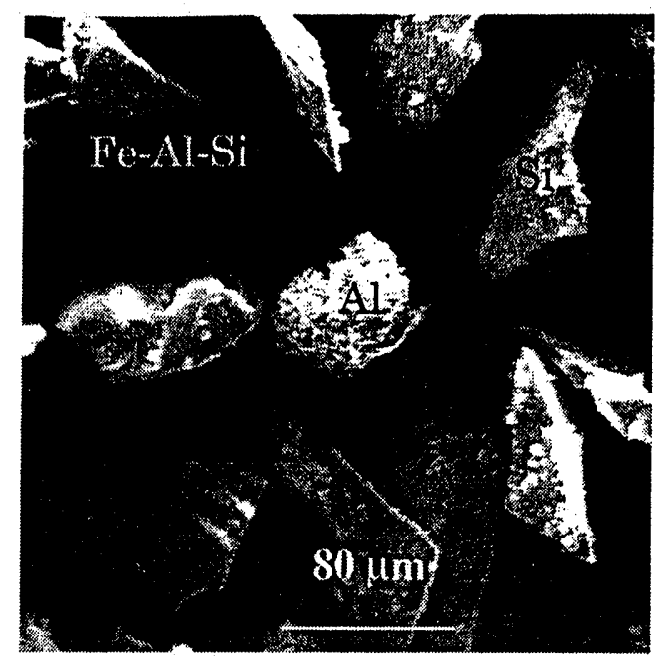

Figure V-9b. Aluminum particle surrounded by silica shards in Drum 7 \#230 mesh 


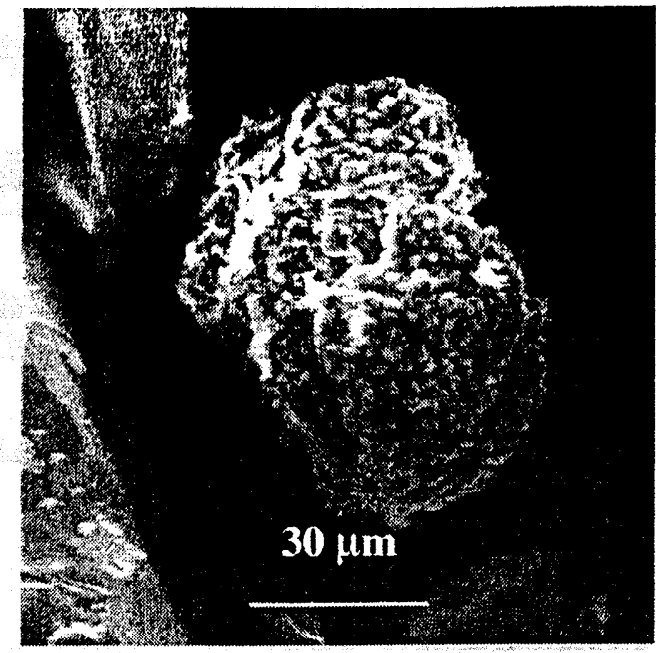

Figure V-9c. Close-up of Fig. 1b. showing porous $\mathrm{Al}$ rich particle.

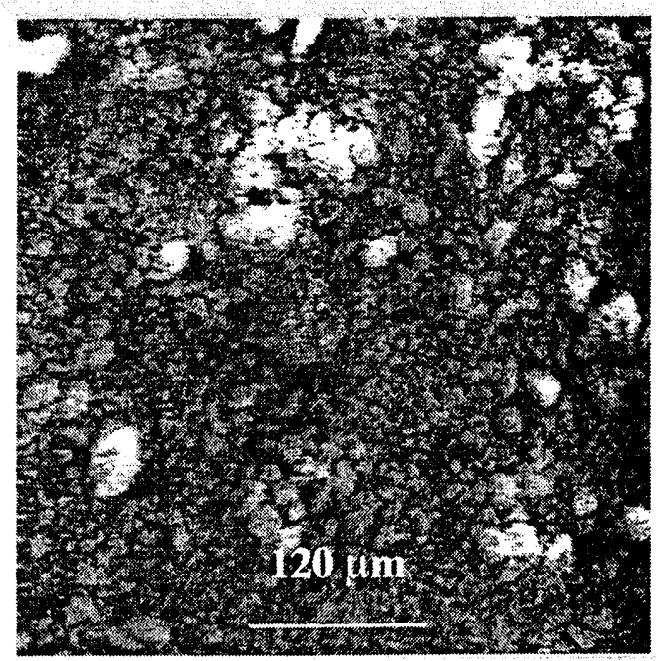

Figure V-10a. Wide view of Drum 7 bottoms fraction. The EDX showed the prevalence of $\mathrm{Fe}, \mathrm{Si}, \mathrm{O}$, $\mathrm{Al}, \mathrm{Mn}$, and lesser presence of $\mathrm{K}$, $\mathrm{Ca}, \mathrm{Na}, \mathrm{Ni}$.

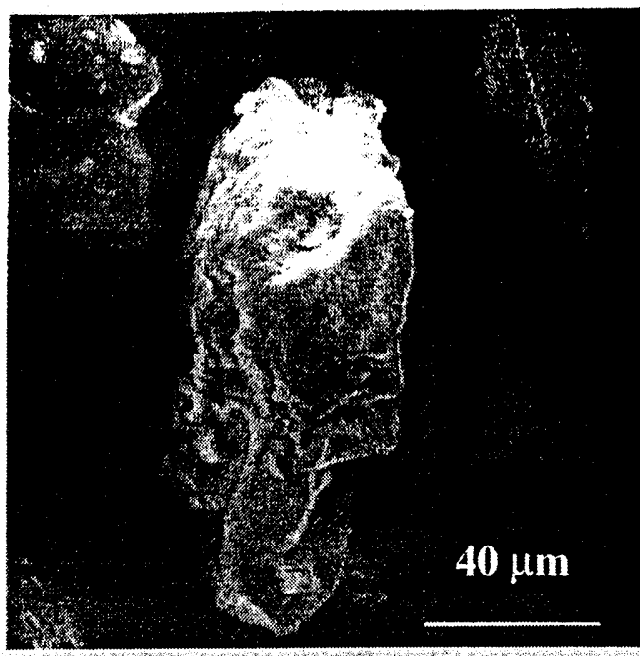

Figure V-9d. Irregular shaped O$\mathrm{Fe}-\mathrm{Al}-\mathrm{Si}$ with identifiable $\mathrm{Mn}-\mathrm{Ca}$ $\mathrm{Ni}-\mathrm{Cu}$.

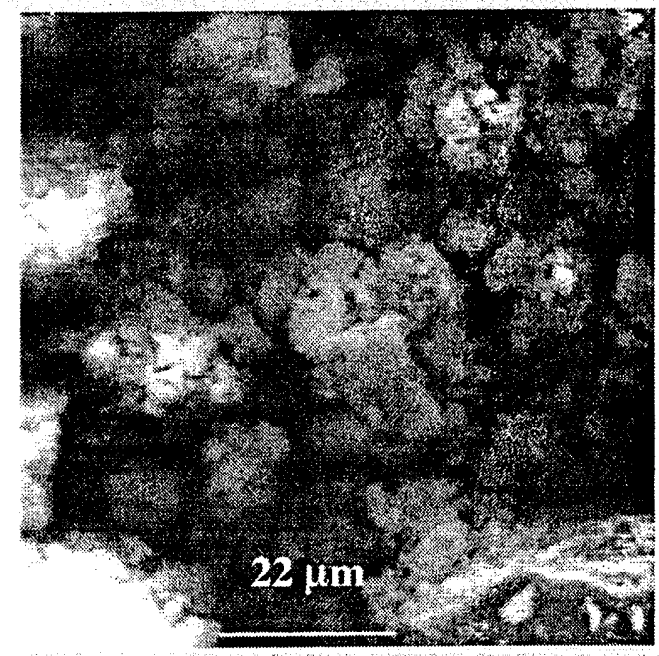

Figure V-10b. A close-up of the bottoms fractions shows the nanometer-sized particles clustered.

Phases identified by X-ray diffraction measurements are shown in Table V-9. All of the major phases identified by X-ray are diamagnetic, thus a large fraction of these minerals would be retained in the center of the OGMS magnetic separator. 
Table V-9. Drum 7 Mineral Phases Identified by X-Ray Diffraction

\begin{tabular}{cc}
\hline Mineral & Compound \\
\hline soda Niter & $\mathrm{NaNO}_{3}$ \\
gibbsite & $\mathrm{Al}(\mathrm{OH})_{3}$ \\
quartz & $\mathrm{SiO}_{2}$ \\
niter & $\mathrm{KNO}_{3}$ \\
\hline
\end{tabular}

Tank Sludge Drum 9

SRS Drum 9 is composed of $11 \%$ by weight of solids (as received). It is composed mostly of an indigestible fraction $(440 \mathrm{mg} / \mathrm{g}$ ) of $\mathrm{Si}$ and $\mathrm{Ca}$ plus others. The bulk of digestible particles are composed of iron $(279 \mathrm{mg} / \mathrm{g})$. The sludge is bright red in color. From optical microscopy three types of particles are distinguishable 1) red, red-brown spheres, colorless shards, and scattered black chunks. There are no particles of $>1 \mathrm{~mm}$ size. The bulk of the ash is $<45 \mu \mathrm{m}$. The relative size fraction compositions are Table V-10. Previous analysis identified hematite $\left(\mathrm{Fe}_{2} \mathrm{O}_{3}\right)$, corundum $\left(\mathrm{Al}_{2} \mathrm{O}_{3}\right)$, and calcite $\left(\mathrm{CaCO}_{3}\right)$ as the major phases.

Table V-10. Relative masses of Drum 9 sludge as a function of mesh size

\begin{tabular}{cc}
\hline Sieve \# (in $\mu \mathrm{m})$ & $\%$ mass \\
\hline $18(1000)$ & $<0.1$ \\
$120(125)$ & 0.7 \\
$170(88)$ & 6.2 \\
$230(63)$ & 6.9 \\
$325(44)$ & 3.16 \\
Bottom $(<44)$ & 83.0 \\
\hline
\end{tabular}

Using SEM/EDS, the presence of silica shards dominated the scan in the \#230 fraction. It was very difficult to distinguish the three particle morphologies identified in the optical analysis. Figure V-11a shows the typical profile of fractions greater than $45 \mu \mathrm{m}$. All the shards in the micrograph are silica. We were able to identify characteristic morphologies of Ca particles and $\mathrm{Al}$ rich particles as shown in Figure $\mathrm{V}-11 \mathrm{~b}-\mathrm{c}$, respectively. 


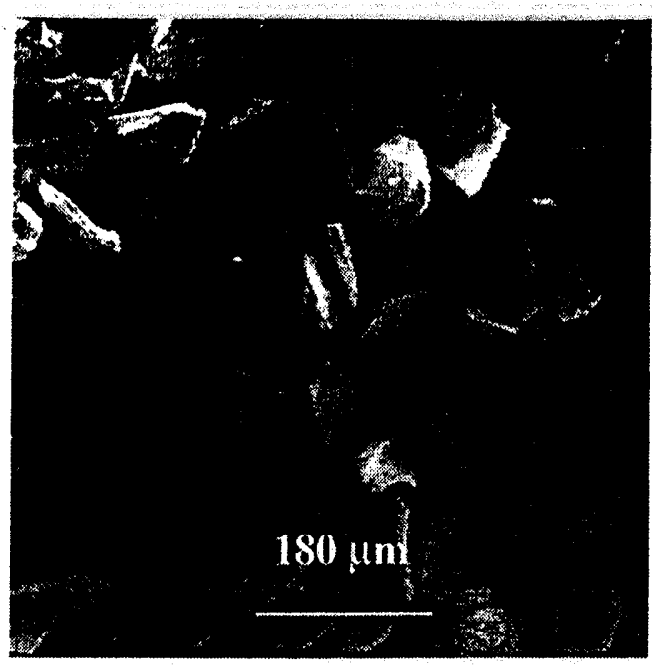

Figure V-11a. The host particles were silica rich colorless shards. The silica must be amorphous which would explain its absence from the XRD analysis.

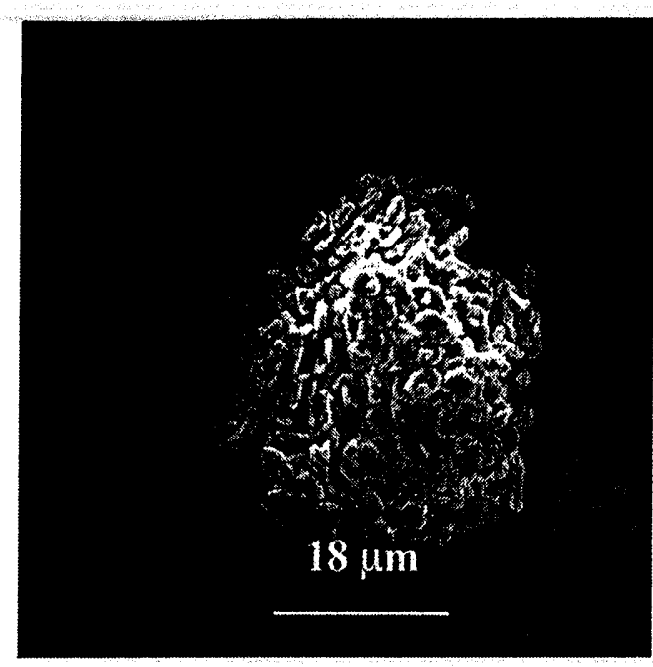

Figure V-11b. Some $\mathrm{Al}$ rich conglomerates were found. Only Al and $\mathrm{O}$ were detected with EDS. 


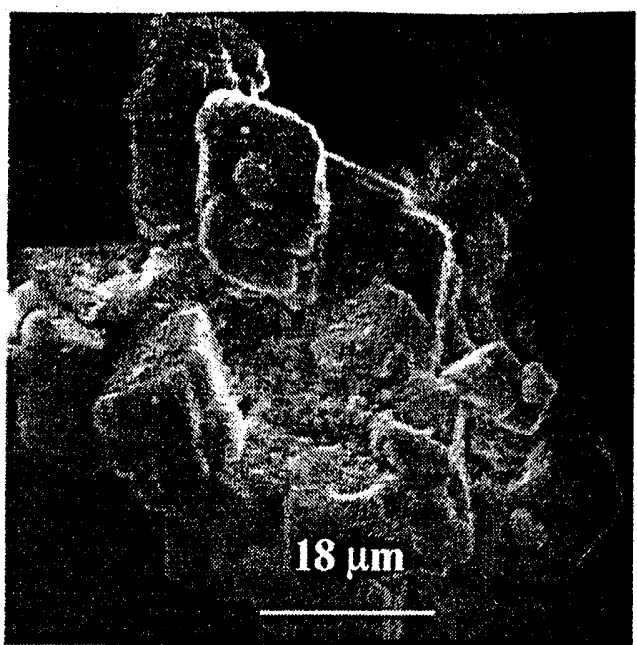

Figure V-11c. Drum 9 \#230 mesh. A number of Ca rich particles formed conglomerates of fused blocks.

The $<45 \mu \mathrm{m}$ fraction constituted the bulk of the sludge material and was composed primarily of sub-micron sized iron rich particles. A highly magnified image of an iron particle is shown in Figure V-12.

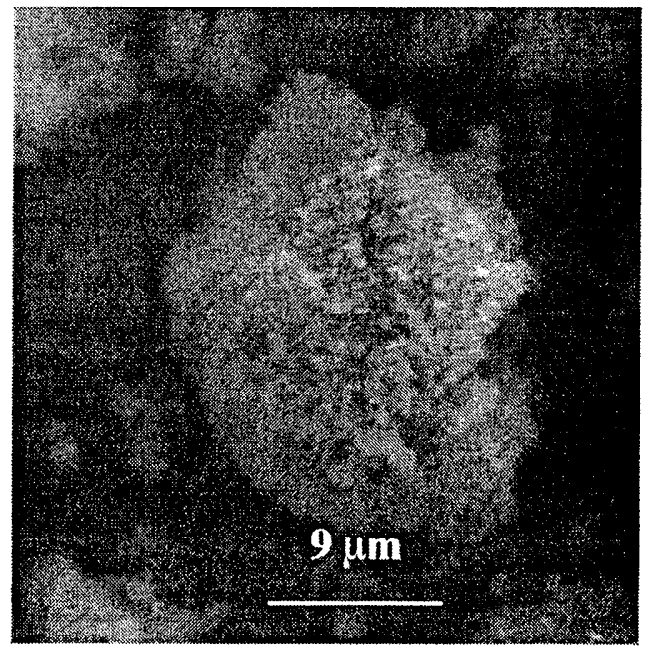

Figure V-12. The fraction of sludge $<45 \mu \mathrm{m}$ was composed almost exclusively of tiny, porous iron rich masses. EDS of this particle also showed the presence of small amounts of $\mathrm{O}, \mathrm{Al}, \mathrm{Si}, \mathrm{Ni}, \mathrm{Mn}$, and $\mathrm{Ca}$ in order of X-ray peak intensity.

The mineral phases identified by X-ray diffraction measurements are shown in Table V-11. All of the major phases identified by X-ray are diamagnetic, except the hematite that is paramagnetic and predicted to segregate with the prefiltering HGMS or OGMS. 
Table V-11. Drum 9 Mineral Phases Identified by X-Ray Diffaction.

\begin{tabular}{cc}
\hline Mineral & Compound \\
\hline hematite & $\mathrm{Fe}_{2} \mathrm{O}_{3}$ \\
corundum & $\mathrm{Al}_{2} \mathrm{O}_{3}$ \\
calcite & $\mathrm{CaCO}_{3}$ \\
\hline
\end{tabular}

\section{Magnetic Susceptibility}

The magnetic susceptibility is a vital physical property for the magnetic separation of materials from the feed waste streams. As shown from magnetic separation studies in coal, uranium, and even plutonium ash, the susceptibilities for the major phases must be determined. The particle size distribution and composition will determine the extent of constituent liberation and size range to apply magnetic separation. For example, the simulant from the Hanford C-103 tank sludge simulant contains various sizes of colloidal $\mathrm{SiO}_{2}$, gibbsite $\mathrm{Al}(\mathrm{OH})_{3}$, boehmite $\mathrm{AlOOH}, \mathrm{Ca}_{10}(\mathrm{OH})_{2}\left(\mathrm{PO}_{4}\right)_{6}$, $\mathrm{Fe}\left(\mathrm{NO}_{3}\right)_{3} * 9 \mathrm{H}_{2} \mathrm{O}$ as initially prepared. After heat treatment and storage these particle sizes are expected to vary significantly; sludge simulants and other waste streams will have similar problems. However, due to the high susceptibility of the transition metals and the micrometer particle size range, these constituents can be separated with an OGMS system if sufficient particle liberation exists. The magnetic susceptibilities of the components of the four different SRS tank sludge waste streams are shown in Tables V-12, 13. Each simulant waste stream was received from the SRS site and was identified by drum number. 
Table V-12. Magnetic Susceptibility of SRS Tank Sludge Waste Components (all values are in cgs units of $\mathrm{cm}^{3} / \mathrm{mol}$ except where indicated).

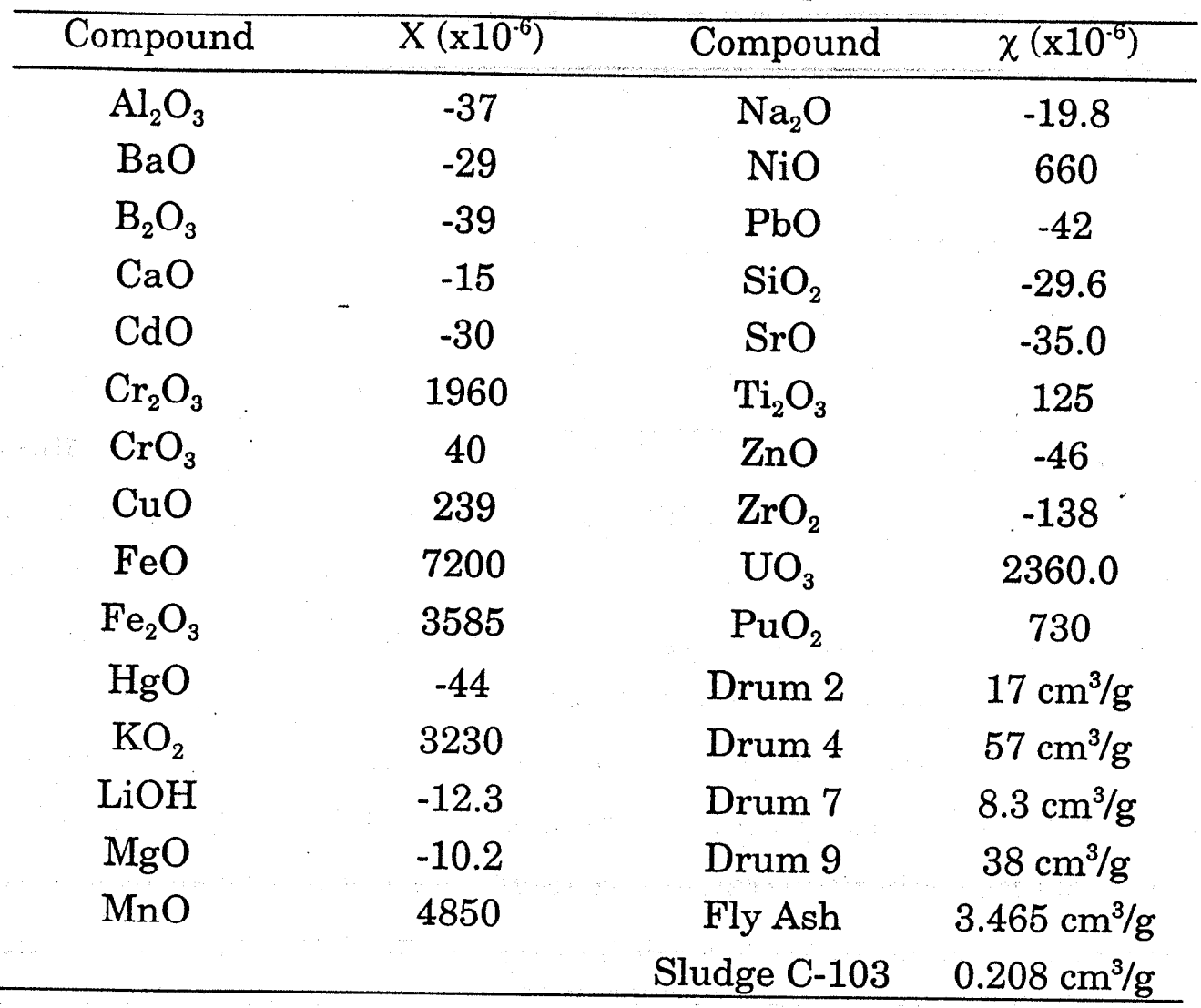

Table V-13. Magnetic Susceptibility of SRS Tank Sludge Mineral Components.

\begin{tabular}{ccc}
\hline Mineral & Compound & $\chi\left(\times 10^{6}\right) \mathrm{cgs}$ \\
\hline Hematite & $\mathrm{Fe}_{2} \mathrm{O}_{3}$ & 3585 \\
Corundum & $\mathrm{Al}_{2} \mathrm{O}_{3}$ & -37 \\
Calcite & $\mathrm{CaCO}_{3}$ & -38 \\
soda Niter & $\mathrm{NaNO}_{3}$ & -25.6 \\
Gibbsite & $\mathrm{Al}(\mathrm{OH})_{3}$ & - \\
Goethite & $\mathrm{FeO}(\mathrm{OH})$ & - \\
Quartz & $\mathrm{SiO}_{2}$ & -29.6 \\
Niter & $\mathrm{KNO}_{3}$ & -33.7 \\
Ni-ferrite & $\mathrm{NiFe}_{2} \mathrm{O}_{4}$ & antiferromagnetic \\
Mg-ferrite & $\mathrm{MgFe}_{2} \mathrm{O}_{4}$ & antiferromagnetic \\
\hline
\end{tabular}




\section{Characterization Summary}

Insofar as OGMS applications are concerned, the fly ashes from the Consolidated Incinerator Facility (CIF) are problematic due to their submicron size range. Run as a dry system, electrostatic effects may cause agglomerations and severely reduce separation efficiency and predictability. Hanford

The C-103 sludge from Hanford is a good candidate for OGMS. It contains a plethora of iron salts that could be easily removed by magnetic separation (if, of course, simple sludge washing was not employed to dissolve the soluble iron salts). The particle sizes are in the 10's of micrometer range. Rocky Flats

The Rocky Flats ash is another good candidate with $\mathrm{Pu}$ contained in diamagnetic silicate phases. Therefore, separation of the iron magnetic phases would not result in two waste streams. Instead, the iron rich particles would segregate favorably from the diamagnetic silicate-Pu phases. Also, the size range of particles is favorable.

Savannah River Site (SRS)

The sludges analyzed from Savannah River Site were very rich in iron oxides and typically composed mostly of particle fines less than $44 \mu \mathrm{m}$. The only exception is Drum 7 sludge, which contained moderate quantities of iron and $84 \%$ of the particles greater than $44 \mu \mathrm{m}$ in diameter. The concern with processing the high iron rich sludges is that clogging of the OGMS would occur predicating the need for an HGMS prefilter. If the iron rich particles contain distributions of actinides as well (e.g., from coprecipitation of iron) then the actinides would be, at least, partially removed with the iron in an OGMS process. This action would produce two waste streams as one would expect the actinides to be incorporated in diamagnetic phases such as the silicates, as well, as seen with the Hanford C-103 sludge. 


\section{RADIONUCLIDE SORPTION ON SPINEL PHASES}

As part of the characterization of the waste feed for OGMS applications, the disposition of dissolved radioactive species needs to be identified. The actinide elements and fission products will exist either in solution as dissolved species, as precipitates on or within the soil or sludge matrix solids, or reversibly sorbed onto the surface of soil and sludge materials. In many cases, the alkalinity of the waste solutions dictate that much of the radioactivity will have been partitioned to a solid phase either as sorbed species or as precipitates. Many of the sorbents will be iron and spinel precursor oxides. If the goal of the separation process is to remove spinel precursors from the feed, leaving less voluminous high-level waste for vitrification, then it is imperative that alpha-emitting radionuclide adsorption onto these spinel precursors be minimized prior to OGMS processing. Otherwise, two waste streams may be created and additional measures will have to be taken to wash the magnetic fraction to remove highlevel waste radionuclides. In some cases, iron salts were added to the waste solutions to coprecipitate the radioactivity out of solution to reduce radioactivity levels. In these cases, it is very well known that the spinel precursors will contain appreciable amounts of radioactivity imbedded or incorporated into the precipitate matrix. Therefore, if the spinel precursors are removed from solution via magnetic separation, the magnetic fraction will be high-level waste and the diamagnetic fraction may be low-level waste. Thus, OGMS may be able to significantly reduce the volume of high-level waste under two scenarios. The processing scenario can be adjusted and this section describes the $\mathrm{pH}$ dependence on the adsorption of key radionuclides onto soil and sludge particle surfaces.

Adsorption phenomena are usually monitored through the partition or distribution coefficient, D. Formally,

$$
D=\frac{C_{r} / m}{C_{f} / V}=\frac{C_{i}-C_{f}}{C_{f}} \frac{V}{m}
$$


where $C_{r}$ is the concentration of sorbing metal removed from solution, $C_{f}$ is the final solution equilibrium concentration, $C_{i}$ is the initial solution concentration, $\mathrm{V}$ is the volume of solution, and $\mathrm{m}$ is the mass of metal oxide in solution. This quantity is derived from mass balance arguments and is related to the equilibrium constant for the reaction.

\section{Sorption Theory for Oxide Surfaces}

The area of actinide and heavy metal sorption onto hydrous oxide surfaces has received a fair amount of attention. The applications for this research are toward remediation and environmental barrier systems -- a cheap sorbent to contain underground contamination plumes from accidental spills or existing contamination, or redundant safety measures for storage facilities (e.g., nuclear waste storage). The surfaces of oxides including hydrous iron oxide, chromium, manganese, titanium, tin, niobium, aluminum, zirconium. In the short term, the accepted mechanism for sorption relies on the ion exchange of protons with the hydroxyl group of the oxides. Longer term sorption display different characteristics and have been attributed to surface reordering which possibly incorporates the sorbed species into the oxide lattice through dissolution-precipitation mechanisms [Girvin-1991]. However, these mechanisms do not account for the observed affinity of oxides for certain dissolved metals over other metals. The role of the dissolved hydroxy-complexes of metals has been pointed out [Mishra1998]. Researcher data seem to agree that the $\mathrm{pH}$ effect regarding adsorption of heavy metals onto hydrous metal oxides is based on the surface properties of the oxide and the hydrolysis of the adsorptive ions [Mishra-1998]. The metal oxides carry a surface charge that is dependent on the $\mathrm{pH}$ of solution. Below the point of zero charge (PZC) (2.3-3.0 for hydrous manganese oxides) the surface has a positive charge. That is, the addition of hydroxyl anions to solution occupies the positive charged sites until the oxide surface is neutralized at the PZC. Above this $\mathrm{pH}$ range, the oxide surface becomes negatively charged; the proton concentration in solution is obviously decreased. The negatively charged surface acts as a cation exchanger. The negative charge can be neutralized by hydronium ions or heavy metal cations 
and there is competition between these positively charged species for a particular negatively charged site. As the $\mathrm{pH}$ continues to rise the hydronium ion concentration decreases and thus there is less competition afforded by the hydronium ion for the negative sites. Thus, the usual trend is a steady increase in the adsorption of cation onto hydrous metal oxide surfaces as $\mathrm{pH}$ increases, assuming the cation species does not change its complex. But as is often the case, the cation species will change as the $\mathrm{pH}$ is changed so dramatically. Hydroxyl, carbonate, chloro-, etc., complexes change the size and charge (i.e., charge density) of the cation and thus the adsorption curve will reflect this. Figure VII-1 illustrates a typical sorption curve for heavy metal cations onto hydrous metal oxide surfaces as a function of $\mathrm{pH}$.

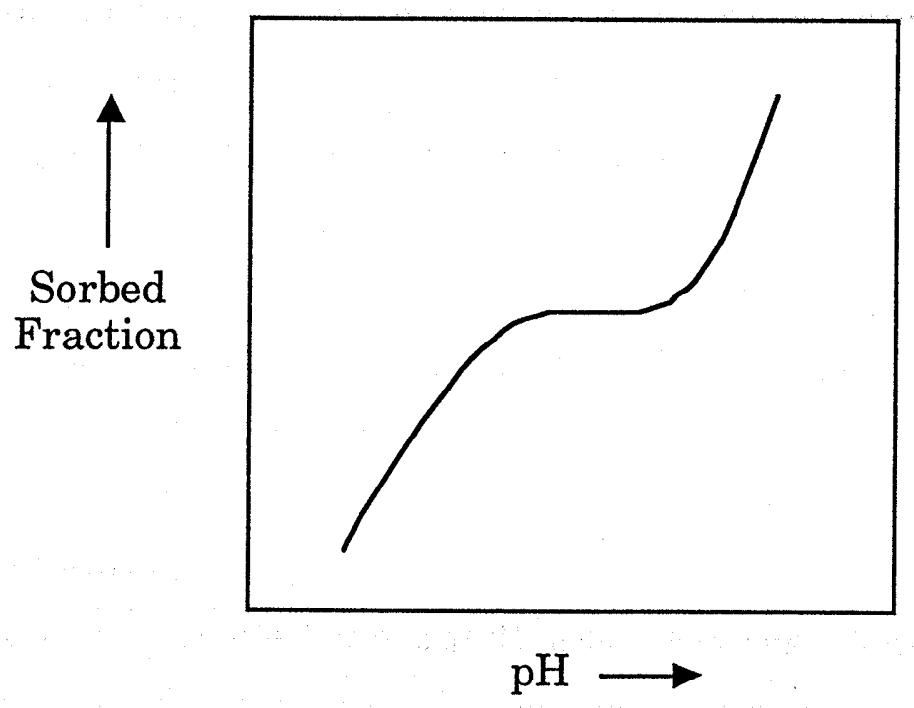

Figure VII-1. Typical adsorption curve for heavy metal cations onto hydrous metal oxide surfaces.

\section{Computer Models}

Over the years, various computer models have been generated to aid in simulating adsorption for complex systems. The Diffuse Layer Model (DLM) describes the oxide solution surface as two parallel planes [Cromieres-1998]. The thin layer immediately adjacent to the oxide surface consists of surface hydroxide groups that undergo proton exchange and ion adsorption. The second layer is a diffuse layer between the thin layer and the bulk solution 
and consists of ions to counterbalance the charge of the first layer. The model, and most other models, represents the sorption as below:

$$
\begin{aligned}
& \overline{\mathrm{XOH}}+H^{+} \leftrightarrow \overline{\mathrm{XOH}_{2}^{+}} \quad K_{+}=\frac{[\overline{\mathrm{XOH}}]}{[\overline{\mathrm{XOH}}] \times\left[\mathrm{H}^{+}\right]} \times P S I \\
& \overline{\mathrm{XOH}} \leftrightarrow \overline{\mathrm{XO}}+H^{-} \quad K_{-}=\frac{[\overline{\mathrm{XO}}] \times\left[\mathrm{H}^{+}\right]}{[\overline{\mathrm{XOH}}]} \times P S I
\end{aligned}
$$

where $\mathrm{K}_{+,-}$are the acidity constants for the hydroxide groups on the surface of the hydrous metal oxide (determined by experiment) and PSI is the electrostatic term, which describes the work necessary to transport an ion from the bulk solution to the oxide surface and is equal to $\pm e^{\left({ }^{F} \psi_{0} / R T\right)}$, where $\mathrm{F}$ is Faraday's constant, $\psi_{\mathrm{o}}$ is the mean surface potential, $R$ is the gas constant, and $\mathrm{T}$ is absolute temperature.

Another model, the Kurbatov model, is similar to that described above except for the absence of the electrostatic term, PSI [Cromieres-1998].

For sorption of cations, hydrolysis of the species must be considered for each cationic complex of a particular metal cation and the formalism is:

$$
\begin{gathered}
\overline{X O H}+M^{n+}+(m-1) H_{2} O \leftrightarrow \overline{X O M(O H)_{m-1}^{n-m}}+m H^{+} \\
K_{m}=\frac{\left[\overline{X O M(O H)_{m-1}^{n-m}}\right] \times\left[H^{+}\right]^{m}}{[\overline{X O H}] \times\left[M^{n+}\right]} \times P S I
\end{gathered}
$$

where $K_{n}$ is the surface complexation constant which is merely the equilibrium constant multiplied by the electrostatic work term. Along with the above experimental data the DLM and Kurbatov models require the input of the specific surface area and concentration of adsorption sites [Cromieres-1998]. 
The triple layer model (TLM) is a more complex expansion of the DLM and has seven adjustable fitting parameters (as opposed to three adjustable parameters for the DLM) including two capacitance parameters and two electrolyte surface-binding constants in addition to the three parameters of the DLM [Hayes-1987].

Another popular model was developed by Bethke [1994] and is called the Geochemist's Workbench. This model operates under similar formalism as described in Eqns. VI-1-3 using the PSI term but also explicitly incorporates experimental activity coefficients, $\gamma$, into the model (except for the oxide hydroxyl group concentration which is assumed $\gamma=1$ ). The DLM and Kurbatov model assume that the ratio of activity coefficients for sorbed species is unity.

All models have distinct limitations when applied to real systems. The complexity of a real environ is nearly impossible to describe mechanistically and would require massive amounts of experimental data for empirical models. The nuances of organic matter, colloids, electrochemical interactions at oxide-solution interfaces, heterogeneous surface chemistry and composition of mineral phases, etc. are still not well understood. Therefore, current predictive models may serve as a basis for arguments on the direction of action or mitigation but must be substantiated with experimental data for that particular system.

\section{Sorption studies}

Mishra et al. [1998] studied Cd(II) adsorption onto hydrous manganese oxide (HMO) having the stochiometry of $\gamma-\mathrm{Mn}_{2} \mathrm{O}_{3}$ for the purpose of evaluating HMO for remediation or mitigation goals. The adsorption data was fit well with the Freundlich isotherms at $\mathrm{pH} 7.2$ with a single slope suggesting a single energy site for sorption. They found that Cd(II) was bound strongly (energy of activation $=6.7 \mathrm{~kJ} / \mathrm{mol}$ ) to the anionic sites of the HMO with increasing adsorption with increasing temperature. In fact, the relatively large enthalpy of reaction $(21.4 \mathrm{~kJ} / \mathrm{mol})$ suggested that the sorption process cannot be entirely explained by simple ion exchange and may have contributions from complex formation of the metal oxide surface. They noted 
that $\mathrm{Cd}$ (II) does not hydrolyze at neutral $\mathrm{pH}$ and exists as the uncomplexed cation but at $\mathrm{pH}>8.5$ the formation of $\mathrm{Cd}(\mathrm{OH})^{+}$species dominates. In Figure VII-1, the inflection point before the second rise in the curve exists at $\mathrm{pH} 8.5$ for their study corresponding to this change in complexation for $\mathrm{Cd}(\mathrm{II})$ onto HMO.

Zasoski and Burau [1988] were interested in elucidating the behavior of $\mathrm{Cd}$ and $\mathrm{Zn}$ adsorption onto hydrous manganese oxide ( $\mathrm{PZC}=\mathrm{pH} 1.5-2.0)$ of the form $\gamma-\mathrm{MnO}_{2}$. They identified two or more sorption sites for $\mathrm{Cd}(\mathrm{II})$ and $\mathrm{Zn}$ (II) species at $\mathrm{pH} 4$ reflected by two distinct slopes on Langmuir and Freundlich isotherm plots. When $\mathrm{Cd}$ and $\mathrm{Zn}$ were added simultaneously to solution, $\mathrm{Cd}(\mathrm{II})$ sorption was more preferred to $\mathrm{Zn}$ (II) sorption. They explained that the high energy site or sites had a greater affinity for Cd(II). The HMO in their study was able to remove $99 \%$ of the $\mathrm{Cd}(\mathrm{II})$ and $75 \%$ of the $\mathrm{Zn}$ (II) at $\mathrm{pH} 4$ proving that the HMO is a very effective scavenger for $\mathrm{Cd}$ and $\mathrm{Zn}$. At higher $\mathrm{pH}$, the sorption of $\mathrm{Cd}(\mathrm{II})$ and $\mathrm{Zn}$ (II) is increased, as expected, with the affinity for $\mathrm{Zn}$ (II) stronger than at $\mathrm{pH} 4$. This was attributed to the formation of zinc hydroxy complexes $\left(\mathrm{ZnOH}^{+}\right.$and $\mathrm{Zn}(\mathrm{OH})_{2}{ }^{0}$ ), which are more prevalent in solution at $\mathrm{pH}$ than cadmium hydroxy complexes. Another explanation could be the nucleation of $\mathrm{Zn}(\mathrm{OH})_{2}$ precipitates which are less soluble than their cadmium counterparts. They found that the alkali earth metal $\mathrm{Ca}$ (II) did not offer any competitiveness for the sorption sites at $\mathrm{pH} 4$ but interfered with $\mathrm{Zn}$ (II) adsorption at higher $\mathrm{pH}$.

The formation of hydroxy-complexes of the sorbing metal is extremely important in that 1) it reduces the charge of the sorbing species which lowers the solvation barrier to adsorption (i.e., the propensity for the adsorbing ion to lose water from its outer shell and thus open up room for metal oxide coordination) 2) the reduced charge helps overcome electrostatic repulsion against a positively charged oxide surface at certain $\mathrm{pH}$ below the $\mathrm{PZC}$ of the metal oxide, and 3) the hydroxy complexes may provide hydrogen bonding opportunites for the sorbing metal and metal oxide surface. The importance of the hydroxyl complexes of metal adsorbing species has been studied extensively. By using ammoniacal solutions [Crawford-1997, Osseo-1979, 1980, Fuerstenau-1987] and chloride solution [Forbes-1974] to hinder 
hydroxyl complexes, they found sorption of certain heavy metals to be suppressed as opposed to systems absent in ammonia and chloride. They attributed specificity of metal ion adsorption (i.e., Cd sorption over $\mathrm{Zn}$ adsorption in a mixed system) to the formation constants for the hydroxy complexes. This says that those species that do not form hydroxy complexes will only exhibit electrostatic and solvation influences to sorption and not chemisorption. And it is the chemisorption phenomenon that governs the preference of one metal ion complex over another [Crawford-1997].

Adsorption of divalent and trivalent cations onto synthetic and natural iron oxide and aluminum oxides has been carried out to determine the $\mathrm{pH}$ dependence on sorption [Tochiyama-1996]. Adsorption of $\mathrm{Eu}$ (III) and $\mathrm{Co}$ (II) on the various iron and aluminum oxides followed similarly to studies performed with $\mathrm{Np}(\mathrm{V})$ as $\left(\mathrm{NpO}_{2}^{+}\right)$in that the slope of the $\operatorname{logD}$ versus $\mathrm{pH}$ was a single value for the $\mathrm{pH}$ range of natural waters ( $\mathrm{pH} \mathrm{5-7).} \mathrm{Also,} \mathrm{the}$ adsorption was higher for the synthetic and amorphous iron and aluminum oxide than for the natural goethite and gibbsite. Also of note, although the oxide surfaces are heterogeneous the adsorbing metals can be modeled assuming a homogeneous occupation of available sites and the Langmuir isotherm.

Because of the importance of long term migration of stored radioactive waste, neptunium ( $\mathrm{Np}$ ) species have been studied extensively. Adsorption studies of $\mathrm{Np}$ onto aluminum oxides [Tochiyama-1996], iron oxides [Tochiyama-1995, Girvin-1991], humic [Marquardt-1998a] and fulvic acids [Marquardt-1998b] have all been completed. Sorption studies of $\mathrm{Np}(\mathrm{V})$ onto the aluminum and iron oxides and hydrous oxides show a linear dependence for the $\log D_{\mathrm{Np}(\mathrm{V})}$ with $\mathrm{pH}$ in the range of $\mathrm{pH} 3-10$. The magnitude of the $\log \mathrm{D}$ depends on the type and method of production of the metal oxides which is testament to a dependence on the crystallinity of the oxide [Tochiyama-1995]. The triple layer model was used to model the sorption and determine sorbed species [Girvin-1991] with good success showing that $\mathrm{NpO}_{2}{ }^{+}$is sorbed as the single hydrolyzed and neutral species, $\mathrm{XOH}-\mathrm{NpO}_{2}(\mathrm{OH})$, where $\mathrm{XOH}$ is the surface hydroxide group of the iron oxide. 
In another study, researchers determined two surface sites on natural hematite for occupation by $\mathrm{Eu}(\mathrm{III})$ through the deprotonation of surface hydroxyl groups at $\mathrm{pH}<6.0$ [Rabung-1998]. They also pointed out the importance of anionic ligands such as oxalate and their complexation with the $\mathrm{Eu}$ (III) thereby reducing surface complexation. Also, the presence of organic matter fulvic and humic acids can occupy sorption sites and further reduce adsorption of metal cations from theoretical values. In another study with hematite colloids [Cromieres-1998], the adsorption of $\mathrm{Th}$ (IV) was strongly $\mathrm{pH}$ dependent with sorption occurring well below ( $\mathrm{pH} \mathrm{2-5)} \mathrm{the} \mathrm{PZC}$ ( $\mathrm{pH}$ 7.2-7.8) indicating a high affinity despite the electrostatic repulsion of the positive oxide surface and suggesting the formation of inner sphere complexes.

Collins et al. [1998] studied the sorption characteristics of $\mathrm{Sr}^{2+}$ onto geothite at the atomistic level. Their concern was over the high Curie content of $\mathrm{Sr}-90$ in radioactive waste tanks such as those at Rocky Flats, $\mathrm{CO}$, where $93 \%$ of radioactivity is due to $\mathrm{Sr}-90$. The sorption of $\mathrm{Sr}^{2+}$ begins at around $\mathrm{pH}$ 8 , which is near the $\mathrm{PZC}$ for goethite. Their results show that at $\mathrm{pH} 9.2 \mathrm{Sr}^{2+}$ is outer spherically bound to goethite, meaning its hydration shell is not at all disturbed upon sorption. At $\mathrm{pH} 10.2$ the data reveals that two water molecules are ejected and replaced in the coordination sphere with two nearest neighbor iron atoms of goethite forming an inner sphere complex. The inner sphere complex is more stable and thus a stronger bond, which is significant because there would be a hysteresis effect upon desorption of the sorbed cations at the high $\mathrm{pH}$ making the removal of sorbed species more difficult.

The environmental chemistry of the long-lived actinides has been studied with particular focus on the behavior or actinides leaking from an interim or permanent nuclear fuel and/or waste storage facility. The chemistry of uranium has not been studied extensively for disposition in soils. It is believed that the dominant species in soil environments are $\mathrm{UO}_{2}{ }^{2+}$, $\mathrm{UO}_{2}\left(\mathrm{CO}_{3}\right)_{3}{ }^{4-}, \mathrm{UO}_{2}\left(\mathrm{CO}_{2}\right)_{2}{ }^{2}, \mathrm{UO}_{2}\left(\mathrm{CO}_{3}\right)_{3}{ }^{4-}$ but most of the work has been limited to non-nuclear related soils [Alloway-1995]. Uranium contamination at DOE sites is usually a result of accidental spillage or leakage of storage tanks. The 
chemistry of the waste solution, therefore, is characterized by a high ionic strength and $\mathrm{pH}$. The $\mathrm{pH}$ is high $(>10.5)$ to protect against corrosion of the tank structure and the ionic strength is high $(>1 \underline{\underline{M}})$ due to evaporation of the waste solution to minimize volume. As expected both the $\mathrm{pH}$ and ionic strength of solution will play key roles in determining the sorption of uranium, not to mention the actual composition of the soil (e.g., carbonates, iron oxides, humic matter, clays). For pure mineral phases and natural sediments, $\mathrm{U}(\mathrm{VI})$ adsorption tends to increase with increasing $\mathrm{pH}$ from $\mathrm{pH}$ 3.5 to about 8. At $\mathrm{pH}>9$ the adsorption declines due to the formation of anionic carbonate/hydroxyl complexes. The increase in adsorption as the $\mathrm{pH}$ rises from acidic to neutral is attributed to the opening of sorption sites vacated by the ever decreasing proton concentration in clays and mineral surfaces [Kaplan-1998]. The opposite effect is typically seen for increasing ionic strength in that adsorption is reduced due to competition effects and lowering of the thermodynamic activity of $U(V I)$ in high ionic strength solution. However, precipitation-coprecipitation phenomena can occur in high ionic strength solution and thus remove U(VI) from the solution phase even though this is not strictly chemisorption onto the soil surfaces.

The chemistry of plutonium is remarkably complex due to its many oxidation states (III, IV, V, VI) in solution, tendency for $\mathrm{Pu}(\mathrm{IV})$ to disproportionate, and the slow rate of reaction of $\mathrm{Pu}$-oxygen species (e.g., $\mathrm{PuO}_{2}{ }^{+}$and $\mathrm{PuO}_{2}{ }^{2+}$ ) [Alloway-1995]. According to thermodynamic models [Watters-1983] the oxidized species of $\mathrm{Pu}$ (e.g., $\mathrm{Pu}(\mathrm{V})$ ) should be the most stable but this is not observed as both the reduced and oxidized forms are prevalent. Organic matter and iron oxide surfaces can electrochemically reduce $\mathrm{Pu}(\mathrm{V})$. Rai and Serne calculated stable $\mathrm{Pu}$ minerals to determine the most stable solid $\mathrm{Pu}$ phase. Their results predicted that $\mathrm{PuO}_{2}$ would be most stable in both oxidizing and reducing conditions at $\mathrm{pH} 4$ or greater [Rai1977]. This prediction was later corroborated with experimental justification [Strickert-1982]. Transport chemistry of Pu has been largely focused on the role of $\mathrm{Pu}$ colloids and $\mathrm{Pu}$ adsorption onto colloids of oxides and organic matter. In one report, about $75 \%$ of $\mathrm{Pu}$ was adhered to colloids allowing rapid transport of the contamination through an aquifer [Champ-1982]. 
Another study showed that $\mathrm{PuO}_{2}{ }^{+}$was adsorbed from solutions onto goethite and $\gamma-\mathrm{MnO}_{2}$, among others [Keeney-1985]. The goethite surface interacted with the $\mathrm{Pu}(\mathrm{V})$, disproportionating it into $\mathrm{Pu}(\mathrm{IV})$ and $\mathrm{Pu}(\mathrm{VI})$ and a much slower transformation of $\mathrm{Pu}(\mathrm{VI})$ into $\mathrm{Pu}(\mathrm{IV})$. The hydrolytic nature of $\mathrm{Pu}(\mathrm{IV})$ and $\mathrm{Pu}(\mathrm{VI})$ in solution was related to the adsorption behavior as well [Sanchez-1985]. In regard to Pu colloids, $\mathrm{Lu}$ et al. [1998] studied the sorption/desorption behavior of these colloids on iron oxide surfaces (geothite and hematite). Using synthetic and natural J13 groundwater, they found that the colloidal $\mathrm{Pu}(\mathrm{IV})$ and soluble $\mathrm{Pu}(\mathrm{V})$ rapidly and efficiently adsorbed onto both hematite and geothite colloids. The difference in adsorption was seen in the kinetics where $\mathrm{Pu}(\mathrm{V})$ adsorbed slowly and colloidal $\mathrm{Pu}(\mathrm{IV})$ quickly [Lu-1998]. Desorption, though, was a much different story as both forms desorbed slowly ( $<1 \%$ desorbed after 150 days) into $\mathrm{J} 13$ and synthetic groundwater. It is imperative to add that $\mathrm{pH}$ adjustment was not studied so there was little mass action incentive for desorption. Lu et al [1998] described the adsorption to the hydroxyl surface $(=\mathrm{SOH})$ as,

$$
\equiv \mathrm{SOH}+\mathrm{PuO}_{2}^{+}+\mathrm{H}_{2} \mathrm{O} \leftrightarrow \equiv \mathrm{SO}-\mathrm{PuO}_{2}(\mathrm{OH})^{0}+2 \mathrm{H}^{+}, \quad \mathrm{K}_{\mathrm{l}, \mathrm{app}}
$$

where $\mathrm{K}_{1, \mathrm{app}}$ is the apparent equilibrium constant. Other hydrolytic species of $\mathrm{Pu}$ may form as well but the experimental hydrolysis constants for adsorption are not well known. There is certainly a lack of experimental and theoretical understanding of the chemistry of $\mathrm{Pu}$ in natural systems.

The information provided by past research has shown that, in regard to OGMS applications and spinel precursors, we can expect significant adsorption of actinide species and fission product metal cations onto the particulate surfaces within the contaminated soils and sludges of candidate waste streams. The general trend is for increased sorption as $\mathrm{pH}$ is increased. To remove the sorbed species the $\mathrm{pH}$ would need to be adjusted to the acidic range provided that aging effects are minimal; the fate of sorbed species on oxide surfaces is not well understood but it is believed that as time passes a slow reaction becomes important. This slow reaction serves to incorporate the metal ion into the matrix of the host metal oxide through 
precipitation/dissolution reactions or diffusion through the gel layer of the oxide.

In the following subsection we present our data regarding the sorption of key radionuclides onto some spinel and simulant sludge phases.

\section{Sorption Data}

In order to determine the disposition of the radionuclides and the hazardous components in solution, we are studying the ability of mineral phases to absorb a series of nuclides. The mineral phases that have been selected include a series of spinel phases, $\mathrm{Fe}_{3} \mathrm{O}_{4}, \mathrm{NiFe}_{2} \mathrm{O}_{4}$, and $\mathrm{MgFe}_{2} \mathrm{O}_{4}$, iron oxides (hematite, and goethite), and a sludge simulant from Savannah River Site Drum \#7. Table VI-1 illustrates the BET surface area measured by nitrogen desorption of the three mineral phases and the mass susceptibility measured with the SQUID.

Table VI-1. Surface Area Measurements

\begin{tabular}{ccc}
\hline Compound & Diameter $(\mu \mathrm{m})$ & $\begin{array}{c}\text { Surface Area } \\
\left(\mathrm{m}^{2} / \mathrm{g}\right)\end{array}$ \\
\hline $\mathrm{Fe}_{3} \mathrm{O}_{4}$ & 44 & 5.64 \\
$\mathrm{NiFe}_{2} \mathrm{O}_{4}$ & 44 & 1.66 \\
$\mathrm{MgFe}_{2} \mathrm{O}_{4}$ & 44 & 1.47 \\
$\mathrm{FeO}(\mathrm{OH})$ & 44 & -- \\
\hline
\end{tabular}

Data has been collected describing the sorption behavior of hazardous metals, fission products, and actinide metals onto the spinel phases listed in Table VI-1. The data includes the equilibrium time necessary for maximum sorption, sorption as a function of solution $\mathrm{pH}$, solution ionic strength, and temperature. This battery of tests will help in predicting the partitioning of the various radionuclides in a real system and also provide a means to better optimize the waste stream for separation using the OGMS system. Preliminary data (Figure VI-2-4) indicates that the sorption of $\mathrm{Zn}, \mathrm{Cd}$, and $\mathrm{Pu}$ onto the three spinels and the sludge Drum 7 is low in the acidic $\mathrm{pH}$ range and increases as the acidity is reduced. The formation of hydroxy-species of 
the metals and the reduced competitiveness of the acid proton are most likely reasons for this trend. The basic trend alluded in Figure VI-1 is followed.

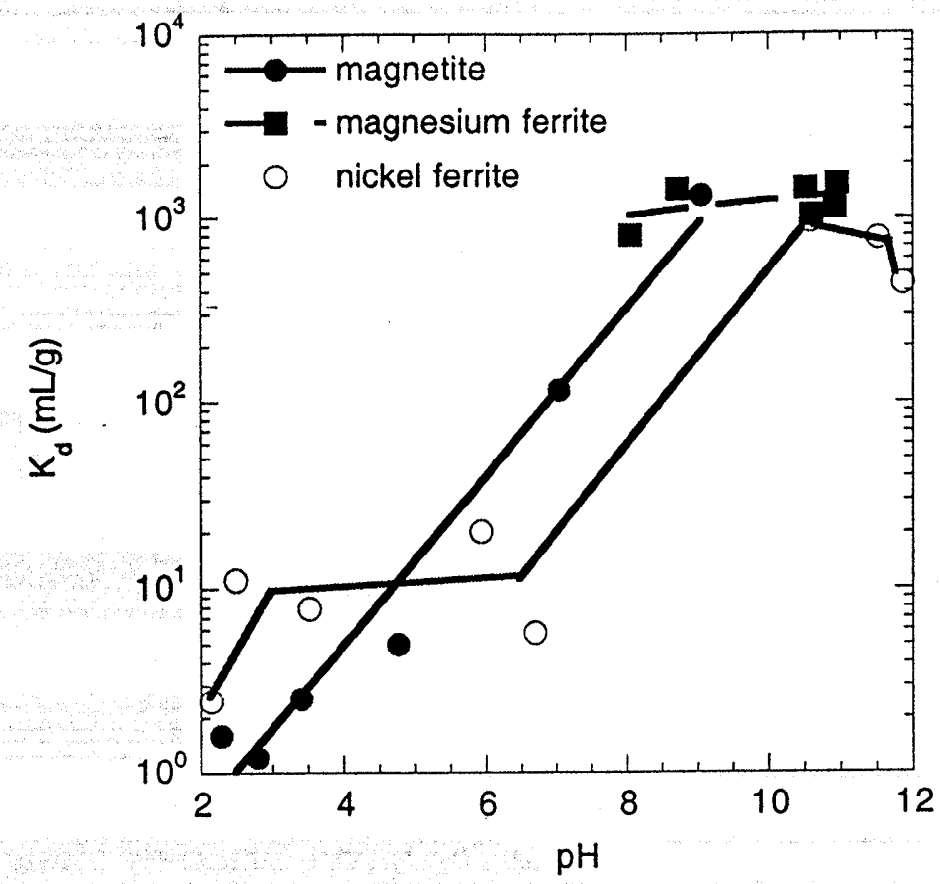

Figure VI-2. Sorption of $\mathrm{Zn}$ onto $\mathrm{Fe}_{3} \mathrm{O}_{4}, \mathrm{MgFe}_{2} \mathrm{O}_{4}$, and $\mathrm{NiFe}_{2} \mathrm{O}_{4}$.

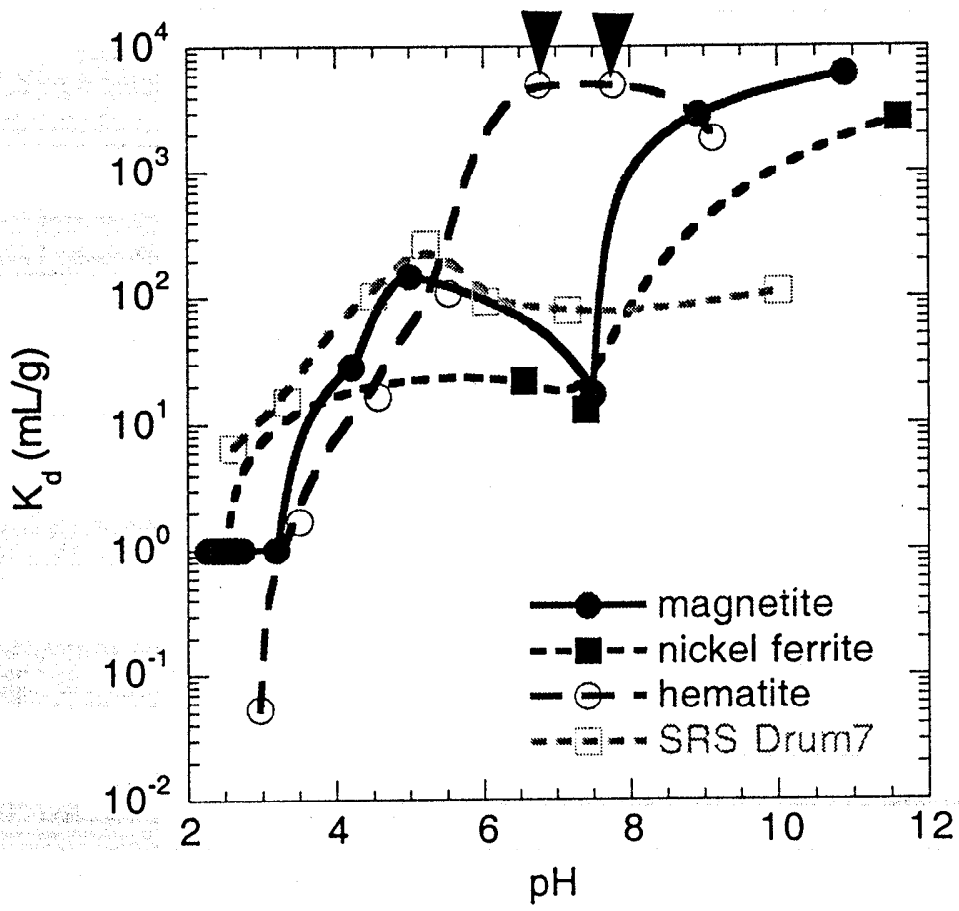

Figure VI-3. Sorption of $\mathrm{Cd}$ onto $\mathrm{Fe}_{3} \mathrm{O}_{4}$, hematite, and $\mathrm{NiFe}_{2} \mathrm{O}_{4}$. The pointers designate the data points that are minimum $\mathrm{K}_{\mathrm{d}}$ values dictated by detection limits. 


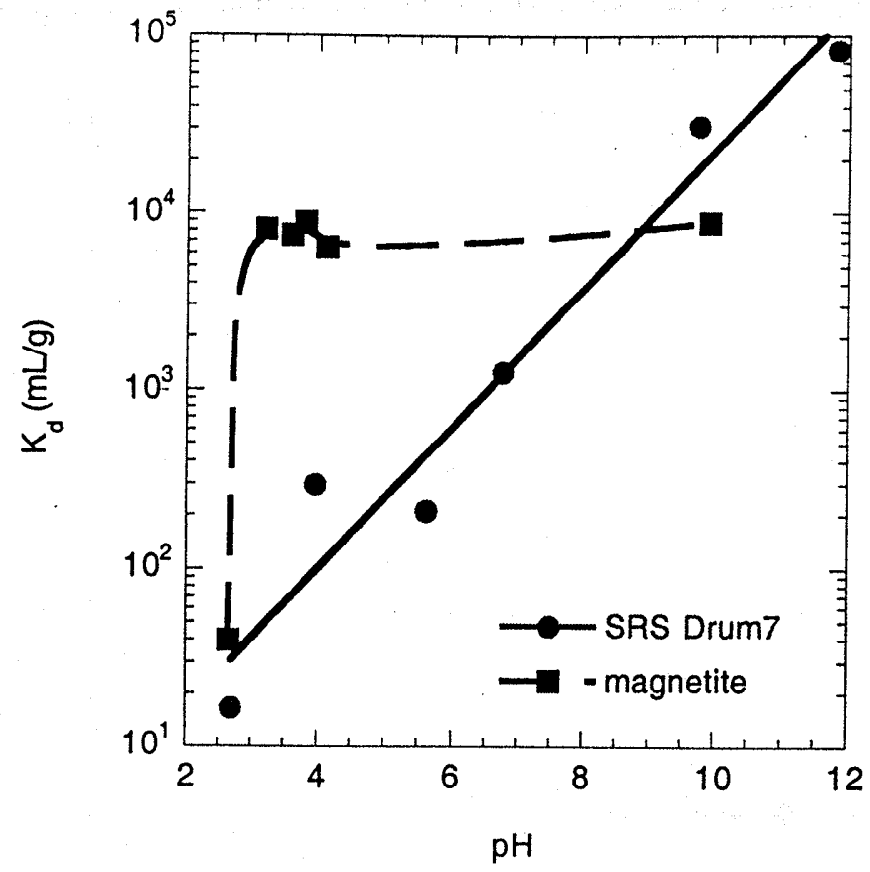

Figure VI-4. Sorption of $\mathrm{Pu}$ onto $\mathrm{Fe}_{3} \mathrm{O}_{4}$ and Drum \#7 sludge.

We also performed Cs sorption tests and found that Cs does not show any significant sorption throughout the $\mathrm{pH}$ range of 3-11 for $\mathrm{Fe}_{3} \mathrm{O}_{4}, \mathrm{MgFe}_{2} \mathrm{O}_{4}$, and $\mathrm{NiFe}_{2} \mathrm{O}_{4}$ where the $\mathrm{K}_{\mathrm{d}}$ values were less than $10 \mathrm{~mL} / \mathrm{g}$.

\section{Suggested Experimental Studies}

Once the baseline saturation levels have been determined, we will begin a series of experiments in order to determine conditions to maximize the sorbancy of each combination. The factors that were initially held constant will now be varied one at a time. As each of the conditions are varied, data shall be recorded in an attempt to determine trends, and ultimately, to determine maximum sorbancy conditions. In addition, this data will be used to develop thermodynamic models to predict the partitioning of the radionuclides in the waste streams. It is desirable to experiment first with the non-radioactive nuclides, both in order to minimize the radioactive waste problem, and to assist in the development of acceptable procedures. 


\section{HGMS DEVELOPMENT}

The purpose of this sub-task is to research and evaluate the application of HGMS for the pretreatment of radioactive and mixed waste vitrification feeds. In particular, the performance of HGMS is being compared with OGMS being evaluated at the ANL, with the intent of optimizing the engineering parameters in the complex separation of magnetic components from sludges present at the Savannah River Site and other DOE sites. The objectives also include gaining a deeper understanding of the underlying and controlling principles governing HGMS for treating these complex waste streams. Both experimental and theoretical studies are currently being carried out using non-radioactive sludges provided by the Savannah River and Hanford Sites.

\section{Hanford C-103 Sludge}

The HGMS system has been set up for evaluating the separation of magnetic species from radioactive and mixed waste vitrification feeds. Simulant HLW sludge of Hanford Tank C103 HLW has also been received and characterized (Tables VII-1-3). Very small amounts of $\mathrm{Fe}, \mathrm{Al}, \mathrm{Ca}$, and $\mathrm{Si}$ were detected in the soluble phase, which implied that almost of these metals were in solid or insoluble states. After filtering (see experimental section) and treating the insoluble phase with nitric acid, $\mathrm{Fe}, \mathrm{Al}$, and $\mathrm{Ca}$ were detected in the digestible phase. Table VII-2 is close to the concentration provided by PNNL, but differs from that obtained by ICP measurements in Table V-1 and this is due to difference in technique and sample inhomogeneity. 
Table VII-1. Bulk metal content and physical properties of the C-103 Hanford sludge simulant.

\begin{tabular}{cc}
\hline $\mathrm{pH}$ & 8.80 \\
Total solids, wt\% & 17.05 \\
Insoluble solids, wt\% & 9.20 \\
Soluble solids, wt\% & 7.13 \\
Density, g/mL & 1.08 \\
& \\
Digestible fraction of & \\
insoluble phase & \\
$(\mathrm{mg} / \mathrm{g})^{\mathrm{a}}$ & \\
$\mathrm{Fe}$ & 212.73 \\
$\mathrm{Al}$ & 37.35 \\
$\mathrm{Ca}$ & 40.00 \\
$\mathrm{Si}$ & $\mathrm{ND}$ \\
$\mathrm{Nondigestible}$ & \\
fraction of insoluble & \\
phase (mg/g) & \\
$\mathrm{SiO}_{2}$ and CaO & 327.00 \\
aluble $\mathrm{Phase}(\mathrm{mg} / \mathrm{L})^{\mathrm{c}}$ & \\
$\mathrm{Fe}$ & $<0.40$ \\
$\mathrm{Al}$ & $<0.20$ \\
$\mathrm{Ca}$ & 3.20 \\
$\mathrm{Si}$ & $\mathrm{ND}^{\mathrm{b}}$ \\
\hline
\end{tabular}

${ }^{\text {a }}$ Based on insoluble solids

${ }^{\mathrm{b}}$ None detected

${ }^{\mathrm{c}}$ Based on total sludge volume

Table VII-2. Comparison of the bulk metal content of the sludge obtained with flame AA with the calculated from the final Pacific Northwest National Laboratory recipe.

\begin{tabular}{|c|c|c|c|c|c|}
\hline \multirow[b]{2}{*}{ Element } & \multicolumn{3}{|c|}{ Flame AA } & $(\mathrm{mg} / \mathrm{L})^{\mathrm{a}}$ & Recipe \\
\hline & Soluble & Digested & Nondigested & Total & $(\mathrm{mg} / \mathrm{L})$ \\
\hline $\mathrm{Fe}$ & $<0.4$ & 18,121 & - & 18,121 & 16,950 \\
\hline $\mathrm{Al}$ & $<0.2$ & 3,183 & - & 3,183 & 3,450 \\
\hline$\overline{\mathrm{Ca}}$ & 3.92 & 3,407 & - & 3,411 & 5,200 \\
\hline$\overline{\mathrm{Si}}$ & - & - & 27,856 & 27,856 & 32,550 \\
\hline
\end{tabular}

${ }^{a}$ Based on total sludge volume. 
Table VII-3. Relative elemental weight percentages and ratios from EDS analysis of the insoluble solids in the initial sample and different fraction from the first stage.

\begin{tabular}{|c|c|c|c|c|}
\hline \multicolumn{5}{|c|}{ Wt \% } \\
\hline Element & Initial & Head & Drain & Retained \\
\hline $\mathrm{Fe}$ & 49.7 & 47.3 & 40.7 & 61.8 \\
\hline $\mathrm{Si}$ & 30.6 & 34.3 & 38.2 & 25.2 \\
\hline$\overline{\mathrm{Ca}}$ & 11.0 & 10.7 & 12.7 & 5.6 \\
\hline $\mathrm{Al}$ & -4.8 & 5.3 & 6.2 & 3.6 \\
\hline $\mathrm{Cu}$ & 3.6 & 2.3 & 2.0 & 3.6 \\
\hline & & Wt \% & Ratio & \\
\hline Ratio & Initial & Head & Drain & Retained \\
\hline $\mathrm{Fe} / \mathrm{Al}$ & 10.3 & 9.0 & 6.6 & 17.1 \\
\hline $\mathrm{Si} / \mathrm{Al}$ & 6.3 & 6.5 & 6.2 & 6.9 \\
\hline $\mathrm{Ca} / \mathrm{Al}$ & 2.3 & 2.0 & 2.0 & 1.6 \\
\hline
\end{tabular}

Approximately one liter of the HLW sludge was processed through the HGMS system at $150 \mathrm{ml} / \mathrm{min}$ with the magnet field turned on. To separate gross filtration from magnetic filtration, with the magnetic field still on, the filter canister was flushed with water at the same $\mathrm{pH}$ as the initial sludge until the water effluent was relatively clear. Then the magnetic field was turned off and the system was backed flushed again with water at the same $\mathrm{pH}$ as the initial sludge (see Figure VII-1). A small amount of sludge was present in this step, indicating the presence of magnetic particles in the HLW sludge. 


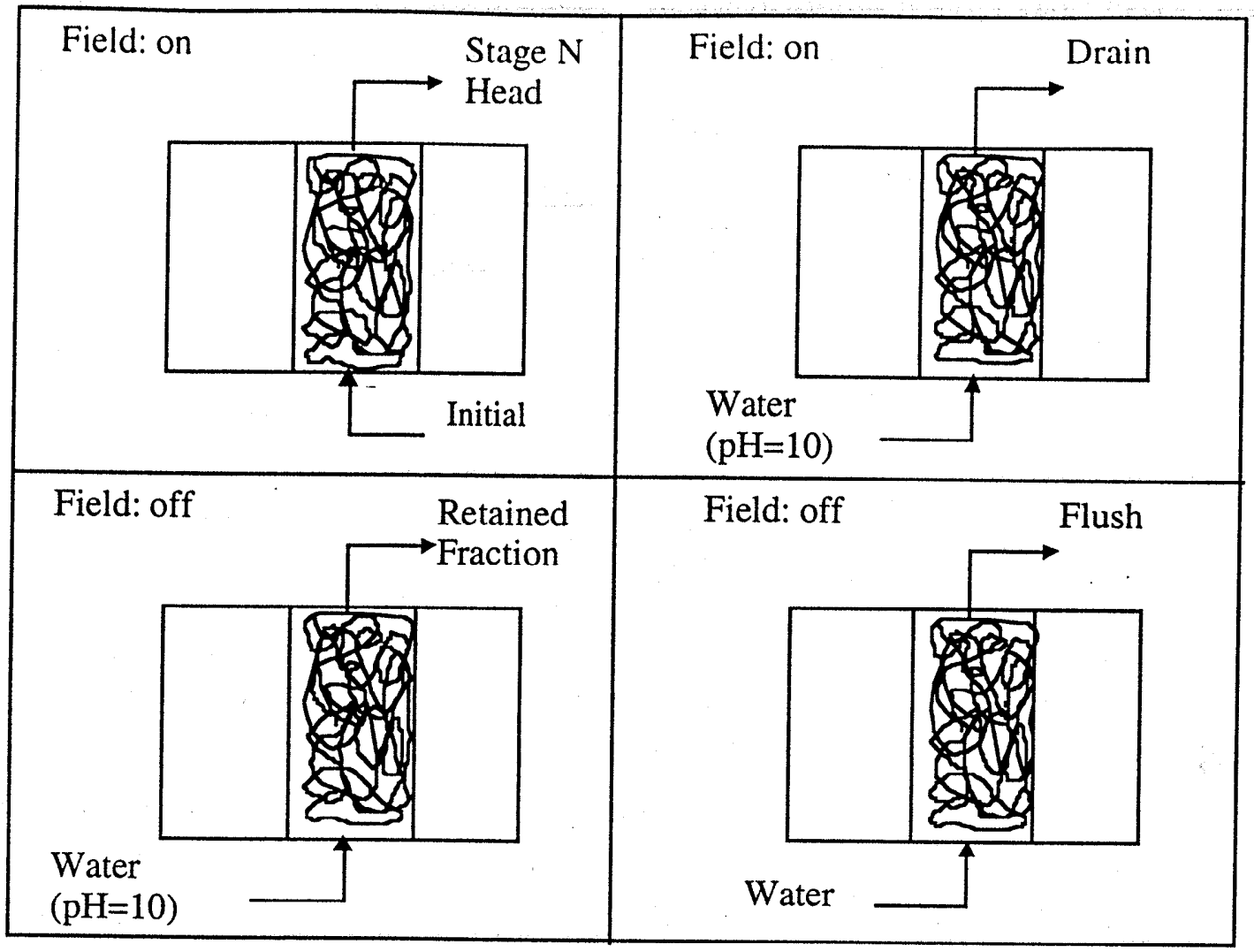

Figure VII-1. Depiction of the four-step experimental procedure.

Figure VII-2 shows the volumetric particle size distribution (see experimental section Chapter II) obtained from the initial sample, as well as from the head, drain, and magnetically retained fractions from the first stage. Although not shown, similar results were obtained with stages 2,3 , and 4 . Two peaks were normally observed in all the samples. The first one, or the small-particle fraction, ranged from 0.5 to $0.15 \mu \mathrm{m}$, while the second peak, or the large-particle fraction, ranged from 2 to $14 \mu \mathrm{m}$. Compared with the initial sample, the magnetically retained fraction contained a larger proportion of the largest particles and very few small particles.

The drain fraction contained a larger proportion of the smallest particle fraction and a larger proportion of the smallest particles from the large particle fraction. Compared to the initial sample, the head fraction contained similar proportions of the large and small particles, but it was devoid of the largest particles. In general, these results showed that the 0.3 
T magnetic ficld was capable of removing only the large magnetic particles. The results also suggest that most of the species were only the larger magnetic particles. These results are consistent with HGMS performance which always shows an optimal size range for the capture of particles. This result also suggest that most of the chemical species were only weakly magnetic, based on a comparison with the HGMS specification quoted by the manufacturer.
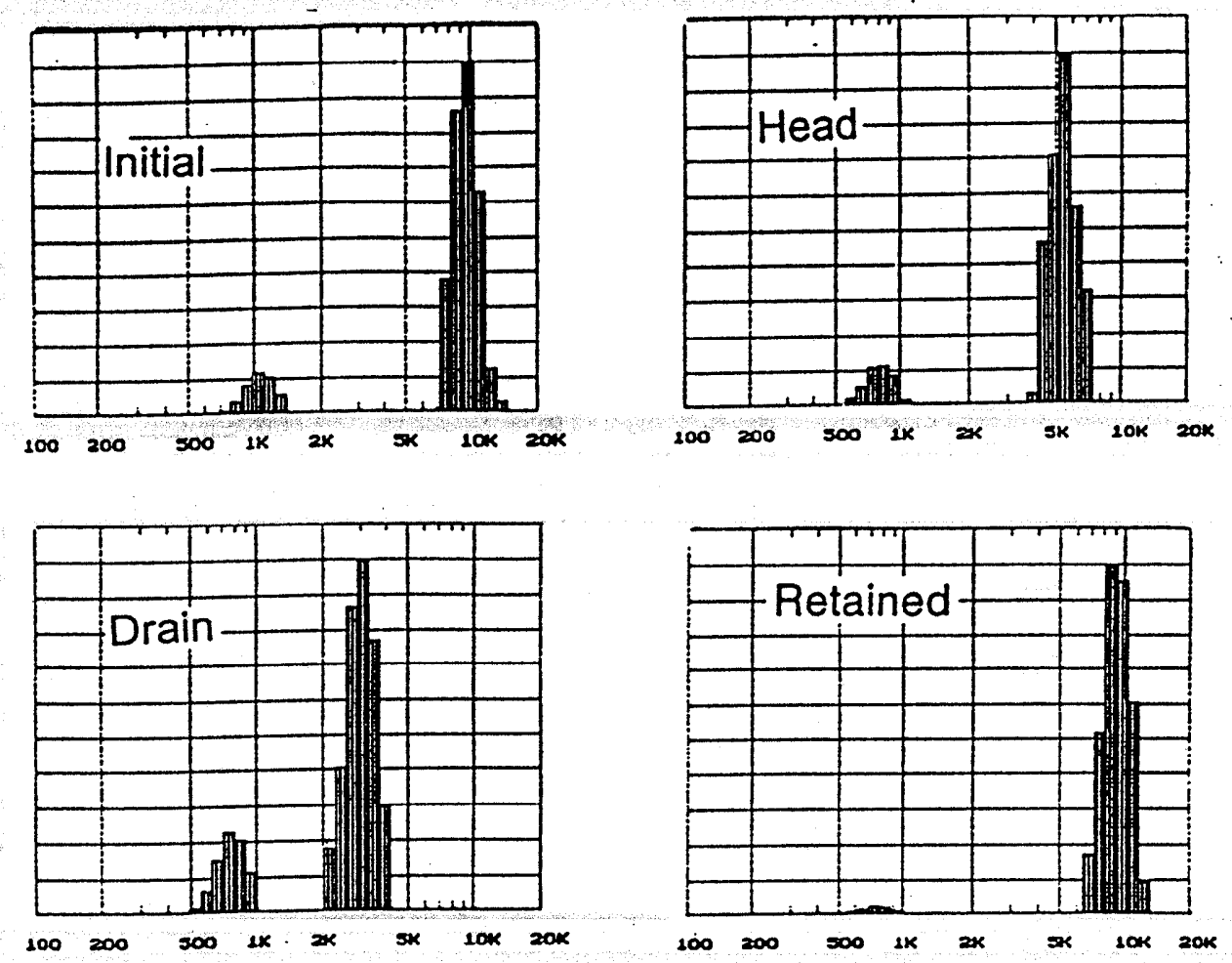

Figure VII-2. Volumetric particle size distributions of the initial sample, and the head, drain, and magnetically retained fractions from the first stage. The $\mathrm{y}$-axis is the number of particles and the $\mathrm{x}$-axis is the particle size. The particle size unit is in nanometer (nm).

Figure VII-3 shows a summary of the mean particle sizes (represented by the bars) and the corresponding dry weight percentages (represented by the symbols and lines) of the large-particle fractions of all the samples from the first four stages and the initial sample. The wt\% was based on the grams of insoluble solid in each of the samples. Again, the magnetically retained fraction always contained the largest particles and the highest dry weight percentages $(>90 \%)$. The drain fraction always contained the smallest 
particle from the large-particle fraction, with dry weight percentages between 83 and $90 \%$. The head fraction was again similar to the initial sample, but it always had a slightly smaller mean particle size and a slightly higher dry weight percentage, on average amount the four stages. The SEM and EDS spectrum of the fractions (not shown) agree with the size distribution and the magnetic material assumption.

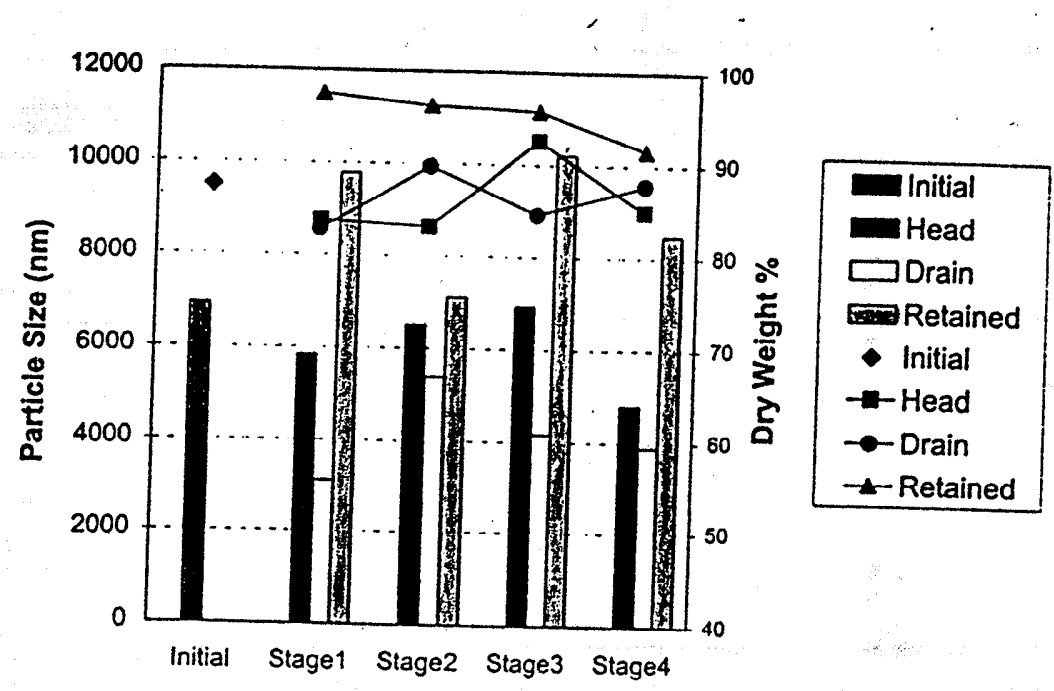

Figure VII-3. Average values (bars) of the mean particle sizes and dry weight percentages (lines and dots) of the large-particle fraction in the initial sample, and in the head, drain, and magnetically retained fraction from the first four stages.

An important effect of the magnetic field (0.3T) on the adsorption of $\mathrm{Fe}$ was observed. The relative weight percentage of iron in the magnetically retained fraction was about twice that in the other stages: and the relative 
weight percentages of the least paramagnetic element and the diamagnetic element were less than in the other stages. However, segregation among the other species (i.e., $\mathrm{Si}, \mathrm{Al}$, and $\mathrm{Ca}$ ) was not significant in all of the samples. The results was expected, since $\mathrm{Fe}$ is very paramagnetic as opposed to the other three elements, which are weakly diamagnetic. Similar results were obtained with the element analyses obtained with the flame AA.

Figure VII-4 shows the dry weight percentages of (a) $\mathrm{Fe}$, (b) indigestible solids (mainly $\mathrm{SiO}_{2}$ ) and (c) Al obtained with the flame AA. Figure VII-4a also shows the weight of sludge removed by the HGMS unit in each of the stages (circles with lines). As with the EDS, the iron content was much larger in the magnetically retained fraction. Also the iron content in the magnetically retained fraction remained relatively constant throughout the 13 stages of processing. Clearly, the HGMS unit saturated during each of the 13 stages, indicating that the working capacity of this bench-scale unit was low relative to the removable iron in the high-solid-content $(99.4 \mathrm{~g} / \mathrm{L}) \mathrm{C}$ 103 sludge simulant. Nevertheless, between 1 and $2 \%$ of the total Fe in the sludge was removed during each stage; over $18.5 \%$ was removed in the 13 stages. More stages could have been carried out, but not without diluting the head volume, since the head volume became too small to process through the HGMS unit after the thirteenth stage. In fact, experiments carried out with a highly diluted sludge (insoluble content of about $10 \mathrm{~g} / \mathrm{L}$ ) showed that this HGMS system is capable of removing more than $99 \%$ of the insoluble solids, in agreement with manufacturer's specification and the trends presented in Figure VII-4. 

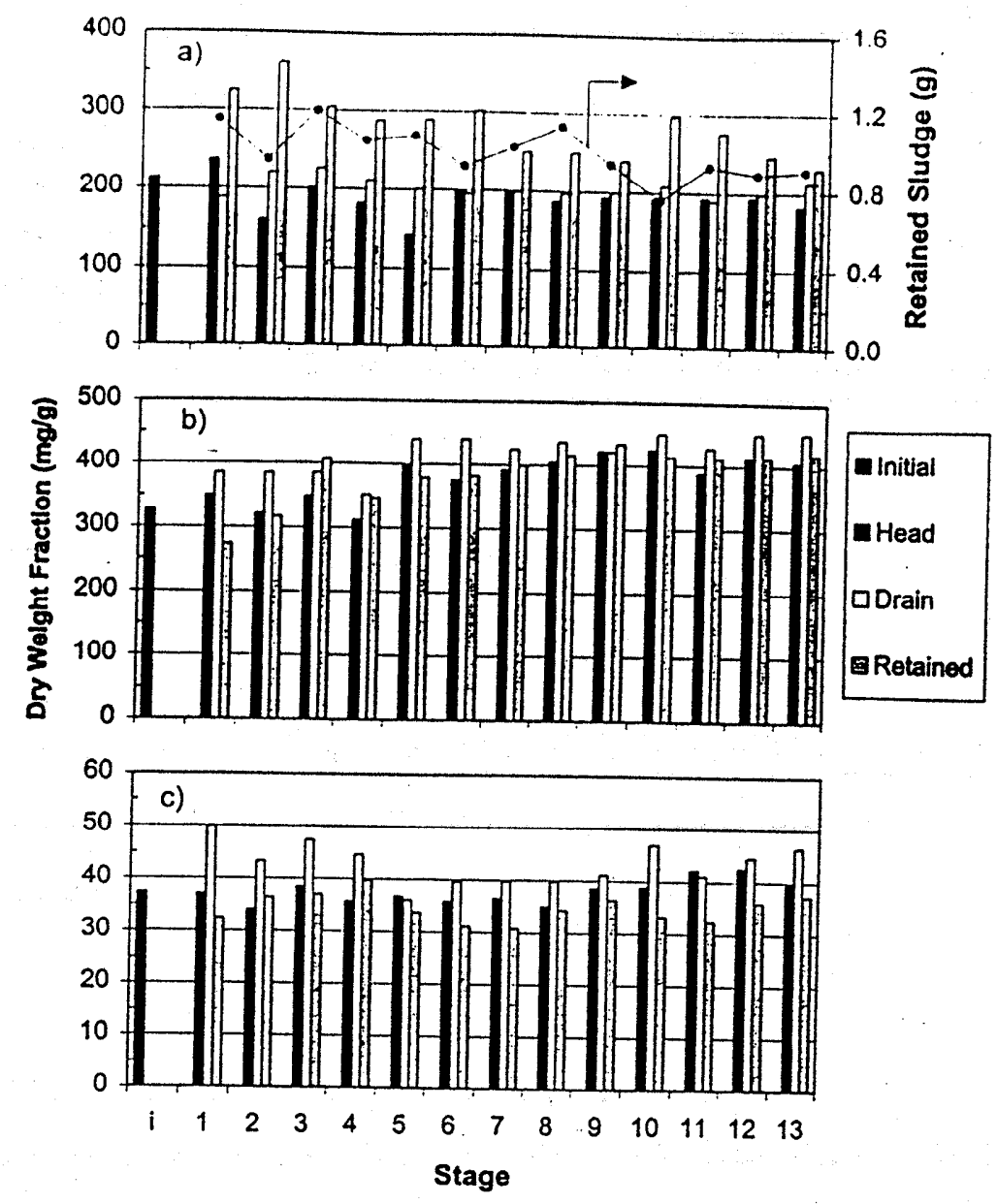

Figure VII-4. (a) Dry-weight percentages of $\mathrm{Fe}$ and the amount of sludge removed by the HGMS system, (b) dry-weight percentages of the nondigestible fraction, and (c) dry-weight percentages of the $\mathrm{Al}$ in the initial, and in the head, drain, and magnetically retained fractions for each of the 13 stages.

Figure VII-4 also shows that the fractionation between the different species was not great, indicating that the fractionation was essentially based on the difference in size of the particle, which undoubtedly and a spectrum of volumetric magnetic susceptibilities. This result suggested that the oxides such as silica, gibbsite, and boehmite were most likely acting as nucleation or coordination agents for the precipitated $\mathrm{Fe}$ (i.e., $\mathrm{Fe}$ adsorbents), since significant amounts of diamagnetic oxide were present in the magnetically retained fraction. It was also interesting that the drain contained relatively higher $\mathrm{Al}$, which can be deleterious to the vitrification process; but the drain 
solution were very dilute, and the effect was not pronounced enough to have an effective separation of $\mathrm{Al}$.

In summary, the results obtained show that HGMS was capable of removing a considerable amount of Fe from the C-103 Hanford tank waste simulant with the magnetic field of only $0.3 \mathrm{~T}$. For example, in 13 stages, the bench-scale HGMS unit removed almost $20 \%$ of the total Fe in 1L of sludge with fairly constant loading in every stage. This latter result also suggested that the unit capacity was low relative to the total removable iron and that further separation could be carried out. However, along with the higher concentrations of iron in the magnetically retained fraction, diamagnetic oxides like silica, gibbsite, and boehmite were present in considerable amounts. These results also show that the fractionation was based essentially more on size differences between the particles, as the larger particles were found in the magnetically retained fraction. This is reflected in the HGMS unit capability to remove particle larger than $5 \mu \mathrm{m}$, which were probable composed of iron in a weakly magnetic state. Also for the sludges with high insoluble solid content $(99.4 \mathrm{~g} / \mathrm{L})$ and relatively small fields $(0.3 \mathrm{~T})$, this HGMS system cannot be used to further concentrate the sludge due to its relative small loading capacity per column volume (about 4 to $5 \mathrm{~g} / \mathrm{L}$ ). Nevertheless, HGMS seems plausible as a pretreatment step to OGMS to prevent OGMS from clogging in the treatment of HLW.

\section{SRS-Tank Sludge}

HGMS breakthrough experiments have been carried out with dilute solutions of the sludge simulants from Drums 2, 4, 7 and 9 of the Savannah River Site. The purpose of these experiments is to analyze the effect of the flow rate and the inlet concentration on the retention capacity of the $0.3 \mathrm{~T}$ HGMS unit. Prior to entering the HGMS unit, all of the solutions are passed through a settling column to remove the sand $\left(\mathrm{SiO}_{2}\right)$ or larger particles contained in the sludge. Therefore, the inlet concentration is assumed to be the outlet concentration after breakthrough occurs.

Table VII-4 lists the flow rates and solution concentrations studied for each of the different drums. The flows in bold type have been completed for 
each of the four different flow rates. Over the next two months the remainder of the experiments will be finished. Numerous preliminary experiments have also been done to determine, among other things, the proper inlet volume that is required to obtain a well defined breakthrough curve, and gross filtration effects when the magnetic field is off. The latter effect proved to be negligible and no further work will be done to study this aspect.

Table VII-4. Flow Rates and Solution Concentrations Studied in the HGMS Unit at USC.

\begin{tabular}{ccc}
\hline & Flows $(\mathrm{mL} / \mathrm{min})$ & $\begin{array}{c}\text { Solution concentration } \\
(\mathrm{g} / \mathrm{L})^{*}\end{array}$ \\
\hline Drum 2 & $20,50,100,150$ & 10,20 \\
Drum 9 & $20,50,100,150$ & 10,20 \\
Drum 7 & $20,50,100,150$ & 5,10 \\
Drum 4 & $20,50,100,150$ & 10,20 \\
\hline * concentration before entering the settling column
\end{tabular}




\section{ENGINEERING HGMS/OGMS APPARATUS}

The open gradient magnetic separator (OGMS) that is currently housed at ANL building 370 was designed to process dry feeds such as fluid cracking catalyst and pulverized coal. The extension of the OGMS concept to the processing of radioactive sludges, slurries, soils, and ashes requires that both dry and wet processing capabilities exist with our unit. To this end, we have adapted the OGMS system to accommodate slurries. This section describes the design and construction of the supporting pump and piping structures needed to modify the OGMS unit in order to handle liquid streams. In addition, the requirement for an HGMS filter precluded the need to design and construct filters that would be compatible with the current bore dimensions of the unit.

The specifications of the OGMS unit for dry processing is documented in Appendix $\mathrm{V}$ of this report along with the operating procedures for the magnet cool-down and pumping procedures for slurries.

\section{OGMS Unit Modifications}

An aerial and ground level view of the OGMS unit for dry processing is shown in Figure VIII-1. The top of the unit is located approximately $4.5 \mathrm{~m}$ above the ground and is accessible by the three story platform surrounding the unit. The ground level space is occupied with the magnet support equipment such as the vacuum pump, power supply, and tool cabinets. The essential modifications that were needed to handle slurry feeds had to do with how the streams would be fed and collected from the unit. Any modifications had to be restricted to the southeast corner of the cage. Solids are fed at the top of the OGMS unit using a screw type feeder-meter (see Figure VIII-2). This feeder was disconnected, the feeder port was covered with a rubber sleeve, and the sleeve was clamped at both ends. 

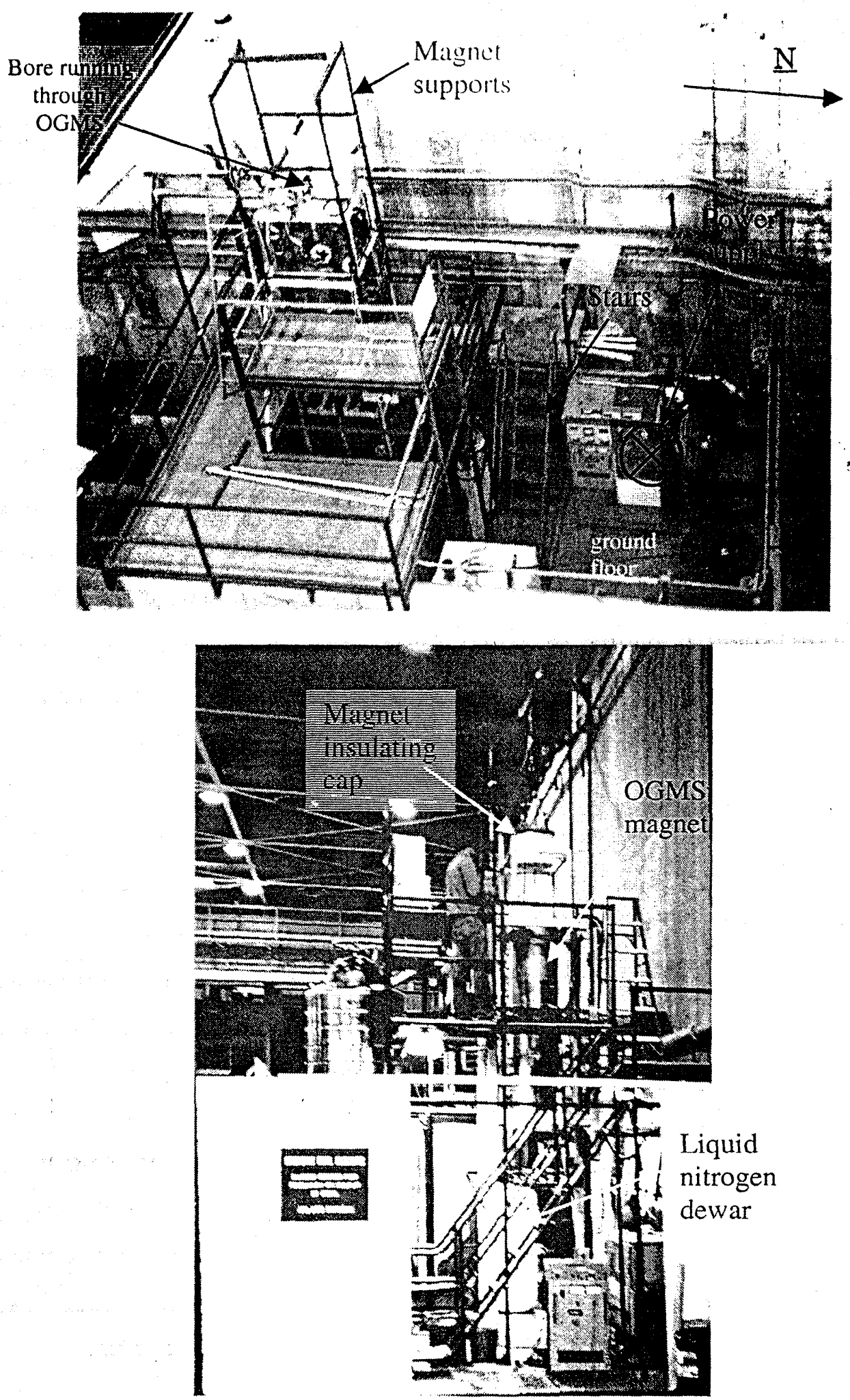

Figure VIII-1. Aerial and side view of the cage area housing the OGMS unit in Blg. 370. The space between the stairs and the north side of the cage is occupied by the high amperage power supply and vacuum pump. The magnet has been hoisted out of the cryostat in this picture. 


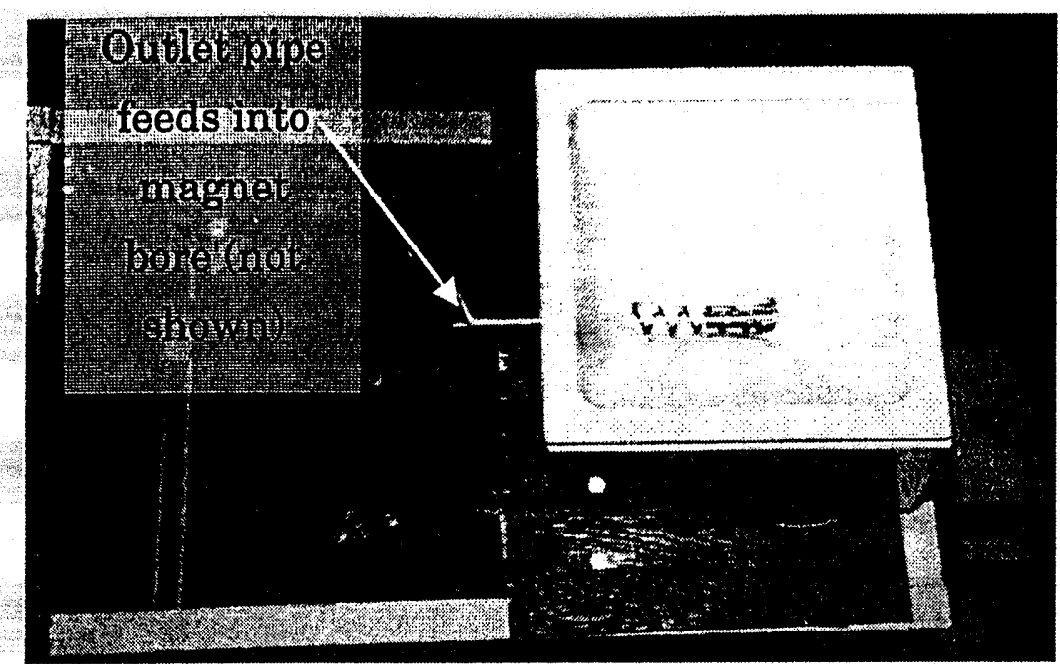

Figure VIII-2. Screw feeder atop the OGMS unit for dry solid feeds.

For safety reasons the drums containing the slurry waste streams would have to be located at ground level. The liquid slurries need to be fed at the top of the OGMS unit in a turbulent flow so the particles in the slurry stay in suspension. As explained throughout this report, a high gradient magnetic separation (HGMS) prefilter would be need to ensure the removal of copious amounts of ferromagnetic and highly paramagnetic materials. Since the magnetic field tails off from the top of the magnet windings (see later in this section) the field generated by the OGMS unit is sufficiently strong above the magnet to accommodate an HGMS filter system. This hybrid system should produce a highly efficient separation. The schematic of the proposed OGMS/HGMS system for slurry wastes is shown in Figure VIII-3. The raw waste feed will be fed into a recirculation loop combining with water for dilution. A two-horse power progressive cavity pump is used to both, keep the slurry in constant agitation and pump the slurries up to the top of the HGMS unit. This pump functions by forming cavities, between a screw type rotor and the carcass of the pump. These cavities travel from the inlet to the outlet, keeping the slurry in turbulent state. The flow in the recirculation loop will ensure a turbulent flow and proper mixing of the diluted slurry. Control valves regulate the flow to the diffuser at the top of the magnet. The diffuser will lower the Reynolds number of the flow so that a laminar flow is provided to the HGMS filter located just above the superconducting magnets. The bore of the magnet will 
have to be filled with water prior to slurry feeding to ensure a homogeneous and controllable feed through the magnet.

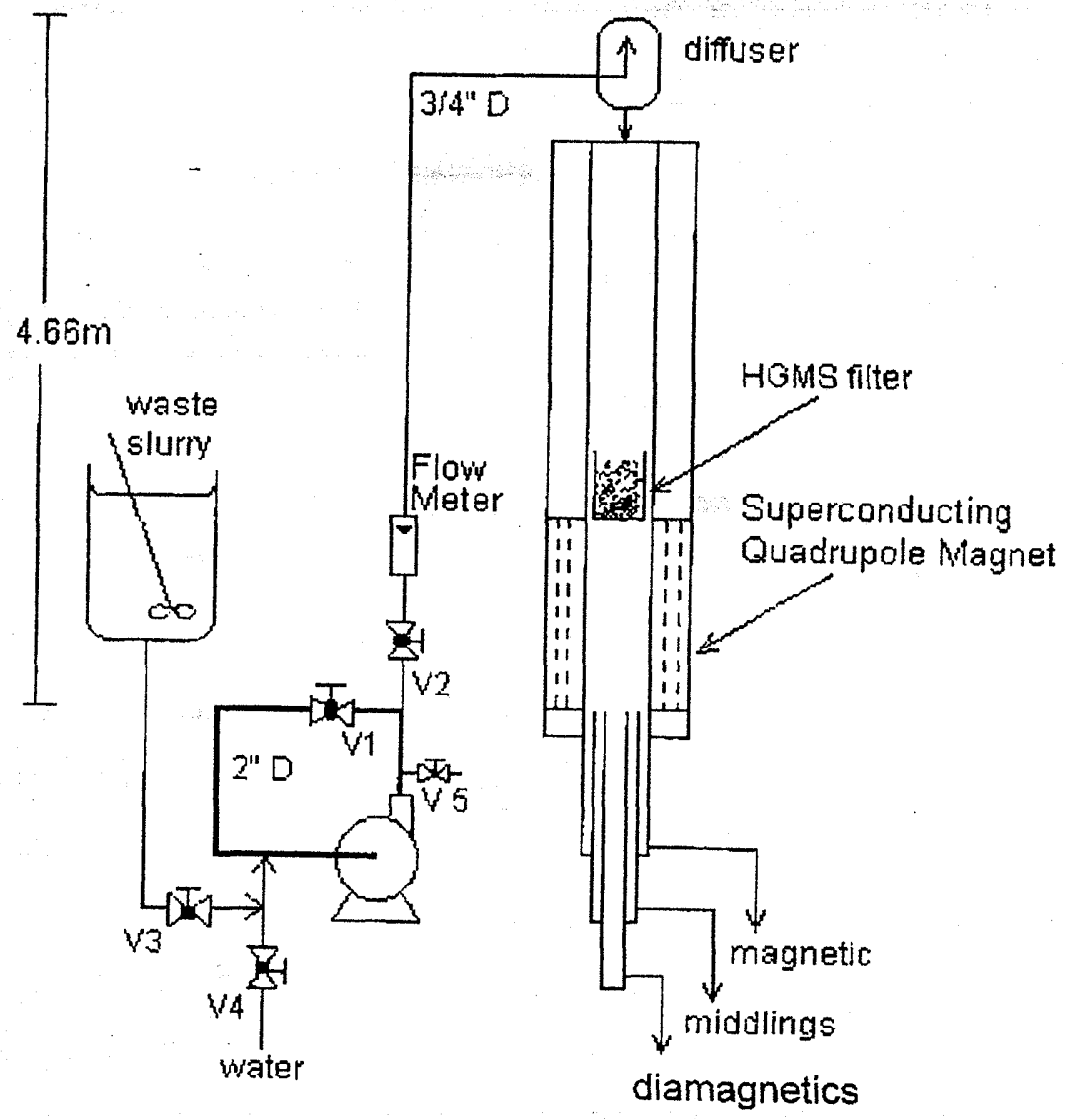

Figure VIII-3. Modified HGMS/OGMS unit.

A short description of the piping system is described here. For a full synopsis and standard operating procedures for this and the procedures for operating the magnet see Appendix IV of this report.

The recirculation loop is made of $5.1 \mathrm{~cm}$ inside diameter Schedule (Sch) $40 \mathrm{PVC}$ pipe. It forms a rectangular loop of dimensions $1.0 \mathrm{~m} \mathrm{X} 0.89 \mathrm{~m}$. The $2.05-\mathrm{cm}$ conveyance pipe is connected to the loop on the outlet side of the pump. The pressure is regulated by ball valve V1 on the recirculation loop (see flow diagram in Figure VIII-3). The flow is regulated by ball valve V2, and metered by a turbine type electronic flow meter. At the top of the OGMS 
unit a diffuser is used to change the direction and velocity of the flow. This diffuser consists of a $36 \mathrm{~cm}$-section of a $10.16 \mathrm{~cm}$-diameter PVC pipe. The top of the diffuser has an elliptical dome where the slurry will impinge and change direction from vertically up to vertically down, without causing an irregular radial distribution of the suspended particles. The ratio of velocity change is from 28:1. The slurry then flows 1.83 meters downward and eventually acquires a laminar regime when flowing through the magnetic field zone.

The mechanical resistance of the available structure does not permit placing a 55 gallon drum above the recirculation loop, so a 5 gallon carboy was placed on a structure resting on a strut beam, above the recirculation

loop. This 5-gallon carboy contains the slurry that will be gravity fed to the inlet side of the recirculation loop. Ball valve V3 regulates the flow of slurry. The slurry is continuously diluted by water entering through valve V4. The slurry inside the 5-gallon carboy is stirred constantly by a variable speed impeller.

The HGMS filter will be placed immediately above the quadrupole superconducting magnet, to take advantage of the existing high magnetic field.

\section{Pressure Calculations}

Because this unit will be expected to handle radioactive feeds, the forces acting on the pipes must be computed to ensure safe operation. Figure VIII-4 is a schematic representation of the recirculation loop used in this analysis. Ball valve V1 controls the flow and pressure through the loop. This pressure is utilized to pump the slurry to the diffuser at the top of the OGMS unit. Point 1 is at the outlet of the pump, Point 2 is at the inlet of the pump. 


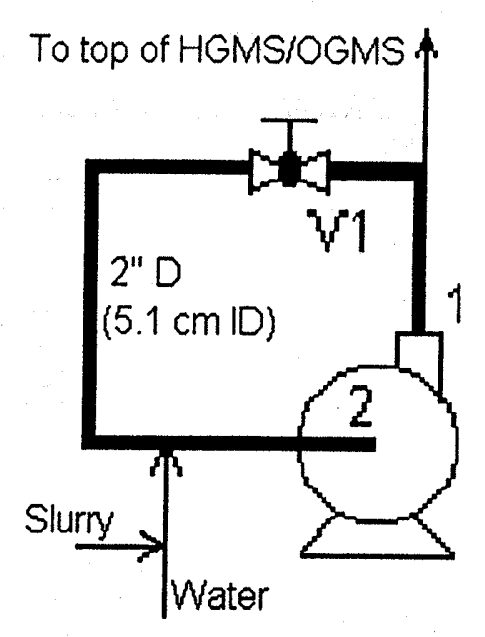

Figure VIII-4. Schematic of the recirculation loop for pressure analysis.

The following is Table VIII- 1 with calculations of pressure drop and equivalent head for various flow rates in English and metric units. 
Table VIII-1. Calculated flow rates in the recirculation loop

\begin{tabular}{ccccc}
\hline $\mathrm{Q}(\mathrm{gal} / \mathrm{min})$ & $\mathrm{Q}(\mathrm{L} / \mathrm{min})$ & $\Delta \mathrm{P}_{\mathrm{a}}\left(\mathrm{lb} / \mathrm{in}^{2}\right)$ & $\Delta \mathrm{Pa}\left(\mathrm{kg} / \mathrm{cm}^{2}\right)$ & $\begin{array}{c}\text { Head }(\mathrm{m} \text { of } \\
\text { water })\end{array}$ \\
\hline 20 & 75.7 & 73.50 & 5.16 & 51.60 \\
30 & 113.6 & 55.33 & 3.88 & 38.80 \\
40 & 151.4 & 37.08 & 2.60 & 26.00 \\
50 & 189.2 & 17.66 & 1.24 & 12.40
\end{tabular}

Note: To obtain gage pressure, subtract $14.7 \mathrm{lb} / \mathrm{in}^{2}$ or $10.33 \mathrm{~kg} / \mathrm{cm}^{2}$ from the absolute pressure.

Figure VIII-5 is a plot of the calculated pressures for different mass flows.

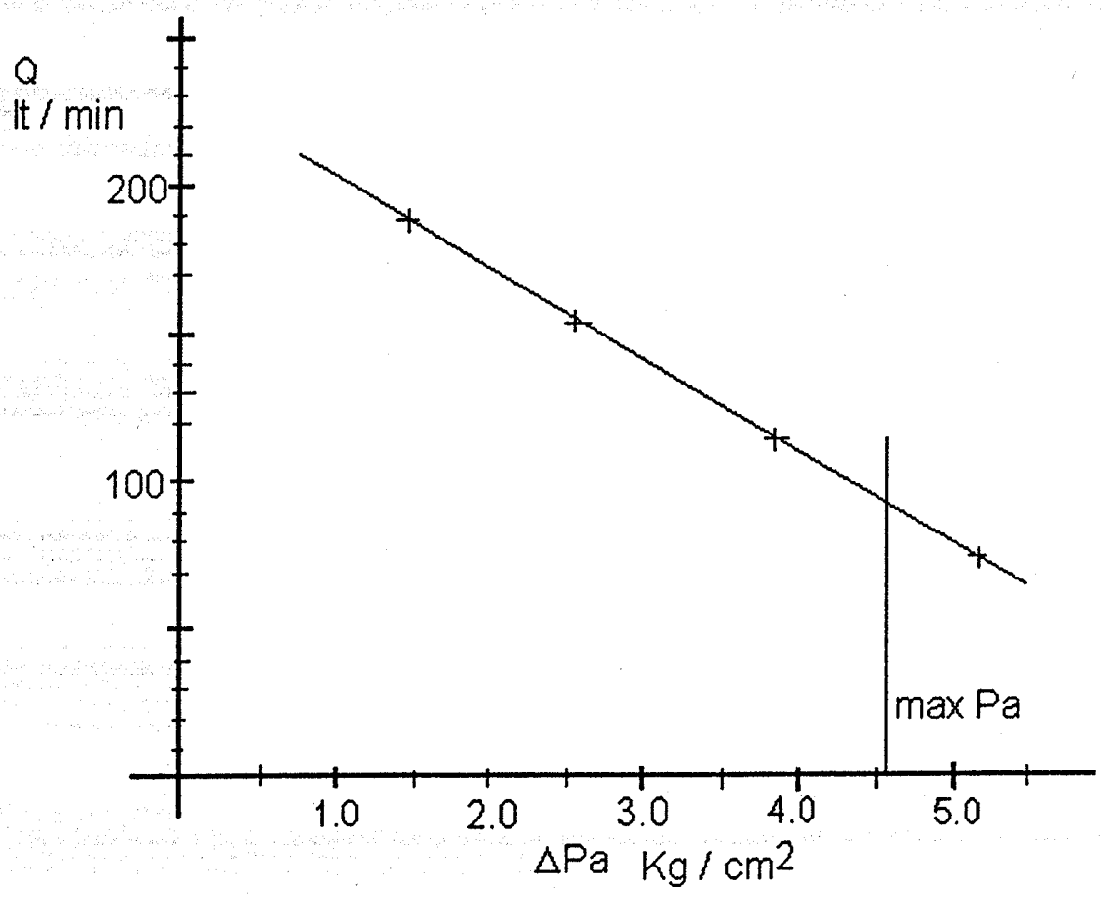

Figure VIII-5. Pump curve for the Monyo 2HP progressive cavity pump.

The manufacturer's pump performance shows a maximum pressure of 50 psig or $4.54 \mathrm{~kg} / \mathrm{cm}^{2}$ absolute, which is well below the maximum allowable for SCH 40, $5.1 \mathrm{~cm}$ PVC pipe of $280 \mathrm{psi}$. Therefore, our calculations show that with this 2 -HP progressive cavity pump, and piping design, we will be operating with a minimum factor of safety of 5.6 . 
The difference in height from the recirculation loop to the top of the OGMS unit is 4.66 meters. Even at high flow, within the two-inch pipe loop, there will be enough head ( 26 meters @ $151.4 \mathrm{~L} / \mathrm{min}$ ) to pump the slurry to the diffuser. At $151.4 \mathrm{~L} / \mathrm{min}$, the flow inside the $5.1 \mathrm{~cm}$. pipe is turbulent $(\mathrm{Re}=63,196)$. This turbulent flow will keep the slurry well agitated. All calculations are for water, however, the properties of the dilute slurry are reasonably close to those of water for these parameters.

\section{Laminar Flow Calculations}

Of paramount importance for separation efficiency is that the flow be in the laminar regime. Turbulent flows will increase particle-particle interactions and cause random shear forces. The following calculations define the flow regime and set upper limits to the flow velocity through the bore of the magnet.

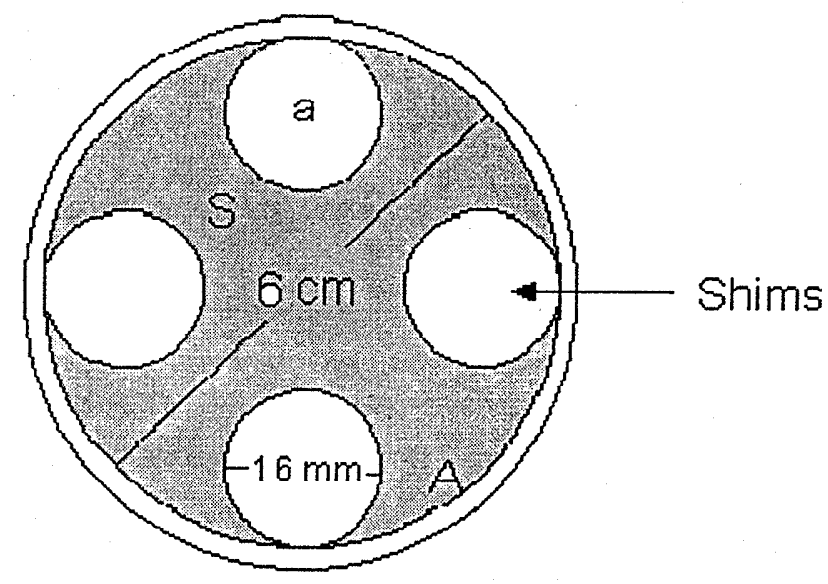

Figure VIII-6. Cross section of pipe going through the magnet.

The Reynolds number is defined by the diameter of the tube, its roughness, and the flow velocity. In this case the slurry will flow through the bore of the magnet. The bore is not a true cylinder because of shims placed in the space to force particles from the zero gradient fields positioned radially between the magnet poles. The true flow area is the space left after placing the shims along the inside wall of the pipe. This area was darkened in Figure VIII-6. This cross section is not circular. In this case the diameter must be 
substituted by an appropriately chosen variable or group of variables that describe the system with a single linear dimension which is equivalent in behavior to $\mathrm{D}$. The geometrical factor is introduced into the flow equations in the force balance:

$$
(-\Delta P) S=\tau_{y} A
$$

where:

$\Delta \mathrm{P}=$ pressure drop

$S=$ cross sectional area open to flow

$A=$ pipe wall area

$\tau_{\mathrm{y}}=$ momentum transfer to the wall

Substituting terms for cylindrical geometry:

$$
\begin{aligned}
& S=\frac{\pi D^{2}}{4} \\
& A=\pi D L=b L \\
& -\Delta P \frac{\left(\pi D^{2}\right)}{4}=\tau_{y}(\pi D L) \\
& D=\frac{4\left(\tau_{y}\right) L}{(-\Delta P)}=\frac{4 S}{b}
\end{aligned}
$$

where $b=$ wetted perimeter $=$ perimeter of large pipe section + perimeter of rod's section

For shapes other than circular in cross section, a replacement term $D_{\text {eq }}$ defined in Equation VIII-12 may be written for the geometrical factor D.

$$
D_{e q}=\frac{4 S}{b}
$$

So,

Cross-sectional area of large pipe: $\quad \mathrm{A}=\pi \mathrm{R}^{2}=3.1416 \times 32=28.27 \mathrm{~cm}^{2}$

Cross-sectional area of rods: $\quad \mathrm{a}=\pi \mathrm{r}^{2}=3.1416 \times 0.82=2.01 \mathrm{~cm}^{2}$

Area open to flow of fluid: $\quad \mathrm{S}=\mathrm{A}-4 \mathrm{a}=28.27-4(2.01)=20.23 \mathrm{~cm}^{2}$ 
Wetted perimeter $=$

$\mathrm{b}=\pi \mathrm{D}+4 \pi \mathrm{d}=3.1416 \times 6+4(3.1416 \times 1.6)=38.96 \mathrm{~cm}$

Using these values the equivalent diameter is determined,

$$
D_{e q}=\frac{4 S}{b}=\frac{4\left(20.23 \mathrm{~cm}^{2}\right)}{38.96 \mathrm{~cm}}=2.08 \mathrm{~cm}
$$

For laminar flow, the Reynolds number is $\mathrm{N}_{\mathrm{Re}}<2100$. To give a sufficient safety factor $\mathrm{N}_{\mathrm{Re}}=210$ will be used. Therefore,

$$
N_{\mathrm{Re}}=\frac{D \bar{v} \rho}{\mu}=\frac{(2.08 \mathrm{~cm}) \bar{v}\left(1.0 \mathrm{~g} / \mathrm{cm}^{3}\right)}{0.01 \mathrm{~g} / \mathrm{cmsec}}=210.0
$$

Solving for the mean flow velocity,

$$
\bar{v}=\frac{N_{\mathrm{Re}} \mu}{D \rho}=\frac{210.0(0.01 \mathrm{gr} / \mathrm{cm} \mathrm{sec})}{(2.08 \mathrm{~cm})\left(1 \mathrm{gr} / \mathrm{cm}^{3}\right)}=1.01 \mathrm{~cm} / \mathrm{sec}
$$

or a volumetric flow of less than $1.23 \mathrm{~L} / \mathrm{min}$ using $2.02 \mathrm{~cm}^{3}$ for the diameter of the bore. This translates to a throughput rate of 1.8 tonnes/day.

\section{Design and Construction of the HGMS Filter.}

The HGMS filter is supposed to permit a reasonable flow of slurry, while at the same having a closed, random structure or mesh, to trap the paramagnetic particles. It also has to resist the crushing magnetic force on the filtering media. All designs would permit the filter housing to rest at the top of the shims.

We proposed several designs, including the following:

1) A section of 2 in $(5.1 \mathrm{~cm})$ inside diameter PVC pipe, where a ferromagnetic steel or stainless steel wire would be sown from the outside wall of the pipe, forming inside, the pattern of a helicoidal staircase (see Figure VIII- 
7). This design offers enough open space for the solution to flow through. It could also give the slurry a mild agitation effect by part of the liquid following the helicoidal pattern. It could be terminated at the bottom by a piece of $6-\mathrm{mm}$ thick metacrylate plastic with sufficiently large perforations to avoid clogging or a large grid screen. A small piece of 434 stainless steel wool could be placed at the bottom of the filter.

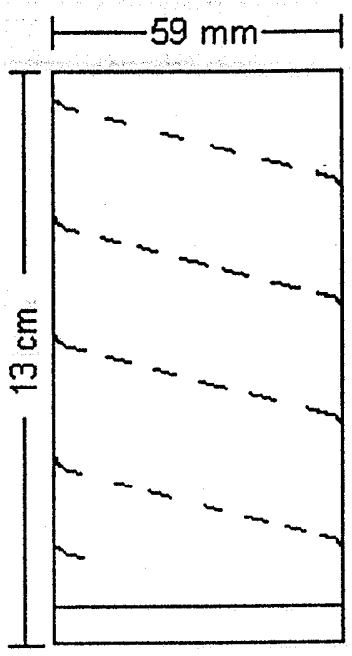

Side View

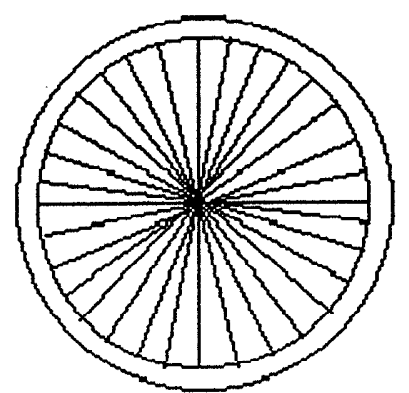

Top View

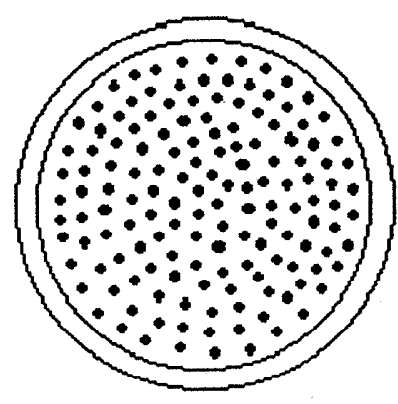

Bottom View

2)

Figure VIII-7. Design 1 of the HGMS filter and housing showing the perforations in the bottom cap. A large grid wire screen may be suibstitued for the perforated cap to avoid clogging.

3) A section of $4.0 \mathrm{~cm}$ ID PVC pipe with $3.2 \mathrm{~mm}$ perforations on the wall (see Figure VIII-8). This cylinder would be covered circumferentially by a layer of 434 stainless steel on the outside, followed by a nylon fabric of a mesh that permits the flow of the largest particles. This is also terminated by a plate of metacrylate plastic at the bottom, with wide $(3.2 \mathrm{~mm})$ holes on the edge, and smaller holes in the center. This design offers a much bigger area of flow holes $(1.6 \mathrm{~mm})$ in the center and a much bigger flow area. Again, a large grid screen may be substituted for the perforated cap to allow unrestricted flow. 


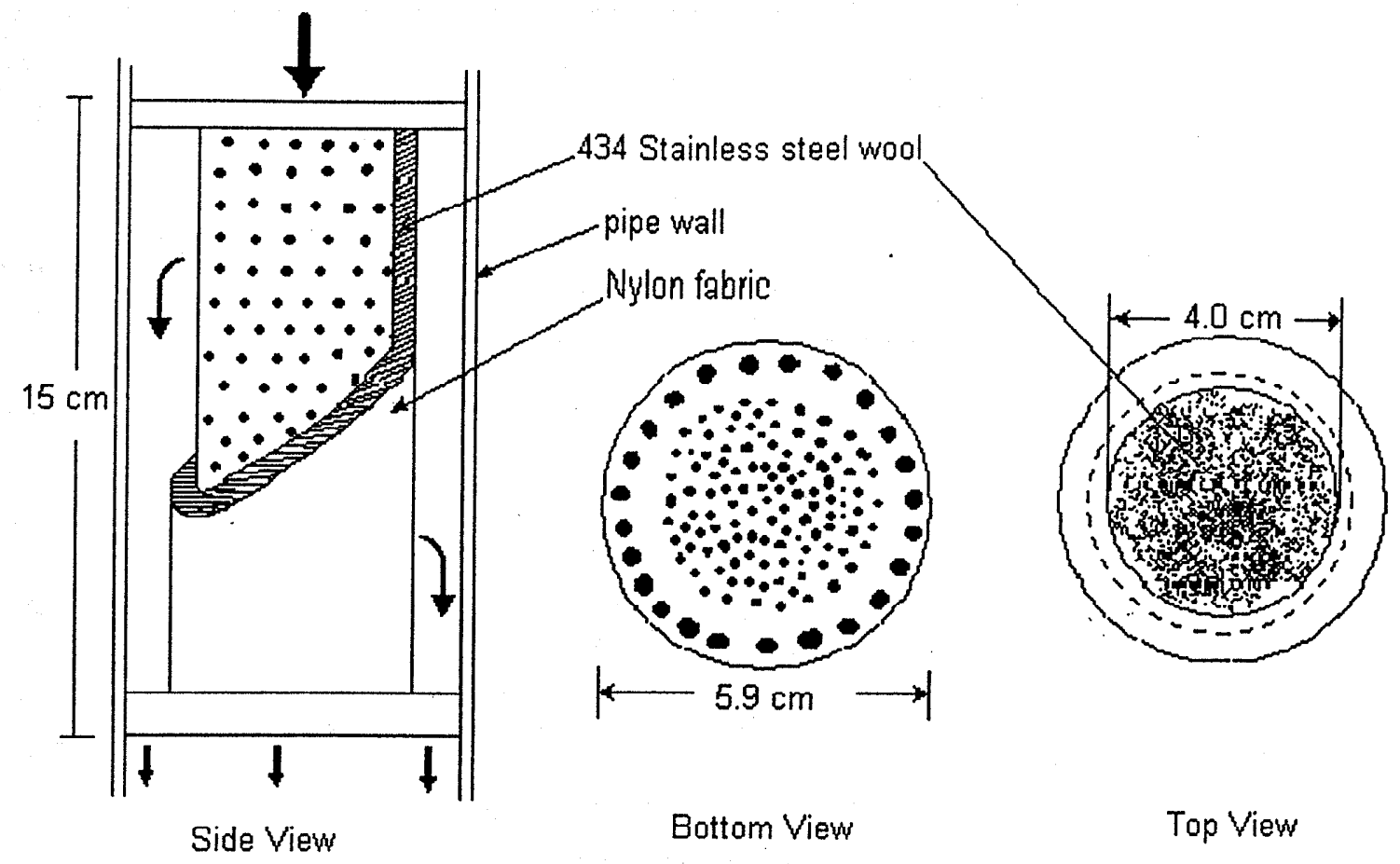

Figure VIII-8. Design 2 for the HGMS filter and housing.

3) A section of pipe similar to the one described in Design 1, but filled with several layers of 434 SS wool (see Figure VIII-9). The layers would be separated by sections of a smaller diameter pipe capped with perforated plates of metacrylate plastic or wide grid screen. This design offers good resistance to the compressing force of the magnet. 

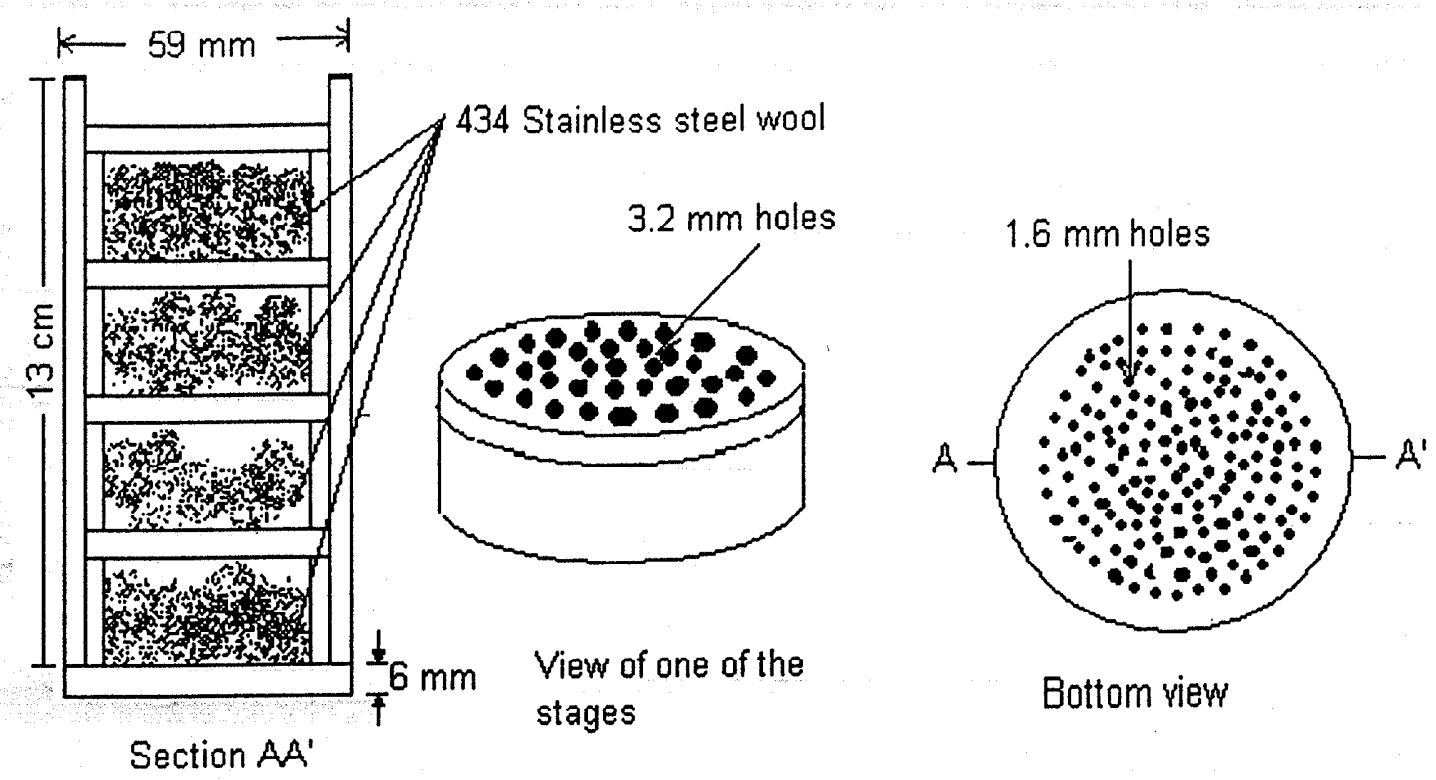

Bottom view

Figure VIII-9. Design 3 of the HGMS filter and housing.

\section{Final HGMS Filter Design}

The filter shown in Figure VIII-10 was built. It is made of a 13-cm section of 2-in. nominal PVC pipe. The tube was filled with 1 vol\% of fine 434 stainless steel. This stainless steel alloy was chosen because its combination of magnetic and non-corroding properties. Copper wire (18 gauge) is strung through the walls of the tube, forming a 3 -dimensional network. It is expected that this copper frame will keep the steel wool from being compressed to the bottom of the filter during operation of the magnet.

The flow characteristics of the filter were tested using a $100 \mathrm{ml}$ sample of Drum \#7 slurry, diluted to $3.785 \mathrm{ml}$ (1 gal.), or $2.6 \%$ slurry. Without the stainless steel wool, it permits a maximum flow of 19.9 liters per minute. It was found that $7.086 \mathrm{~g}$ of the 434 steel wool displaces $1.0 \mathrm{ml}$ of water. After filling the filter with $1 \%$ volume of SS wool, the maximum flow is reduced to 10.6 L/min. To test against network failure and possible backpressure, the stainless steel wool was compressed to the bottom of the filter. As a result, the flow was reduced to $7.6 \mathrm{~L} / \mathrm{min}$. This flow is within the range needed for laminar flow. 


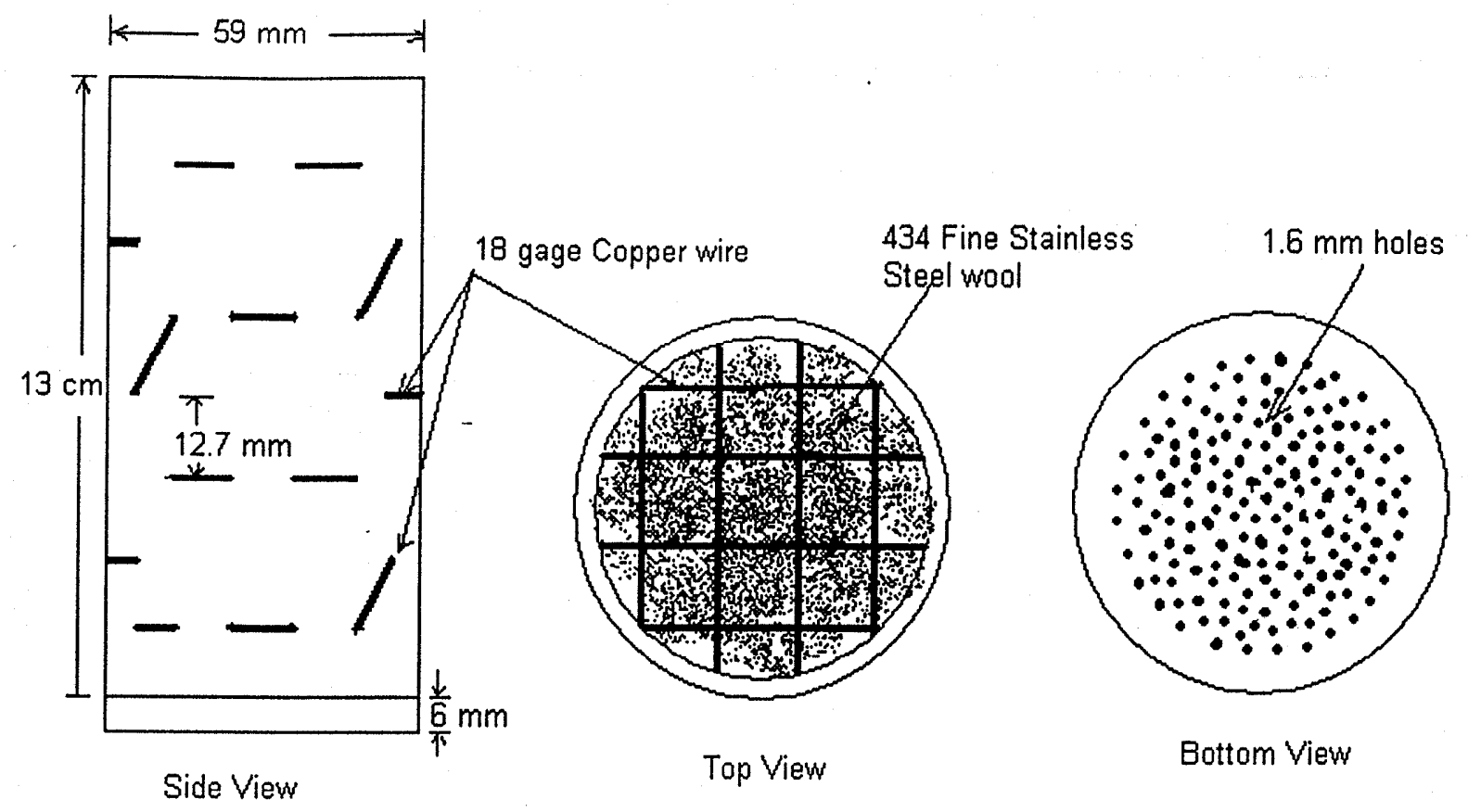

Figure VIII-10. Chosen design for the HGMS filter and housing.

The newly constructed piping was tested, and no leaks were found. There was a leak, however, in the coupling that joins the two pipe sections that run inside the cryostat, as shown in Figure VIII-11. This was corrected by placing one O-ring in each side of the coupling. 


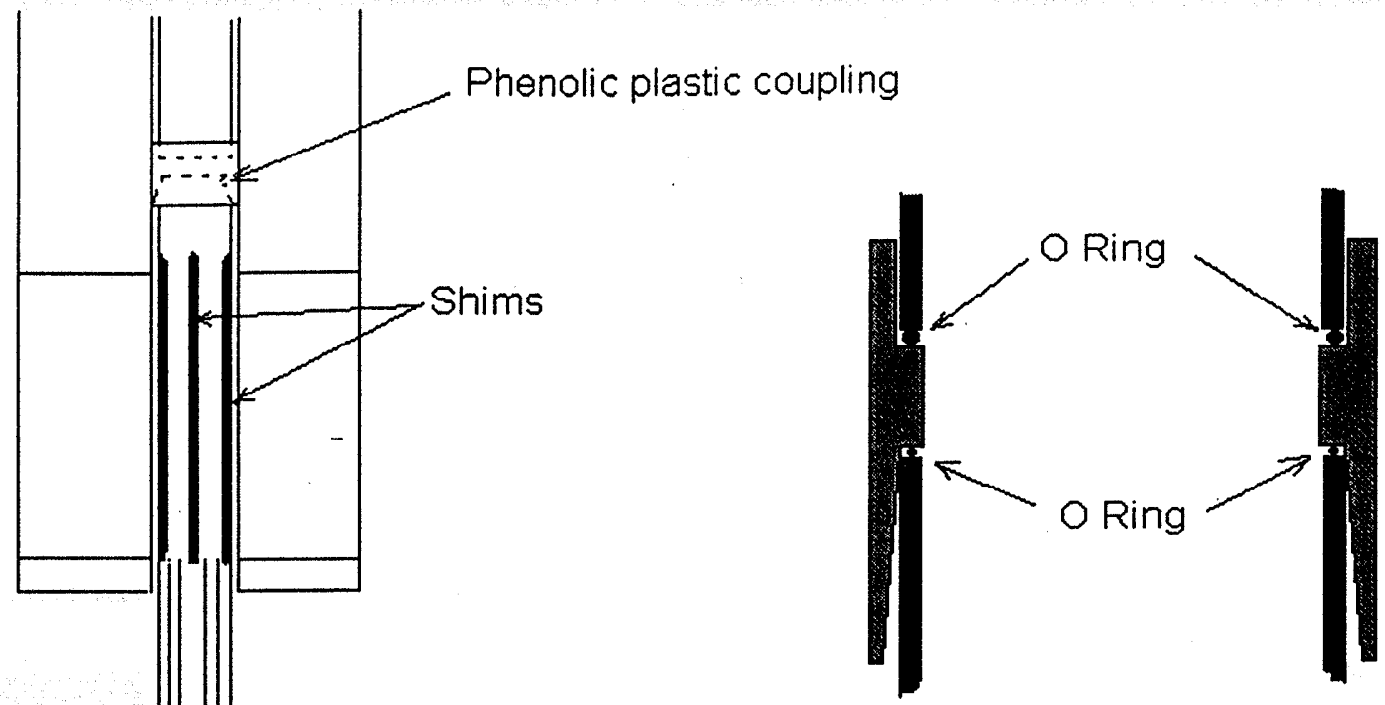

Enlarged view of phenolic coupling section

Figure VIII-11. Description of O-ring inserts in the bore of the OGMS. These O-rings are necessary for liquid processing to prevent leakage at the splitter assemblies.

It is planned to place the HGMS filter resting on the top of the shims. However, the rods seem to extend beyond the upper limit of the superconducting magnet. After measuring the effective magnetic field throughout the bore, it might be necessary to shorten these rods down to size, to take advantage of the strong magnetic field immediately above the magnet.

\section{Magnetic Field Profile Model}

In order to determine the optimal vertical location of the HGMS prefilter, the magnetic field profile is needed. The existing trajectory model assumes a constant magnetic field exists along the length of the magnet. Using a Hall probe, the magnetic field, at the bore wall and at the North Pole $\# 1$, was measured at various distances along the length of the magnet. The recorded data is shown in Table VIII-2. 
Table VIII-2. Magnetic field measured in the z-direction with a Hall Probe.

\begin{tabular}{cc}
\hline Distance* $\left.^{*} \mathrm{~cm}\right)$ & $\begin{array}{c}\text { Magnetic } \\
\text { Field (Tesla) }\end{array}$ \\
\hline 28.58 & 0.60 \\
$-\quad 33.02$ & 1.40 \\
48.26 & 1.85 \\
62.23 & 1.90 \\
75.57 & 1.95 \\
80.65 & 1.75 \\
90.17 & 0.40 \\
101.6 & 0.00
\end{tabular}

*Distance from the tip of the Hall Probe to bottom of cryostat

For ease of analysis the experimental data was converted into a continuous function in the z-axis. First the above data was converted into MKS units, where distance is in meters and the magnetic field is in $\mathrm{Wb} / \mathrm{m}^{2}$ or Tesla. The skewness of the plots may be due to the Hall probe being off center. The variation of the magnetic field was then assumed to be symmetric about a point $0.6 \mathrm{~m}$ down from the top of the one-meter magnet. It was also assumed that for the distance of approximately 0.35 meters in the middle of the magnetic field, the field is a constant $1.95 \mathrm{~T}$.

The magnetic field generated by the curve-fitting is effective for only 0.6306 meters, rather than the 0.68 meter length of the magnet. The length of the magnet was normalized to match the effective length of the 0.6306 meters. Therefore, $z=0$ is now at the top of the magnetic field rather than at the top of the magnet. This signifies that a falling particle will not be effected for the first 0.25 meters of its fall. A set of empirical equations, $B(z)$ were generated to describe the magnetic field, $B$, at any distance, $z$, down the magnet.

The magnetic field also varies in the $\theta$ direction around the circumference of the magnet. This is not accounted for in the existing model. In this case, the field is assumed to vary sinusoidaly in the $\theta$ direction, with 
points of maximum intensity at the poles and points of zero intensity at $45^{\circ}$ between the poles. Another equation $\mathrm{B}(\theta)$, was derived to determine the magnetic field at any point, $\theta$ (specified in degrees $0^{\circ}$ being the North Pole \#1), along the circumference of the magnet. The magnetic field is known to be zero at the center of the magnet $(r=0)$. But it was previously assumed that the magnetic field gradient, $\mathrm{dB} / \mathrm{dr}$, was a constant $60 \mathrm{~T} / \mathrm{m}$ from $\mathrm{r}=0$ to $\mathrm{r}$ $=0.032$ meters (at the bore wall). However, since the magnetic field varies so does the gradient. The equations (VIII-16-28) for the magnetic field and the magnetic field gradient in terms of $\mathrm{z}, \theta$, and $\mathrm{r}$ are given below.

For the magnetic field as a function of position,

$$
\begin{array}{ll}
\hline B(z): r \text { at Bore Wall and } \theta=0^{\circ} \\
B=-104.80 \mathrm{z}^{2}+28.652 \mathrm{z}-3.454 \times 10^{-4} \mathrm{~T} & 0 \leq \mathrm{z} \leq 0.14335 \mathrm{~m} \\
\mathrm{~B}=1.95 \mathrm{~T} & 0.14335 \leq \mathrm{z} \leq 0.48652 \mathrm{~m} \\
\mathrm{~B}=-102.03 \mathrm{z}^{2}+100.33 \mathrm{z}-22.704 \mathrm{~T} & 0.48652 \leq \mathrm{z} \leq 0.6306 \mathrm{~m}
\end{array}
$$

$B(\theta): r$ at Bore Wall and $z=0.3153$

$\mathrm{B}=1.95\left|\sin \left(2 \theta-90^{\circ}\right)\right| \mathrm{T}$

(VIII-19)

$B(r): z=0.3153 m$ and $\theta=0^{\circ}$

$\mathrm{B}=\frac{1.95 \mathrm{r}}{0.032} \mathrm{~T}$

(VIII-20)

$$
\begin{array}{ll}
\hline B(z, \theta, r) & \\
\mathrm{B}=\left(-104.80 \mathrm{z}^{2}+28.652 \mathrm{z}-3.454 \times 10^{-4}\right)\left|\sin \left(2 \theta-90^{\circ}\right)\right| \frac{\mathrm{r}}{0.032} \mathrm{~T} \\
\mathrm{~B}=1.95\left|\sin \left(2 \theta-90^{\circ}\right)\right| \frac{\mathrm{r}}{0.032} \mathrm{~T} & 0 \leq \mathrm{z} \leq 0.14335 \mathrm{~m} \\
& 0.14335 \leq \mathrm{z} \leq 0.48652 \mathrm{~m}
\end{array}
$$




$$
\begin{aligned}
& B=\left(-102.03 z^{2}+100.33 z-22.704\right)\left|\sin \left(2 \theta-90^{\circ}\right)\right| \frac{r}{0.032} T \\
& 0.48652 \leq \mathrm{z} \leq 0.6306 \mathrm{~m}
\end{aligned}
$$

For the gradient of the magnetic field as a function of position, we simply divide the expressions by the radial position which eliminates the radial dependence $\left(\theta_{0}\right.$ is a point of maximum field intensity $\left(0^{\circ}, 90^{\circ}, 180^{\circ}\right.$, $\left.270^{\circ}\right)$ ).

$$
\begin{array}{ll}
\hline \frac{d B}{d r} \mid=\frac{B(z, \theta)}{r}=\frac{B\left(z, \theta_{0}\right)}{r} \sin \theta & \text { for all } \mathrm{z} \\
\frac{d B}{d r}=\left(-104.80 \mathrm{z}^{2}+28.652 \mathrm{z}-3.454 \times 10^{-4}\right) \frac{\left|\sin \left(2 \theta-90^{\circ}\right)\right|}{0.032} \mathrm{~T} / \mathrm{m} & \text { (VIII-24) } \\
\frac{d B}{d r}=1.95 \frac{\left|\sin \left(2 \theta-90^{\circ}\right)\right|}{0.032} \mathrm{~T} / \mathrm{m} & 0.14335 \leq \mathrm{z} \leq 0.48652 \mathrm{~m}
\end{array}
$$

A plot of the magnetic field and magnetic field gradient can be found in Figures VIII-12 and 13. 


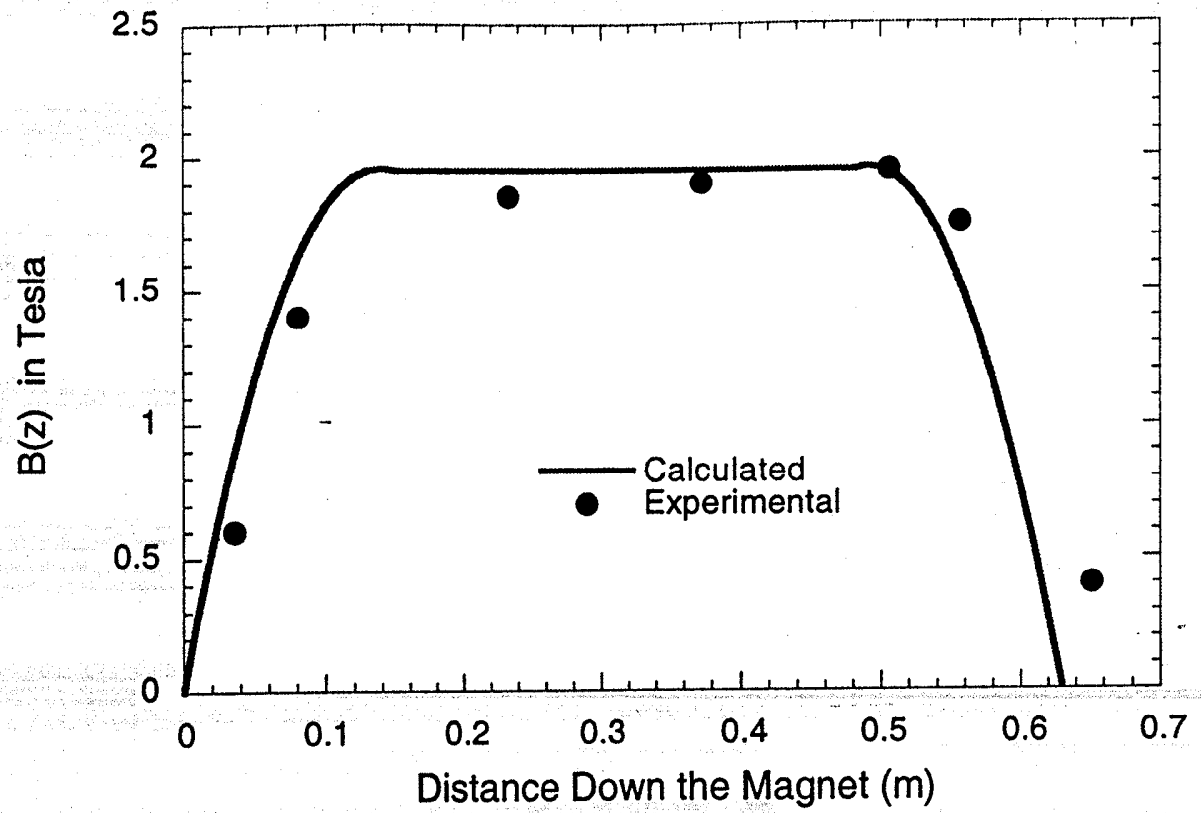

E

Figure VIII-12. B(z) determined experimental and calculated for the OGMS

E. unit

1

E

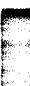

2

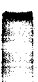




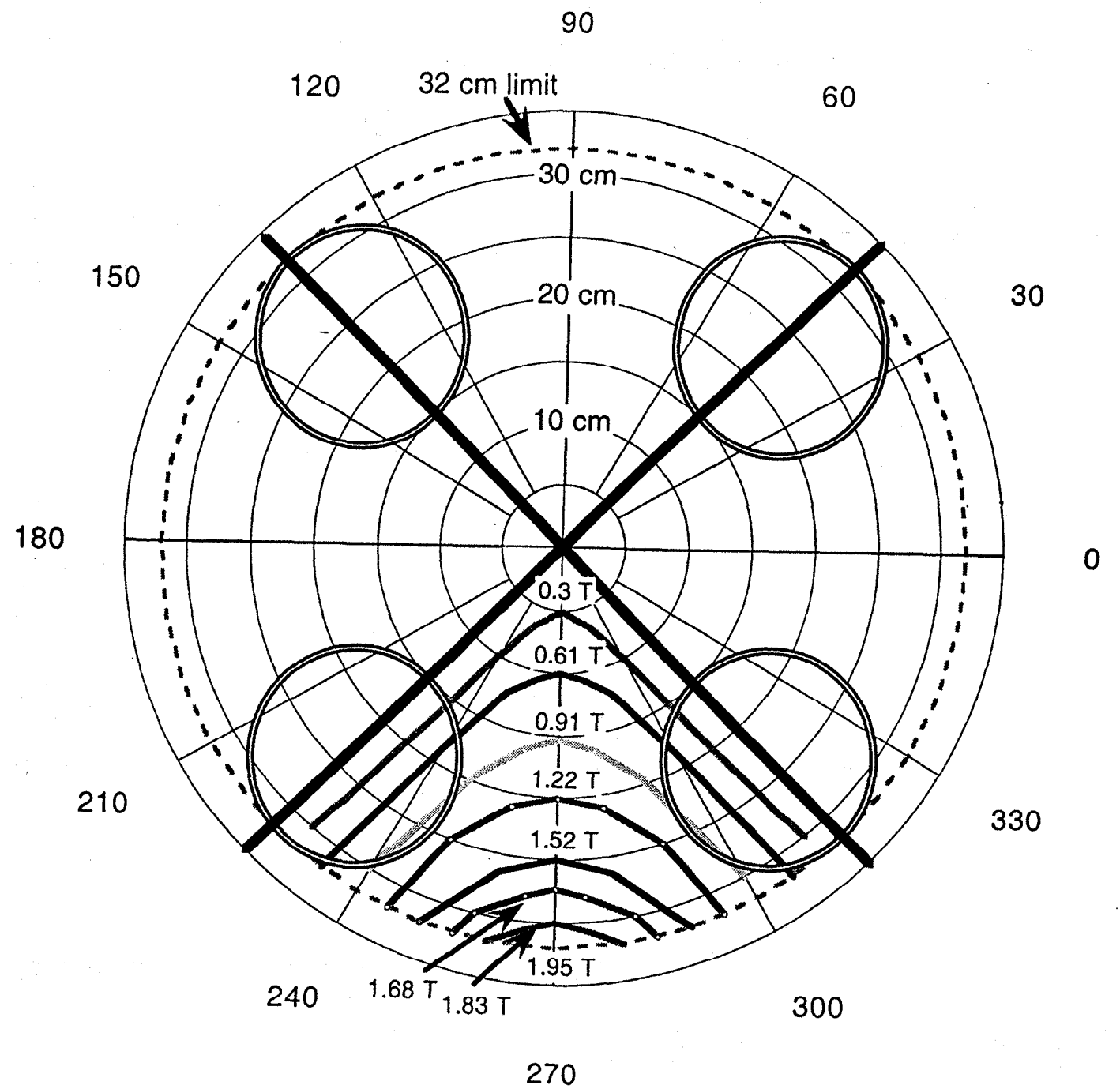

Figure VIII-13. $\mathrm{B}(\theta, \mathrm{r})$ for the Open Gradient Magnetic Separator unit at Argonne. Only one quadrant is shown. The other quadrants follow isotropically. The shims are designated by the double-lined circles. The radial limit of the bore hole is $0.032 \mathrm{~m}$ or $32 \mathrm{~cm}$ and is designated by the dashed circle. The zero Tesla isolines are shown as the thick black lines about $45,135,225$, and $315^{\circ}$. 


\section{OPEN-GRADIENT MAGNETIC SEPARATION: COSTS}

\section{Open-Gradient Magnetic Separation-Overview for Field Application}

A life-cycle cost study is presented here for the Open-Gradient Magnetic Separation System as applied to the remediation of soils. OpenGradient Magnetic Separation (OGMS) may be directly applicable to volume reduction of $\mathrm{Pu}$-contaminated soils at the Rocky Flats site, where it would be used following a segmented gate system [Doctor-1999]. The benefits of OGMS are that it works with solid matrices that contain paramagnetic materials such as $\mathrm{Pu}$ and $\mathrm{Pu}$-oxides to effect their separation from the lower susceptibility bulk soils and clays. An open-gradient magnetic separation (OGMS) process is being developed and tested at Argonne by the EMSP program, originally, with a focus on volume reduction of vitrification feeds. This builds upon earlier work with the ANL OGMS system which has been awarded two U.S. Patents [Doctor-5,250,482; Doctor- 4,778,594].

In the presence of a magnetic field paramagnetic particles (e.g., U, $\mathrm{Pu}$, fly ash, ferrite, pyrite) are deflected towards the field when free falling, or moving downward on a vibrating-screw. For the configuration employed here this means they are attracted toward the bore wall of the magnet. Diamagnetic particles (e.g., clay, alkali and $\mathrm{Al}$ salts) are repulsed from the magnetic field toward the center of the bore. Using intense magnetic field gradients generated by a superconducting magnet, spatial separations of different fractions are achieved in a short distance as is shown both by modeling and experimental studies [Doctor-1986, Doctor-1987]. This presents a life-cycle cost advantage over physical and chemical separation techniques when applied to radioactive and hazardous waste streams: (1) the separation has minimal mechanical parts, (2) no chemical additives are required, (3) it is effective with solid or liquid waste, (4) the system employs continuous processing, (5) the magnetic field in the separator space is not limited by saturation properties of iron ( $\left.\mathrm{B}_{0} \sim 2 \mathrm{~T}\right)$, (6) high feed throughput, and (7) low power cost. Because a definitive economic study will depend on the results of bench-scale testing of the OGMS system these results must be considered preliminary. 


\section{Commercial Development of Magnetic Separation}

Magnetic beneficiation of kaolin clay, mostly for the use of the paper industry, is a well-established commercial process. The commercial use of superconducting magnets for kaolin cleaning is now commercial [Winston-1990] where Winston reports on superconducting technology's "first move towards more conventional applications." Of related interest is the development of magnetic separation technology for paramagnetic materials such as petroleum refining fluid catalytic cracking (FCC) catalysts. This development has been underway for a number of years by Ashland Oil, Nippon Oil and Fuji-Davison [Takase-1982; Kimura and Levenspiel-1989]. Typically, these studies employ conventional non-superconducting high-gradient magnetic separation (filter type) separators, and OGMS represents an advancement of the technology.

\section{Soil Remediation Using a Segmented-Gate System - Rocky Flats Application}

A Segmented-Gate System may be used for soil remediation [Cummings-1996] as shown in Figure IX-1. The argument in support of these technologies is that they represent a good waste management technique for reducing the volume of soil needing treatment.

For the Segmented Gate System the contaminated soil is excavated via front-end loader and emptied into a hopper. There the soil is introduced to a hammermill to break up chunks and rocks, and then screened so that the soil particles are relatively uniform in size. The soil is transported via a conveyor belt underneath two banks of sodium iodide scintillation detectors which transmit data to a hoist computer that evaluates the amount of contamination in the soil. The detectors measure a minimum activity of approximately $30 \mathrm{pCi} / \mathrm{g}$ and use this measurement to divert soils which show activity. The option of using Containerized Vat Leaching as opposed to offsite transport and storage of the Pu-contaminated soils is still under active consideration. 


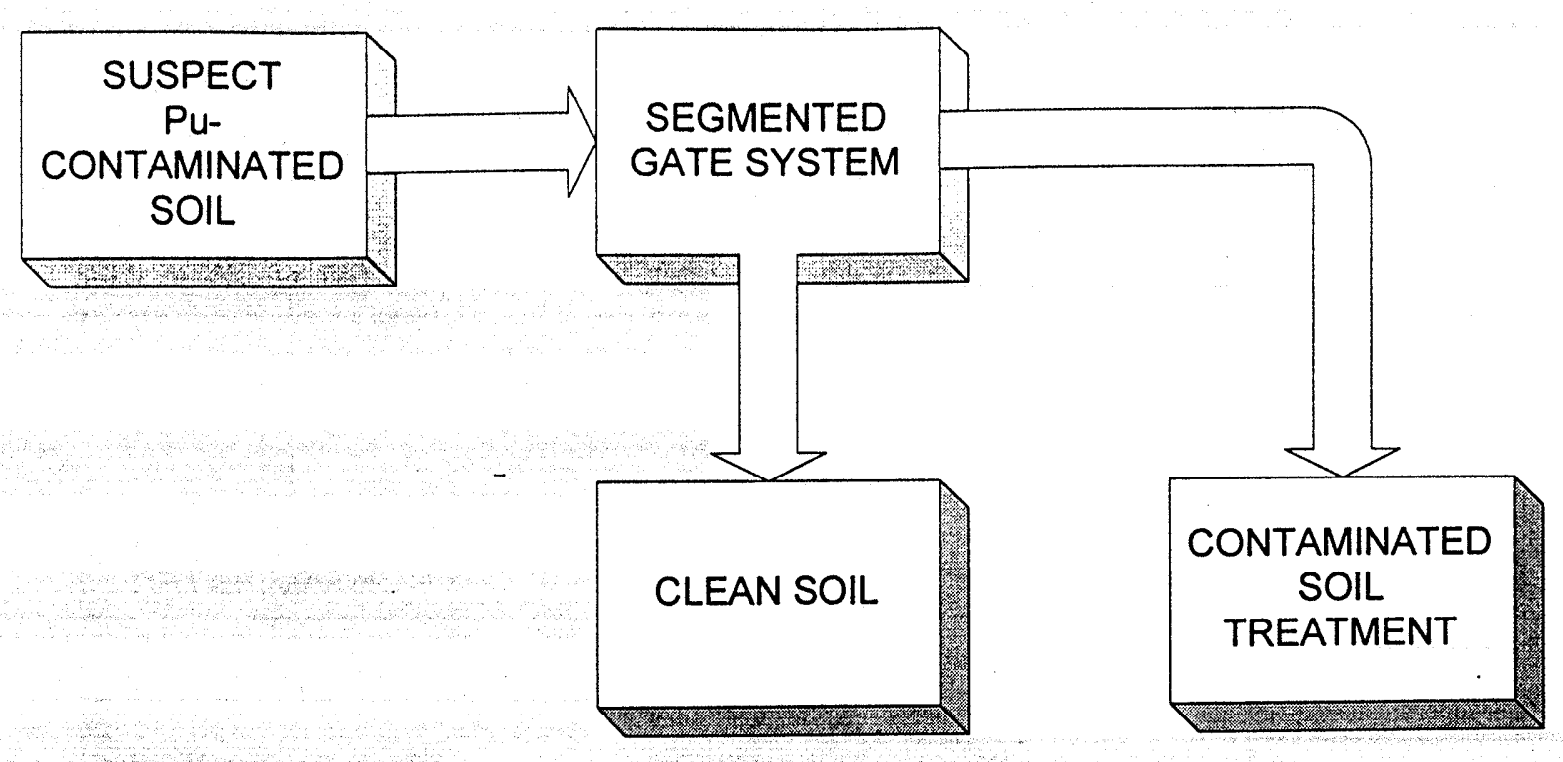

Figure IX-1. Segmented-Gate System combined with soil treatment.

Current plans for remediation of Pu-contaminated soils at sites such as Rocky Flats may employ some such variant on this system, although preliminary studies suggest that the Pu-contamination at Rocky Flats "is broadly distributed as to particle size and not associated with fines as in many Superfund sites where simple size separation solves the problem." [Maloney-1999]. This focuses on a critical issue where physical separation processes such as this may be of unusual importance. There will be an economic trade-off between material processing rates and the effective separation of the material. Care in the handling of the soil after comminution will be repaid by better performance of the system in not incorporating clean soils into the product going to final soil treatment.

\section{Soils: Open-Gradient Magnetic Separation Linked to the Segmented Gate}

With the OGMS System linked to the Segmented Gate, the volume of material being sent to contaminated soil treatment must be reduced sufficiently to justify incorporating an additional handling step. OGMS will be added as an incremental operation as shown in Figure IX-2. Clean soils produced by this technique will be returned to the belt conveyor for final inspection and disposition. As shown, the OGMS system will be working with soils. 


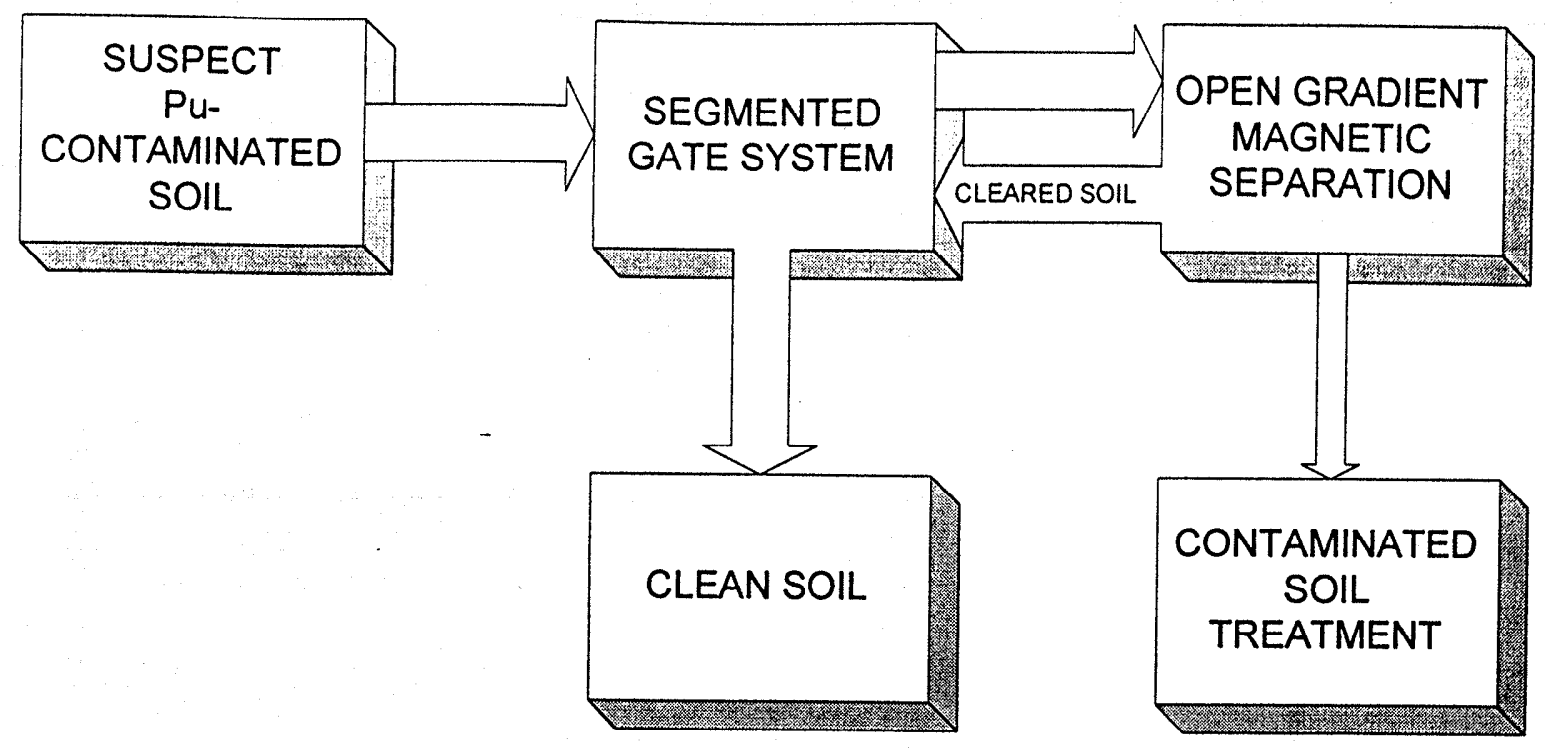

Figure IX-2. Segmented-Gate System combined with Open-Gradient Magnetic Separation prior to soil treatment.

Tank Sludge: Open-Gradient Magnetic Separation Linked to the Segmented Gate

Conceptually, this approach could also be applied to the treatment of tank sludge as long as the water content is adjusted so that the density of the slurry permits the magnetic materials to be mobile. This represents a special case for which we believe that OGMS will show an advantage over the current technologies. However, this effort will focus on Rocky Flats applications for Pu-contaminated soils.

\section{Open-Gradient Magnetic Separation Conceptual Scheme}

A conceptual scheme for the OGMS block that expands on the previous figure appears in Figure IX-3. Here, in order to better improve the recovery of only the Pu-contaminated fraction of the soil, an additional comminution step is proposed so that the material feed to the OGMS system will consist of 50 mesh and finer materials.

Size classification should be employed so that large rocks that will have Pu-contamination on their surface may be rinsed and returned for 
inspection by the Segmented Gate System. The rinse from this system is taken to Vat-Leaching if that is available, otherwise it will be incorporated into the contaminated stream. An OGMS feed bin is used as a holding area for materials to even out the flow rate from the Segmented Gate System.

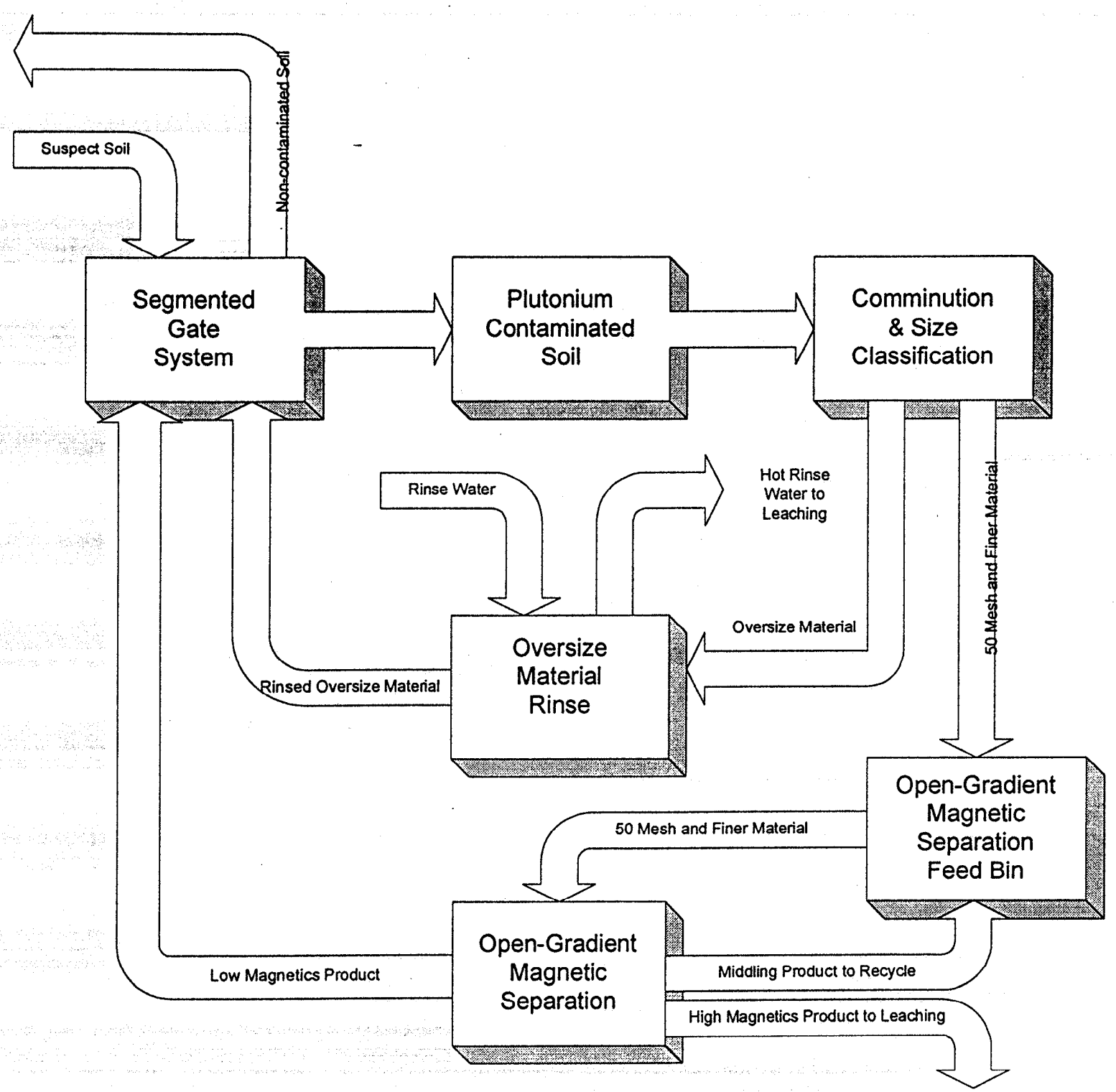

Figure IX-3. Open-Gradient Magnetic Separation reduces the material flows to soil treatment.

The base case will employ a flow rate of $2 \mathrm{~m}^{3} / \mathrm{hr}$ (550 gallons per minute) consistent with the best commercial practice for high-gradient superconducting magnetic separators. The low magnetic susceptibility product should be highly depleted in $\mathrm{Pu}$. This is taken back to the 
Segmented Gate System for clearance to go to the clean soil product stream. The Middlings product of mid-susceptibility material is returned to the separator to recover any misplaced $\mathrm{Pu}$. The high-susceptibility material consists of the product to disposal or treatment by vat leaching.

\section{Superconducting Quadrupole Magnet Annualized Costs}

\section{Coil Winding}

Even though the construction of superconducting quadrupole magnets is a well-established commercial industry, limited information about their costs is available in the open literature. The costs for these magnets will be presented here in some detail because discussions on the feasibility of magnetic separation invariably raise this question. An approach to calculating costs will be presented based on previously anecdotal guidelines gleaned from discussions with the superconducting magnet support group at the Ferrmilab Tevatron Accelerator (Batavia, IL). For this study both the strength of the magnetic field and the size of the bore are of interest. The suggested relationship is:
Quadrupole magnet capital cost $(\$$ Million $)=\$ 0.15^{*}($ Bore Volume - $\left.\mathrm{m}^{3}\right)^{0.8 *(\text { Tesla })^{1.2}}$

The specific design parameters for this magnet are listed in Table X-1.

Table IX-1. Superconducting Quadrupole Magnet Design Parameters.

\begin{tabular}{lc}
\hline Magnet Field & 3.6 Tesla \\
Effective length & $0.68 \mathrm{~m}$ \\
Cold Bore diameter & $0.10 \mathrm{~m}$ \\
Operating current & $1000 \mathrm{~A}$ \\
Operational Refrigeration & $2.5 \mathrm{~W}$ \\
\hline
\end{tabular}

Employing the capital cost formula:

Quadrupole magnet capital cost $(\$$ Million $)=\$ 0.15^{*}\left(0.00534 \mathrm{~m}^{3}\right)^{0.8} *(3.6$ Tesla $)^{1.2}=\$ 10,609$ 
As an accuracy check, this formula was compared against an earlier internal Fermilab communication [Smith-1982] specifically concerned with the fabrication of the quadrupole magnet employed in these tests. Included were the costs of setting up a winding station for these magnets of $\$ 216 \mathrm{~K}$, Start-up and Design costs of $\$ 216 \mathrm{~K}$, and Fabrication costs of $\$ 190 \mathrm{~K}$ for 18 magnets/yr. The first two figures are one-time costs, which were levelized to yield the following costs per magnet:

Quadrupole magnet construction costs $(\$$ Million $)=(0.216+0.216) * \$ 153,000+$ $\$ 190,000 / 18 / \mathrm{yr}$

$$
=\$ 14,227
$$

Inspection will show that these two formulae converge remarkably well as the start-up costs for magnet fabrication are written off. To be conservative for these calculations, the following magnet fabrication costs will be employed:

Quadrupole magnet capital cost $(\$$ Million $)=4 / 3^{*}\left[\$ 0.15^{*}\left(\text { Bore Volume }-\mathrm{m}^{3}\right)^{0.8}\right.$ * $\left.(\text { Tesla })^{1.2}\right]$

For the magnet used in the laboratory tests this yields a cost of $\$ 14,145$. It is important to note that this covers only the cost of winding the magnet, a process that basically employs the technology that would be used for fabricating a precision motor or generator.

\section{Ancillary Equipment}

The quadrupole superconducting magnet must be kept in a cryostat at liquid Helium temperatures. A breakdown of the costs for this ancillary equipment consistent with the work of Masuda is presented in Table X-2 [Kwok-1988] with reported operating costs [Wolsky-1989]: 
Table IX-2. Installed Capital Costs for Quadrupole Superconducting Magnet with Spiral Screw Separator (U.S. Patent \#4,778,594).

\begin{tabular}{lcr}
\hline Magnet Coil - Quadrupole & $\$ 14,146$ & $36 \%$ \\
Cryostat & $\$ 12,708$ & $32 \%$ \\
He Refrigeration \& transfer lines & $\$ 6,203$ & $16 \%$ \\
Power supply \& controls & $\$ 6,052$ & $15 \%$ \\
TOTAL & $\$ 39,109$ & $100 \%$ \\
& $\$ 43,020$ & $10 \%$ \\
Assembly & $\$ 55,926$ & $30 \%$ \\
Indirect Costs & $\$ 61,518$ & $10 \%$ \\
Contingency & $\$ 15,000$ & \\
SPIRAL SCREW installed & $\$ 76,518$ & \\
& & \\
Quadrupole Magnet with Spiral Screw & \\
OGMS with classification, conveyors, & $\mathbf{\$ 1 0 1 , 7 6 9}$ & \\
and bins & & \\
\hline
\end{tabular}

This estimate focuses on the available magnet used by the Argonne program. It may not represent the optimum magnet costs that would emerge from further study of site-specific Pu-contamination. Much of the support equipment for the commercial application of liquid Helium temperature superconducting technology is now available off-the-shelf, and is showing improved performance at lower costs. One example of this is the introduction of a low-maintenance Wankel engine for the Air-Products line of Helium refrigerators. The introduction of magnetic heat pumps for refrigeration promises even further operating cost reductions.

\section{Suspect Soil Throughput Rates}

Reports on the Segmented Gate System yield throughput rates of 4.6 to 49.6 cubic yards of material processed per day [Cumings-1996]. The existing magnet will be sized for just under 9 tons/day of operation, well within the envelope of operating experience (see Table IX-3). 
Table IX-3. Suspect Soil Throughput for Magnet with Spiral Screw

Separator.

\begin{tabular}{lcl}
\hline Soil & 70 & $\mathrm{lb} / \mathrm{ft}^{3}$ \\
Flat plate area - bore & 2.375 & in. dia \\
Loading on "plate" - & & \\
depth & 0.20 & $\mathrm{in}$. \\
Residence time on & & \\
"plate" & $4.00 \mathrm{sec}$ \\
Magnet length & $0.68 \mathrm{~m}$ \\
Screw pitch & $0.03 \mathrm{~m}$ \\
Equivalent "plates" & 22.7 & \\
THROUGHPUT & $\mathbf{8 . 7 9}$ & tons/day \\
\hline
\end{tabular}

At higher throughput rates it may be desirable to have parallel OGMS systems separating the contaminated soils. Adjustments to the dimensions and the throughput of the OGMS magnet will require that samples of the typical soil expected be tested at Argonne. One of the easiest ways to do this would be to take soils characteristic of the Rocky Flats area and mix them with paramagnetic beads specifically engineered to match the size and susceptibilities of the Pu-contamination. Following this, final optimization of the magnets and ancillary equipment could take place.

\section{Annualized Operating Costs}

The proposed application is for the Rocky Flats site. This is a "fast track" project that should be concluded by the year 2006. Hence, this is a four-year project. Because of this accelerated performance, the typical capital levelizing charge will not be employed for the OGMS system. There is no expectation that the equipment used for this project will have a salvage value although that would not be unreasonable. A reasonable on-stream factor is employed (85\%) to allow for maintenance and downtime on the system.

Because the magnet is superconducting, it will not draw current once it is charged. However, it will likely be operated so that there some cycling of the magnet. Hence, an electrical cost equal to that of refrigeration has been added into the estimate. At facilities such as Fermilab, it is typical for the magnets to operate up to 6 months before they are shut down and shed their power. If the facility is designed for this type of operation, the infrequent 
charging of the magnet and the one-time costs for the Helium-fill become low cost components assumed to be no greater than $3 \%$ of the capital charge (Table IX-4).

Table IX-4. Annualized Costs of treating Suspect Soil with an OGMS System using a Spiral Screw Separator

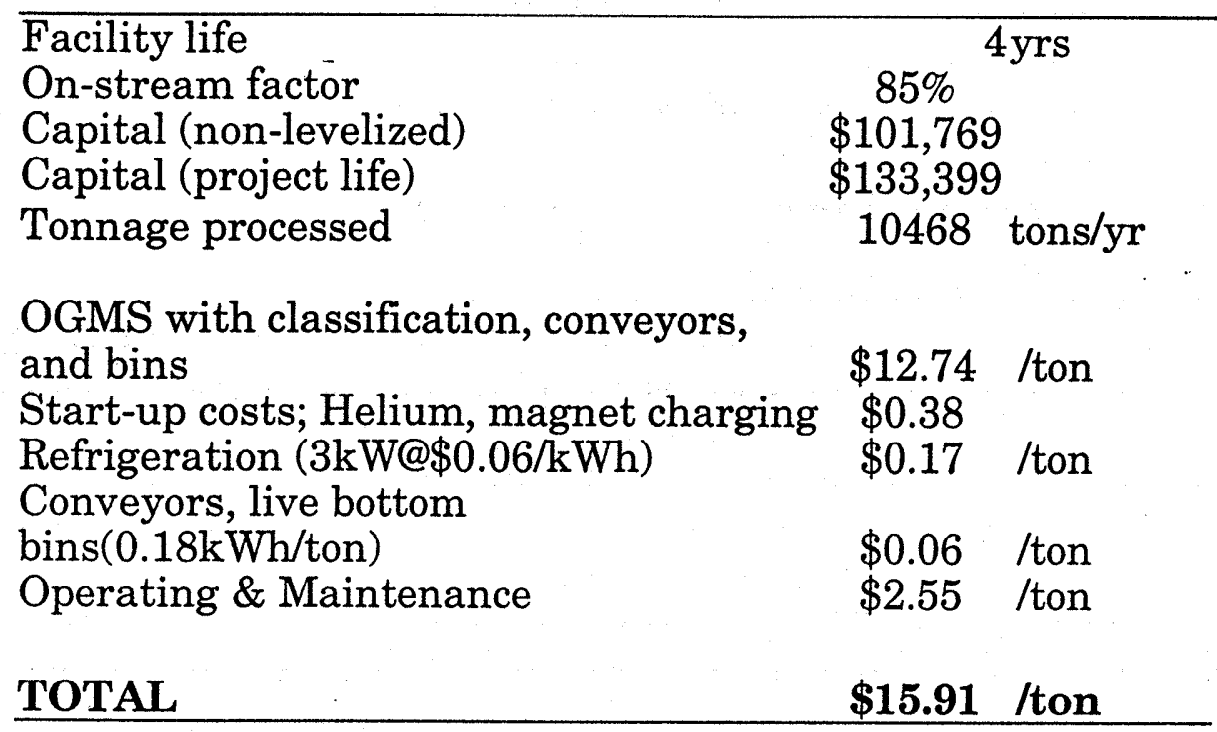

\section{Economic Summary}

Several Conclusions may be drawn from this cost analysis:

A Superconducting Quadrupole Open-Gradient Magnetic Separator operating in the mode where it employs a Spiral Screw Separator on soils with $\mathrm{Pu}$-contamination was investigated.

Proto-type scale tests are needed to optimize and validate the system design for the specific application on Pu-contaminated soils at Rocky Flats.

The present tests are a reasonable match to the required throughput rates of 9 tons/day

All the equipment excepting the internal spiral-screw separator may be procured as "off-the-shelf" equipment

The operating costs for this system appear to be attractive at less than $\$ 16 /$ ton. Even if a prototype system were to be constructed and the high costs for prototype magnets were to be used, the system still seems to have a high enough profit margin to prove economical. 


\section{SUMMARY}

The preliminary evaluation of the Open Gradient Magnetic Separation (OGMS) process shows that the process has potential to separate radionuclides and hazardous elements from solid particulate waste streams due to magnetic nature of the particles. The results of the physical and chemical measurements indicate that the OGMS process shows potential for use under actual waste conditions for sludges and radioactive fly ash. However, some difficulties may arise in the segregation of the Consolidated Incinerator Facility fly ash due to the presence of fine particles. The Rocky Flats ash is a good candidate for segregation of $\mathrm{Pu}$ oxide from the waste stream using OGMS. In continuing developmental activities, the process was optimized with High Gradient Magnetic Separator (HGMS) as a prefilter for ferromagnetic particles and models where revised for the separation of the waste streams. Some of the issues yet to be resolved with this OGMS apparatus are the determination of the grade, separation performance, and production rates with radioactive and hazardous waste feed streams. Further work is necessary to determine the separation mechanism and to further test the OGMS process on simulant and radioactive waste streams. 


\section{ACKNOWLEDGMENTS}

The authors would like to acknowledge J. S. Luo and E. C. Buck for the TEM micrographs, U. Welp for the magnetic susceptibility measurements, Brian Golchert for the Eulerian code development, the undergraduate summer research students Ann Visser, LaTerra Holden, Russ Pesavento, Jennifer Putty, Paul Huggins, and Manuel Almazan, Karen Chess for the aid in computer model development, Connie Cicero, Shen-Lin Chang, Michael Petrick, Sheldon Landsberger, and A. D. Ebner for HGMS development. This work was supported by the U.S. Department of Energy under Contract W-31109-ENG-38. 


\section{REFERENCES}

Avens, L., J. T. McFarlan, and U. F. Gallegos, "Magnetic Separation as a Plutonium Residue Enrichment Process," Separation Science and Technology, 25 (13-15) pp. 1967-1979 (1990).

Bates, J. K., E. C. Buck, N. L. Dietz, D. J. Wronkiewicz, X. Feng, C. Whitworth, K. Filius, and D. Battleson, "Applicability of Slag as Waste Forms for Hazardous Waste," Proceedings of Spectrum '94, International Topical Meeting on Nuclear and Hazardous Waste Management, Atlanta, GA, Aug. 24-28 (1994).

Behrens, R. G., E. C. Buck, N. L. Dietz, J. K. Bates, E. Van Deventer, and D. Chaiko, "Characterization of Plutonium-Bearing Waste by Chemical Analysis and Analytical Electron Microscopy," ANL-95/35.

Bethke, C. M., The Geochemist's Workbench, A Users Guide to Rxn, Act2, Tact, React, and Gtplot, Version 2.0, 1994.

Bickford, D. F., and C. M. Jantzen, "Devitrification Behavior of SRL Defense Waste Glass," Mat. Res. Soc. Symp. Proc. 26, 557-566 (1984).

Bickford, D. F. and C. M. Jantzen, "Devitrification of Defense Nuclear Waste Glasses-Role of Melt Insolubles," J. Non-Crys. Sol. 84, 299-307 (1986).

Buechele, A. C., X. Feng, H. Gu, and I. L. Pegg, "Alteration of Microstructure of West Valley Glass by Heat Treatment," Mat. Res. Soc. Symp. Proc. 176, 393-402 (1990).

Champ, D. R., Merritt, W. P., Young, J. L., "Potential for the Rapid Transport of Plutonium in Groundwater as Demonstrated by Core Column Studies," in The Scientific Basis for Radioactivity Waste Management, 745-754, 1982.

Collins, C. R., Sherman, D. M., and Ragnarsdottir, K. V., "The Adsorption Mechanism of $\mathrm{Sr}^{2+}$ on the Surface of Geothite," Radiochim. Acta, 81, 201206, 1998.

Crawford, R. J., Mainwaring, D. E., and Harding, I. H., "Adsorption and Coprecipitation of Heavy Metals from Ammoniacal Solutions Using Hydrous Metal Oxides," Colloids and Surfaces A: Physicochemical and Engineering Aspects, 126, 167-179, 1997.

Cromieres, L., Moulin, V., Fourest, B., Guillaumont, R., and Giffaunt, E., "Sorption of Thorium onto Hematite Colloids," Radiochimica Acta, 82, 249$255,1998$. 
Cummings, M., and S. Booth,. "Remediation of Uranium Contaminated Soil Using Segmented Gate System and Containerized Vat Leaching Techniques: A Cost Effectiveness Study," Remediation, Wiley, 1996.

Doctor, R. D., Apparatus for Magnetic Separation of Paramagnetic and Diamagnetic Materials, U.S. Patent No. 4,778,594 (Oct. 18, 1988).

Doctor, R. D., Argonne National Laboratory; private communication to M. David Maloney, Kaiser-Hill Company, 1999 July $21^{\text {st }}$. "Open-Gradient Magnetic Separation (OGMS) Technology for Pu-Contaminated Soils,"

Doctor, R. D., C.B. Panchal, and C.E. Swietlik, A Model of Open-Gradient Magnetic Separation for Coal Cleaning Using a Superconducting Quadrupole Field, Argonne National Laboratory, monograph in Recent Advances in Separation Techniques-III; N.N.Li, ed., AIChE Symposium Series, American Institute of Chemical Engineers, 82(250):154-68 (1986).

Doctor, R.D., Livengood, C.D., Genens, L.E., Swietlik, C.E., and Foote, K.,. "Investigation of Open-Gradient Magnetic Separation for Illinois Coal," Processing and Utilization of High Sulfur Coals II, Y.P. Chugh and R.D. Caudle, eds., Elsevier Science Publishing Company, Inc., 149-160, 1987.

Doctor, R.D., Process for Magnetic Beneficiating Petroleum Cracking Catalyst, U.S. Patent No. 5,250,482, (Oct. 5, 1993).

Ebner, A. D., J. A. Ritter, L. Nuñez, "High Gradient Magnetic Separation for the Treatment of High Level Radioactive Waste," Separation Science and Technology, 34 (6\&7), 1330-1350, 1999.

Forbes, E. A., Posner, A. M., Quirk, J. P., “ ,” J. Colloid Interface Sci., 49, 403, 1974.

Fuerstenau, D. W, and Osseo-Asare, K., J. Colloid Interface Sci., 118, 524, 1987.

Girvin, D. C., Ames, L. L., Schwab, A. P., and McGarrah, J. E., "Neptunium Adsorption on Synthetic Amorphous Iron Oxyhydroxide," J. of Colloid Interface Sci., 141 (1), 67-77, 1991.

Hayes, K. F., and Leckie, J. O., "Modelling Ionic Strength Effects on Cation Adsorption at Hydrous Oxide/Solution Interfaces," J. Colloid and Interface Sci., 115(2), 564-572, 1987.

Hench, L. L., L. Werme, and A. Lodding, "Barial Effects in Nuclear Waste Glass," Sci. Basis for Nuc. Waste Mgt. V, Plenum Press, New York, 153-162 (1982).

Hoegler, J. M. and W. M. Bradshaw, "Magnetic Separation of Department of Energy Wastes," ORNL-DE89 012908 (1989). 
Hoegler, J. M., "Magnetic Separation of Uranium from Waste Materials," $8^{\text {th }}$ Symposium on Hazardous and Industrial Solid Waste Testing and Disposal, Clearwater FL, Nov. 12-13 (1987).

Jantzen, C. M., and D. F. Bickford, "Leaching of Devitrified Glass Containing Simulated SRP Nuclear Waste,” Mat. Res. Soc. Symp. Proc. 44, 135-146 (1985).

Jantzen, C. M., D. F. Bickford, and D. G. Karraker, "Time-TemperatureTransformation Kinetics in SRL Waste Glass," Adv. Ceram. 8, 30-38 (1984).

Kaplan, D. I, Gervais, T. L., and Krupta, K. M., "Uranium(VI) Sorption to Sediments Under High $\mathrm{pH}$ and Ionic Strength Conditions," Radiochimica Acta, 80, 201-211, 1998.

Keeney-Kennicutt, W. 1., Morse, J/ W., Geochim. Cosmochim. Acta, 49, 25772588, 1985.

Kelly, J. A., "Evaluation of Glass as a Matrix for Solidification of Savannah River Plant Waste," DP-1397, E. I. DuPont de Nemours Report, October (1975).

Kimura, S. and O. Levenspiel, 198. "Magnetic Filter for Solids: Theory and Experiments," Ind. Eng. Chem. Res. 28:803-808.

Kwok, H.S., and D. Shaw, 1988. Superconductivity and it's applications, Elsevier.

Lu, N., Cotter, C. R., Kitten, H. D., Bentley, J., and Triay, I. R., "Reversibility of Sorption of Plutonium-239 onto Hematite and Geothite Colloids," Radiochim. Acta, 83, 167-173, 1998.

Lummetta, G. J., M. J. Wagner, F. V. Hoopes, and R. T. Steele, "Washing and Caustive Leaching of Hanford Tank C-106 Sludge," PNNL-11381, Pacific Northwest National Laboratory Report, October (1996).

Liu, Y. A., "Industrial Applications of Magnetic Separation," IEEE, New York (1979) and "Wet High Intensity Magnetic Separation Could Improve Gold Recovery," Coal, Gold and Base Minerals of Southern Africa 27(7): 87 (1979).

Maloney, D., 1999 July 16. "Magnetic Separation Technology for PuContaminated Soils-MDM-005-99," Kaiser-Hill, private communication to R. Doctor, Argonne National Laboratory.

Marquardt, C., and Kim, J. I., "Complexation of $\mathrm{Np}(\mathrm{V})$ with Fulvic Acids," Radiochimica Acta, 81, 143-148, 1998. 
Marquardt, C., and Kim, J. I., "Complexation of $\mathrm{Np}(\mathrm{V})$ with Humic Acid: Intercomparison of Results from Different Laboratories," Radiochimica Acta, 80, 129-137, 1998.

Mishra, S. P., and Tiwary, D., "Inorganic Particluates in Removal of Toxic Heavy Metal Ions: Efficient Removal of Cadmium Ions from Aqueous Solutions by Hydrous Manganese Oxide," Radiochimica Acta, 80, 213-217, 1998.

Osseo-Asare, K., and Fuerstenau, D. W., Int. J. Miner. Process., 6, 85, 1979.

Osseo-Asare, K., and Fuerstenau, D. W., Int. J. Miner. Process., 7, 219, 1980.

Plodinec M. J., and J. R. Wiley, "Evaluation of Glass as a Matrix for Solidifying Savannah River Plant Waste: Properties of Glass Containing $\mathrm{Li}_{2} \mathrm{O}$," DP-1498, E. I. DuPont de Nemours Report, February (1979).

Rabung, T., Geckeis, H., Kim, J. I., and Beck, H. P., "The Influence of Anionic Ligands on the Soprtion Behavior of Eu(III) on Natural Hematite," Radiochim. Acta, 82, 243-248, 1998.

Rai, D. and Serne, R. J., J. Environ. Qual., 6, 89-95, 1977.

Sanchez, A. L., Murray, J. W., and Sibley, T. H., Geochim. Cosmochim. Acta, 49, 2297-2307, 1985.

Smith, R.P., Argonne National Laboratory; private communication to Thomas Kirk, Fermi National Accelerator Laboratory, 1982 August $3^{\text {rd }}$. "Superconducting Quadrupole Magnets for the TEV II Project."

Sproull, J. F., S. L. Marra, and C. M. Jantzen, "High Level Radioactive Waste Glass Production and Product Description," Material Research Society Meeting, Boston, MA, Nov. 29-Dec. 3 (1993).

Strickert, R. G., and Rai, D., "Predicting Pu Concentrations in Solutions Contacting Geologic Materials," in The Scientific Basis for Nuclear Waste Management, S. V., Topp, Ed., 215-221, 1982.

Takase, S., et al., 1982 Sept. 12-17. "Magnetic Separation of FCC Equilibrium Catalyst by HGMS," Symposium on Recovery of Spent Catalysts, American Chemical Society, Kansas City, MO.

Tochiyama, O., Endo, S., and Inoue, Y., "Sorption of Neptunium(V) on Various Iron Oxides and Hydrous Iron Oxides," Radiochimica Acta, 68, 105111, 1995.

Tochiyama, O., Yamazaki, H., and Mikami, T., "Sorption of Neptunium(V) on Various Alumnium Oxides and Hydrous Alumnium Oxides," Radiochimica Acta, 73, 191-198, 1996. 
Tochiyama, O., Yamazaki, H., Li, N., "Effect of the Concentration of Metal Ions on Their Adsorption on Various Hydrous Iron and Aluminum Oxides," Journal of Nuclear Science and Technology, 33 (11), 846-851, 1996.

Turcotte, R. P., J. W. Wald, and R. P. May, "Devitrification of Nuclear Waste Glasses," Sci. Basis for Nuc. Waste Mgt. II, Plenum Press, New York, 141146 (1979).

Watters, R. L., Hakonson, T. E., Lane, L. J., Radiochimica Acta, 32, 89-103, 1983.

Winston, A. and J. Selvaggi, 1990 Jan. 'Large Superconducting Separator for Kaolin Processing," Chemical Engineering Progress, p.36-40.

Wolsky, A.M, et al., 1989. Applied Superconductivity, Noyes Data Corporation, Park Ridge, NJ.:

Wronkiewicz, D. J., X. Feng, N. R. Brown, and T. DiSanto, "Radionuclide and Hazardous Element Retention in Glass-Crystal Composite Waste Forms," Proceedings of the I\&EC Special Symposium, American Chemical Society, Atlanta, GA, Sept. 19-21 (1994).

Zasoski, R. J., and Burau, R. G., "Sorption and Sorptive Interaction of Cadmium and Zinc on Hydrous Manganese Oxide," Soil Sci. Soc. Am. J., 52, 81-87, 1988. 
-

$-$

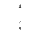

$-$

-

:

$-$

$=$

-

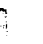

.

-

$-$

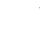

$-$

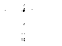

-

-

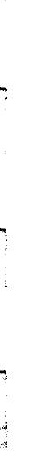


APPENDIX I

7

SRS WASTE SIMULANT CHARACTERIZATION REPORT

1

$E$

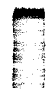

17:

5

I

$F$

1

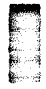

2

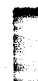

1

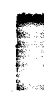

1

2

5 


\title{
WESTINGHOUSE SAVANNAH RIVER COMPANY INTER-OEEICE MEMORANDUM
}

\author{
SRT-GEM-97-056
}

september 17, 1997

\author{
TO: David A. Crowley, 773-43A \\ EROK: Connie A. Cicero-Herman, 773-41A \\ CC: Kim A. Howard, 773-43A \\ Richard DOCtOI, ANL \\ Luls Nunez, ANL
}

\section{SUBJECT: $\frac{\text { SBTC Status Repert for Activities in supoest of two }}{\text { ANT 97-9B-01 }}$}

The Savannah River Technology Center (SRTC) is being funded by the Argonne National Laboratory (ANI) to assess the feasibility of using Superconducting Open-Gradient Magnetic Separation (OGMS) as a pretreatment method for vitrification of radiouctive wastes. The Vitrification Technology Section (VTS) of SRTC is currently supporting or pursuing several vitrification programs, including vitrification of radioactive and/or hazardous wastes and stabilization of excess nuclear materials.

The SRTC has recognized expertise in the vitrification field because of the more than 25 years experience in research and development of vitrification technology. Currently, the VTS of SRTC provides technical support to the Defense Waste Processing Facility (DWPE) at the Savannah River Site (SRS). The DWPE is the United States' largest working plant for the vitriflcation of liquid High Level Wastes (HLW). To date, more than 200 canisters of HIW have been vitrlfied in this facility. It is expected that the DWPF Will continue treating $\mathrm{HIW}$ for the next 20 years. Additionally, the VTS is supporting the start-up and operation or the SRTC designed Transportable Vitrification system (TVS). The TVS was designed to demonstrate the treatment of Low-Level Mixed Wastes (IIMW), but can be used to treat small waste streams in their entirety. The TVS is currently located at Oak Ridge Reservation and is scheduled to commence treatment of actual wastes in September 1997. The SRIC is also involved in many other vitrification programs to support vitrification of radioactive wastes for the Tanks and Mird Waste Focus Areas of the office of Science and Techuology Development and the disposition of excess/surplus weapons materials (94-1 materialis) for the Department of Energy (DOE).

The ANL, on the other hand, has expertise in the field of magnetic i. separation. They are pursuing the use of superconducting oGMs as a 
pre-treatment method for vitrification streams because it has the potential to sepazate some of the more difficult to vitrify species from the waste streams. For example, many of the DOE waste streams contain iron which impedes the waste loading possible in the glass because of the potential for formation of spinel crystals. By using magnetic separation as a pre-treatment step, the potential is increased for obtaining higher waste loadings with amorphous products that do not present a problem during processing. In addition, the separation process has the potentlal to reduce the volume of waste that needs to be vitrifled. It is anticipated that the material that is separated will be considered Low-Level waste (ILW) so it would not have to be treated to the same extent as the original sLW.

Through an Intra-DOE work Order (IWO) between SRTC and ANI, SRTC will provide vitrification technical expertise to the program. They will also help direct the activities of ANL so they are beneficial to vitrification programs. The long-term goal is for SRTC to provide a waste stream amenable to the separation process, for ANL to perform the separation process on the stream and provide the pre-treated stream to SRTC, and for SRTC to vitrify the stream in a pilot-scale melter. The benefits of the pre-treatment method can then be determined as compared to direct vitrification methods.

In fiscal year 1997, the main focus of SRTC's efforts involved the identification and characterization of the candidate waste streams. Characterization included determination of chemical composition, radionuclide content, particle size distribution, and phase identification.

A kick-off meeting was held in November at ANL with all interested parties. This meeting defined the roles of the individual sites and researchers involved in this program. During the meeting, several waste streams were discussed which would have applicability to the superconducting OGMS process. The three different waste matzices selected were sludges, ashes, and soils.

After this meeting, some background research was performed at SR'C and then a meeting was held in July at the SRTC. At the meeting at the SRTC, specific streams and wastes to be tested were determined. SRTC's progress to date with characterizing and obtaining the necessary surrogate and actual waste samples will be discussed below.

\section{SIUDGES}

The SRTC is supporting vitrification treatment of HIN sludges at the SRS and at the Hanford Reservation and LiMW siudges at the Oak Ridge Reservation and other DOE sites. Some of these sludges contain significant amounts of iron and other transition metal compounds. These compounds limit waste loading because of the crystalline species that can form upon cooling or during melter temperature excursions. Therefore, if these compounds can be separated from the wastes, higher waste loadings can be obtained in the glass wasteform and potentially a smaller volume of waste can be treated. Higher waste loadings and smaller volumes of waste to be treated lead to 
less production time and fewer packages of final waste, which both correspond to cost savings for DOE and the operational facility.

HLW sludges

The SRTC has performed several demonstrations using different SRS IILW compositlons to show the feasibility of vitrification treacment. In the process, characterization of several tanks of waste have been 3. - gives the results of an earlyositions could be determined. Table SRS HIW tanks. This table aly elemental characterization of three SRS HLW tanks. This table also shows an oxide composition range that was determined from the analyses of several SRS HLW tanks.

\section{TABLE $y$ - MAJOR SPECIES OF SRS EWW SLUDGE (WTE)}

\begin{tabular}{cccc} 
Elemant & Tank $5^{1}$ & Tank $13^{1}$ & Tank 15 \\
\hline Fe & 27.5 & 27.9 & 3.1 \\
$\mathrm{Al}$ & 1.5 & 7.1 & 33.5 \\
$\mathrm{Mn}$ & 10.8 & 8.8 & 2.3 \\
$\mathrm{O}$ & 15.4 & 4.0 & 0.9 \\
$\mathrm{Na}$ & 6.1 & 3.1 & 1.2 \\
$\mathrm{Ni}$ & 5.1 & 0.5 & 0.5 \\
$\mathrm{Ca}$ & 0.6 & 2.3 & 0.2 \\
$\mathrm{Hg}$ & 0.1 & 2.1 & 0.9
\end{tabular}

4

exide
$\mathrm{Ee}_{2} \mathrm{O}_{3}$
$\mathrm{Al2O}_{3}$
$\mathrm{MnO}_{2}$
$\mathrm{U}_{3} \mathrm{O}_{8}$
$\mathrm{Na}_{2} \mathrm{O}$
$\mathrm{NiO}$
$\mathrm{CaO}$
$\mathrm{HgO}$
$\mathrm{SiO}_{2}$
$\mathrm{NO}_{2} \mathrm{O}_{3}$

\section{Banre 2}

$4.5-46.9$

$2.8-63.3$

$2.7-17.1$

$0-18.5$

$3.3-8.2$

$0.4-8.0$

$0.3-1.1$

$0.1-3.0$

$0.4-6.8$

$0.3-1.2$

Table $z$ lists the radionuclides contained in the samples taken from the three tanks listed in Table $\frac{1}{3}$.

TABIE 2 - TYPICAL RAOIONUCIIDES

IN SRS HLN SLUDGE $(\mathrm{mCi} / \mathrm{g})^{1}$

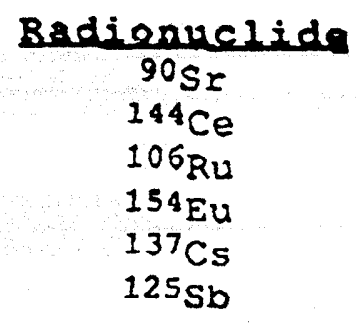

Total $\alpha$

Tank 5
74.7
4.8
2.7
0.5
1.3
0.4
0.1

Tant 13
15.5
2.0
0.4
0.3
0.3
0.1
0.3

Tank 15
25.6
16.9
1.7
1.2
0.1
1.3
0.1

More recent analyses of the tanks at SRS have resulted in the determination of a representative sludge composition and radionuclidc content. The representative sludge components are shown in Table $\not, 5$ while the representative radionuclides are shown in Table 4.

Most of the vitrification demonstrations that have been performed have been on surrogates formulated from the waste characterizalions. Eour drums of surrogate from pilot-scale demonstrations wefo lucater at the SRTC, with each drum representing a different SRS HLW composition. Characterization of the drums is currentily being performed to quantify and qualify the contents. The major species of the drums are shown in Table, 5 . 


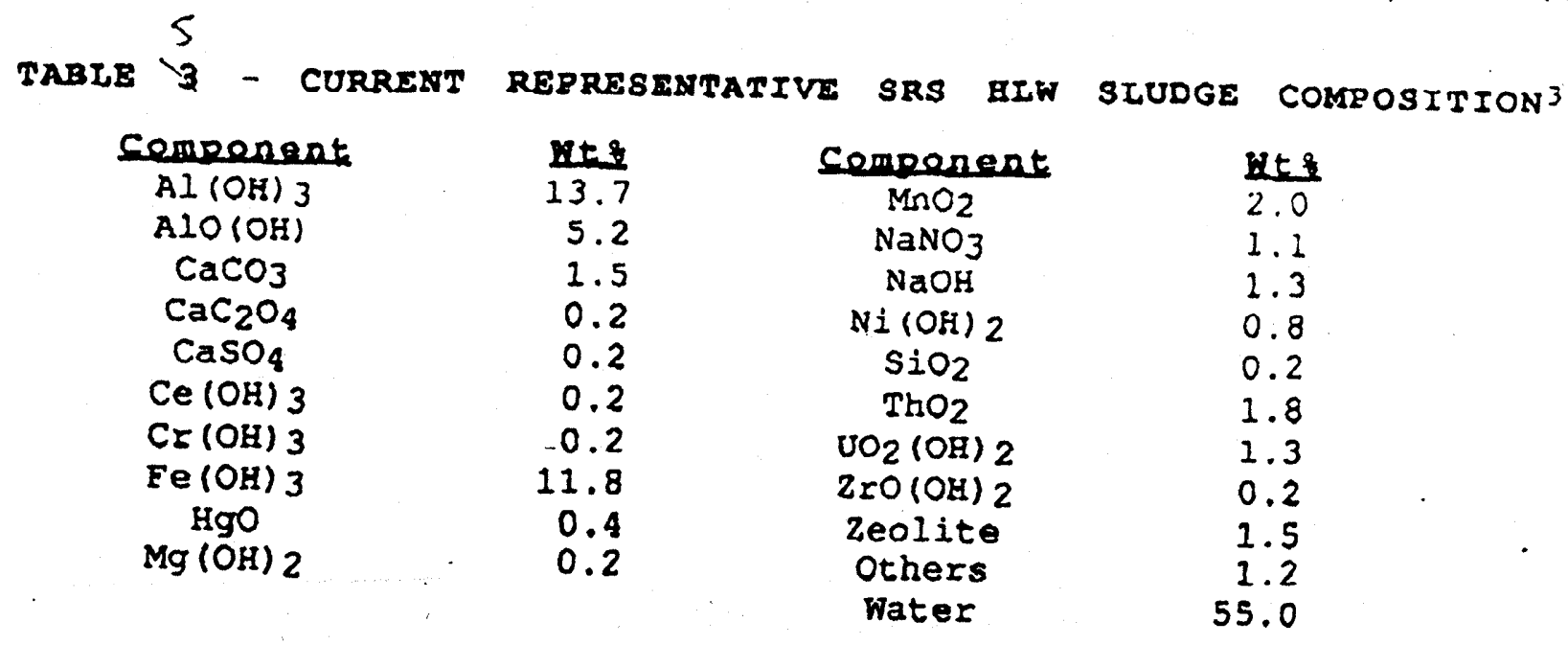

TABLE $\frac{6}{4}$ - RERRESENTATIVI RADIOWUCLIDES IN SRS HLW SLUDGE 3

Badienualide Amount (Ci) Badienuclide

${ }^{90} \mathrm{Sr}$
$90 \mathrm{Y}$
$99_{\mathrm{TC}}$
$106_{\mathrm{Ru}}$
$106_{\mathrm{Rh}}$
$125_{\mathrm{Sb}}$
$137_{\mathrm{Cs}}$
$137_{\mathrm{Ba}}$
$144 \mathrm{Ce}$
$144 \mathrm{Pr}$

${ }^{90} \mathrm{Sr}$

${ }^{99} \mathrm{TC}$

$106_{\mathrm{Ru}}$

$10 \mathrm{Rh}^{\mathrm{Rh}}$

$137 \mathrm{Cs}$

$137_{\mathrm{Ba}}$

$144 \mathrm{Pr}$
1.24E+08

1. $24 E+08$

2. $11 E+04$

3. $98 \mathrm{E}+05$

3. $98 E+05$

$2.12 E+05$

1. $14 E+07$

$1.05 E+07$

2. $46 E+06$

2. $46 E+06$

$147 \mathrm{Pm}$
$233 \mathrm{U}$
$235 \mathrm{U}$
$238 \mathrm{U}$
$238 \mathrm{Pu}$
$239 \mathrm{Pu}$
$240 \mathrm{Pu}$
$241 \mathrm{Pu}$
$242 \mathrm{Pu}$
$244 \mathrm{Cm}$

Amount (ci)

$2.32 \mathrm{E}+0 \%$

$2.60 E-01$

2. $80 E-01$

2. $20 E+01$

1. $6015+05$

2. $30 E+04$

1. $00 E+04$

1. $40 E+06$

1. $70 E+01$

1. $40 E+04$ 
TABLE 5 - MAJOR SPECIES IN DRUMS OE SRS HLW SURROGATE
SLUDGES (HTY)

\section{Species}

$\begin{array}{lr}\text { Ag } & \text { Drum } \\ \text { AI } & 0.015 \\ B & 2.330 \\ \mathrm{Ba} & 2.305 \\ \mathrm{Ca} & 0.032 \\ \mathrm{Cd} & 0.460 \\ \mathrm{Cr} & 0.016 \\ \mathrm{Cu} & 0.041 \\ \mathrm{Eg} & 0.126 \\ \mathrm{Hg} & 3.986 \\ \mathrm{~K} & 0.047 \\ \mathrm{II} & 5.549 \\ \mathrm{Mg} & 0.834 \\ \mathrm{Mn} & 0.164 \\ \mathrm{Na} & 1.110 \\ \mathrm{Ni} & 1.739 \\ \mathrm{P} & 0.246 \\ \mathrm{~Pb} & 0.022 \\ \mathrm{Si} & 0.051 \\ \mathrm{SI} & 5.964 \\ \mathrm{Ti} & 0.087 \\ \mathrm{Zn} & 0.126 \\ \mathrm{ZI} & 0.041 \\ & 0.148\end{array}$

Doum 4
0.016
4.514
0.168
0.004
2.160
0.002
0.214
0.208

23.073

0.001

0.356

0.068

0.063

4.213

8.494

2.144

0.044

0.052

3.620

0.097

0.090

0.025

0.078

Roum I I
0.023
1.504
1.962
0.113
0.950
0.002
0.091
0.325
10.647
0.086
3.233
0.789
0.383
1.923
9.734
1.213
0.022
0.137
10.830
0.020
0.166
0.176
1.465

Drum 9

0.019

1. 734

3.069

0.031

0.671

0.002

0.035

0.115

10.721

0.039

0.996

1. 542

0.600

0.767

6.927

0.705

0.023

0.052

19.160

0.006

0.091

0.069

0.518

These drums are being packaged for shipment to the ANL in september for particle size distribution.

The phases contained in the sludges were also identified using $x-R a y$ Diffraction (XRO). These are shown in Table 6.

\section{TABLE 6 - PHASES IN SIMULATED SRS HLW SLUDGE}

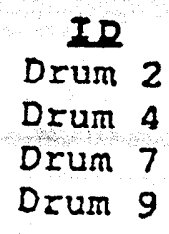

Phrser Identified

$$
\begin{gathered}
\mathrm{NaNO}_{3}, \mathrm{Al}(\mathrm{OH})_{3}, \mathrm{SiO}_{2}, \mathrm{KNO}_{3} \\
\mathrm{NaNO}_{3}, \mathrm{Al}(\mathrm{OH})_{3}, \mathrm{FeO}(\mathrm{OH}), \mathrm{SiO}_{2} \\
\mathrm{NaNO}_{3}, \mathrm{Al}(\mathrm{OH})_{3}, \mathrm{SiO}_{2}, \mathrm{KNO}_{3} \\
\mathrm{Fe}_{2} \mathrm{O}_{3}, \mathrm{Al}_{2} \mathrm{O}_{3}, \mathrm{CaCO}_{3}
\end{gathered}
$$

A portion of the original samples taker from the SRS HIW tanks fos characterization still remains in the Shielded celis facility at several years ago. However, in order on of the wastes was pertormed homogeneous and to determi, in order to ensure that the sample was. and what compounds are present much of the radicactivity romains characterization. If present, the SRTC will perform additional contents of the SRS HLW tanks L to the ANL for veriflcation of the pre-treatment process on HLW. 
Iike the SRS, Hanford Roservation is also planning to vit=ify theis HLW. A pilot-scale melter demonstration with representaive Hanford HLW sludge was performed by the SRTC in 1994. The sludge used ir. this demonstration represented the Hanford Neutralization Current Acld waste (NCAW). The composition used to formulate the surrogate. is shown in Table $\pi^{2}$ along with the chemical compounds used to make the surrogate.

\section{TABLE $\frac{?}{x}$ - HANEORD WCAN SLUDGE SIMOLANT4}

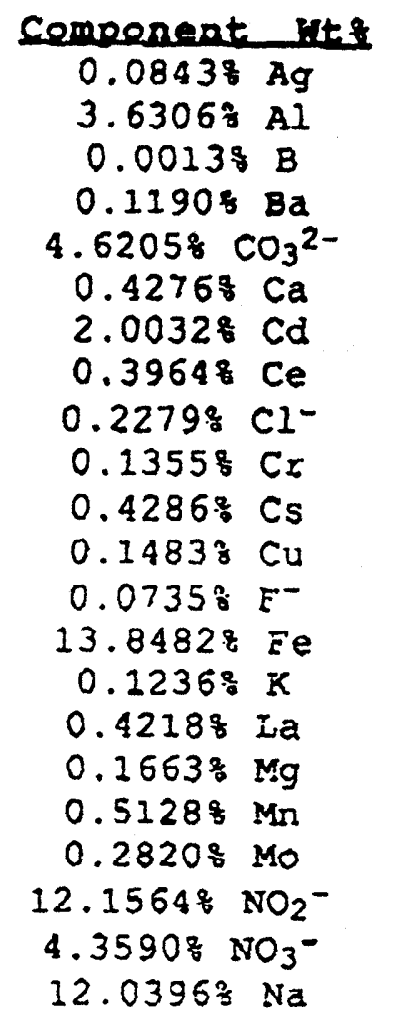

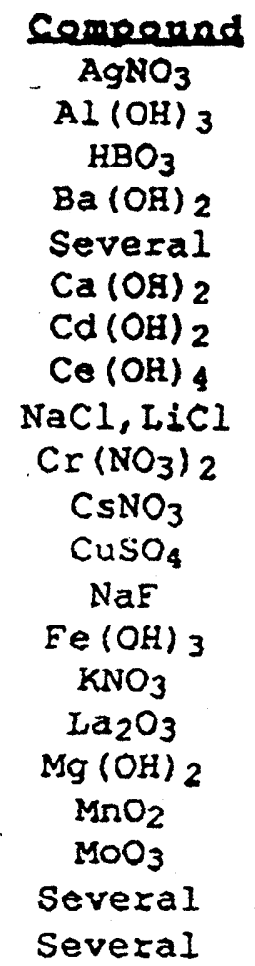

$\mathrm{Na}_{2} \mathrm{CO}_{3}, \mathrm{NaC}_{2} \mathrm{O}_{4}, \mathrm{NaI}$ $\mathrm{NaNO}_{2}, \mathrm{NaNO}_{3}, \mathrm{NaOH}$

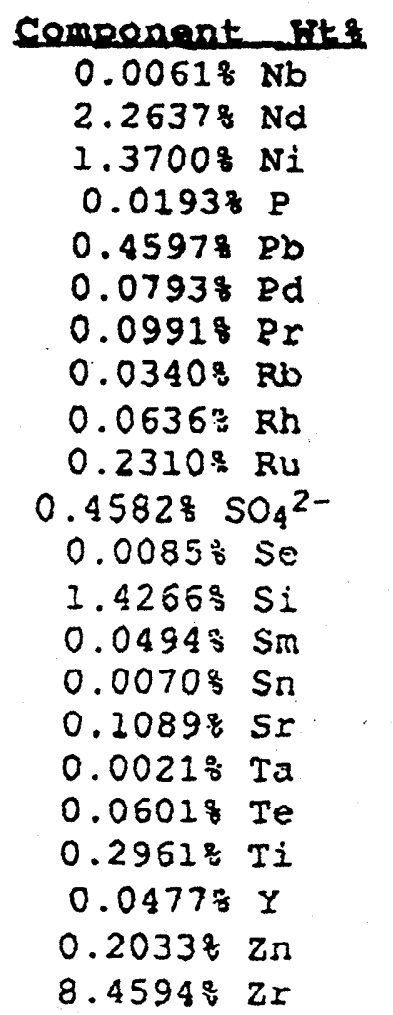

A drum of the Hanford surrogate material has been located for the foint work with ANL. A verification of the chemical composition and a determination of the particle size distribution are now being performed. This sludge will also be shipped to ANL so the viability of pre-treatment can be determined.

\section{LIMW sludges}

The DOE has begun to determine a path forward for treatment of it: large inventory of LIMW. The SRTC has been funded to purslie vitrification. treatment of ILMW and has desigred and built a IVS $=0$ demonstrate the vitrification process. The TVS was designeo for ti.e treatment of LIMW sludges and soils. Oak Ridge Reservation wastes will be the first wastes treated in the TVS. The wastes to be treated are wastewater treatment sludges which contain some amount of iron and transition metals. One waste stream in particular, the Central Neutzalization Eacll1ty (CNE) sludge, can contaia up to 
twenty weight percent iron. This presents a significant operation Thallenge to vitrification because of the problems described above. determine the viabi CNE sludge has a wide varlablitictic separation pre-treatment. The CNE sludge has a wide varlablitity in composition because of the sludge is shown in Table Q based on several anasition range for the Ridge. Once the contents of the sample to be sent performed by Oak characterized, a batch of surrogate sample to be sent to ANL are weli. sent to ANL for pre-treatment stude can also be made by the sRTC and determine the fcasibility of the process The surrogate can help working with radioactive wastes. process without the concerns of

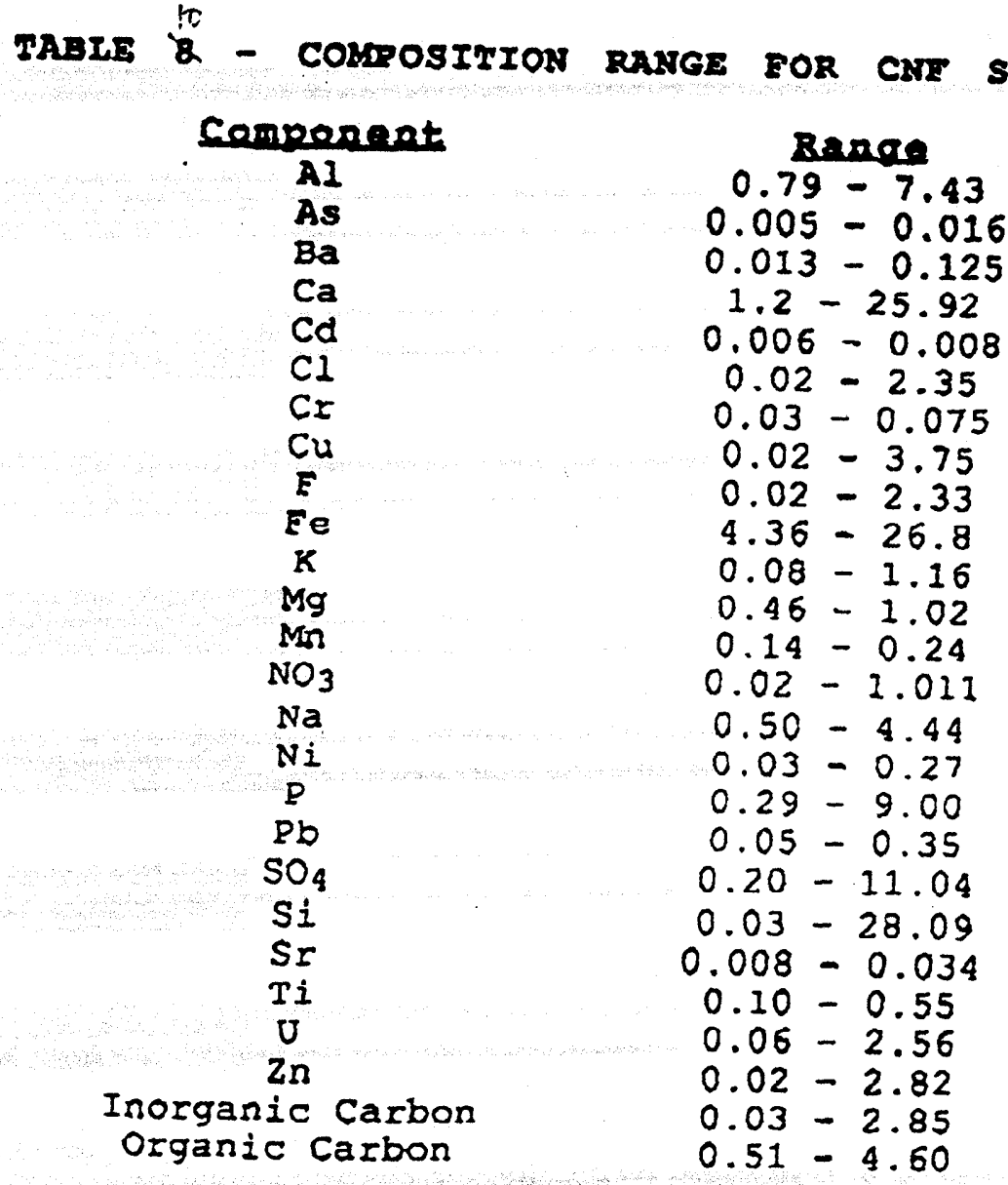

\section{ASHES}

Another vitrification program that the SRTC is involved with involves the stabilization of Rocky flats ash. Rocky flats ash was produced from the incineration of combustible materials highly contaminated with plutonilim. Some of these materials included graphite scarfings and fines, Mgo ceramic crucibles, fizebrick, dirt, sand, slag, and sand. Extensive charactezization of the ash materials has nor been performed at the SRTC to due constraints on nasding listrd wastes. 
However, some informacion was available from a Rocky Flats papers and the Rocky flats papers is given ping the ash. The composttion from the average composition based on the RF column of Table p, while in the Average colums of Table ' $a$.

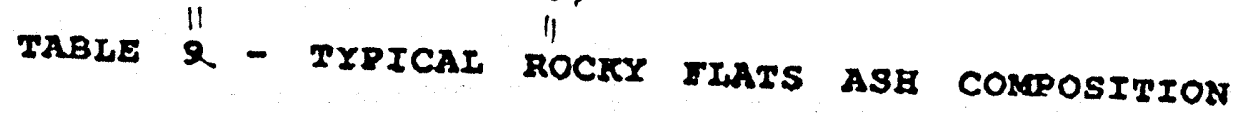

\section{Censtituent}

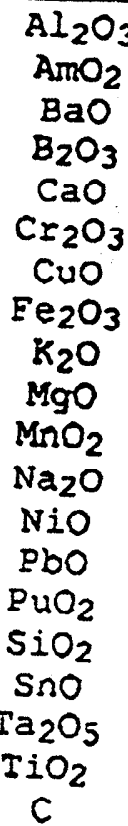

\begin{tabular}{l} 
BTHE-5 \\
\hline 3.3 \\
N/A \\
0.9 \\
1.8 \\
4.0 \\
0.7 \\
1.0 \\
5.7 \\
0.7 \\
4.6 \\
0.1 \\
1.2 \\
0.5 \\
0.8 \\
2.8 \\
48.5 \\
$N / A$ \\
0.4 \\
1.4 \\
22.0
\end{tabular}

Ayerage Nes
3.5
0.1
0.9
1.8
4.2
0.7
1.0
6.0
0.8
4.8
0.1
1.3
0.5
0.8
2.9
46.1
0.1
0.4
1.4
22.7

To date, only limited vitriflcation studies have been performed with this material. However, vitrification studies show that some materlals present in the ash. can remove some of these materiat the superconducting OGMS process be a viable option.

Once a composition of the material is finalized, a surrogate will by SOIIS

Most of the solis that the SRTC has pursued vitrification treatment for were from the SRS. These soils contain very large amounts of Therefore, it was not felt that of calcium, aluminum, and iron. ANL's pre-treatment process. However, material would be amenable to site is identified as a potential for, if a soil from another DOE treatment, tinen the pre-treatment candidate for vitrification 


\section{REFERENCES}

1. J.A. Kelley, "Fraluation of Glass as a Matrix for

Solidification of suvannah River plant Waste", DP-1397, E.I.

2. M.J. Plodinec and J.R. Wiley, "Evaluation of Glass as a Matrix for Solidifying savannah Rivar plant Waste: Nemours Report, Eebruary $1979 . \quad$ :

3. E.W. Holtzscheiter, "Data for Integrated Data Base", WSRC-RP92-673, Rev. 1, June 1992.

4. N.D. Hutson, "Hanford Mast

Process Demonstration". Witxification Plant (BWVP)

5. T.C. Johnson, "Recovery of Plutonium from Incinerator Ash at Rocky Flats". REP-2520, Rocky Flats Environmental Technology
Site Report. 


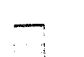

$-$

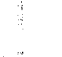

$\longrightarrow$

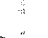

$-$

$-$

$-$

- 


\section{CHANGES TO PARTICLE TRAJECTORY PROGRAM EQUATIONS}

2

$\sqrt{3}$

2

2

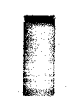

?

$P$

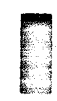

2

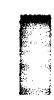

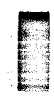

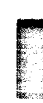

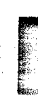

2

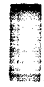

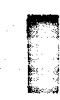




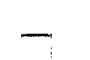

7

-

-

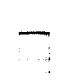

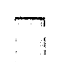

7

-

7

$-$

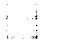

-

.

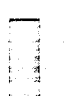

$-$

1

$-$ 
Open Gradient Magnetic Separation: Revisions to the Single Particle Trajectory Model Karen Chess

\section{Introduction}

Open gradient magnetic separation (OGMS) is a process by which solid particle streams may be sorted according to the magnetic susceptibilities of the individual particles, which vary according to the particles' chemical constituents. Particles with net positive magnetic susceptibility (i.e., paramagnetic particles) will move toward a region of higher magnetic field intensity, whereas particles with net negative magnetic susceptibility (i.e., diamagnetic particles) will move toward a region of lower field intensity. It has been proposed and demonstrated that a superconducting quadrupole magnet provides the necessary magnetic field gradient and working volume for separating the pyritic and maceral components of coal. Streams of current interest for the application of OGMS include the separation of fresh and spent catalysts and the sorting of solid streams containing radioactive materials.

As part of the coal cleaning investigation, a computer model was developed to calculate the trajectories of individual particles falling through the bore of the quadrupole superconducting magnet. Doctor et al. ${ }^{1}$ developed the equations of motion for the particles and wrote the original Basic program to calculate trajectories for paramagnetic particles in the early 1980's. In 1985, Karen Foote translated the program to Fortran 77 and added several sign change tests such that the original formulation could be extended to solve diamagnetic particle trajectories.

With interest in OGMS being extended beyond the original coal cleaning application, a second update to the particle trajectory model has been made. This update has been written in Fortran 90 ("freeform" Fortran) and includes improvements in three areas. First, several changes to the governing equations and solutions have been made: additional equations for Stokes flow radial solutions make the program generally applicable to all particle susceptibilities, additions to all $z$-direction solutions make them applicable to working fluids for which buoyancy is not negligible, and changes in the expression for the coefficient of drag and the equation of motion used by the non-Stokes flow solution have been added to replace errors in the earlier work. Second, changes to the solution algorithm employed by the original program have been made in the revised edition to take advantage of the additional computational power not available in 1985. These changes increase the accuracy of the program considerably. Third, minor conveniences, such as an option to calculate terminal particle velocities to be used as initial conditions and the formatting of output to be easily analyzed in spreadsheet software, have been included in the program update.

Changes in each of these areas - equations, algorithms, and other additions - are detailed in the next three sections of the report. Afterwards, the effect of these changes on the original coal cleaning results is presented. Attached to the end of the report, Appendix A contains errata found in the papers describing the original coal cleaning analysis, ${ }^{1,2}$ and Appendix $B$ contains a copy of the updated particle trajectory program and an informal users' guide. 


\section{Changes to Program Equations}

The equations of motion in the Foote version of the trajectory model contain errors in both the Stokes and non-Stokes flow regime solutions. Since none of the coal cleaning scenarios originally tested involved Stokes flow, and since the errors in the non-Stokes solutions were only applicable for $\mathrm{V}_{\mathrm{z}}(0) \neq 0$ (a condition not explored in the coal cleaning work), these particular errors do not affect Foote's results. It is easier, however, to use the original derivations by Doctor et al. as described in Reference 1 as the starting point to explain the changes made in the current version of the model. It should be noted that while these derivations were read thoroughly for understanding and led to some program modifications, a formal re-derivation of all of the equations was not made as part of the current work. Errata found in the coal cleaning papers during this process are included in Appendix A.

One area where the original derivation needed only to be extended is in the solution for the radial motion of particles in the Stokes flow regime. The second order linear differential equation governing this motion is given in Equation A.3 in Reference 1 and is:

$$
\frac{d^{2} r}{d t^{2}}+\frac{18 \eta}{\rho_{p} D_{p}^{2}} \cdot \frac{d r}{d t}-\frac{X\left(\frac{d B}{d r}\right)^{2}}{\rho_{p} \mu_{o}} \cdot r=0
$$

where $r$ indicates radial position, $t$ is time, $X$ is the magnetic susceptibility of the particle, and all other variables are positive and defined in Reference 1 . The general form of the solution to this equation depends on the form of the roots to the characteristic equation:

$$
a s^{2}+b s+c=0
$$

where

$$
\begin{aligned}
& \mathrm{a}=1 \\
& b=\frac{18 \eta}{\rho_{\mathrm{p}} \mathrm{D}_{\mathrm{p}}^{2}} \\
& \mathrm{c}=-\frac{\mathrm{X}\left(\frac{\mathrm{dB}}{\mathrm{dr}}\right)^{2}}{\rho_{\mathrm{p}} \mu_{\mathrm{o}}}
\end{aligned}
$$

The roots of Equation 2 take the general form of $A_{1} \pm B_{1}$ where

$$
\begin{aligned}
& A_{1}=-\frac{b}{2 b} \\
& B_{1}=\frac{\sqrt{b^{2}-4 a c}}{2 a}
\end{aligned}
$$


If $B_{1}$ is positive, then the roots to Equation 2 are real and distinct and the solution to Equation 1 takes on the form equivalent to that derived by Doctor et al.'.

$$
\begin{aligned}
& r(t)=k_{1} e^{\left(A_{1}+B_{1}\right) t}+k_{2} e^{\left(A_{1}-B_{1}\right) t} \\
& k_{1}=r_{0} \frac{A_{1}-B_{1}}{-2 B_{1}} \\
& k_{2}=r_{0} \frac{A_{1}+B_{1}}{2 B_{1}}
\end{aligned}
$$

This solution was adequate for the coal cleaning analysis; however, two other solutions are possible and have been added to the particle trajectory program to make it universally applicable. Specifically, if $B_{1}$ is zero, then the roots to Equation 2 are real but repeated, and the solution to Equation 1 is of a different form:

$$
\begin{aligned}
& r(t)=k_{1} e^{A_{1} t}+k_{2} t e^{A_{1} t} \\
& k_{1}=r_{0} \\
& k_{2}=-r_{0} A_{1}
\end{aligned}
$$

Finally, when $B_{1}$ is complex, the solution to Equation 1 takes on the form:

$$
\begin{aligned}
& r(t)=k_{1} e^{A_{1} t} \cos \left(B_{1} t\right)+k_{2} e^{A_{1} t} \sin \left(B_{1} t\right) \\
& k_{1}=r_{o} \\
& k_{2}=-\frac{r_{0} A_{1}}{B_{1}}
\end{aligned}
$$

- With regard to the z-direction solutions for both the Stokes and non-Stokes regimes, changes in the governing equations themselves have been made. First, an error in the original formulation for the non-Stokes z-direction equation of motion has been corrected. The original equation is represented by Equations D.1 and D.2 in Reference 1 as:

$$
\begin{aligned}
& {[F]_{z \text {-inertia }}=[F]_{\text {gravity }}+[F]_{\text {fluid drag }}+[F]_{z \text {-inertia(o) }}} \\
& \mathrm{m} \frac{\mathrm{dv}}{\mathrm{dt}}=\mathrm{mg}-\frac{\pi}{8} \mathrm{C}_{\mathrm{D}} \mathrm{D}_{\mathrm{p}}^{2} \rho_{\mathrm{f}} \mathrm{v}^{2}+\frac{1}{2} \mathrm{mv}_{\mathrm{o}}^{2}
\end{aligned}
$$

The final term in Equation 8 should be deleted for two reasons. First, it has units of energy (Newton-meter) and not force (Newton). Second, it does not represent a physical phenomenon acting on the particle throughout its trajectory that should be included in the general equation of motion. Instead, it represents an initial condition $\left(v(0)=v_{0}\right)$ to be imposed on the solution. The removal of the term does not affect the derivation of the solution considerably, requiring only the removal of the $(1 / 2) v_{0}^{2}$ from Equations 16,17 , and D.4B in Reference 1 . 
Next, an extension to Equation 8 and to the Stokes z-motion derivation has been made such that the resulting equations are applicable when the particles are suspended in a liquid slurry, as well as when they are falling in air. For the slurry cases, the buoyancy of the particles cannot be neglected, as in Reference 1. For the Stokes regime, the governing equation becomes:

$$
\begin{aligned}
& \mathrm{m} \frac{\mathrm{dv}}{\mathrm{dt}}=\mathrm{m}^{\prime} \mathrm{g}-3 \pi \eta \mathrm{D}_{\mathrm{p}} \mathrm{v} \\
& \mathrm{m}^{\prime}=\left(\rho_{\mathrm{p}}-\rho_{\mathrm{f}}\right) \cdot\left(\frac{4}{3} \pi\left(\frac{\mathrm{D}_{\mathrm{p}}}{2}\right)^{3}\right)
\end{aligned}
$$

The solution for this equation is obtained by the same method employed in Reference 1 and is:

$$
\begin{aligned}
& z(t)=\left(\frac{1}{3 \pi \eta D_{p}}\right) \cdot\left[m^{\prime} g t+k_{1}\left(\frac{m}{3 \pi \eta D_{p}}\right) e^{-\frac{3 \pi \eta D_{p} t}{m}}\right]+k_{2} \\
& v(t)=\left(\frac{1}{3 \pi \eta D_{p}}\right) \cdot\left[m^{\prime} g-k_{1} e^{-\frac{3 \pi \eta D_{p} t}{m}}\right] \\
& k_{1}=m^{\prime} g-3 \pi \eta D_{p} v_{o} \\
& k_{2}=-\frac{m k_{1}}{\left(3 \pi \eta D_{p}\right)^{2}}
\end{aligned}
$$

For z-motion in the non-Stokes regime, the buoyancy effect is similarly added to the governing equation, which becomes:

$$
\mathrm{m} \frac{\mathrm{dv}}{\mathrm{dt}}=\mathrm{m}^{\prime} \mathrm{g}-\frac{\pi}{8} \mathrm{C}_{\mathrm{D}} \mathrm{D}_{\mathrm{p}}^{2} \rho_{\mathrm{f}} \mathrm{v}^{2}
$$

Solution to this equation also follows Reference 1, replacing Equation D4.B with $B=m^{\prime} g$.

The above changes to the Stokes and non-Stokes flow solutions represent changes made to the equations of motion of the particles in the model. In addition, one other equation was changed, affecting the non-Stokes motion solutions. Reference 1 lists two expressions (Equations B.4 and D.3 in the paper) for the empirical drag coefficient $\left(C_{D}\right)$, a function of the Reynolds number $(\mathrm{Re})$ :

$$
\begin{aligned}
C_{D} & =\frac{18.5}{\operatorname{Re}^{0.6}} \\
C_{D} & =\frac{24}{\operatorname{Re}}\left(1+0.15 \operatorname{Re}^{0.687}\right)
\end{aligned}
$$


These equations are both listed in derivations for non-Stokes flow $(0.3<\operatorname{Re}<1000)$, but differ considerably over the lower portion of this regime. Table 1 lists the calculated values of $C_{1}$ for several low (but non-Stokes) Reynolds numbers:

Table 1: Comparison of drag coefficients $\left(C_{D}\right)$ calculated with alternative expressions.

\begin{tabular}{|c|c|c|}
\hline $\mathbf{R e}$ & $\mathbf{C}_{\mathbf{D}}$ (Equation 12) & $\mathbf{C}_{\mathbf{D}}$ (Equation 13) \\
\hline 0.3 & 38.1 & 85.3 \\
0.5 & 28.0 & 52.5 \\
1.0 & 18.5 & 27.6 \\
1.5 & 14.5 & 19.2 \\
3.0 & 9.6 & 10.6 \\
\hline
\end{tabular}

Karen Foote used Equation 12 in her modeling work; unfortunately, a literature search for empirical drag coefficient formulae ${ }^{3,4,5,6}$ showed that Equation 13 yields the accepted values. One reference $e^{5}$ indicated that Equation 13 is valid for $2<\operatorname{Re}<500$, which does not include the full range of interest for the modeling work. Thus, an alternative equation, yielding similar values to Equation 13 but valid for $\operatorname{Re}<1000$, has been chosen for the revised particle trajectory model: ${ }^{6}$

$$
C_{D}=\frac{24}{\operatorname{Re}}\left(1+0.14 \operatorname{Re}^{0.7}\right)
$$

The effect of this change on the coal cleaning results, in combination with the changes to the original trajectory model's algorithm, is shown in a later section.

\section{Changes to Program Algorithm}

The basic structure of the revised trajectory model is similar to the Foote version. That is, the program still solves for radial and axial motion of the particles using either Stokes or nonStokes solutions, depending on the calculated Reynolds' number of the particle at each solution step. Further, the programs use a similar set of subroutines for these calculations. However, a number of computational shortcuts in these subroutines were used in the Foote version, which were either errors or were necessary given the state of computer technology at the time. These shortcuts have been removed in the revised model, leading to a more accurate solution algorithm. In addition, there were a few other, subtle errors found in the Foote algorithm, which have been corrected or mitigated in the revised model (as described below).

The most significant changes to the Foote algorithm have been made to the solution of trajectories for non-Stokes particles. In the Foote version, a set of constants and a fixed time step is used to advance a $4^{\text {th }}$ order Runge-Kutta solution algorithm from an initial radial position toward a target radial position. The march continues until the new r-position calculated is beyond the target. Once the radial motion is solved, a single call to a separate subroutine calculates z-position and z-velocity based on the time found in the r-solution. 
In the revised algorithm, the first problem corrected is that the "constants" calculated only once at the beginning of the Foote subroutine RINTMD are not constant at all, but depend on $r$-position, $r$-velocity, and $C_{1}$ ( which itself will change with both $r$ - and $z$-velocity). They are now recalculated with every time step. Second, because these variables change with $C_{D}$ and thus with $z$-velocity, the solution of the radial and axial equations of motion should be coupled. To do so, the non-Stokes subroutine for solving z-motion (ZINTMD) is now called at the end of each time step in the radial solution routine. (Since $r$ - and $z$-motion are now solved within the old RINTMD, that routine has been renamed NONSTOKE in the new program.)

A third problem with the original algorithm when attempting to apply it over a wide range of OGMS applications is that a single value of the time step used in the Runge-Kutta routine is not universally appropriate. For example, if a high susceptibility particle advances beyond the r-resolution of the solution routine in a single time step, it is possible that the next time the routine is called, it will try to solve for a target r-position it has already passed. (This scenario occurred in modeling $100 \% \mathrm{PuO}_{2}$ particles at a fixed time step of 0.01 seconds.) To prevent this problem in the future, a self-adjusting time step has been added to the NONSTOKE (RINTMD) routine. If a solved $r$-position results in an $r$-step of more than half the resolution of the routine $(0.001 \mathrm{~m})$, the time step is halved and the solution is retried. Of note, a similar test to increase the time step if the radial step is very small was not added since there is no need to conserve computations (the entire program takes only a few seconds to run).

Two other subtle errors in the earlier model have been corrected in the revised version. First, the Runge-Kutta march proceeds until the calculated r-position passes the target r-position. At this point in the original program, the time to the actual target is calculated via linear interpolation between the old and new time steps. However, the r-velocity was not similarly corrected in the earlier model, but it is in the revised edition. Second, to start the non-Stokes solution, it is necessary to have a non-zero $r$-velocity (a condition imposed mathematically by the test for exactness in Reference 1, Equation B.15, and confirmed by a collapse of the solution algorithm when $\mathrm{V}_{\mathrm{r}}=0$ ). In the original program, the $\mathrm{r}$ - and $\mathrm{z}$-velocities calculated by the Stokes solution algorithm at the first $r$-step were passed to the non-Stokes solution as initial conditions, and a new time to the first r-step was computed. Using the Stokes r-velocity to start the nonStokes routine is a reasonable approximation (it is small) and is adopted in the revised model, but there is no reason to pass the Stokes z-velocity into the non-Stokes routine. In the revised model, the $z$-velocity is reset to the initial z-velocity, $V_{z}(0)$, as specified by the user, and a limit on $C_{D}$ in the NONSTOKE routine to be within the limits for the non-Stokes regime has been added.

Changes to the original program algorithm outside of the non-Stokes solution are minor. As noted, the Stokes solutions have been extended to include all possible solution forms. In the original Stokes solution algorithm, the time at which the particle reaches a target radial position is solved for using a simple "shooting" loop that adjusts the guessed time until the target is "hit". The initial time guess in this routine (RSTOKE2) is now the time at the last $r$-step (when $t \neq 0$ ), which will work universally over all Stokes solution forms. In addition, while the original and revised programs are still structurally similar, a comparison of the main loops of each will show that their grammars are different. The revised main loop is written without nested GOTOs and flags for clarity. 


\section{Other Program Additions}

A few new features have been added in the revised particle trajectory program strictly for the convenience of the user. First, although much of the "hardwiring" in the original program related to the magnet size and the number of particle diameters analyzed per run remains, the user may now specify the particle diameters to be analyzed by changing the values in the DATA statement for the variable "Psizes." As noted in the program comments on that line, the sizes are to be stated in micrometers.

Second, there was some interest expressed by the new OGMS modeling clients to specify a non-zero initial z-velocity, and it was decided that setting the initial z-velocity to the terminal velocity of each particle in freefall would be a reasonable upper bound on $V_{2}(0)$. Thus, two new subroutines (TERMVZO and NSVTERM) were added to the program to pre-calculate the terminal velocities of the particles. When the flag "useVzterm" is set to 1 , these subroutines are called and $\mathrm{V}_{\mathrm{z}}(0)$ is set to either the Stokes or non-Stokes terminal freefall velocities, whichever is appropriate. When useVzterm $\neq 1$, these routines are not used and the $V_{2}(0)$ set explicitly by the user is applied over all the particles. As is noted in Appendix $B$, there is currently no warning for the user that he/she has set $\mathrm{V}_{\mathrm{z}}(0)$ above the theoretical terminal velocity, although one could be added easily for the uneducated user.

Finally, all of the subroutines and lines in the original program that control output files have been deleted since the graphing package for which they were written is obsolete. In their place, statements generating four output files directly readable by Microsoft Excel (and presumably other spreadsheet software) have been added. The user sets the names of these files in the OPEN statements. Referring to the unit numbers, file 10 provides detailed information at various solution steps, including the flow regime, Reynolds number, particle $r$ - and $z$-velocities, and so forth. File 11 contains trajectory ( $r, z$ position) data, file 12 contains data on the time required for the particles to reach the magnet wall or center, and file 13 contains data giving the required magnet length for the particles to reach the wall/center. These files are all generated as comma-delimited files to be opened in Excel. 


\section{References}

1. Doctor, R.D., Panchal, C.B., and Swietlik, C.E., 1986. "A Model of Open-Gradient Magnetic Separation for Coal Cleaning Using a Superconducting Quadrupole Field," Recent Advances in Separation Techniques-III, N.N. Li, Ed., American Institute of Chemical Engineers Symposium Series, 82:250:154-168.

2. Doctor, R.D., Livengood, C.D., Genens, L.E., Swietlik, C.E., and Foote, K., 1987. "Investigation of Open-Gradient Magnetic Separation for Illinois Coal," Processing and Utilization of High Sulfur Coals II, Y.P. Chugh and R.D. Caudle, eds., Elsevier Science Publishing Company, Inc., 149-160.

3. Eskinazi, S., 1962. Principles of Fluid Mechanics, Allyn and Bacon, Inc., Boston.

4. Giles, R.V., 1962. Theory and Problems of Fluid Mechanics, $2^{\text {nd }}$ Edition, Schaum's Outline Series, McGraw-Hill, Inc., New York.

5. Seinfeld, J.H., 1986. Atmospheric Chemistry and Physics of Air Pollution, John Wiley \& Sons, New York.

6. Perry, R.H., Green, D.W., and Maloney, J.O., Eds., 1984. Perry's Chemical Engineers' Handbook, Sixth Edition, McGraw-Hill Inc., New York. 


\section{Appendix A: Errata in Coal Cleaning Papers}

This appendix identifies errata in Reference 1, which contains the derivations of the equations of motion for the single particle trajectory model, and Reference 2, which is a second coal cleaning paper containing some of the same errors, as noted. Important: the changes to the equations identified here represent only errors found in the original coal cleaning work, and do not include equation changes relating to extending the equations beyond the coal cleaning cases. For example, the extra radial Stokes solutions and the buoyancy effects in the z-solutions outlined in "Changes to Program Equations" are not included here.

\section{Reference 1 Errata}

\# Page Error Correction
1. 159 Eq. 12, [F]z-inertia(o)
$[\mathrm{F}]_{\text {z-inertia }}=[\mathrm{F}]_{\text {gravity }}+[\mathrm{F}]_{\text {fluid drag }}$
should be deleted, as
explained in "Changes to
Program Equations"

2. 159 Eq. 13, missing “" “ in exp. $z=\frac{g D_{p}^{2} \rho_{p}}{18 \eta}\left[t+\left(\frac{D_{p}^{2} \rho_{p}}{18 \eta}-\frac{v_{o}}{g}\right)\left(\exp \left(\frac{-18 \eta t}{D_{p}^{2} \rho_{p}}\right)-1\right)\right]$

3. 159 Eq. 14, "8" should be " $4 / 3$ " $\quad z=\frac{4 D_{p} \rho_{p}}{3 C_{D} \rho_{f}} \cdot \ln \left(\frac{1+k_{1} \exp (t / \theta)}{1+k_{1}}\right)-\gamma t$

4. 159 Eq. 16, effect of Error \#1 $\quad \theta=\left[\frac{3 C_{D} \rho_{f} g}{D_{p} \rho_{p}}\right]^{-\frac{1}{2}}$

5. 159 Eq. 17, effect of Error \#1 $\quad \gamma=\left[\frac{4 D_{p} \rho_{p} g}{3 C_{D} \rho_{f}}\right]^{\frac{1}{2}}$

6. $\quad 162 \quad$ First $C_{D}$ Eq., range of applicability

doesn't match citable reference, as

explained in "Changes to Program

Equations."

7. $162 \quad$ Second $C_{D}$ Eq., expression not

consistent with other references,

as explained in "Changes to

Program Equations." 
8. $\quad 164 \quad$ Eq. B.4, same error as \#7.

9. $165 \quad$ Eq. B. 23 , missing ““" (RHS) $\quad-2 \beta v e^{-2 \beta r}=-2 \beta v e^{-2 \beta r}$

10. 166 Text before Eq. C.6 is incorrect.

No integration is necessary to

proceed from Eq. C.5 to C.6.

11. 167 Eq. D.1, same érror as \#1.

12. 167 Eq. D.2, remove $\mathrm{mv}_{\mathrm{o}}^{2} / 2($ effect of $\# 1) \quad \mathrm{m} \frac{\mathrm{dv}}{\mathrm{dt}}=\mathrm{mg}-\frac{\pi}{8} \mathrm{C}_{\mathrm{D}} \mathrm{D}_{\mathrm{p}}^{2} \rho_{\mathrm{f}} \mathrm{v}^{2}$

13. 167 Eq. D.3, replace with more

appropriate $C_{D}$ expression given in

"Changes to Program Equations."

14. 167 Eq. D.4B, remove $v_{0}^{2} / 2$, (effect of \#1) $B=m g$

\section{Reference 2 Errata}

\# Page

Error

Correction

15. 152 Eq. 8, “ \pm " should be “." $\quad \frac{\pi \rho_{p} D_{p}^{3}}{6} \frac{d^{2} r}{d^{2}}=\frac{\pi D_{p}^{3} \chi}{6 \mu_{0}}\left(\frac{d B}{d r}\right)^{2} \cdot r-3 \pi \eta D_{p} \frac{d r}{d t}$

16. 152 Eq. 12, same error as \#1

17. 152 Eq. 13, same error as \#2

18. 153 Eq. 14 , same error as \#3

19. 153 Eq. $16, "-1 / 2$ " on all, del. $v_{0}^{2} / 2 \quad \theta=\left[\frac{3 C_{D} \rho_{f} g}{D_{p} \rho_{p}}\right]^{-\frac{1}{2}}$

20. $153 \quad$ Eq. 17, " $1 / 2$ " on all, del. $v_{0}^{2} / 2 \quad \gamma=\left[\frac{4 D_{p} \rho_{p} g}{3 C_{D} \rho_{f}}\right]^{2}$ 


\section{Appendix B: Users' Notes and Source Code for Revised Single Particle Trajectory Model}

The revised single particle trajectory model was developed in Microsoft Fortran PowerStation 4.0, and the source code is provided at the end of this appendix. In addition, the following informal notes are provided for the benefit of potential users.

\section{User Inputs}

Like its predecessor, the new trajectory model remains a stand-alone program and does not use a separate input file. Thus, user inputs are edited into the source code directly, and the program must be recompiled whenever these or other changes are made. (The alternative, to provide a formatted input file and compiled code, might have been harder to transport to other Fortran platforms.)

For each type of particle to be analyzed, the user must specify a density and magnetic susceptibility. To do so, edit the beginning of loop 90 to include the number of particle types to be analyzed (e.g., for three particle types, "do 90 set=1,3"), and enter the required density and susceptibility for each set in the if-elseif clause that follows. As noted in the source code comments, density is to be entered in $\mathrm{kg} / \mathrm{m}^{3}$ and susceptibility is to be volume-based, using the m.k.s. convention.

The particle diameters to be analyzed for each type of particle are entered on the data declaration line for the variable "Psizes" (e.g., "data Psizes $/ 50,100,150,200 /$ "). The program expects four sizes to be given, so if you need to analyze less than four, make the remaining sizes up, and if you need to analyze more than four, run the program more than once. Particle sizes should be entered in micrometers on this line.

The user should also specify the initial z-velocity $(\mathrm{Vz} 0)$ of the particles. A single $\mathrm{Vz} 0$ may be entered explicitly to apply to all particles on the line directly after the Psizes data line. Alternatively, if the "useVzterm" variable is set to 1, the program will automatically precalculate the terminal freefall velocity of the particles under both Stokes and non-Stokes assumptions, and then assign $\mathrm{VzO}$ to whichever of these is appropriate for the particle. (That is, if the non-Stokes terminal velocity results in a Reynolds number greater than 0.3 , the non-Stokes value is used, and so forth.) Note: if $\mathrm{VzO}$ is entered explicitly, no warning is given to the user that he/she has specified a Vz0 below or above the terminal velocity of the particle, but he/she might want to add such a feature if circumstances make it useful.

The user may alter other constants at the beginning of the program at his/her discretion (e.g., fluid properties, magnetic field gradient, etc.). The units expected by the program are provided in the comment lines (everything after an exclamation point is a comment in the source code).

Finally, the user should edit the names of the output files that will be generated by the program (in the "open" statements). Referring to unit numbers, file 10 will contain general information for the user at various time steps, and files 11,12 , and 13 will contain commadelimited fields for particle trajectories, time to magnet wall/center, and required magnet length to reach radial destination, respectively. 


\section{Outputs and Data Analysis}

Once the user edits the program to his/her application conditions, it must be compiled and run in a compatible Fortran environment. The result will be the four files mentioned above, which are all easily opened in Microsoft Excel. Open Excel, choose Open from the File menu, locate each named output file and click Open. Text Wizard in Excel will go through three screens to convert the data to spreadsheet format. Choose Delimited on the first screen, Commadelimited on the second screen, and General formatting on the third screen. Standard procedures for graphing in Excel can then be used to analyze the data.

\section{User Caveats}

The user should note that the transition between the solutions for Stokes and non-Stokes particle trajectories is not continuous. This is a condition imposed by the field of fluid mechanics, not by the program. However, it has not proven to be a major problem to date; that is, particles that end up in the non-Stokes flow regime tend to enter that regime very early in the solution (often within the first solution step). If a particle moves from the Stokes to the nonStokes regimes within the output resolution of the program, the user can see the effects in two places. First, the output data from files 11-13 will show a discontinuity at the transition point. Second, the "information" file (file 10) will indicate the change from Stokes to non-Stokes explicitly at each print step. The only solution to this problem is to analyze particle diameters slightly above and below the troublesome specification, to get an idea of the bounds on the transition particle.

A second, and even more unusual, way the discontinuous transition could be seen is for the user to specify an initial Vz0 so large as to sustain a particle in the non-Stokes regime for a significant part of its trajectory when its terminal velocity would actually indicate it will end up in the Stokes regime. Since no limits are placed on the user's ability to set Vz0, this transition would show up in the output files, as described above. Clearly, the solution would be to set a lower Vz0 explicitly, or to use the terminal velocity option (useVzterm=1) provided in the program.

The final user caveat relates to the analysis of particles on which the effect of the magnetic field will be negligible. The first case is obvious and corresponds to specifying a magnetic susceptibility equal to zero. In this case, the program will simply print "Susceptibility is zero, so no radial motion" in file 10 before moving on to the next particle. In the second case, when $A_{1}+B_{1}$ is equal to zero (within the resolution of computer mathematics), this implies that the magnet's effect on the particle is very small (i.e., "c" in Equation 4 is negligible compared to " $b$ "" in the computation of $B_{1}$ ). In this case, a similar message will be written in file 10 before proceeding to the next particle.

\section{Source Code}

In the following source code print out, please note that an exclamation point at any location on a line in Fortran90 indicates that everything that follows on that line is a comment and is ignored by the program. In general, variables are identified in a comment on the same line as their first appearance in the program. Additional comments are provided to identify the purpose of the major loops and operations of the model as they occur. 


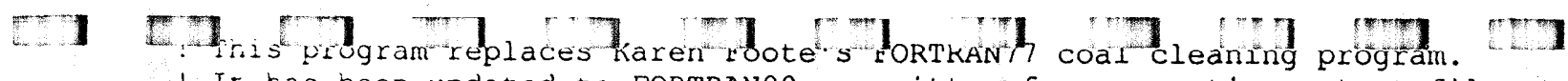

! It has been updated to FORTRAN90, rewritten for generating output files to

- be directly opened in Excel (spreadsheet software), and corrected to be

generally applicable to a wider range of magnetic susceptibilities and to

non-zero initial vertical velocities $\left(V_{z} 0\right)$. Also, corrections to the

! computation of cd (coefficient of drag) and to the non-Stokes solution

algorithm have been made. Particle sizes'are also now a data input, and

not hardwired into the program. (Other hardwiring still remains, however

as noted below.

! Hacker of this version: Karen Chess, circa January 5, 1998.

! Note: This program still contains the original hardwiring of dimensions

specific to the $0.064 \mathrm{~m}$ bore magnet used in coal cleaning studies, as

well as some other hardwired constraints (e.g., number of particles

per run, $r$ steps $(0.001 \mathrm{~m})$, etc.).

\section{program magnetkc}

implicit none

! Stating and initializing variables

real chi, mu, visc, Vz0, Dpx, Dp, DENp, DENf, Mp, dB, g

real Re, NSVzmax, SVzmax, cd, regime

real $A 1, B 1, L x$, last, step, $x, y$, holdVr, holdVz

real $t, r$, ro, $r x$, brx, $V r$, bore, $z, V z, t c$, holdt, holdr, Vrc

real $\operatorname{ROGR}(33), \operatorname{TFGR}(4,33), \operatorname{ZFGR}(4,33), \mathrm{Z} 2 \mathrm{GR}(31,33)$, Psizes(4)

integer set, out 1 , out2, tag, $n, q$, usevzterm

data ( $($ TFGR $(n, q), n=1,4), q=1,33) / 132 * 0.0)$

data $((2 F G R(n, q), n=1,4), q=1,33) / 132 * 0.0 /$

! Setting constants

data Psizes $/ 50,75,100,125 /$ ! Particle sizes in microns

$\mathrm{VzO}=1.0 \quad$ Initial z-velocity

usevzterm=0 ! Set to 1 to override previous line and use particle terminal freefall velocities as Vzo

ROGR $(1)=0.0005 \quad$ ! Initial radial positions array (set up for specific magnet)

do $5 n=2,33$

$\operatorname{ROGR}(n)=(n-1) * 0.001$

5 continue

$\mathrm{mu}=4 * 3.14159 * 1 e-07$

visc $=1.75 e-05$

$\mathrm{DEN} f=1.2$

$\mathrm{dB}=60.0$

$g=9.81$

! Permeability of free space

! Viscosity $\left(\mathrm{N}-\mathrm{s} / \mathrm{m}^{*} * 2\right)$ of fluid (here, nitrogen)

$!$ Density $(\mathrm{kg} / \mathrm{m} * \star 3)$ of fluid (here, nitrogen)

! Magnetic field gradient ( $\mathrm{Wb} / \mathrm{m} * * 2$ per meter)

! Opening output files...

open (unit $=10$, file= 'TESTinfo. out', status='REPLACE' )

open (unit=11, file=' TESTtraj.out', status='REPLACE')

open (unit $=12$, file='TESTtime.out', status='REPLACE')

open (unit=13, file='TESTleng.out', status='REPLACE')

! Per type of particle (100p 90)

do 90 set $=3,3$

if (set.eq.1) then

DENP $=2304$

Define DENp and chi for each type of particle...

! $(0.18 \mathrm{~V})$

! Particle density $(\mathrm{kg} / \mathrm{m} \star \star 3)$ 
$\operatorname{chi}=2.75 e-06$

elseif (set.eq.2) then DENP $=2307$

$\operatorname{chi}=4.899 \mathrm{e}-06$

elseif (set.eq.3) then $\mathrm{DENp}=2306$

$\operatorname{chi}=4.476 \mathrm{e}-05$

elseif (set.eq.4) then $\mathrm{DENp}=2300$ chi $=-5.418 e-06$

endif

! Radial direction of motion for solution (i.e., for loop 55 below)

if (chi.gt.0.0) then$$
\begin{aligned}
& \text { last }=31 \\
& \text { step }=1
\end{aligned}
$$

elseif (chi.lt.0.0) then

last $=1$

step $=-1$

elseif (chi.eq.0.0) then

write $\left(10,{ }^{*}\right)$ 'Susceptibility is zero, so no radial motion.' goto 90

endif

! Per particle diameter (loop 85)

\section{do $85 \mathrm{Dpx}=1,4$}

$\mathrm{Dp}=\mathrm{Psizes}(\mathrm{Dpx}) * 1 \mathrm{e}-06$

$M P=(4.0 / 3.0) \star 3.14159 *((D p / 2) * \star(3.0)) * D E N P$

! HARDWIRED NUMBER OF PARTICLE DIAMETERS PER RUN

! Particle diameter converted to meters

! Particle mass ( $\mathrm{kg})$

out $1=0$

! out1 counts to 4 for printing results for every 4 th ro

! Implementation of $\mathrm{VzO}=$ terminal velocity option...

if (usevzterm.eq.1) then

call termVzO (SVzmax, NSVzmax, regime, g, visc, DENp, Dp, DENf)

if (regime.eq.0) write(10,*) 'Error: flow regime flag not set.'

if (regime.eq.1) $\mathrm{VzO}=\mathrm{SVzmax}$ ! regime=1 means stokes flow

if (regime.eq.2) $\mathrm{Vz} 0=\mathrm{NSV}$ max

1 regime $=2$ means Non-Stokes

endif

write $\left(10,{ }^{\star}\right) \quad \mathrm{Vz} 0=', \mathrm{VzO}$

call RSTOKE1 (Lx, A1, B1, visc, Dp, Mp, chi, dB, mu, DENp)

write $\left(10,{ }^{*}\right)$ 'Lx, $A 1, B 1$ ' , Lx, $A 1, B 1$

if $((A 1+B 1)$.eq.0.0) then

write $(10, *)$ 'Warning: $L 1=0 \ldots$ implies negligible radial motion in stokes solution' goto 85

endif

! Per initial radial position of particle...

do $60 \mathrm{rx}=1,31$
$r 0=r \times \star 0.001$
$t=0.0$
$r=r 0$
$\mathrm{Vz}=\mathrm{VzO}$
! Initial radial position
! Time
! R-position at time $t$
! z-velocity at time $t$
$V r=0.0$
! R-velocity at time $t$

magnet.f90 - 1/17/98 - 2 
out $2=0$

if (outl.eq.4) then

write $\left(10,{ }^{*}\right)$ ' $R(0)=1, r, ' m$ ',', Set=', set, ', Particle Diameter $(m)=1, D p$ endif

write $\left(10,{ }^{*}\right)$ 'r-position (m), r-velocity (m/s), z-position (m), z-velocity (m/s), time (s), Re'

call CDF (cd, Re, Dp, DENf, visc, Vr, Vz)

! Calculates initial Reynolds number

! loop was set above for radial motion direction based on sign of chi do 55 brx=rx, last, step

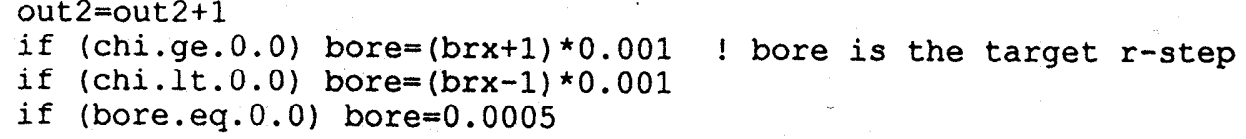


! Trajectory outputs for single particle diameter, all ICs... write $\left(11,{ }^{*}\right) \mathrm{Dp}^{\star} 1 \mathrm{e} 6, \mathrm{\prime}^{\prime}=\mathrm{Dp}$ (microns), ', set, '=Set'

write $(11, *)$ 'Array values are $z$-position of particle...'

write $(11, *)$ 'r-position (m), $r(0)$ (m) $\rightarrow->$ '

if (chi.ge.0.0) then

write $(11, \star) 1,0.004,0.008,0.012,0.016,0.020,0.024,0.028^{\prime}$

! tag is cheesy way to get print loop right

do $63 \mathrm{y}=33,5,-1$

! Note: $-1.0 *$ added just for graphing convention...

write (11, '(F6.4,7(a1, F8.4))') $\operatorname{ROGR}(\mathrm{y}),\left({ }^{\prime}, ',-1.0 * \mathrm{Z} 2 \mathrm{GR}(\mathrm{x}, \mathrm{y}-1), \mathrm{x}=4, \operatorname{tag}, 4\right)$

if (y.eq.29) $\mathrm{tag}=24$

if (y.eq.25) tag $=20$

if (y.eq.21) $\mathrm{tag}=16$

if $(y . e q .17) \mathrm{tag}=12$

if $(y \cdot$ eq.13) $\operatorname{tag}=8$

if $(y . e q .9) \quad \operatorname{tag}=4$

endif

if (chi.1t.0.0) then

write $(11, *) 1,0.028,0.024,0.020,0.016,0.012,0.008,0.004$ '

$\operatorname{tag}=4$

do $64 y=1,29$

write $(11, '(F 6.4,7(a 1, F 8.4)) ') \operatorname{ROGR}(y),(', ',-1.0 * Z 2 G R(x, y+1), x=28, \operatorname{tag},-4)$

if $(y . e q .5) \quad \mathrm{tag}=8$

if (y.eq.9) $\quad \mathrm{tag}=12$

if $(y . e q .13)$ tag $=16$

if $(y . e q .17) \quad \operatorname{tag}=20$

if $(y . e q .21) \quad \operatorname{tag}=24$

if $(y . e q .25) \quad \operatorname{tag}=28$

endif ntinue

write $(11, '(a 1 /) ')$ ' '

do $75 \mathrm{n}=1,31$

do $70 \mathrm{q}=1,33$

! Reset trajectory array

continue

continue

85 continue

! Outputs for time to wall/center and for required magnet length...

write $(12, *)$ set, '=Set', ', Array is time to wall/center (s)'

write $\left(12,{ }^{*}\right)$ ' $R(0)(\mathrm{m})$, Particle diameters (micrometers) $\rightarrow$ '

write $\left(13,{ }^{*}\right)$ set, '=Set', 'Array is required magnet length for travel to wall/center (m)'

write $\left(13,{ }^{*}\right)$ ' $\mathrm{R}(0)(\mathrm{m})$, Particle diameters (micrometers) $\rightarrow->$ '

write $(12,)^{\prime}$ ' ,' ',Psizes (1), ', ', Psizes (2), ', ', Psizes (3),' ', ', Psizes (4)

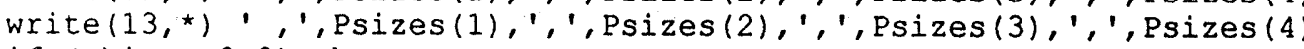

if (chi.ge.0.0) then

do $88 \quad y=2,33$

write $(12, '(F 6.4,4(a 1, F 8.4))$ ') $\operatorname{ROGR}(y),(', ', \operatorname{TFGR}(x, y), x=1,4)$ continue

endif

write $\left(13, '\left(F 6.4,4\left(a 1\right.\right.\right.$, F7.4))') $\operatorname{ROGR}(y),\left({ }^{\prime}, ', \operatorname{ZFGR}(x, y), x=1,4\right)$

if (chi.lt.0.0) then

magnet.f90-1/17/98-4

$1 \quad 1$



continue

, ROGR (y), $(4,4, T F G R(x, y), x=1,4)$ endif

90 continue

close (unit $=10)$

close (unit $=11$ )

close (unit $=12$ )

close (unit=13)

stop

end

! Subroutine NONSTOKE uses 4 th order Runge-Kutta algorithm to compute

the radial position of particle for $0.3<\operatorname{Re}<1000$. Further, it calls

ZINTMD, which computes z-motion at each $\mathrm{R}-\mathrm{K}$ step, thereby coupling the

$r$ - and $z$-motion solutions.

subrout ine NONSTOKE ( $t, t c, D p, V r, V r c, V z, D E N f, v i s c, c h i, D E N p, m u, d B, r, b o r e, R e, g, z, v z 0)$

implicit none

real tc, Dp, Vr, Vz, DENf, visc, chi, DENp, mu, dB, $t, r$, bore

real delt, beta, gamma, h1, h2, h3,c1, Vrc

real $r 1, r 2, r 3, r 4$, Rold, Told, Rnew, Tnew, cd, Re, g, z, Vzo

real $k 1, k 2, k 3, k 4$, betal

delt $=0.02$

! $2 *$ initial time step (halved below)

call CDF (cd, Re, Dp, DENf, visc, Vr, Vz)

! Get cd, Re

95 delt $=\operatorname{del} t / 2$

100 if (cd.gt. 85 ) $\mathrm{cd}=85$

betal $=3.0{ }^{\star} \mathrm{Cd}^{\star} \mathrm{DEN} f /\left(4.0 * \mathrm{DENp} \mathrm{DP}^{\star} \mathrm{Dp}\right)$

if (chi.ge.0.0) beta=-betal

if (chi.lt.0.0) beta=betal

gamma $=\mathrm{chi}^{*}\left(\mathrm{~dB}^{\star \star}\right.$ (2.0))/(DENp*mu $)$

$h I=(V r * \star(2.0) / 2.0) * \exp (-2.0 *$ beta*r $)$

h2 $=$ gamma $* \exp (-2.0 *$ beta*r $) /(2.0 *$ beta $)$

$\mathrm{h} 3=r+1.0 /(2.0 *$ beta $)$

$\mathrm{cl}=\mathrm{h} 1+\mathrm{h} 2 \star \mathrm{h} 3$

! Fourth-order Runge-Kutta calculations in r-direction

$r l=r$

call $\operatorname{DER}(k 1, r l$, gamma, beta, cl, chi)

$r 2=r+(0.5 *$ del $t * k 1)$

call DER (k2, r2, gamma, beta, c1, chi)

$r 3=r+0.5 *$ del $t * k 2$

call DER $(k 3, r 3$, gamma, beta, 1 , chi)

$r 4=r+d e l t * k 3$

call DER ( $k 4, r 4$, gamma, beta, $c 1$, chi)

Rold $=r$

$r=r+(\operatorname{del} t / 6) *(k 1+2.0 * k 2+2.0 * k 3+k 4)$

if $(\mathrm{abs}(\mathrm{r}-\mathrm{Rold}) \cdot \mathrm{gt} .0 .0005)$ then

$r=$ Rold

! In loop, this will halve the time step whenever r-step is too big.

! Limits cd to $\mathrm{N}-\mathrm{S}$ regime (necessary only very early in solution)

goto 95 
! Calculate new $V z$ (and $R e$ and $c d$ ) based on new time and $V r$ )

call ZINTMD (Re, DENp, g, DENf, Dp, z, Tnew, visc, Vzo,Vr,Vz, cd)

! Test to see if new $r$ position is beyond the target $r$ (which is "bore")

if (chi.ge.0.0) then
if (Rnew.lt.bore) goto 100
! Repeat calculation loop if not to "bore" yet

elseif (chi.lt.0.0) then

if (Rnew.gt.bore) goto 100

endif

$t c=$ Told $+($ bore - Rold $)$ * Tnew-Told $) /($ Rnew - Rold $)$

if (abs (tc-Told). It.1e-06) then Vrc $=$ Vr

else

$\operatorname{Vrc}=($ bore-Rold $) /($ tc-Told $)$

! Adjusts solution time to correspond with "bore" and not Rnew

! Accounts for special case where Rold very close to "bore"

! If close, just use $\mathrm{Vr}$

! Otherwise, adjusts r-velocity to correspond to tc and not Tnew endif

call ZINTMD (Re, DENp, g, DENf, Dp, z, tc, visc, Vzo, Vrc, Vz, cd)

! Final calculation of $z$ and $V z$ based on tc

return

end

! Subroutine 2INTMD calculates vertical position of particle for $0.3<$ Re $<1000$.

Routine is a loop since $\mathrm{Vz}$ depends on $\mathrm{cd}$, which depends on $\mathrm{Re}$, which depends on $\mathrm{Vz} .$.

subroutine ZINTMD(Re, DENp, $g$, DENf, Dp, $z, t, v i s c, V z 0, V r, V z, c d$ )

implicit none

real Re, DENp, g, DENf, Dp, z, t, visc, Vzo,Vr, Vz

real cd, gamma, theta, kon, Renew, diff

120 Call CDF (Cd, Re, Dp, DENf, visc, Vr, Vz)

gamma $=\operatorname{sqrt}(4.0 \star D p *(D E N p-D E N f) * g /(3.0 * c d \star D E N f))$

thet $a=1 / \operatorname{sgrt}\left(3.0 * C d^{*} D E N f * g *(D E N p-D E N f) /(D p *(D E N p * \star 2))\right.$

kon $=($ gamma $+V z 0) /(g a m m a-V z 0)$

if $((t /$ theta)..1t.80.0) then $z=2.0{ }^{\star}$ gamma thet $^{*} \log ((1+k o n * \exp (t /$ theta $)) /(1+k o n))-g a m m a * t$

$V z=g a m m a *(k o n \star \exp (t /$ theta $)-1.0) /(k o n * \exp (t /$ theta $)+1.0)$

else $z=2.0^{*}$ gamma ${ }^{*}$ theta* $(t /$ theta $+\log (k o n /(1+k o n)))-g a m m a * t$

! Get initial Re (and cd) ! These constants include buoyancy effects. $\mathrm{V} z=\mathrm{g} a \mathrm{mma}$

endif

call CDE (cd, Renew, Dp, DENf, visc, Vr, Vz) dif $f=a b s$ (Renew-Re)

if (diff.lt.0.001) goto 130

! Calculate new Re based on new $\mathrm{Vz}$

! Difference between old and new Re controls routine loop

magnet.f90-1/17/98-6

,


i30 return

end

! Subroutine DER is used in NONSTOKE to compute Runge-Kutta coefiicients subroutine DER( $k, r$,gamma, beta, cl, chi)

implicit none

real k, r, gamma, beta, $c 1$, chi

real sl, s2

$s 1=2.0^{*} \mathrm{cl} 1^{\star} \exp \left(2.0 \star \operatorname{bet} a^{\star} r\right)$

$s 2=($ gamma $/$ beta $) *(r+1 /($ beta $* 2.0)$

if (chi.ge.0.0) k=sqrt(s1-s2)

if (chi.It.0.0) $\mathrm{k}=-\operatorname{sqrt}(\mathrm{s} 1-\mathrm{s} 2)$

return

end

! Subroutine RSTOKE1 calculates coefficients for RSTOKE2 (Stokes r-solution) subroutine RSTOKE1 (Lx, A1, BI, visc, Dp, Mp, Chi, dB, mu, DENp)

implicit none

real $a, b, c, L x, A 1, B 1$

real visc, Dp, Mp, chi, dB, mu, DENp

$a=1.0$

$\mathrm{b}=3.0 * 3.14159 * \mathrm{visc} * \mathrm{Dp} / \mathrm{Mp}$

$c=-c h i *\left(d B^{*} *(2.0)\right) /(m u * D E N p)$

$L x=b * \star(2.0)-4 * a * c$

$A I=-b /(2.0 * a)$

$\mathrm{Bl}=\operatorname{sqrt}(\mathrm{abs}(\mathrm{Lx})) /(2.0 * \mathrm{a})$

return

end

! Subroutine RSTOKE2 solves radial position for $\operatorname{Re}<0.3$.

Note that three solution forms are possible, depending on sign of Ix,

which was calculated in RSTOKE1.

subroutine RSTOKE2( $\mathrm{Lx}, \mathrm{A} 1, \mathrm{Bl}, \mathrm{t}, \mathrm{Vr}, \mathrm{r} 0$, bore)

implicit none

real $K 1, K 2, t, V r, r 0, L x, A 1, B 1$, bore

real $f, d f$

if (Lx.gt.0.0) then

$K 2=r 0 *(A 1+B 1) /(2.0 * B 1)$

$K 1=r 0 *(A 1-B 1) /(-2.0 * B 1)$

elseif (IX.eq.0.0) then $\mathrm{K} 2=-r 0 * \mathrm{~A} 1$

$\mathrm{Kl}=\mathrm{rO}$

elseif (Ix.It.0.0) then $K 2=-r 0 \star A I / B 1$

endif

$$
\mathrm{K} 1=\mathrm{r} 0
$$

if $(t . e q .0 .0) t=0.1$

! Routine uses previous $t$ as guess for next $t$ except when $t=0$

iE (Lx.gt.0.0) then 
$\tilde{I}=K 1 * \exp ((A I+B 1) * t)+K 2 \times \exp ((A 1-B 1) * t)-$ bore

$d f=(A 1+B 1) * K 1 * \exp ((A 1+B 1) \star t)+(A 1-B 1) * K 2 * \exp ((A 1-B 1) * t)$

Elseif (Lx.eq.0.0) then

$t=K 1 * \exp (A 1 \star t)+K 2^{\star} t \star \exp (A 1 * t)-$ bore

$d f=A . I^{\star} K I^{\star} \exp (A 1 * t)+A I^{\star} \div{ }^{\star} K 2{ }^{\star} \exp (A 1 \star t)+K 2{ }^{\star} \exp (A 1 * t)$

elseif (Lx.It.0.0) then

$f=K 1^{\star} \exp (A 1 * t) * \cos (B 1 * t)+K 2 * \exp (A 1 * t) * \sin (B 1 * t)-$ bore endif

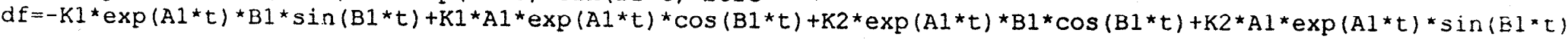

! Basic gist of loop is to iterate on $t$ until rguess minus rtarget is zeroish

if $(a b s(f) .1 t .1 e-06)$ then

else goto 145

$t=t-f / d f$

endif

goto 140

$145 \quad \mathrm{Vr}=\mathrm{df}$

return

end

! Subroutine zSTOKES calculates vertical position and velocity for $\operatorname{Re}<0.3$.

subroutine $2 \operatorname{STOKES}(z, R e, V z, g, t, M p, D p, D E N f, v i s c, V z 0, V r)$

implicit none

real $z, R e, v z, g, t, M p, D p, D E N f, v i s c, V z 0, V x, c d, b p o s$

real kayl, kay2, mprime

bpos $=3 * 3.14159 *$ visc* $D p / M p$

mprime $=M p-D E N f^{*}(3.14159 / 6) * D p * * 3$

kay $1=m p r i m e \star g-3 * 3.141599^{\star} v i s C^{\star} D p * V z 0$

kay $2=-\left(1 /\left(M^{*}\left(b^{*}{ }^{*}{ }^{\star} 2\right)\right)\right) *$ kay 1

$z=\left(1 / M^{*} \text { bpos }\right)^{*}\left(\right.$ mprime* $g^{*} t+k a y 1 * \exp (-t \star b p o s) /$ bpos $)+k a y 2$

$V z=\left(m p r i m e{ }^{\star} g-k a y l * \exp \left(-t^{\star}\right.\right.$ bpos $\left.)\right) /(M p \star b p o s)$

call CDF (cd, Re, Dp, DENf, visc, Vr, Vz)

return

end

! Subroutine CDF calculates Reynold's number and drag coefficient...

subroutine $\operatorname{CDE}$ ( $c d, R e, D p, D E N f, v i s c, V r, V z$ )

implicit none

reall cd, Re, Dp, DENf, visc, Vr, Vz

real Vre

Vre $=\operatorname{sqrt}\left(V_{z^{*}} *(2.0)+V_{r}^{* \star}(2.0)\right)$

if (Vre.eq.0.0) Vre $=0.001$

! At $t=0$, Vre would be zero, blowing up cd calculation, so use Vre=smail

$\mathrm{Re}=\mathrm{Dp} \mathrm{Vre}^{\star} \mathrm{DEN} f / \mathrm{visc}$

$\mathrm{Cd}=(24.0 / \mathrm{Re}){ }^{\star}\left(1+0.14^{*}\left(\operatorname{Re}{ }^{\star *}(0.7)\right)\right)$ ! From Perry's ChemE Handbook, valid for Re<1000

return

end

! Subroutine termvzo calculates terminal freefall velocities (optional call based on usevzterm) subrout ine termVzO (SVzmax, NSVzmax, regime, g, visc, DENp, Dp, DENf)

implicit none

real SVzmax, NSVzmax, regime, g, visc, DENp, Dp, DENf

magnet.f90-1/17/98-8

$1 \quad \ldots 1$


regime $=0$

SVzmax $=g *(D E N p-D E N f) *(D p * \star 2.0) /(18.0 * v i s C)$

! Stokes flow terminal velocity

call CDE (cd, ReStokes, Dp, DENf, visc, 0.0, SVzmax)

call NSVzterm (Dp, DENf, DENp, g, visc, NSVzmax, ReNS)

if (ReStokes.gt.0.3) then

! Non-Stokes terminal velocity

regime $=2$ ! Non-Stokes flow regime?

t If ReStokes>0.3, then Non-stokes Re is too, so definitely N-S regime endif goto 200

if (ReNS.le.0.3) then

regime $=1$ ! Stokes flow regime

endif goto 200

Termavg $=(S V z \max +\mathrm{NSV} z \max ) / 2.0$

call CDF (cd, Re, Dp, DENf, visc, 0.0, Termavg)

if (Re.le.0.3) then

else regime $=1$

200 endif

regime $=2$

return

end

! If NonStokes $\operatorname{Re}<=0.3$, then ReStokes is too, so in Stokes regime

! If final regime is ambiguous, base it on average terminal velocity

! Subroutine NSVterm calculates terminal freefall velocity for Non-Stokes subrout ine NSVzterm(Dp, DENf, DENp, g, visc, Vzo, Re)

implicit none

real Dp, DENf, DENp, g, VzO

real cd, Re, diff, RHS, visc

$\mathrm{V} 2 \mathrm{O}=1$

290 Call $\operatorname{CDF}(\mathrm{cd}, \mathrm{Re}, \mathrm{Dp}, \mathrm{DEN} f, \mathrm{visc}, 0.0, \mathrm{Vz} 0)$

RHS $=\operatorname{sgrt}\left(4.0 * D p \star(D E N p-D E N f){ }^{\star} g /\left(3.0 * C d^{\star} D E N f\right)\right)$

diff $=a b s(V z O-R H S)$

if (diff.lt.0.001) goto 300

$\mathrm{V} z 0=\mathrm{RHS}$

goto 290

300 return

end 


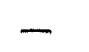

-

7

-

$-$

$\rightarrow$

$-$

$-7$

$-$ 
EFFECT OF PROGRAM CHANGES ON COAL CLEANING STUDIES

.

E.

1

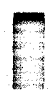

.

I.

2

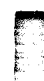

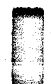

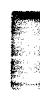

2

2

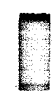

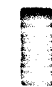




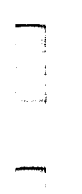

$-$

$-$

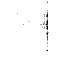

7

$?$

$-$

,

-

.

-

$\vdots$
-
-
-
-

-
-
-
7
-
-
- 


\section{Effect of Program Changes on Original Coal Cleaning Results}

The cumulative effect of the trajectory model revisions on the original coal cleaning results can be seen in Figures 1-6. In all of the figures, dashed lines show the results of the original program and solid lines show the new results. Figure la-b shows the required travel times for pyritic particles to reach the wall and for maceral particles to reach the magnet center. As shown, the net effect of the revisions is to increase the time for the particles to reach their destination. Similarly, Figure $2 \mathrm{a}-\mathrm{b}$ shows the required magnet length for the particles to reach the wall or center. Since the time to destination is longer, it is not surprising that the magnet length requirements generally increase as well.

Figures 3-6 are plots of the trajectories of pyritic and maceral particles ranging from 50 to $200 \mu \mathrm{m}$. Again, dashed lines show the results of the original program while solid lines show the revised results. In all of these cases, trajectory solutions fall in the non-Stokes flow regime, and the Reynolds numbers vary from 0.3 to 32 , depending on the particle type and size. 

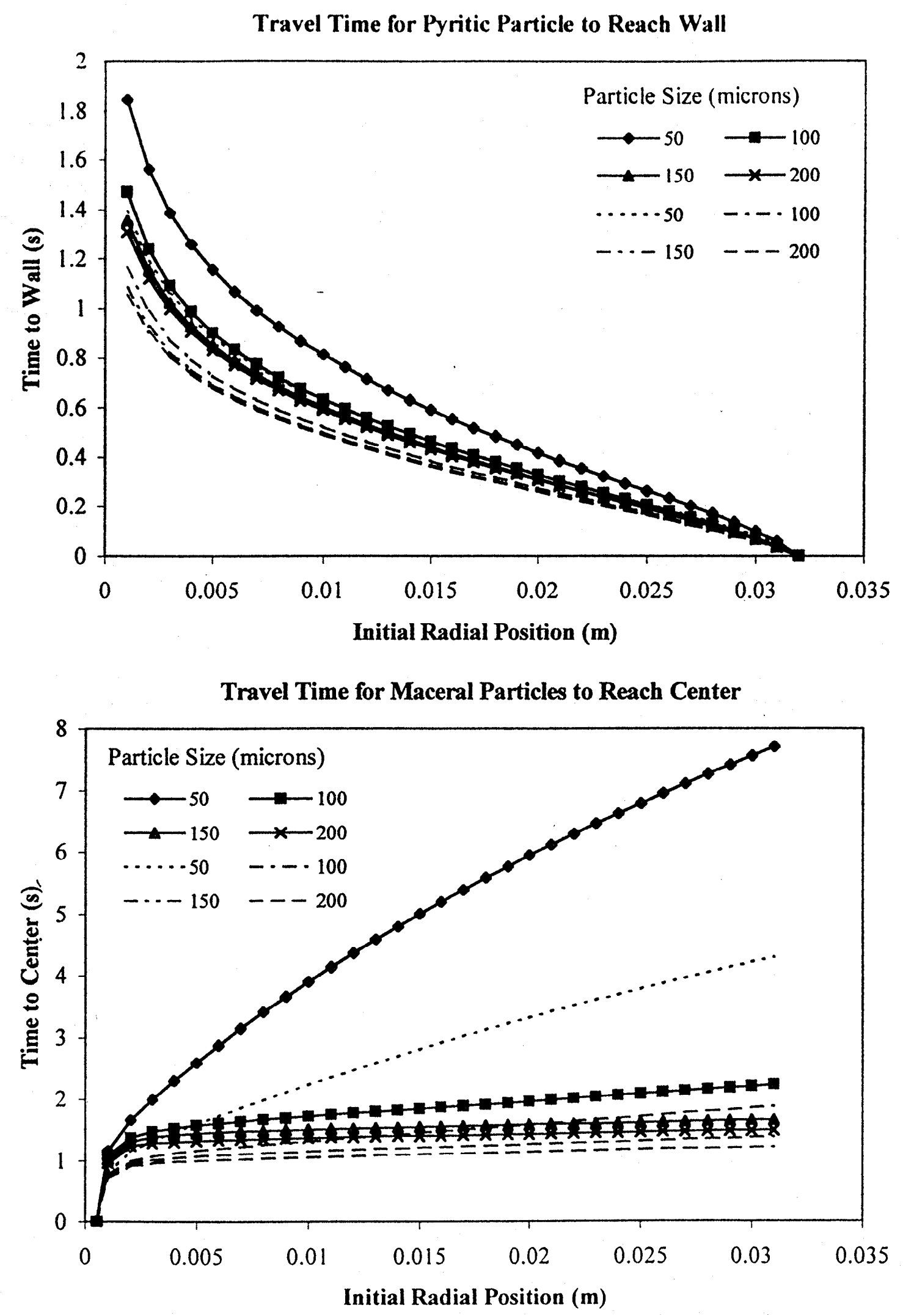

Figure 1a-b: Time for a) pyritic and b) maceral particles to reach the wall or center of the magnet. Dashed lines indicate the original solution, while solid lines show the revised solution. 
Required Magnet Length for Pyritic Particle to Reach Wall

3
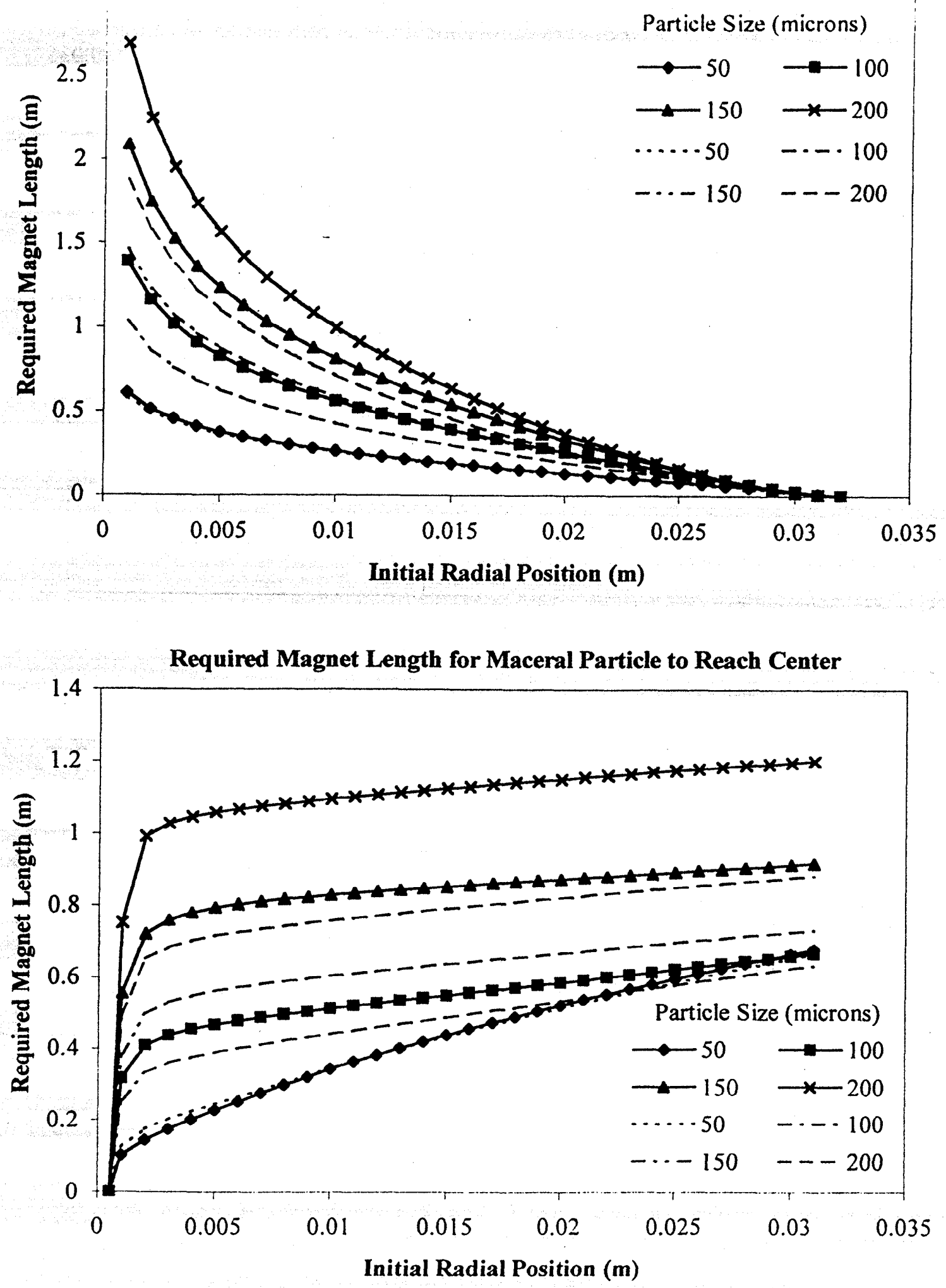

Figure 2a-b: Magnet length for a) pyritic and b) maceral particles to reach the wall or center. Dashed lines indicate the original solution, while solid lines show the revised solution. 

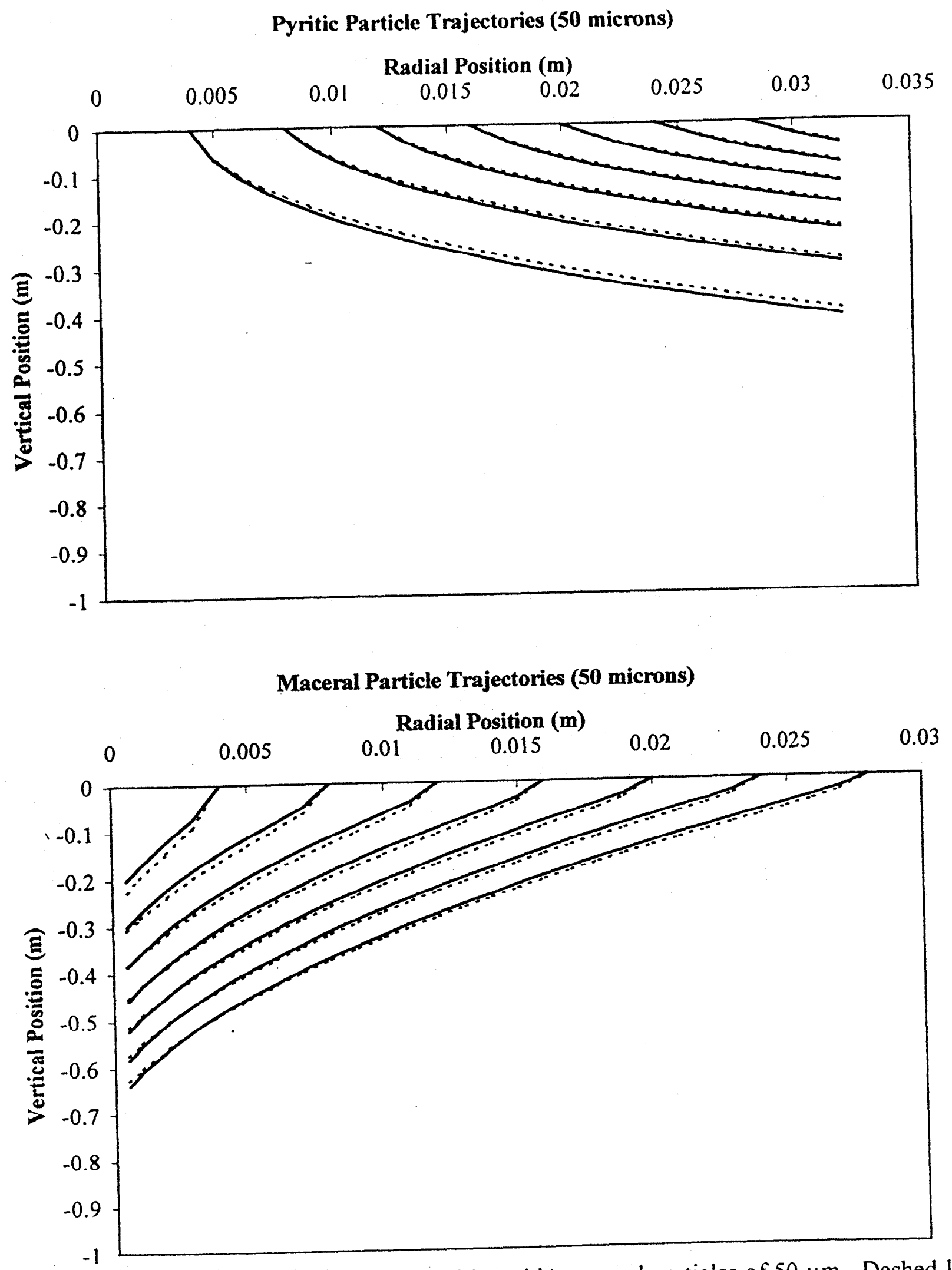

Figure 3a-b: Particle trajectories for a) pyritic and b) maceral particles of $50 \mu \mathrm{m}$. Dashed lines indicate the original solution, while solid lines show the revised solution. 

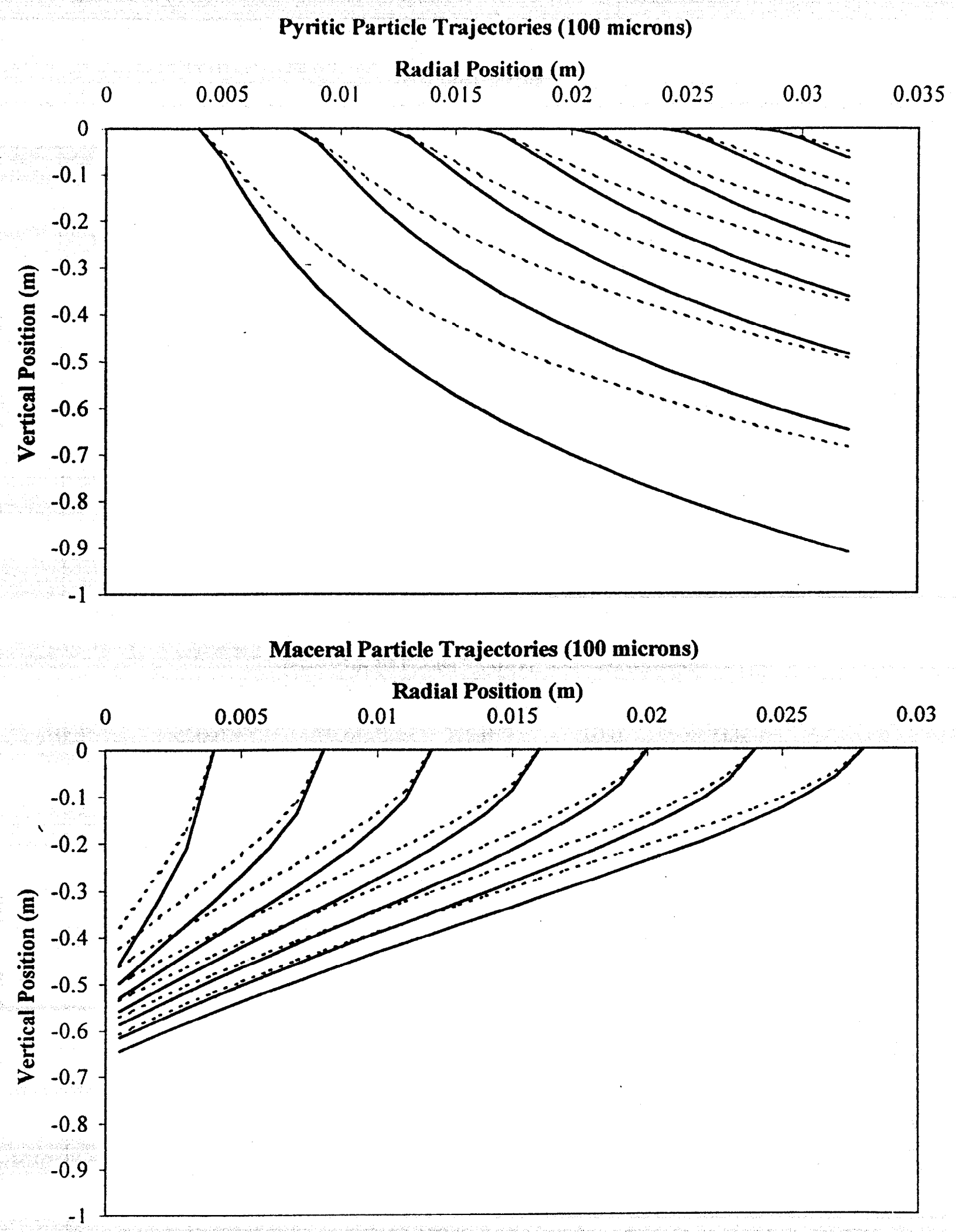

Figure 4a-b: Particle trajectories for a) pyritic and b) maceral particles of $100 \mu \mathrm{m}$. Dashed lines indicate the original solution, while solid lines show the revised solution. 

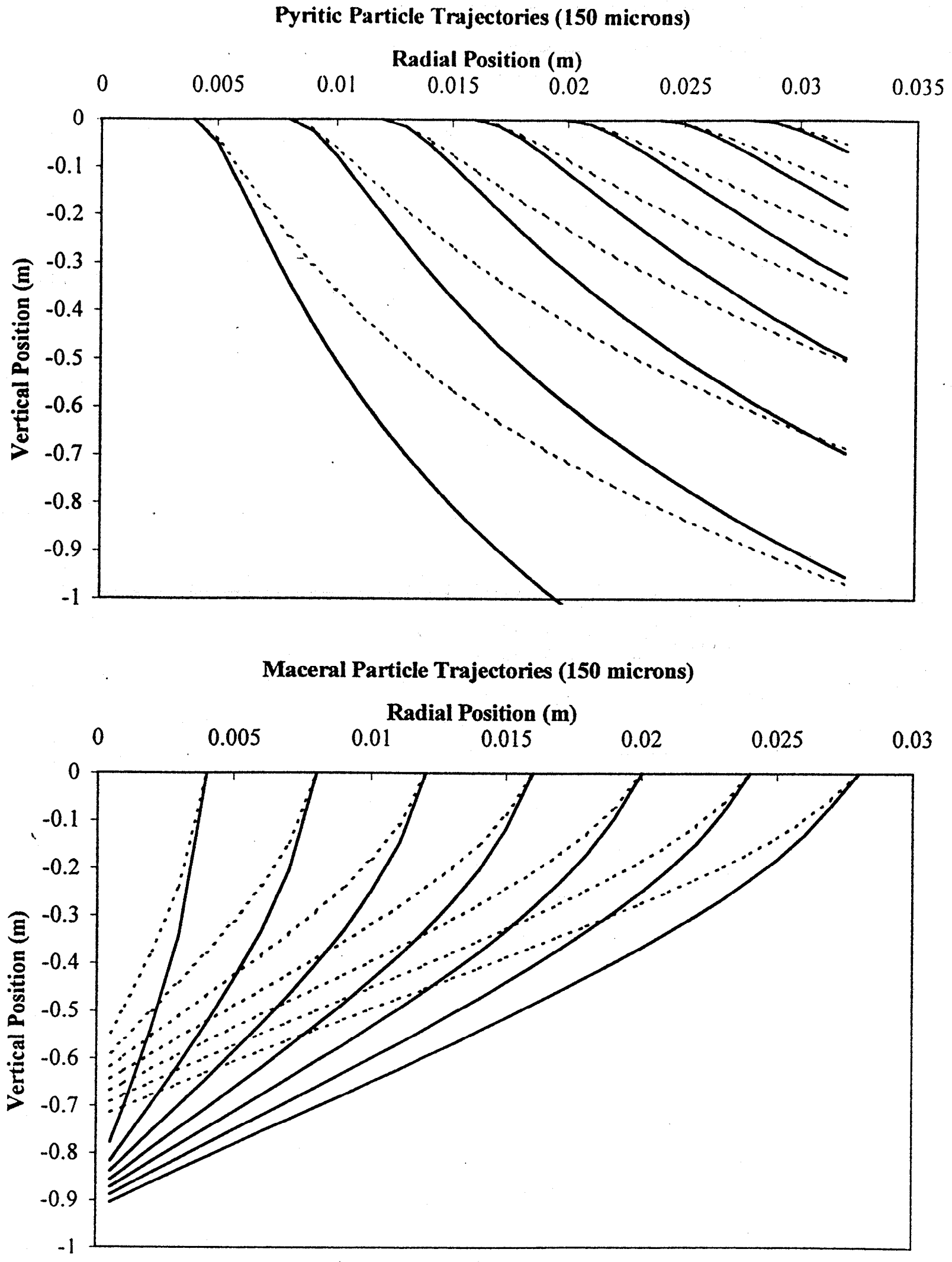

Figure 5a-b: Particle trajectories for a) pyritic and b) maceral particles of $150 \mu \mathrm{m}$. Dashed lines indicate the original solution, while solid lines show the revised solution. 

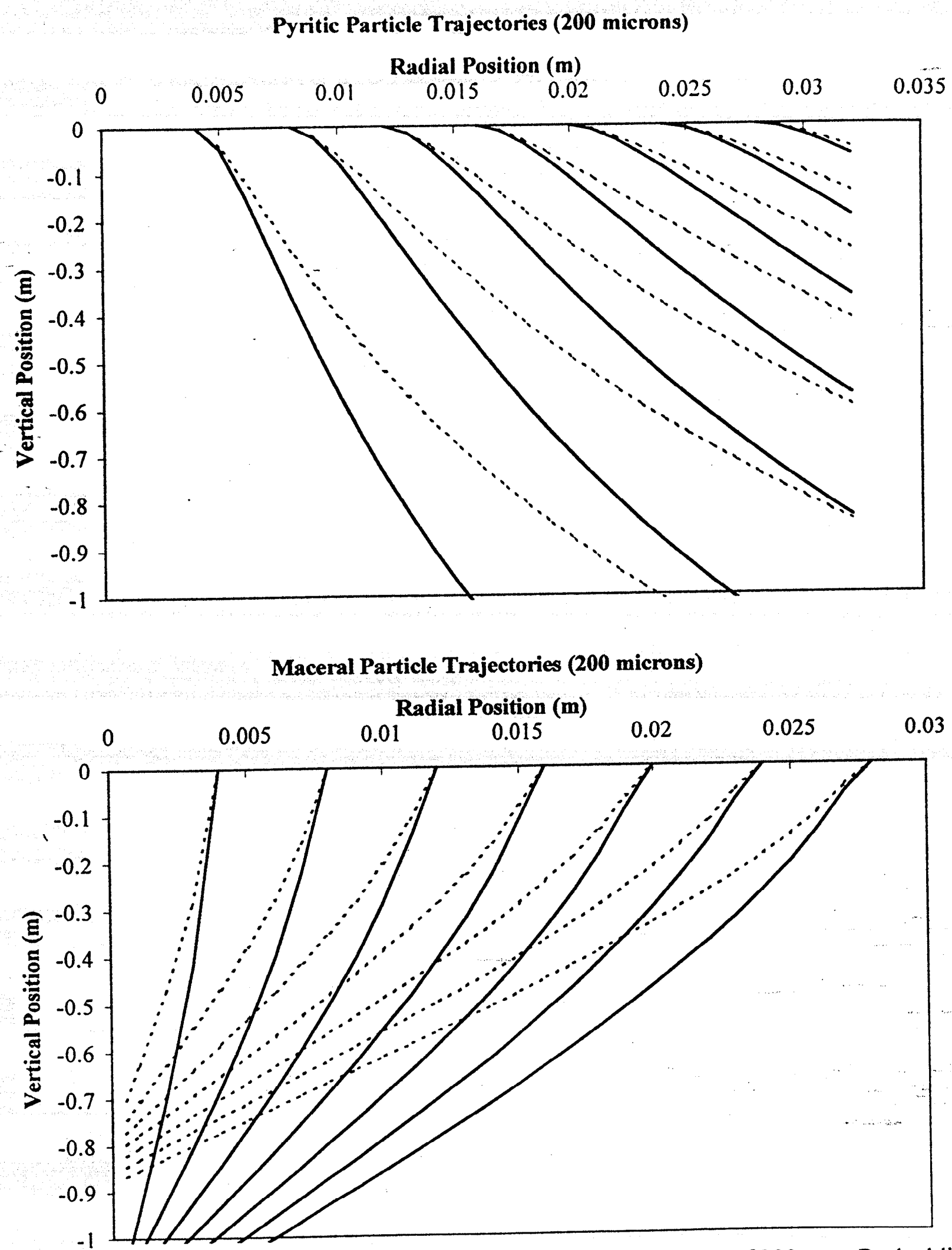

Figure 6a-b: Particle trajectories for a) pyritic and b) maceral particles of $200 \mu \mathrm{m}$. Dashed lines indicate the original solution, while solid lines show the revised solution. 


\section{APPENDIX IV}

EULERIAN MODEL FOR PARTICLE TRAJECTORIES

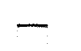

$-$

$-$

$-$

$-$ 


\title{
A Study of Open Gradient Magnetic Beneficiation of
} Spent Fluid Catalytic Cracking Catalysts

\author{
Submitted by \\ Brian Golchert, Shen-Lin Chang, and Michael Petrick \\ Argonne National Laboratory
}


Executive Summary:

A study was undertaken to evaluate the feasibility of using the Open Gradient Magnetic Separation (OGMS) technology to separate contaminated spent fluid catalytic cracking catalyst from clean catalyst. The OGMS is a hollow cylinder surrounded by superconducting quadropole magnets. Catalyst and a forcing gas enter at the top of the device through an annulus located at approximately half the radial distance from the center. As the particles flow through the system, the heavy metal contaminated catalyst particles are separated by the strong magnetic field. A computer simulation of the OGMS system was developed and used to conduct computer scale-up experiments to define the impact of key design and operating parameters on separation efficiency; the computational fluid dynamics (CFD) simulation thus provided a low-cost method for determining the effectiveness of the technology.

The study comprised three main tasks. The first task involved the modification of an existing computational fluid dynamics code (ICRKFLO) to model the selected Open Gradient Magnetic Separation geometry. The force due to the magnetic field was incorporated into the modified version of ICRKFLO to simulate of the OGMS system. In the second task, the OGMS simulation was validated against available experimental data derived from industrial test programs to determine the proper inlet spray angles and catalyst material parameters. In the third task, the validated code was used to conduct scale up studies to evaluate the potential of this technology. Also, limited parametric and sensitivity studies were undertaken to define design and operating parameters that would improve the separation efficiency of the device.

The results from the parametric studies indicated that decreasing the velocity of the forcing gas (thus increasing the residence time) and increasing the magnetic field gradient would enhance the performance of the system to a point where the system can be effectively used on an industrial level. It was also shown that the heavily contaminated particles and the larger sized particles were preferentially separated when compared to those smaller and less contaminated particles.

Several preliminary design studies were performed to determine methods of increasing the efficiency of contamination removal. The initial OGMS system configuration studied (from what data was available) was capable of removing $18.5 \%$ of the heavy metal contamination after four passes. Design modifications studied with the CFD simulation tool indicated that the separation efficiency could be increased substantially. The design modification studies indicated that a forcing gas should be introduced along the breadth of the device. This improvement would minimize the spread of the catalyst particles thus making the magnetic separation more effective. The second major modification considered was the determination of an optimal injection location. The introduction of such design modifications suggest that the OGMS technology has the potential for achieving commercially viable benefication of spent fluid catalytic cracking catalysts. 


\section{A Study of Open Gradient Magnetic Beneficiation of Spent Fluid Catalytic Cracking Catalysts}

Each year, Fluidized Catalytic Cracking (FCC) consumes over 400 million pounds of catalysts. As the catalyst flows through the riser of an FCC, it begins to become coated with carbon deposits and with heavy metal contaminants (such as iron, nickel and vanadium). While the carbon deposits may be burned off in the regenerator, these heavy metal contaminants remain on the catalyst particles and thus reduce the effectiveness of the catalyst. Over time, the catalyst may become deactivated due to excessive amounts of heavy metals. To avoid this deactivation of the catalyst, some of the catalyst is routinely removed from the system and replaced with fresh catalyst. However, this removed catalyst contains both contaminated and clean catalyst.

A method of separating the contaminated catalyst from the fresh (clean) catalyst would result in several immediate benefits. First, the spent catalyst represents a hazardous waste due to the high heavy metal contamination. Until a recent change in the law, this waste was routinely placed in landfills. Reducing the volume of disposed catalyst represents a clear environmental and an economic benefit. Secondly, separation technology allows the re-insertion of clean catalyst back into the system thus reducing the need to purchase new catalyst. Both of these effects would result in significant economic savings to the refinery.

There exist established technologies for the use of high strength magnets to separate heavy metals from mixtures. For example, these technologies are used in the coal and mineral processing industries. Recently, there have been attempts at applying magnetic fields to remove the heavy metal contaminated catalysts from the clean catalyst. MAGNACAT is one such commercial venture that uses magnetic rollers to separate out the heavy metal contamination. However, there exist devices with stronger magnetic fields that may separate the contamination more efficiently.

This study was undertaken to evaluate the potential of one the more promising alternatives, namely the Open Gradient Magnetic Separation technology. This device is a cylinder surrounded by superconducting quadropole magnets. Catalyst enters at the top of the device and the heavy metal contaminated catalyst is then separated by the strong magnetic field as it flows through the device. The technology was evaluated by developing a Computational Fluid Dynamics (CFD) simulation of an OGMS system that was then used to conduct computer experiments. The study was comprised of three main tasks. The first task involved the modification of an existing computational fluid dynamics code to represent the current Open Gradient Magnetic Separation geometry and the physics of the device including the magnetic effects. This computer simulation was then validated against experimental data in the second task. Finally, in the third task, the validated code was used to perform scale up studies to evaluate the potential of this technology. Also, in the third task, the application of the OGMS to radioactive waste separation was investigated. This report describes sequentially the tasks performed for this work and the results obtained.

\section{Task 1: Modification of Existing Code}

The computational analysis of the Open Gradient Magnetic Separation (OGMS) of contaminated petrochemical catalysts was accomplished using a modified form of Argonne National Laboratory's (ANL) computational fluid dynamics (CFD) code. ICRKFLO. The main 
modification involved the inclusion of the magnetic force into the source terms of the particle momentum equations. This force is dependent upon the magnetic field spatial distribution, the magnetic properties of the heavy metals, the distribution of heavy metals on the catalyst particles, and the size spectrum of the particles. First, a physical description of the OGMS will be given. Then, a brief description of the governing equations will be presented below followed by an explanation of the modification to include the magnetic effects.

\subsection{Physical Description of OGMS}

The system geometry was taken from a paper by Doctor et. al. [1]. Essentially, the OGMS is a six centimeter diameter vertical tube with four superconducting magnet windings arranged outside the tube. An axial schematic of the OGMS, with dimensions, is given in Figure 1. The inlet region (the top of the tube) is a 'curtain'-an annular region-where the catalyst enters the device. This region corresponds to the Middling region in Figure 2. At the exit, the particle mass is split into three regions as shown in Figure 2: the Product, the Middling and the Magnetic. It is expected that the Magnetic region will contain the most contaminated catalyst at the exit of the OGMS while the Product region will have the cleanest catalyst.

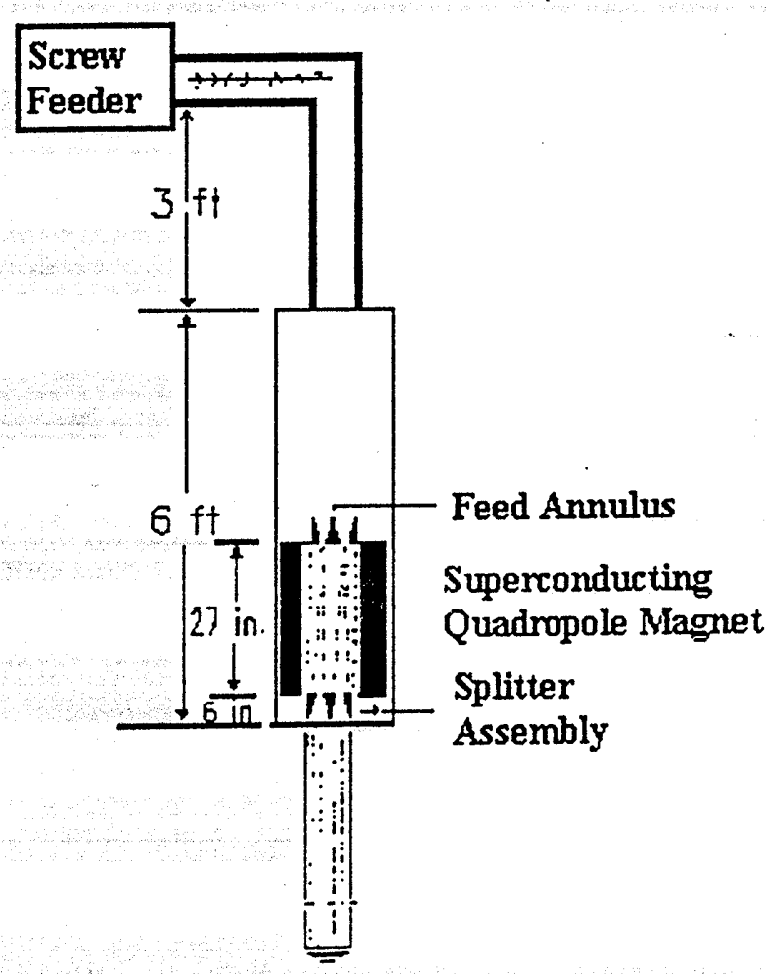

Figure 1: Axial Schematic of OGMS 


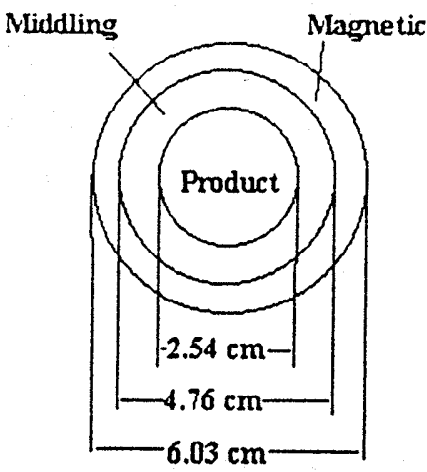

Figure 2: Definition of Exit Regions in OGMS

\subsection{Formulation of the Governing Equations}

ICRKFLO solves the conservation equations of general flow properties for three phases: gaseous species, liquid droplets, and solid particles [2]. For this work, only the solid and gaseous phases are present. General conservation laws, expressed by elliptic-type partial differential equations, are used in conjunction with rate equations governing the mass and momentum for a two-phase flow of catalyst particles and air. For convenience in numerical formulation, the governing transport/conservation equations for the gas phase are put in a common form, Eq.(1):

$$
\frac{\partial}{\partial x}\left(\theta \rho u \xi-\Gamma_{\xi} \frac{\partial \xi}{\partial x}\right)+\frac{\partial}{\partial y}\left(\theta \rho v \xi-\Gamma_{\xi} \frac{\partial \xi}{\partial y}\right)=S_{\xi}
$$

in which $\xi$ is a general flow property (defined in Table 1), $\mathrm{x}$ and $\mathrm{y}$ are spatial coordinates, $\theta$ is the gas volume fraction, $\mathrm{u}, \mathrm{v}$ are velocity components, $\Gamma$ is an effective diffusivity (calculated from both laminar and turbulent diffusivities), and $S_{\xi}$ is the sum of source terms.

Table 1: Gas Flow Properties, Transport Equations, and Source Terms

\begin{tabular}{|c|c|c|}
\hline$\xi$ & Transport Equation & Source Term \\
\hline 1 & Continuity & \\
\hline u & $\mathrm{x}$-momentum & $\begin{array}{l}\text { interfacial drag, pressure, body force, remaining } \\
\text { viscous tensor terms }\left(\mathrm{kg} / \mathrm{m} \mathrm{s}^{2}\right)\end{array}$ \\
\hline $\mathrm{v}$ & $y$-momentum & $\begin{array}{l}\text { interfacial drag, pressure, body force, remaining } \\
\text { viscous tensor terms }\left(\mathrm{kg} / \mathrm{m} \mathrm{s}^{2}\right)\end{array}$ \\
\hline k & Turbulent kinetic energy & $\begin{array}{l}\text { production, dissipation, and interfacial transfer } \\
\left(\mathrm{W} / \mathrm{m}^{3}\right)\end{array}$ \\
\hline & Turbulent dissipation rate & production and dissipation (W/sec $\left.\mathrm{m}^{3}\right)$ \\
\hline
\end{tabular}

Table 1 lists the five gas phase transport equations used in this simulation together with the relevant gas properties and source terms utilized in each of equation. The general flow property is replaced by the scalar 1 in the continuity equation, by a velocity component in a momentum 
equation, or by a lurbulent kinetic energy $k$ or dissipation rate $\varepsilon$ in a turbulence equation. The governing equations contain source terms for interphase and intraphase property exchange rates. The momentum source terms include pressure gradient, body force (gravity), and momentum gain or loss through interfacial drag effects between gas and solid particles.

The turbulence equations are used to determine the turbulent viscosity for the momentum equation. The other three transport equations and the equation of state are used to solve for four unknown gas properties: pressure, density, $x$ - and $y$-velocity components.

The particle phase formulation is based on an Eulerian approach. In this formulation, the particle-phase state of the flow is governed by the elliptic partial differential equations of fluid mechanics, including conservation of particle number density, and momentum. Similar to the gas phase formulation, the governing transport equations for the particle phase is put in a common form, Eq.(2).

$$
\frac{\partial}{\partial x}\left(n_{k} u_{p, k} \xi-\Gamma_{\xi} \frac{\partial n_{k} \xi}{\partial x}\right)+\frac{\partial}{\partial y}\left(n_{k} v_{p, k} \xi-\Gamma_{\xi} \frac{\partial n_{k} \xi}{\partial y}\right)=S_{\xi}
$$

in which $n_{k}$ is the particle number density of the $k^{\text {th }}$ size group, $u_{p, k}$ and $v_{p, k}$ are the particle velocity components of the $\mathrm{k}^{\text {th }}$ size group in the $\mathrm{x}$ and $\mathrm{y}$ direction respectively, $\Gamma$ is the particle diffusivity resulting from interaction with turbulence in the gas phase, and $S_{\xi}$ is the sum of source terms. The formulation and computer code allows for a size spectrum of particles.

Table 2 lists source terms for each of the properties of the condensed phases, noting the applicable governing equation. Each property has a transport equation for each size group, $\mathrm{k}$, and the source terms must be computed for each of the size groups.

Table 2 Source Term List for Condensed Phase Flow Transport Equations (size group k)

\begin{tabular}{|l|l|l|}
\hline$\xi$ & Transport Equation & Source Term \\
\hline 1 & Particle number density & 0 \\
\hline$u_{\mathrm{p}, \mathrm{k}}$ & $\mathrm{x}$-momentum & $\begin{array}{l}\text { interfacial drag, gravitational and magnetic } \\
\text { body force }(\mathrm{kg} / \mathrm{m} \mathrm{s})^{2}\end{array}$ \\
\hline $\mathrm{v}_{\mathrm{p}, \mathrm{k}}$ & $y$-momentum & $\begin{array}{l}\text { interfacial drag, gravitational and magnetic } \\
\text { body force }\left(\mathrm{kg} / \mathrm{m} \mathrm{s}^{2}\right)\end{array}$ \\
\hline
\end{tabular}

\subsection{Inclusion of Magnetic Effects}

As was mentioned earlier, the main modification to ICRKFLO was the inclusion of the magnetic force in the source term of the particle momentum equations. For the arrangement shown in Figure 1, the magnetic force is in the radial direction only. The particle radial momentum equation is:

$$
\frac{\partial}{\partial x}\left(n_{k} u_{p . k} v_{p . k}-\Gamma_{\xi} \frac{\partial n_{k} v_{p . k}}{\partial x}\right)+\frac{\partial}{\partial y}\left(n_{k} v_{p . k} v_{p . k}-\Gamma_{\xi} \frac{\partial n_{k} v_{p . k}}{\partial y}\right)=S_{\xi}
$$


The form for this magnetic force is represented by:

$$
F_{\text {magnelic }}=\frac{\pi}{6} D_{p}^{3} \frac{\chi}{\mu_{0}}\left(\frac{d B}{d r}\right)^{2} r
$$

where:

$D_{p}$ is the equivalent diameter of the particle affected by the magnetic force,

$\chi$ is the magnetic susceptibility of the material,

$\mu_{0}$ is the permeability of free space, and

$\frac{\mathrm{dB}}{\mathrm{dr}}$ is the magnetic field gradient.

Figure 3 depicts the experimentally determined magnetic field distribution for the OGMS. This field was presumably determined without the four aluminum rods (the four circles in the figure) present. In Equation 4, the magnetic force is assumed that the magnetic field is equal to the gradient of the field times the radius. In addition, for an OGMS device, the magnetic field gradient is assumed constant across the radius of the device.

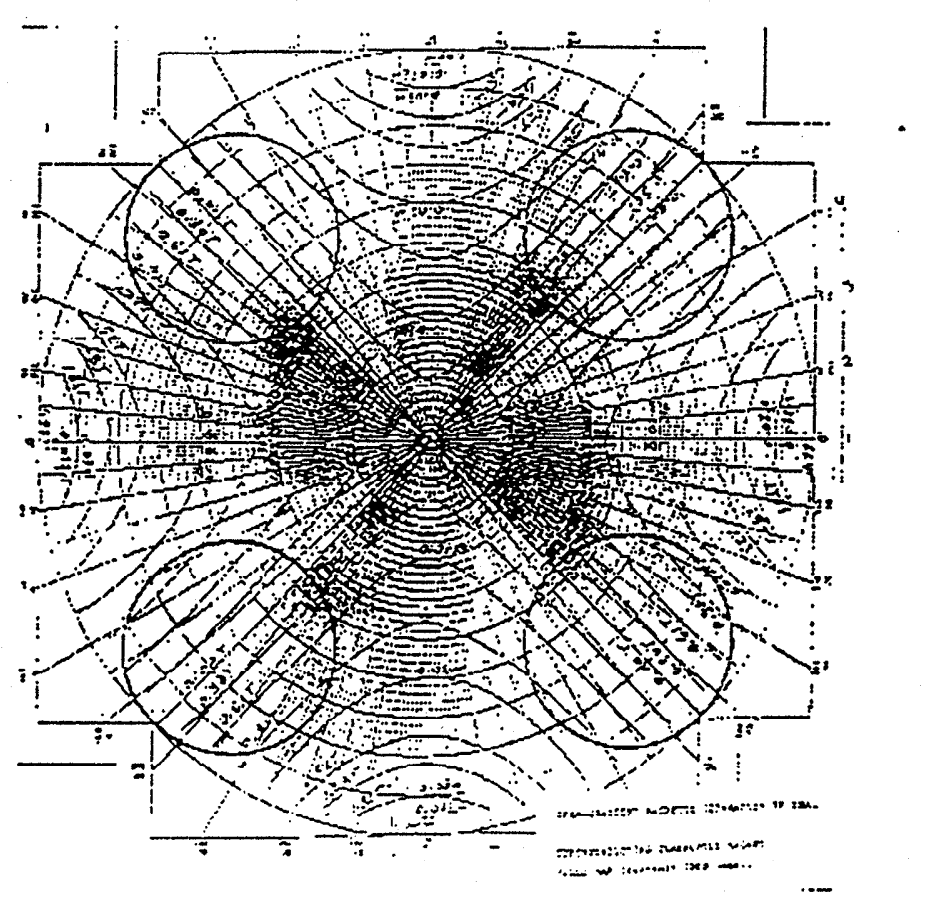

Figure 3: Cross Sectional Magnetic Field Distribution

\section{Task 2: Validation of Modified Code}

Once ICRKFLO has been modified, the code will be validated against experimental data. First, the information from UOP and Amoco catalyst experiments [3.4] was utilized to determine the inlet conditions (particle number density and velocity distributions as they enter the magnetic 
field) to the OGMS. Then. the material magnetic properties were determined from the experimental results.

\subsection{Determination of Inlet Conditions}

\subsubsection{Particle Velocity Profile}

The inlet mass flow rates were taken from the recorded gas and particle mass flow rates. The inlet particle velocity profile was back calculated from the experimental exit mass fraction results with no magnetic field present. This particle velocity profile was then used for the remainder of the numerical calculations. Tables 3 and 4 list the system parameters used to determine the inlet particle velocity profile. Five particle size groups were used to perform the computations.

Table 3: System Parameters Used to Determine Inlet Properties

\begin{tabular}{|l|l|}
\hline Particle Mass Flow Rate (g/s) & 0.879 \\
\hline Gas Mass Flow Rate (g/s) & 1.920 \\
\hline Particle Density $\left(\mathrm{kg} / \mathrm{m}^{3}\right)$ & 4000 \\
\hline Vanadium Concentration (wt \%) & $0.052 \%$ \\
\hline Iron Concentration (wt \%) & $0.58 \%$ \\
\hline Nickel Concentration (wt \%) & $0.054 \%$ \\
\hline Magnetic Field Strength (T) & 0.0 \\
\hline
\end{tabular}

Table 4: Particle Size Distribution

\begin{tabular}{|l|l|}
\hline $\begin{array}{l}\text { Particle Diameter } \\
\text { (microns) }\end{array}$ & $\begin{array}{l}\text { Percent of particles } \\
\text { In this size group }\end{array}$ \\
\hline 183 & $11.50 \%$ \\
\hline 125 & $26.79 \%$ \\
\hline 88 & $31.17 \%$ \\
\hline 62 & $20.17 \%$ \\
\hline 40 & $10.35 \%$ \\
\hline
\end{tabular}

The gas mass flow rate determined the axial velocity. A spray is normally generated for two phase flow systems (gas-solid or gas-liquid) with a restricted inlet such as the one present at the top of the OGMS. To properly characterize a spray, one needs to determine the appropriate spray angles. In order to match the particle mass distribution at the exit, two inlet spray angles were determined. As the catalyst particles enter the magnetic field, they begin to spread out like a spray. This effect is shown in Figure 4. The annular region where the catalyst enters the OGMS (indicated by the downward arrows) is the Middling region. Thus, the spray angles, $\alpha_{1}$ and $\alpha_{2}$, direct the incoming catalyst from the Middling region to the Magnetic and Product regions respectively. 


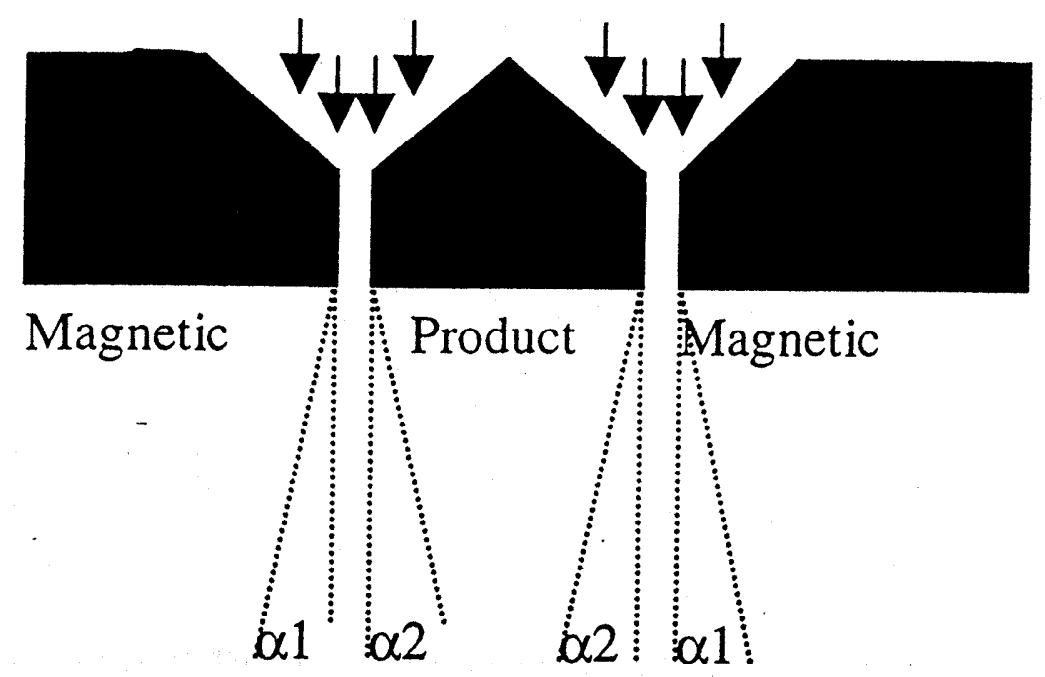

Figure 4: Inlet Feed Annulus and the Definition of Spray Angles

With the proper adjustment of these inlet spray angles, the calculated exit particle mass distribution was matched as is seen in Table 5. In Table 5, the percentages refer to the fraction of the particle mass in each ring.

Table 5: Experimental and Calculated Values of Particle Mass Distribution Without a Magnetic Field Present

\begin{tabular}{|l|l|l|l|}
\hline & Product & Middling & Magnetic \\
\hline Experimental & $32.6 \%$ & $27.9 \%$ & $39.5 \%$ \\
\hline Calculated & $32.63 \%$ & $27.92 \%$ & $39.45 \%$ \\
\hline
\end{tabular}

The calculated inlet spray angles range are $\alpha_{1}=0.1^{\circ}$ (from the Middling region to the Magnetic region) and $\alpha_{2}=1.0^{\circ}$ (from the Middling region to the Product region). The spray angle from the Middling region to the Product region implies that some of the contaminated catalyst is being directed into the product region. The difference between the spray angles arises from the fact that there exists a 'dead' zone in the region between the injection locations. This dead zoneA modification of the OGMS design that would minimize this injection spray angle of the contaminated catalyst into the product region would be beneficial.

\subsubsection{Magnetic Susceptibilities}

Only iron, nickel and vanadium were considered to be significantly affected by the magnetic field. These three elements have large enough contamination weight fractions and large enough magnetic susceptibilites to be impacted by the OGMS magnetic field. The magnetic susceptibilities of the ferromagnetic elements were adjusted to obtain the experimentally recorded product distribution when the magnetic field was applied. Only the ferromagnetic susceptibilities were adjusted since these properties are not known below the Curie temperature and the actual value of the magnetic susceptibility may vary wildly (from zero to infinity) below the Curie temperature [5]. These experiments were done well below the Curie 
temperature. The initial choices for the magnetic susceptibilities for nickel and iron were their magnetic susceptibilities at the Curie temperature. These susceptibilities were then adjusted until the sum of the square of the differences between calculated mass fraction in a region and the average measured value in that region was minimized. This occurred when the susceptibilities were approximately 8.6 times the Curie temperature susceptibility. Table 6 lists the reference and adjusted magnetic susceptibilities.

Table 6: Magnetic Susceptibilities (dimensionless)

\begin{tabular}{|l|l|l|}
\hline Element & $\begin{array}{l}\text { Curie Temperature } \\
\text { Susceptibility }\end{array}$ & $\begin{array}{l}\text { Room Temperature } \\
\text { Susceptibility }\end{array}$ \\
\hline Iron & $5.69 \times 10^{-3}$ & $4.89 \times 10^{-2}$ \\
\hline Nickel & $5.5 \times 10^{-4}$ & $4.73 \times 10^{-3}$ \\
\hline Vanadium & $4.51 \times 10^{-4}$ & $4.51 \times 10^{-4}$ \\
\hline
\end{tabular}

There were three experimental cases reported that used a magnetic field strength of $1 \mathrm{~T}$ and the same system inlet conditions as were listed earlier. These three cases, the average of the three cases, and the computed results are presented in Table 7. The decision to match the average of the three cases was based upon the rather large spread of the experimental data for the three cases.

Table 7: Experimental and Calculated Results with a Magnetic Field of $1 \mathrm{~T}$

\begin{tabular}{|l|l|l|l|}
\hline Trial & Product & Middling & Magnefic \\
\hline FCCB-02 & $28.1 \%$ & $27.0 \%$ & $44.8 \%$ \\
\hline FCCB-03 & $27.3 \%$ & $26.6 \%$ & $46.1 \%$ \\
\hline FCCB-05 & $29.9 \%$ & $27.8 \%$ & $42.4 \%$ \\
\hline Average & $28.42 \%$ & $27.14 \%$ & $44.44 \%$ \\
\hline Calculated & $30.75 \%$ & $24.71 \%$ & $44.53 \%$ \\
\hline
\end{tabular}

It appears that the calculated results preferentially remove contaminated catalyst from the Middling region rather than the Product region. This is evident by the comparison of the calculated results with the experimental results. The slightly higher calculated Product particle mass percentage and the slightly lower calculated Middling particle mass percentage indicate that the particles are being moved more strongly from the Middling region than the Product region. The material moved from the Product region will most probably end up in the Middling region thus increasing the exit mass fraction in the Middling region. So, if the Product region mass fraction is high while the Middling mass fraction is low, this clearly shows that the particles are not being magnetically moved out of the Product region.

The reason for this difference is based on the assumption that the magnetic force is linearly proportional to the radial component of the position vector (radius of the bore). Thus, there is little theoretical magnetic force in the center regions of the cylinder. However, the experimental results indicate that there is a significant magnetic force present in the Product region to move some of the contaminated catalyst. Further work should be performed to further characterize the magnetic field effect in this region. 


\subsubsection{Spatial Particle Loading Description}

A description of how the catalyst particles are distributed inside the OGMS will give additional information on how to optimize the device. Presented in Figure 5 is a spatial description of the calculated normalized particle mass flux (number density times velocity) for the validated case of no magnetic field. The two large spikes on the left of the figure are the inlet cells (the locations where the particles enter the OGMS). After entering the OGMS, the particles begin to spread out (mass flux decreases) as is evident by the decrease in the magnitude of the peaks.

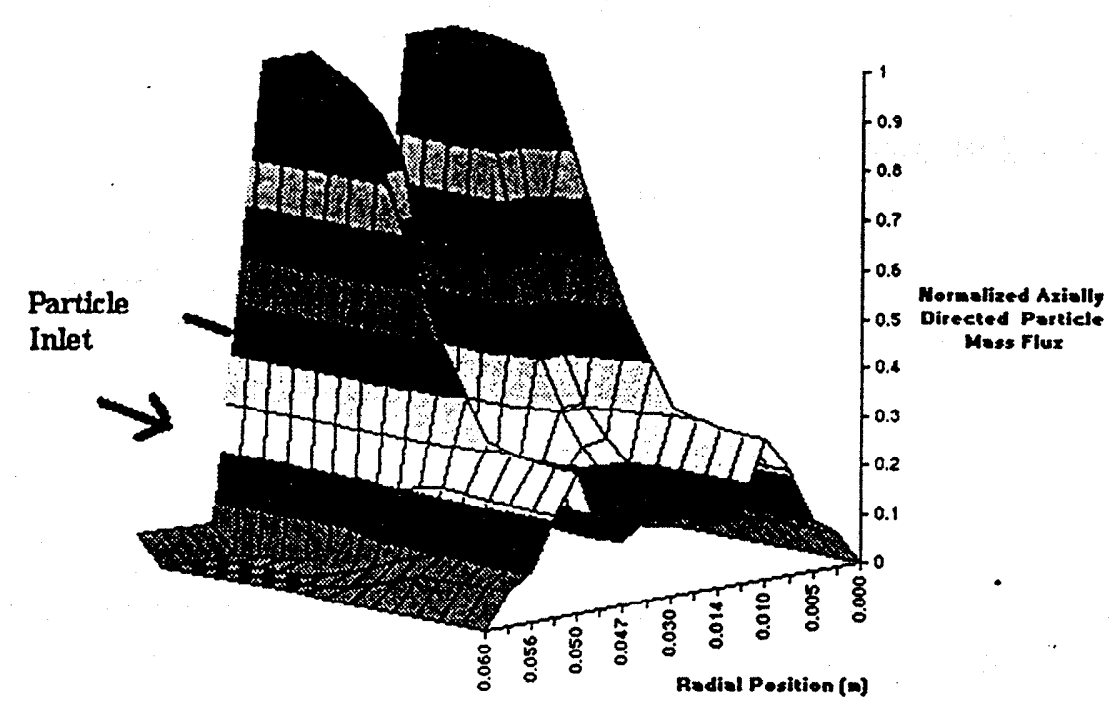

Figure 5: Particle Mass Flux without a Magnetic Field Present

Figure 6 shows the effect of the magnetic field with the same configuration and system properties as in Figure 5. The inlet peak decreases more rapidly due to the magnetic separation. At the exit, the particles begin to amass near the walls of the OGMS. This is seen by the small peaks at the origin and at $r=0.060 \mathrm{~m}$. The magnetic field moves contaminated particles from the center and the middle of the OGMS to outer (Magnetic) region. This is more readily seen in Figure 7 where only the exit particle mass flux profiles are plotted along with the inlet particle mass flux. In Figure 7, the highest peaks indicate the radial locations where the particles are injected. 


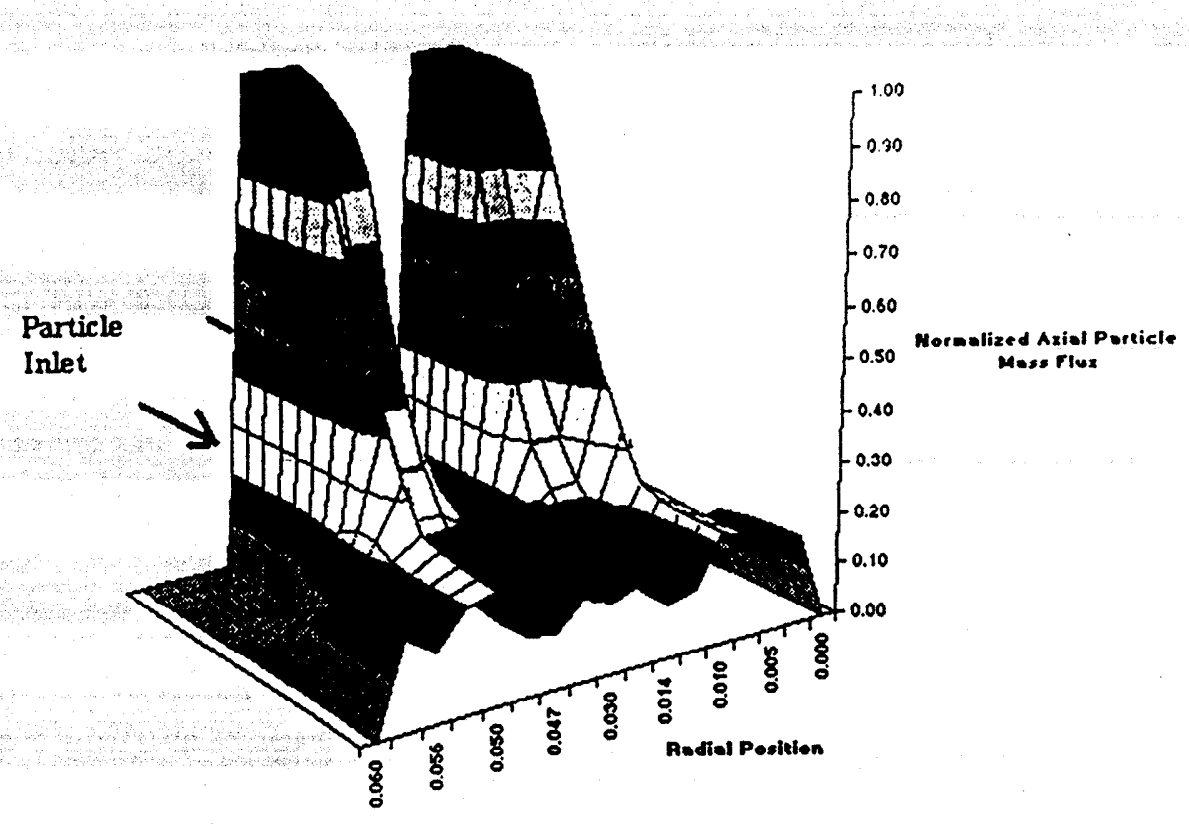

Figure 6: Particle Mass Flux with a Magnetic Field Present

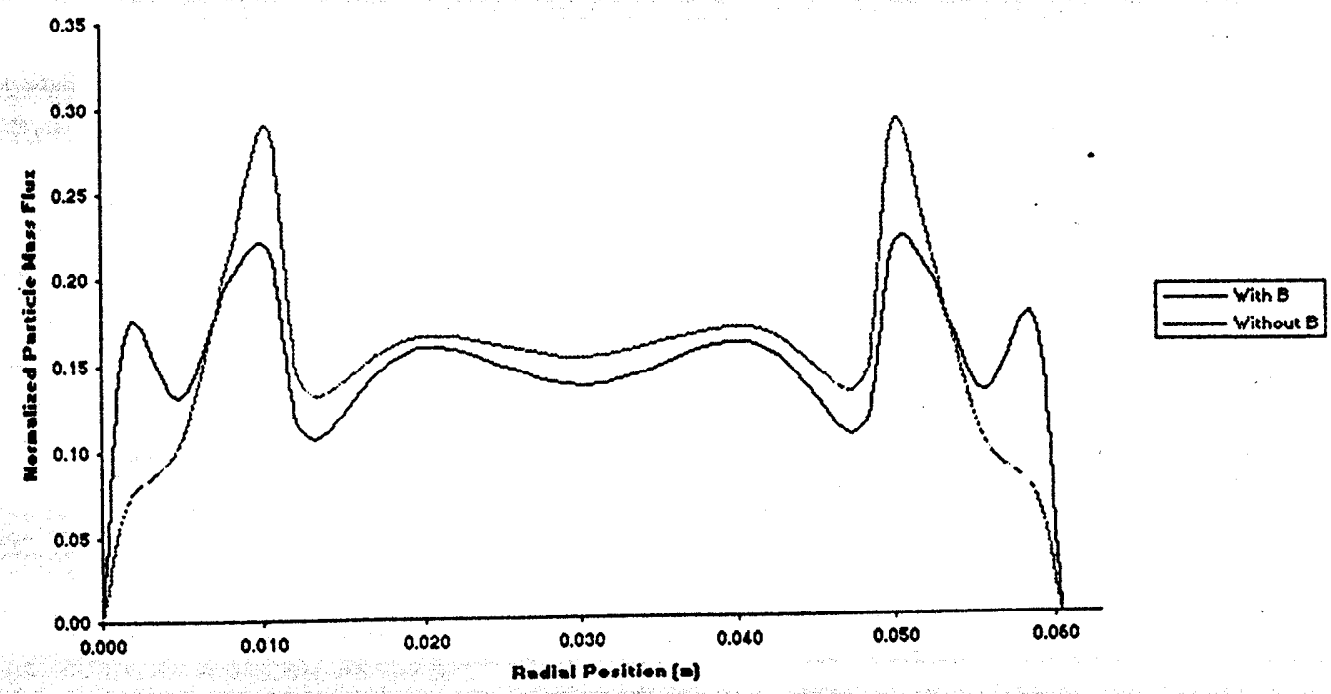

Figure 7: Exit Particle Mass Flux Profiles

\section{Task 3: Scale up and Application Studies}

With the system parameters now set for this configuration and for these material properties, a number of scale up studies were performed to investigate if the separation efficiency could be improved. Again, it should be noted that the same inlet particle spray angles were used for all of these trials. The main parameters of interest are the residence time inside the magnetic field, the distribution of the contamination on the various particle sizes, and the gradient of the magnetic field. 


\subsection{Variation of the Residence Time Inside the Magnetic Field}

It is clear that the longer a particle remains inside the magnetic field. the further the contaminated particles will move towards the wall. There are two mechanisms that will increase the time a particle resides inside the OGMS: changing the forcing gas velocity or changing the length of the bore. Changing the gas flow rate or the length of the bore will produce similar effects.

The forcing gas mass flow rate was allowed to vary while the particle mass flow rate was kept constant. Since the velocities of the particles are proportional to the gas mass flow rate, this variation in the gas mass flow rate corresponds to changing the particles velocity. To keep the particle mass flow rate constant, the particle number density must be adjusted according to the change in the particle velocity. Thus, if the particle velocity was doubled, the particle number density must be halved. This doubling the gas velocity is approximately the same as halving the length of the bore (the particles reside a shorter time inside the OGMS).

Before proceeding, it is necessary to determine a method for evaluating the efficiency of the OGMS. One method would be to examine the difference in the mass fraction in the Magnetic region with the magnetic field on and with the magnetic field off. This would indicate how much additional material has been moved into the Magnetic region. Thus, the larger this difference, the more efficient the OGMS was in (re) moving the contaminated particles. It should be noted that these two computations (with and without magnetic field) must be performed for each trial. The gas velocity and particle size will influence the particle mass flux distribution. This necessitates the repeated calculation of the particle mass flux without a magnetic field present for each case.

Figure 8 is a plot of the separation efficiency as a function of gas velocity (or approximate bore length). The chart clearly shows that higher gas velocities minimize the separation efficiency while minimal gas velocities augment the separation efficiency.

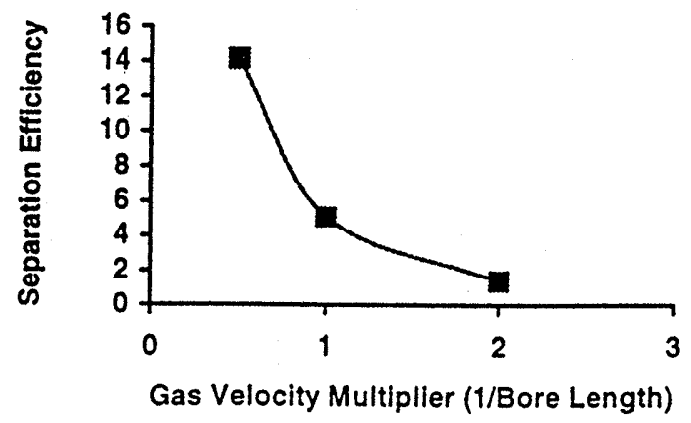

Figure 8: Separation Efficiency as a Function of Gas Velocity or Bore Length

These computational trials were performed with a $1 \mathrm{~T}$ magnetic field in the OGMS. Tables $8 \mathrm{a}, 8 \mathrm{~b}$, and $8 \mathrm{c}$ summarize the results for these numerical experiments with the trials listed under their modification to the forcing gas velocity and the magnetic field strength. 
Table 8a: Effect of Halving the Gas Velocity on Particle Exit Mass Distribution

\begin{tabular}{|l|l|l|l|}
\hline Trial & Product & Middling & Magnetic \\
\hline $0.5 \mathrm{~V}, 1 \mathrm{~T}$ & $27.00 \%$ & $17.56 \%$ & $55.44 \%$ \\
\hline $0.5 \mathrm{~V}, 0 \mathrm{~T}$ & $33.03 \%$ & $25.65 \%$ & $41.31 \%$ \\
\hline Difference & $-6.03 \%$ & $-8.09 \%$ & $+14.13 \%$ \\
\hline Separation Efficiency & & $+14.13 \%$ \\
\hline
\end{tabular}

Table 8b: Effect of Gas Velocity on Particle Exit Mass Distribution

\begin{tabular}{|l|l|l|l|}
\hline Trial & Product & Middling & Magnetic \\
\hline $1.0 \mathrm{~V}, 1 \mathrm{~T}$ & $30.75 \%$ & $24.71 \%$ & $44.53 \%$ \\
\hline $1.0 \mathrm{~V}, 0 \mathrm{~T}$ & $32.63 \%$ & $27.92 \%$ & $39.45 \%$ \\
\hline Difference & $-1.88 \%$ & $-3.21 \%$ & $+5.08 \%$ \\
\hline Separation Efficiency & & $+5.08 \%$ \\
\hline
\end{tabular}

Table 8c: Effect of Doubling the Gas Velocity on Particle Exit Mass Distribution

\begin{tabular}{|l|l|l|l|}
\hline Trial & Product & Middling & Magnetic \\
\hline $2.0 \mathrm{~V}, 1 \mathrm{~T}$ & $31.63 \%$ & $29.93 \%$ & $38.45 \%$ \\
\hline $2.0 \mathrm{~V}, 0 \mathrm{~T}$ & $32.02 \%$ & $30.95 \%$ & $37.04 \%$ \\
\hline Difference & $-0.39 \%$ & $-1.02 \%$ & $+1.41 \%$ \\
\hline Separation Efficiency & & $+1.41 \%$ \\
\hline
\end{tabular}

Tables $8 \mathrm{a}, 8 \mathrm{~b}$, and $8 \mathrm{c}$ clearly show that the lower the gas velocity (the longer the bore), the more pronounced the separation effect. At high gas velocities (short bore length), there is little separation (less than two percent) while with lower gas velocities (roughly equivalent to the estimated free fall velocity of a particle inside the OGMS) or longer bore lengths, the effect of the separation is over fourteen percent. This difference may be explained in terms of residence time. At lower gas and particle velocities, the particles will remain in the system longer and thus be affected more strongly by magnetic force. It seems reasonable that any method that would increase residence time would increase the separation efficiency. The simplest method would appear to be limiting the forcing gas and essentially letting the contaminated catalyst free fall through the OGMS. This would maximize the residence time inside the OGMS by minimizing the gas and particle velocities.

\subsection{Effect of Particle Size and Contamination Distribution}

For this work, five catalyst particle sizes were modeled. It is important to understand how the particle size distribution affects the separation efficiency. In addition, how much contamination is deposited upon each particle size will influence the separation efficiency.

\subsubsection{Particle Size Effects}

Using the trial involving the low gas velocity (discussed in the last section), the effect of particle size was analyzed. This trial had five particle size groups and each size group had only one level of contamination based on weight percent of the particle. The separation efficiency for each particle size group (considered individually) is plotted in Figure 9. This figure shows 
that the efficiency (for this geometry and field strength) increases with particle size until the particle size reaches approximately 40 microns. Any particle size group larger than this size will be separated with approximately the same relative efficiency for this geometry and operating conditions. This indicates that there may exist a maximum separation efficiency for a given geometry, inlet conditions, and magnetic field strength.

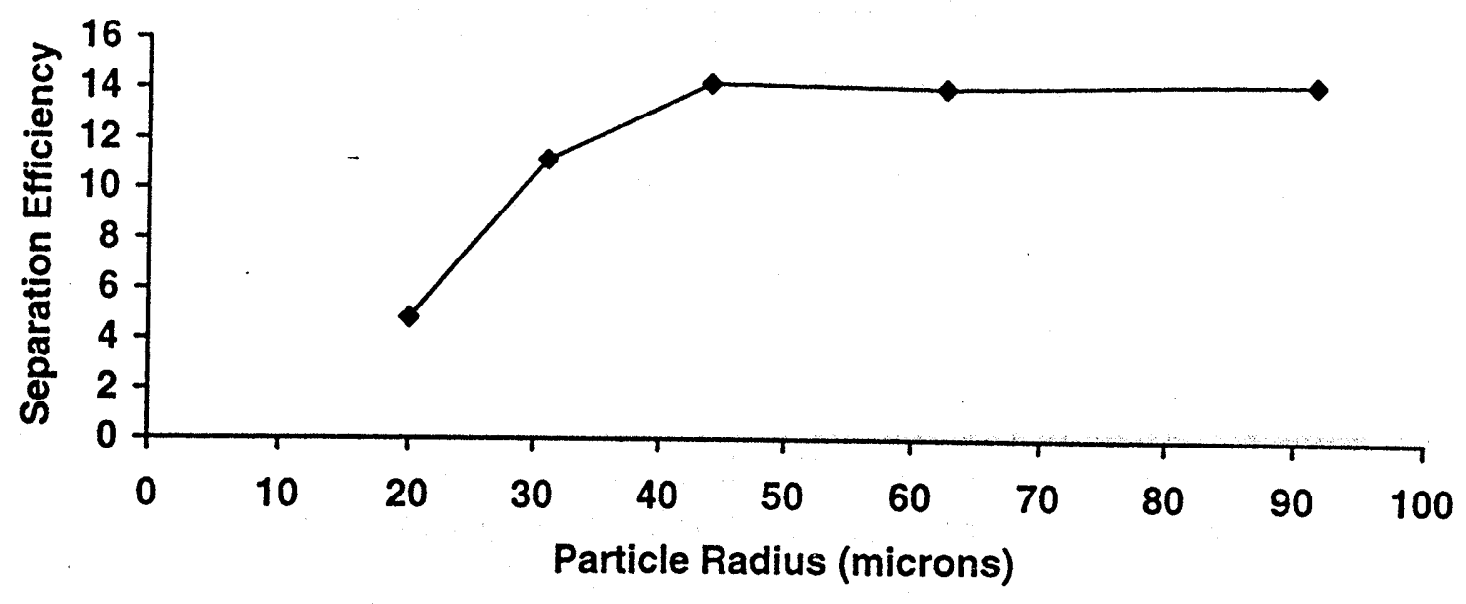

Figure 9: Separation Efficiency as a Function of Particle Size

\subsubsection{Effect of Varying Contamination Levels for a Given Particle Size Group}

In this section, only one particle size is considered and a spectrum of weight percent contamination is assumed. The spectrum must be assumed since the actual weight percent contamination distribution for a given particle size is not known. The assumed spectrum does reproduce the average, measure weight percent contamination. Table 9 gives the three levels of contamination concentration relative to iron. The levels of contamination of nickel and vanadium are in the same weight percent proportion as those of iron. It was assumed that there was an equal distribution of particles among the three groups.

Table 9: Assumed Contamination Spectrum (in weight percent)

\begin{tabular}{|l|l|}
\hline Group & Iron Contamination \\
\hline 1 & $0.0054 \%$ \\
\hline 2 & $0.54 \%$ \\
\hline 3 & $1.08 \%$ \\
\hline
\end{tabular}

A plot of the separation efficiency as a function of the contamination concentration is presented in Figure 10. It can be seen that the particles with higher contamination will be 'preferentially' separated by the OGMS. 


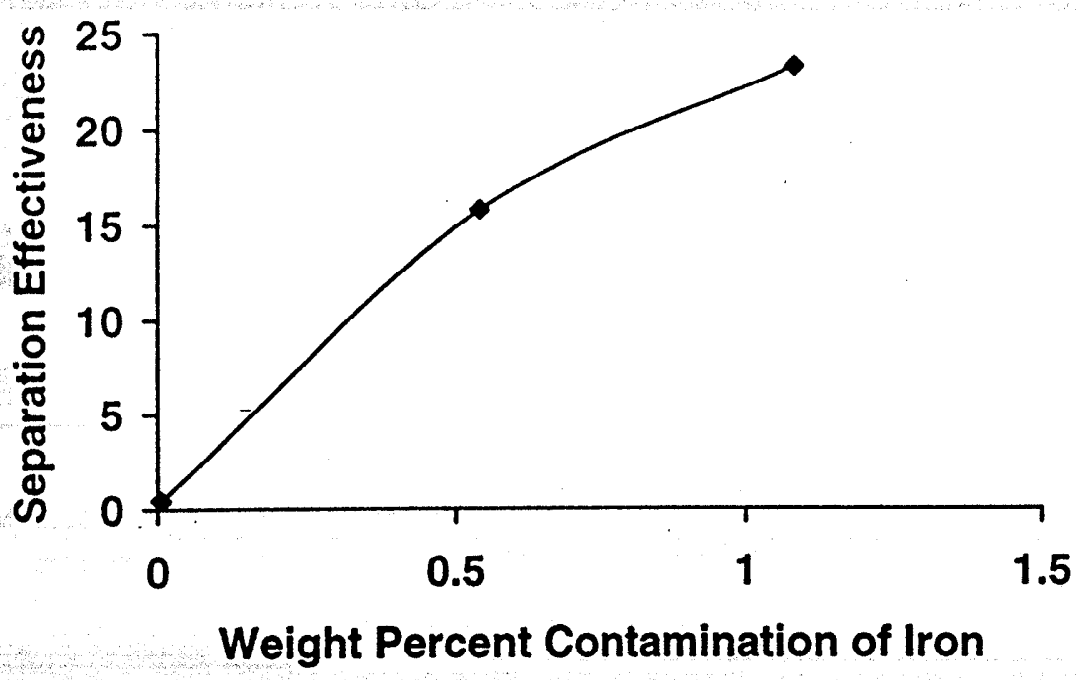

Figure 10: Separation Efficiency as a Function of Contamination Level

\subsection{Variation of Magnetic Field Gradient}

The other major contributing factor to be analyzed is the strength of the magnetic field gradient. The magnetic force is proportional to the square of this gradient. Table 10 indicates how the particles will react to a number of magnetic field gradients. These cases presented in Table 10 are for five particle size groups with one level of contamination using the inlet gas velocity used to validate the code.

Table 10: Effect of Magnetic Field Gradient on Particle Exit Mass Distribution

\begin{tabular}{|l|l|l|l|}
\hline Gradient Strength & Product & Middling & Magnetic \\
\hline No magnetic field & $32.63 \%$ & $27.92 \%$ & $39.45 \%$ \\
\hline $33 \mathrm{~T} / \mathrm{m}$ & $30.75 \%$ & $24.71 \%$ & $44.53 \%$ \\
\hline $61 \mathrm{~T} / \mathrm{m}$ & $27.10 \%$ & $17.76 \%$ & $55.14 \%$ \\
\hline $165 \mathrm{~T} / \mathrm{m}$ & $14.54 \%$ & $7.86 \%$ & $77.60 \%$ \\
\hline
\end{tabular}

It is evident that low magnetic field gradients (less than $33 \mathrm{~T} / \mathrm{m}$ ) will produce no effective separation while a strong magnetic field will create significant separation of the poisoned catalyst. At the present, the maximum OGMS field gradient is $61 \mathrm{~T} / \mathrm{m}$ but even with this gradient, there exists significant separation.

\subsection{Applications of OGMS}

The OGMS was originally intended for separation of contaminated catalysts so that cleaner catalysts may be separated from the contaminated catalysts and re-used in the cracking process. An analysis was made to determine the number of passes through the OGMS that would be necessary to remove enough contamination which would allow the remaining catalyst 
to be re-used. Also, it has been proposed to use the OGMS technology to magnetically separate radioactive waste streams. This application has also been briefly analyzed.

\subsubsection{Number of passes necessary for catalyst purification}

According to industry sources [4], it is believed that an $80 \%$ discard rate may allow the economic feasibility of the OGMS technology. It is assumed that the contaminated catalysts collected in the Magnetic region would be discarded. Those catalysts remaining in the Middling and the Product regions would then be re-inserted into the OGMS. This process would then be repeated until $80 \%$ of the catalysts have been discarded. The contamination level of the remaining catalysts was then calculated.

To perform this analysis, one particle size was used with three levels of contamination (as was discussed earlier). The average inlet weight percent contamination was approximately $0.54 \%$. The exit weight percent of contamination was calculated for both the Magnetic region (which was discarded) and for the Product and Middling regions (which were then recycled). These calculations are presented in Tables $11 \mathrm{a}$ and $11 \mathrm{~b}$. As can be seen from the tables, with an eighty percent discard rate the resulting purified catalyst will have a weight percent contamination of $0.44 \%$. This amounts to a $18.5 \%$ reduction in the weight percent contamination after four passes through the OGMS.

Figure 11 depicts how the OGMS will separate each of the levels of contamination as a function of the number of passes through the device. This figure shows that the remaining mass fraction of the heavily contaminated particles decreases more quickly than the mass fraction of those particles that are not so contaminated. Of course, this is also reflected in Table 11 where one can see that the weight percent contamination for the saved portion is decreasing with the number of passes.

Table 11a: Weight Percent Contamination Remaining for Repeated Purification Passes Through the OGMS

\begin{tabular}{|l|l|l|}
\hline Pass & Discarded & Saved \\
\hline 1 & $0.5957 \%$ & $0.5161 \%$ \\
\hline 2 & $0.5694 \%$ & $0.4893 \%$ \\
\hline 3 & $0.5427 \%$ & $0.4626 \%$ \\
\hline 4 & $0.5160 \%$ & $0.4364 \%$ \\
\hline
\end{tabular}

Table 11b: Mass Fraction Remaining for Repeated Purification Passes Through the OGMS

\begin{tabular}{|l|l|}
\hline Pass & $\begin{array}{l}\text { Mass Fraction Remaining } \\
\text { of Original Feed }\end{array}$ \\
\hline 1 & $67.74 \%$ \\
\hline 2 & $46.60 \%$ \\
\hline 3 & $31.37 \%$ \\
\hline 4 & $21.47 \%$ \\
\hline
\end{tabular}




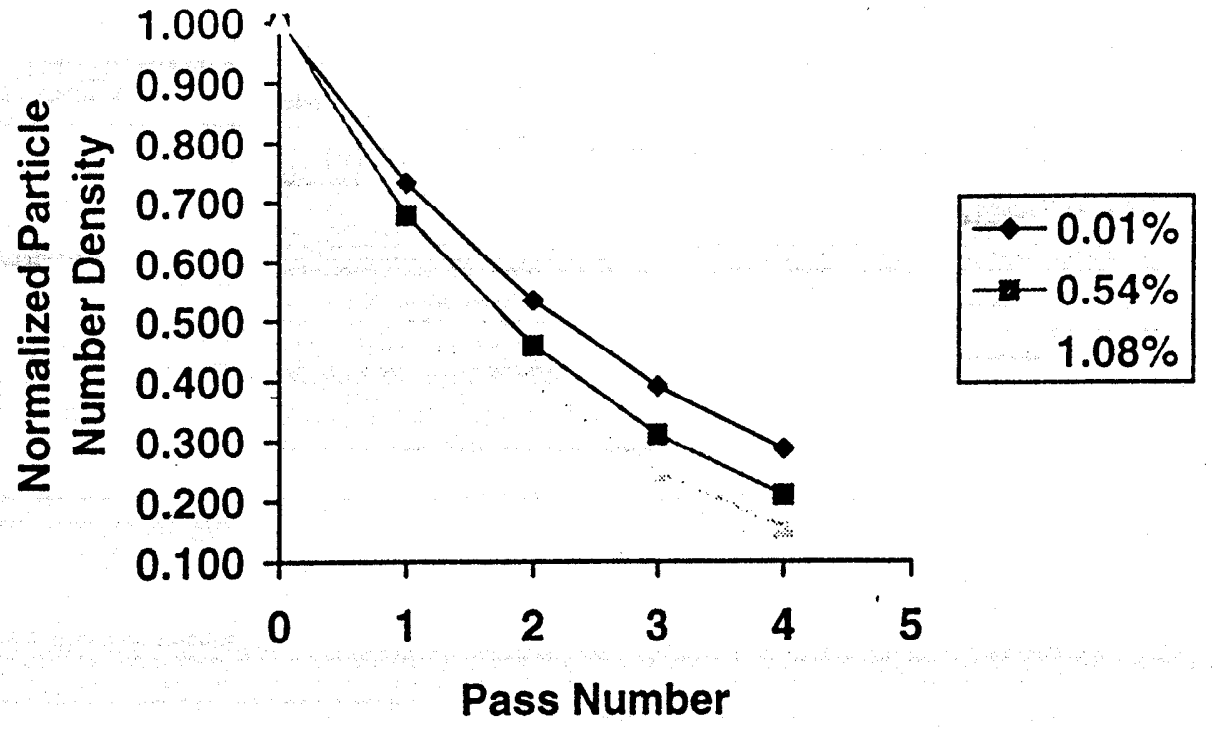

Figure 11: Normalized Particle Number Density as a Function of Contamination Level and Number of Passes Through the OGMS

\subsubsection{Application of the OGMS technology to radioactive waste separation}

In addition to modeling the magnetic separation of contaminated catalyst, this work also investigated the possibility of using the OGMS to separate out plutonium oxide from a radioactive waste stream. Using five particle size groups and the material properties listed in Table 11 along with the maximum field strength and minimum gas velocity, ICRKFLO computed the results presented in Table 12 along with the no magnetic field results.

Table 11: Material Properties for Plutonium Oxide Removal

\begin{tabular}{|l|l|}
\hline Density $\mathrm{g} / \mathrm{cm}^{3}$ & 11.46 \\
\hline Magnetic Susceptibility & $7.60 \times 10^{-4}$ \\
\hline Assumed weight percent contamination & $5 \%$ \\
\hline
\end{tabular}

Table 12: Particle Exit Mass Distribution for Plutonium Oxide Removal

\begin{tabular}{|l|l|l|l|}
\hline & Product & Middling & Magnetic \\
\hline $61 \mathrm{~T} / \mathrm{m}$ field gradient & $30.58 \%$ & $22.27 \%$ & $47.16 \%$ \\
\hline No magnetic field & $32.63 \%$ & $27.92 \%$ & $39.45 \%$ \\
\hline
\end{tabular}

Naturally, the effect of separation will increase with a stronger magnetic field or with a higher weight percentage of contamination. The amount of plutonium separated becomes significant at the highest field strength with a minimal gas inlet velocity. 


\subsubsection{Alternate OGMS Design}

As was mentioned earlier, it might be beneficial to insert the contaminated catalyst into the Product region of the OGMS instead of the Middling region. This would allow the separation of the most contaminated catalysts in the Magnetic region. A brief analysis was done of this design modification using one particle size with three levels of contamination (as in Section 3.4.1). The magnetic field was $2 \mathrm{~T}$ and the gas velocity was the same as the original conditions. Figure 12 depicts the exit particle volume fraction. It is clear that with this design modification, the majority of the particles will remain in the center of the devicc thus allowing 'space' for the magnetic field to separate the contaminated particles. Since less material is moved into the Magnetic region, more passes may be performed to purify the catalyst. However, additional analysis and experimental verification are necessary to validate this design modification.

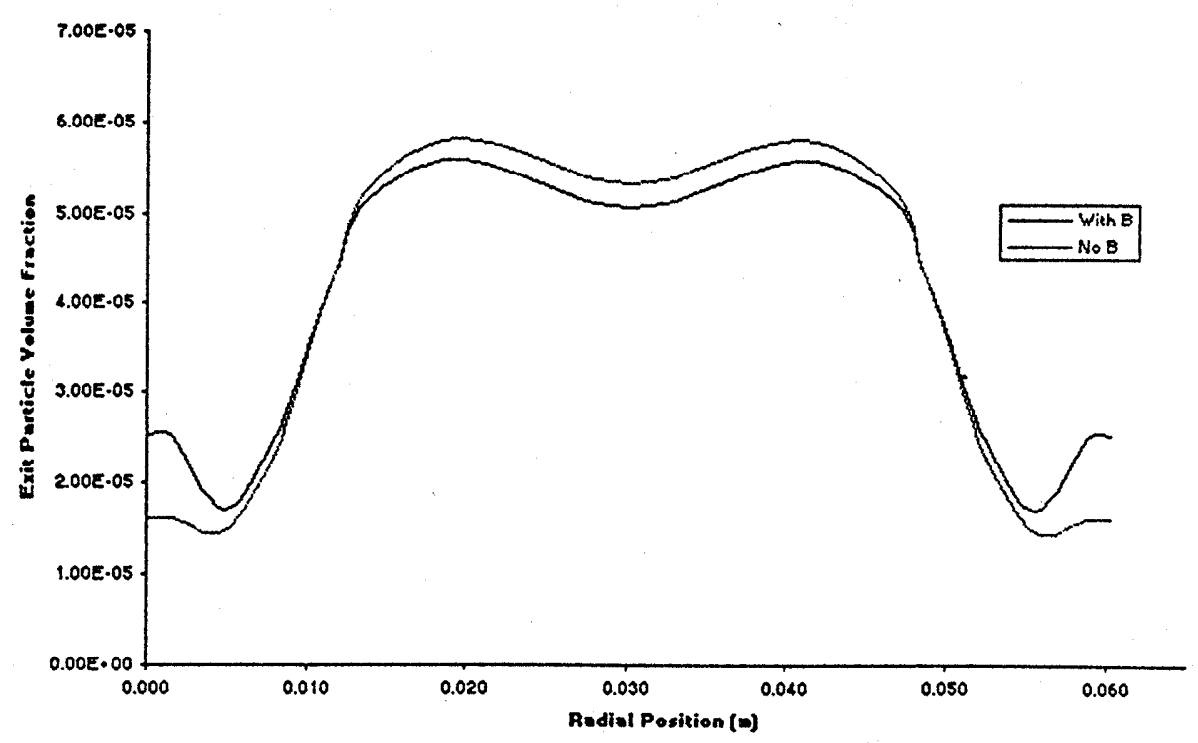

Figure 12: Exit Particle Volume Fraction for Modified OGMS

Another potential improvement to the OGMS separation efficiency would allow the forcing gas to enter along the entire inlet diameter of the OGMS, not just the Middling region. Having the forcing gas present along the width of the OGMS would reduce the spray of the particles as they enter the device since the forcing gas would push the particles through the OGMS rather than allowing them to diffuse. This design modification was briefly analyzed and the effect of adding the forcing gas minimized the spread of the catalyst as it traveled down the length of the OGMS.

For this modification, five particle size groups were used along with three levels of contamination for each particle size. The average inlet weight contamination was $0.592 \%$. Using the OGMS at the maximum current magnetic field gradient resulted in the removal of $2.246 \%$ of the inlet catalyst mass. This removed catalyst mass had an average weight contamination of $0.955 \%$. For all particle sizes, the OGMS removed less than $1 \%$ of those particles with very low levels of contamination while the device removed between $3.4 \%$ to $5.7 \%$ of the highly contaminated particles. Clearly, the location of the inlet of the catalyst is a critical parameter for the efficient operation of the OGMS. 
To determine an optimal location for the catalyst inlet location, a systematic study was performed on the effect of varying this inlet location. With the same particle and gas mass flow rates as described above, the inlet region was concentrated to a relatively narrow point instead of a region as is currently employed in the OGMS. It should be noted that since the inlet location was highly localized, it was impossible to computationally employ spray angles. The fraction of the highly contaminated inlet mass that was collected in a narrow region at the outer radius of the bore was used as a gauge to determine the effectiveness of the inlet location. As the inlet region began to near the outer radius of the bore, it was noted that an increasingly larger fraction of the 'clean' catalyst began to amass in the collection region. This effect was viewed as detrimental to the overall value of the device. To compensate for this loss of good catalyst, the overall effectiveness of the OGMS was analyzed by examining the fraction of the highly contaminated mass removed minus the fraction of the slightly contaminated mass removed. These results are presented in Figure 13.

Figure 13 clearly indicates that there exists a preferred region for the catalyst input to the OGMS. With the given system geometry and field strengths, the optimal inlet position is approximately located where the present Middling region is located. With the high magnetic field and the additional forcing gas, the OGMS would be able to effectively separate most of the contaminated catalyst. Again, it is worth reminding that there are no spray angles associated with this analysis. It is expected that the amount of clean catalyst removed will increase do the presence of the spray angles. This would reduce the efficiency of the OGMS and it would probably shift the peak in the figure below closer to the center of the bore.

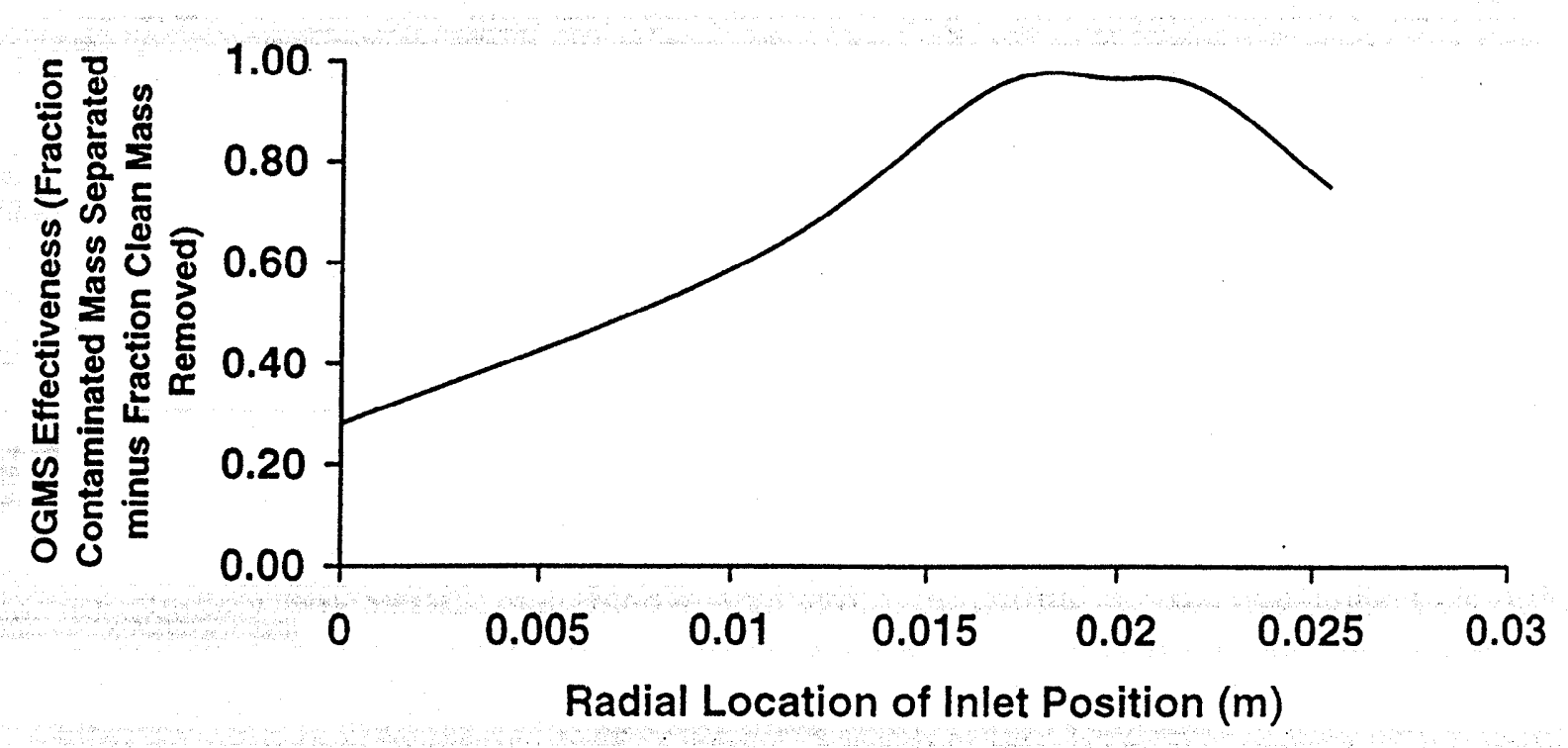

Figure 13: Optimal Location for Inlet Annulus

\section{Conclusion}

The results from the studies conducted on the OGMS suggest the technology holds substantial promise for benefication spent fluid catalytic cracking catalysts. Benefication would reduce the amount of new catalyst needed by the refinery industry and it would minimize the 
amount of the heary metal contaminated catalysts (hazardous waste) requiring disposial. This would result in tremendous savings to the refining industry.

The purpose of this investigation was to numerically model, to validate, and to perform a sensitivity study of the major parameters involved in the scale up of the OGMS. ICRKFLO was modified to allow for the inclusion of the magnetic force. This modified code was then validated against experimental data. Once it was assured that the results from the code provided a reasonable description of the system, parametric studies were performed. The results from these studies indicate that decreasing the velocity of the forcing gas (thus increasing the residence time) and increasing the magnetic field gradient would enhance the performance of the system to a point where the system can be effectively used on an industrial level. It was also shown that the heavily contaminated particles and the larger sized particles were preferentially separated when compared to those smaller and less contaminated particles.

Several preliminary design studies/modifications were performed to determine methods of increasing the efficiency of contamination removal. The initial OGMS design evaluated was shown to be capable of removing $18.5 \%$ of the heavy metal contamination after four passes. Further analysis indicated that the separation efficiency can be increased. One such modification would be the introduction of the forcing gas along the breadth of the device. It was determined that this modification would reduce the spread of the particles due to spray and thus would increase the efficiency of the unit in selectively removing contaminated particles.

It was also determined that an optimal location exists for the injection of the particles into the OGMS. The results obtained from this study suggest that an optimal OGMS system can be effectively used to beneficate spent FCC catalysts.

In addition to the analysis of spent fluid catalytic cracking catalysts, preliminary work was performed to determine if this OGMS technology was applicable to the separation of radioactive waste. It was shown that the OGMS is capable of effectively separating plutonium oxide from a waste stream with the current design.

\section{Recommendations}

More extensive design studies are needed to optimize the OGMS separation efficiency. This work has explored opportunities to optimize performance that need further elaboration, specifically the location of the optimal particle inlet location and the introduction of the entraining gas across the bore width. Also, additional work needs to be performed to more properly characterize the contamination weight distribution as a function of particle size in the contaminated catalysts. Such further investigations would demonstrate the viability of this technology for beneficating spent FCC catalysts.

An investigation also needs to be undertaken to establish the true nature of the magnetic field inside the OGMS. The assumption that the magnetic field is proportional to the gradient of the magnetic field times the radius may be in error. This assumed functional relationship is correct for a pure quadropole magnet. However, the configuration inside the OGMS includes four aluminum tubes that restrict access to low magnetic field areas. These tubes may alter the functional relationship for the magnetic field in the bore. The magnetic field distribution inside the OGMS needs to be experimentally verified. 
References:

1. Doctor, R.D., C.D. Livengood, C. Swietlik, and K. Foote, "Investigation of OpenGradient Magnetic Separation for Illinois Coals," in Processing and Utilization of High Sulfur Coals II (Proc. Second International Cong., Sept.-Oct. 1987, Carbondale, IL); Y. Chugh and R. Caudle, eds., Elsevier Science Publishing Co., Inc., pp. 149-160 (1987).

2. Chang, S.L., S.A. Lottes, C.Q. Zhou, and M. Petrick, "A Hybrid Technique for Coupling Chemical Kinetics and Hydrodynamics Computations in Multi-Phase Reacting Flow Systems," Proceedings of the ASME Heat Transfer Division, International Mechanical Engineering Congress and Exposition, Dallas, TX (Nov. 16-21, 1997).

3. Private communication with R. Doctor concerning UOP experimental data, November 1997. 4. Private communication with R. Doctor concerning Amoco experimental data, November
1997.

5. Touloukian, Y.S., and C.Y. Ho (eds.), Properties of Selected Ferrous Alloying Metals, Vol. III-1 of the McGraw Hill/CINDAS Data Series on Material Properties, McGraw-Hill Book Company, New York. 


\section{Sensitivity Analysis}

- computational grid

- parameter sensitivity

- contamination level

- residence time

- particle size 


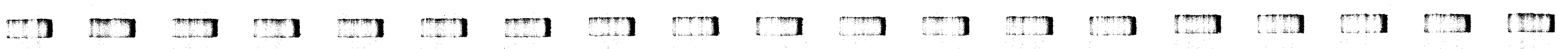

\section{Effects of Residence Time on Separation}

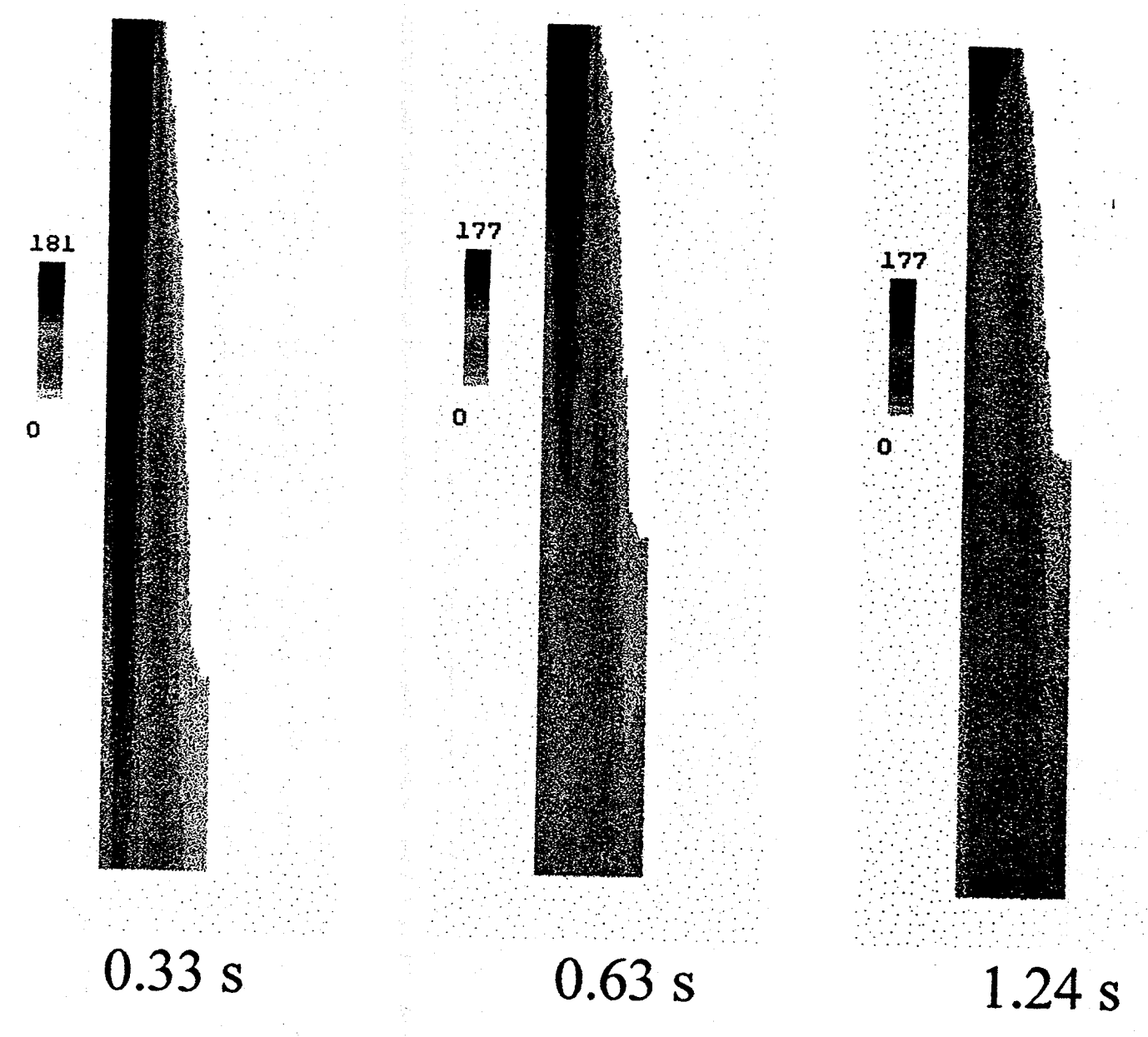


APPENDIX V

OGMS PROCEDURES AND DOCUMENTATION 
日

2

$E$

I

I.

2

I

I

E.

$E$

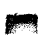

$E$

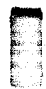

5

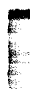

1

E

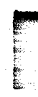

2

F

1 
This section provides auxiliary information regarding the configuration of the OGMS system, piping diagrams, transfer line diagrams, and standard operating procedures. The first section of this appendix provides real photos and representations of the unit so that one is familiar with dimensions (Figures $4 \mathrm{~A}$ and $4 \mathrm{~B}$ ) and the location of important access valves, ports, and lines (Figures $4 \mathrm{C}$ and $4 \mathrm{D}$ ). Following this, the standard operating procedures for the magnet cooldown and slurry pump are provided with figures (Figures $4 \mathrm{E}$ and $4 \mathrm{~F}$, respectively). Finally, pressure calculations for the pumping system are provided.

\section{OGMS Unit at Argonne National Laboratory}

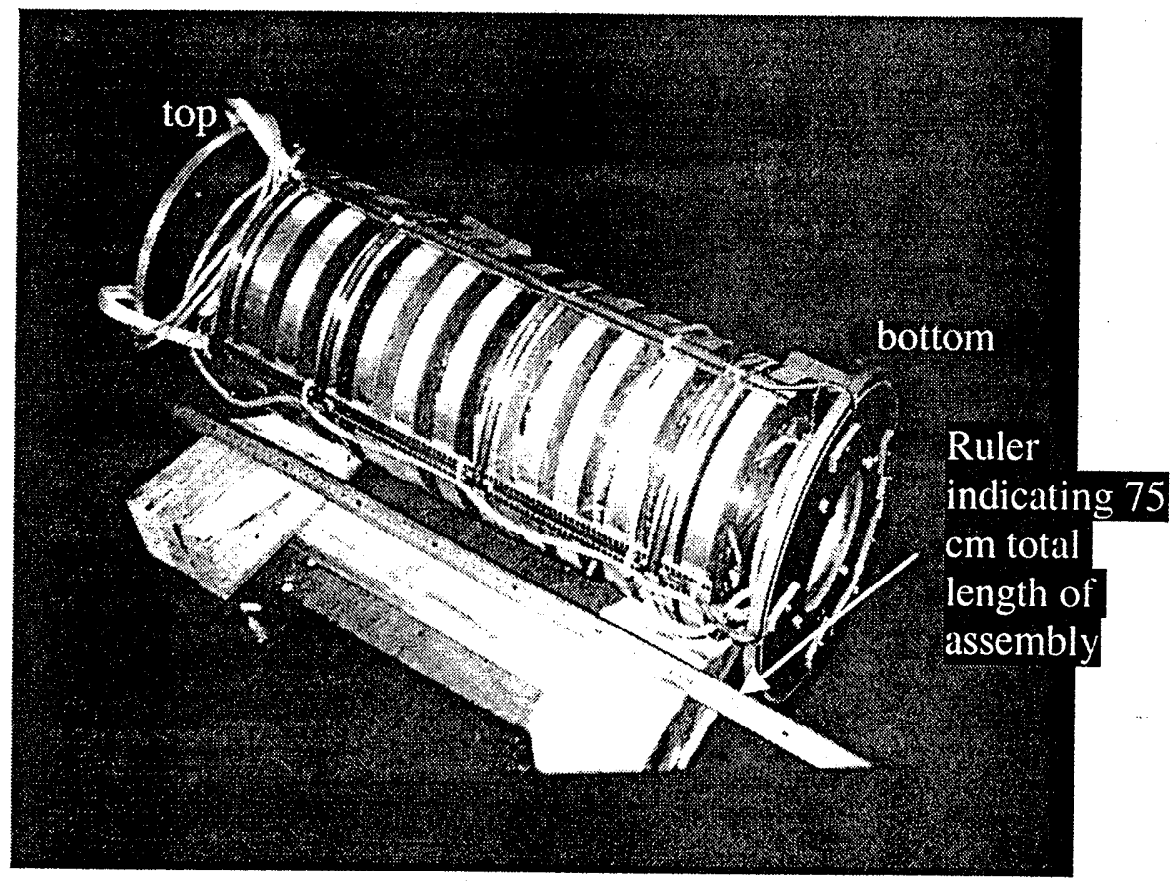

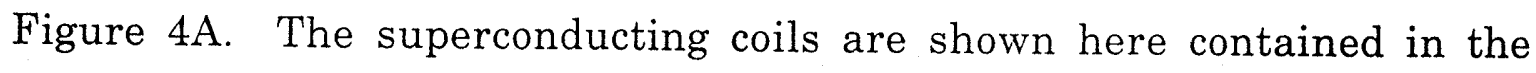
aluminum housing. The meter stick shows that the assembly is $75 \mathrm{~cm}$ in length including support apparatus. The bottom of the magnet sets at the bottom of the cryostat container. 


\section{SUPERCONDUGING QUADRUPOLE MACNEIC FAD}

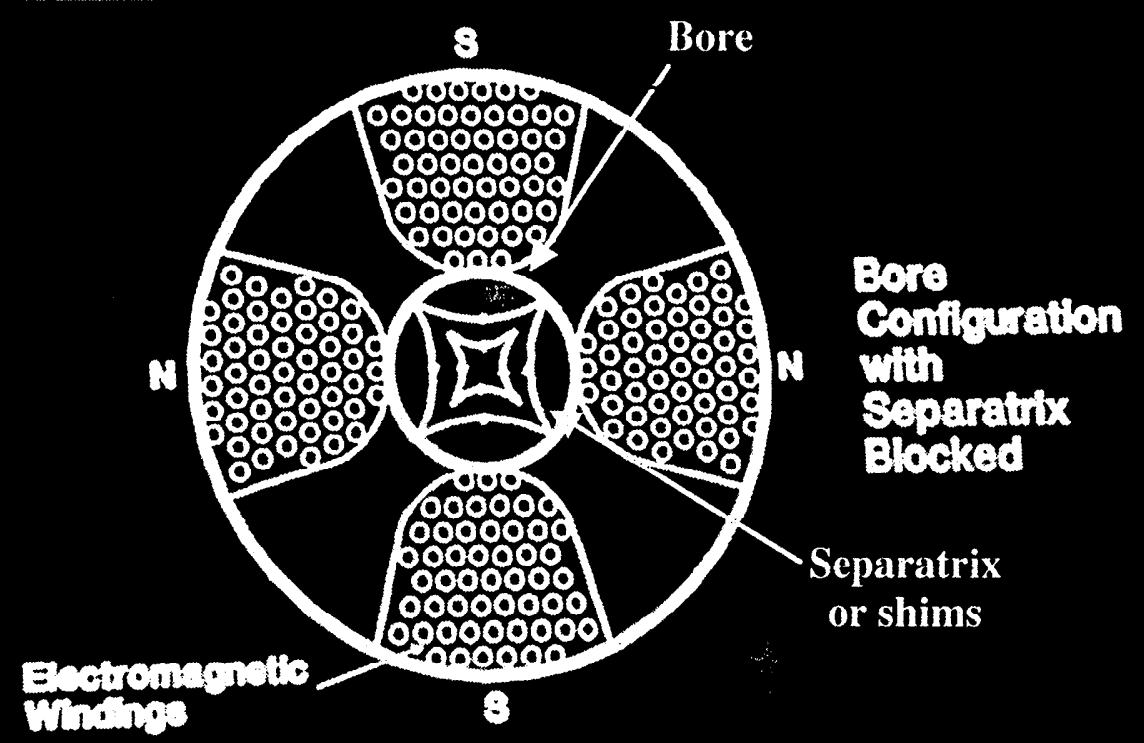

Figure 4B. Schematic representation of the bore configuration for the OGMS unit showing the location of the electromagnetic windings. The separatrix or shims are centered at $\theta=\pi / 4,3 \pi / 4,5 \pi / 4$, and $7 \pi / 4$ where $q=0$ is located at the center of any of the electromagnetic windings 


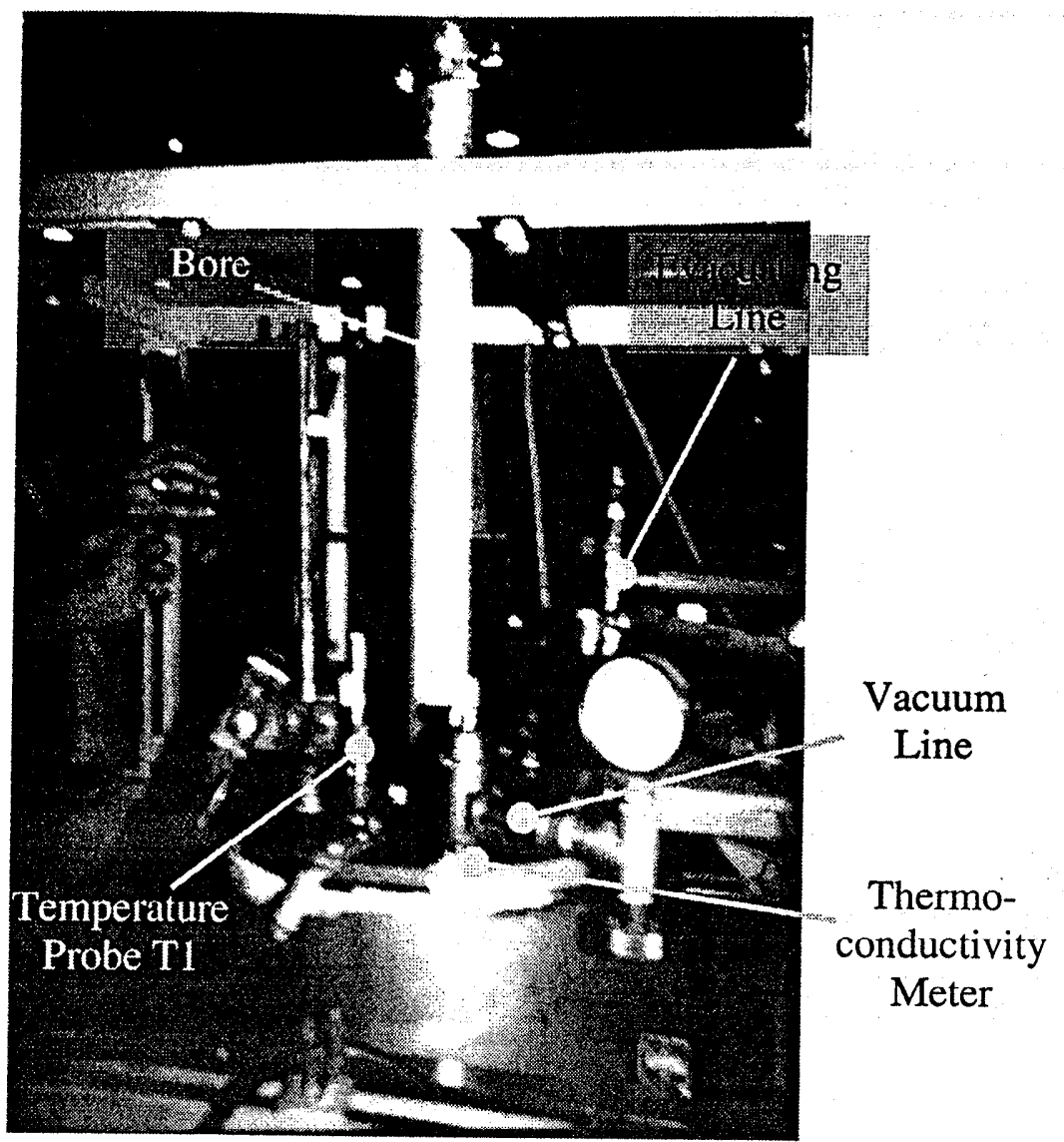

Figure 4C. View of the top of the OGMS insulating cap as seen from the west side of assembly showing the multiple lines penetrating into the cryostat and magnet housing. 


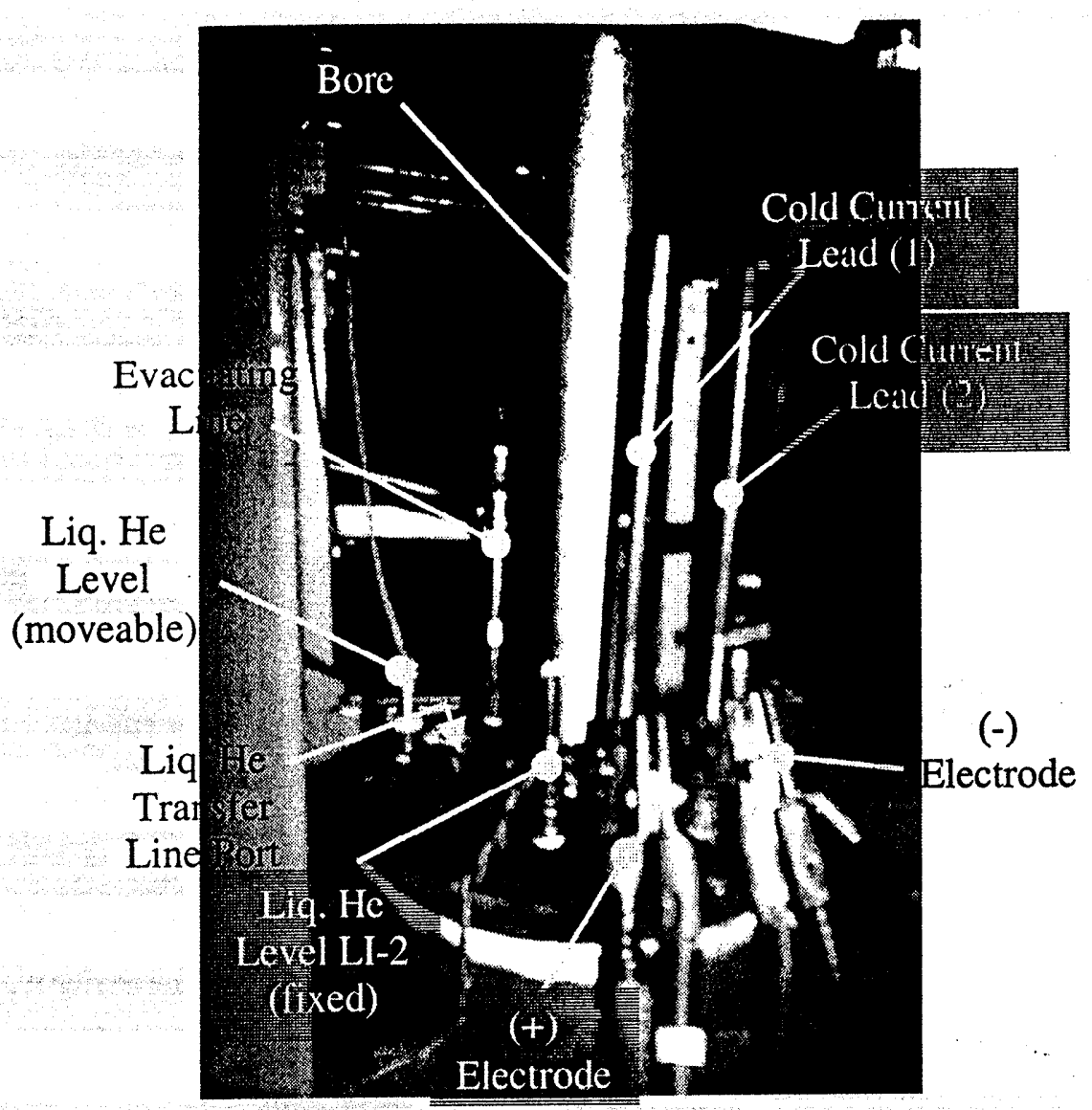

Figure 4D. View of the top of the OGMS insulating cap as seen from the north side of assembly showing the multiple lines penetrating into the cryostat and magnet housing. 


\section{OGMS Superconducting Quadrupole Magnet Cryostat Liquid Helium Filling Procedure}

For the following procedures reference will be made to Figure $4 \mathrm{E}$ which contains the valve and connection numbers corresponding to the OGMS unit in Building 370 at ANL.

\section{Prefilling Conditions}

a) Connect all magnet-related electrical and instrumentation connections, if not connected already, and verify sound connections.

b) Pump down the cryostat insulating vacuum space and valve off by shutting valve \#7 (V7). This will remove the air and moisture from cryostat to prevent freezing during cooldown.

c) Check to make sure ALL cryostat ports are either filled or closed off.

d) Evacuate the liquid helium ( $\mathrm{LHe}$ ) transfer line insulating vacuum by connecting vacuum line to valve on transfer line.

\section{Pump and Purge}

a) Close all helium space isolation valves (V1, V2, V3, V5, V6) so that the He will purge the proper tubing during the purge stage.

b) Connect mechanical pump to pump out connection (labeled C-1). This will remove air and moisture from the LHe feed lines so no freezing occurs.

c) Start pump and run for a minimum of 15 minutes.

d) Open pumpdown valve V1 to begin the pumpdown of the LHe feed lines.

e) Pump for 10 minutes or so. Close V1 but keep vacuum pump running. The following stages are used to ensure complete air and moisture removal in the system.

f) Backfill with gaseous helium (GHe) to $3 \mathrm{psig}$ by opening V3. This low flowrate will slowly remove any moisture and air left in vessel cryostat and any of the feed and instrument lines.

g) Crack open instrument valves V5 and V6 for a few minutes. This will ensure the presence of He in these lines.

h) Close V5 and V6. 
i) Close backfill valve V3.

j) Repeat 2d-f for 2 additional cycles.

k) After repeating steps, leave V3 open and set the GHe regulator to 1 psig to allow a positive pressure of $\mathrm{He}$ in the system.

\section{LHe Transfer}

a) Insert measuring stick or probe into the large dewar containing $\mathrm{LHe}$ and record the baseline liquid level. This will provide a means of determining the total amount of LHe that will be dispensed.

b) Position the LHe transfer line. This will require at least 3 people as one will control the end to be inserted into the dewar, one will support the long vacuum hose, and one will position the end to be inserted into the OGMS cryostat.

c) Insert transfer line part way into the supply dewar. One must insert this end quickly but in a controlled fashion so that freezing does not occur at the insert port of the dewar and impede proper insertion depth. Caution: GHe will be generated. Monitor and control dewar pressure rise.

d) Purge the transfer line with the GHe from the supply dewar for a few minutes to ensure no air in line. There should be a stream of GHe at the cryostat end of the transfer line.

e) Remove cryostat LHe transfer port plug. There should be no fear in introducing air into the system since the port will be purged by the magnet purge gas (see $2 k$ ).

f) Insert transfer line to the bottom of the magnet LHe space and raise -1 inch. Tighten port nut.

g) Close backfill valve V3. This will cut the GHe purge gas off from $2 k$ ).

h) Open cooldown valves V1, V2, and the current lead valves V5, V6 to initiate LHe transfer.

i) Set dewar pressure to 3 psig by adjusting the regulator on the $\mathrm{GHe}$ cylinder.

j) Monitor cryostat liquid level with the level probe LI-2.

k) When level reaches full (??\%) initiate stop transfer operations. 
4. Stop Transfer Operations
a) Close cooldown valves V1 and V2.
b) Isolate supply dewar GHe pressurizing cylinder.
c) Blowdown LHe supply dewar to 1psig.
d) Raise the supply end of the transfer line to the standby elevation.
e) Raise the delivery end of the transfer line to the refill elevation.
f) The transfer line will_remain purged under these conditions.

\section{LHe Refill}

a) When the liquid level on LI-2 drops and requires refilling (??\%) the cryostat should be refilled.

b) Open supply dewar GHe pressurization cylinder isolation valve. The regulator should be wet to 3 psig.

c) Lower supply end of transfer line into the supply dewar. Control supply dewar pressure to 3psig.

d) Transfer should begin within a few minutes. The cooldown valves V1 and V2 may have to be opened to accelerate this process.

e) Fill until LI-2 indicates full as in 3k).

f) Repeat step 4 to terminate. 


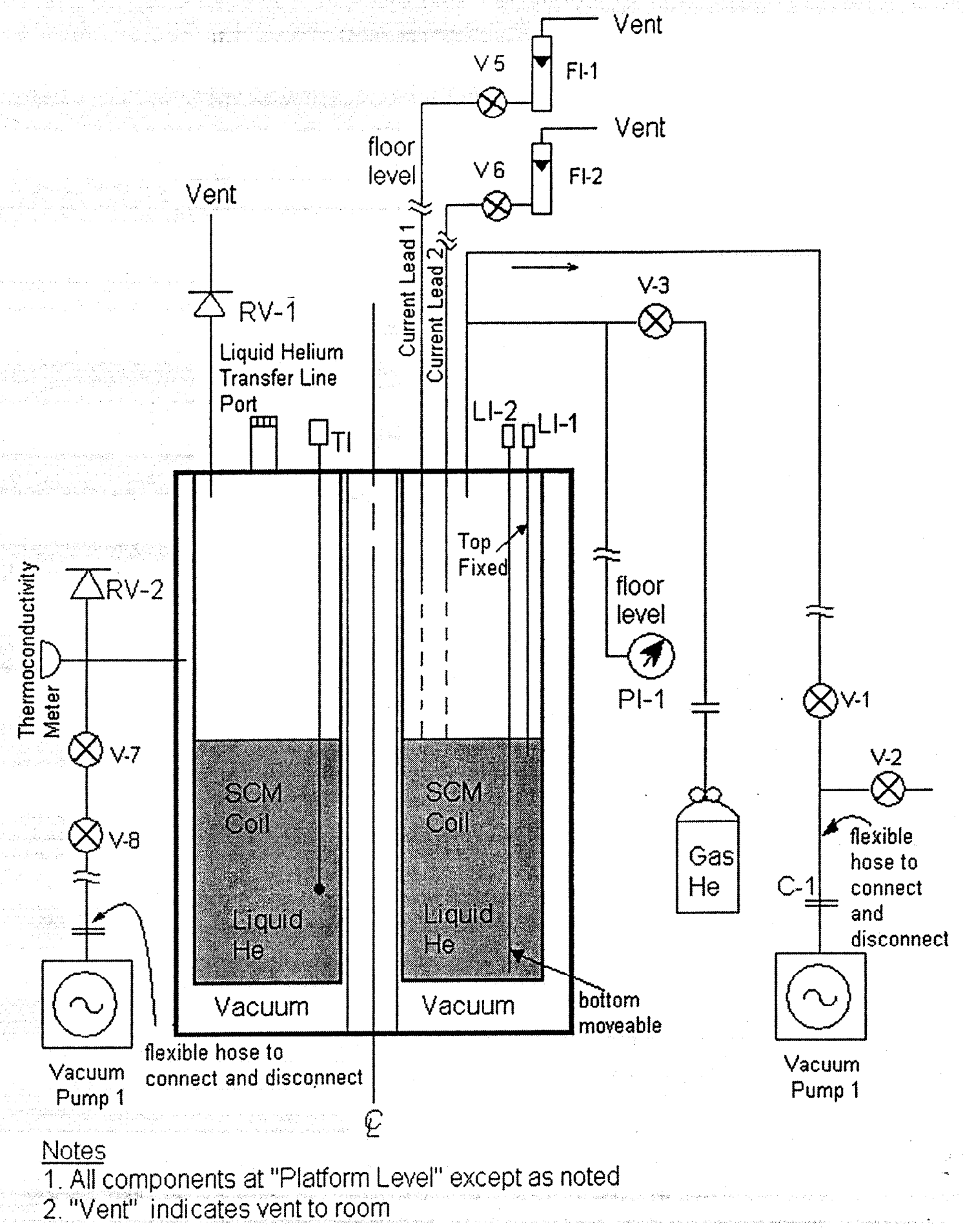

Figure 4E. Operations diagram for cooling the superconducting magnet. 

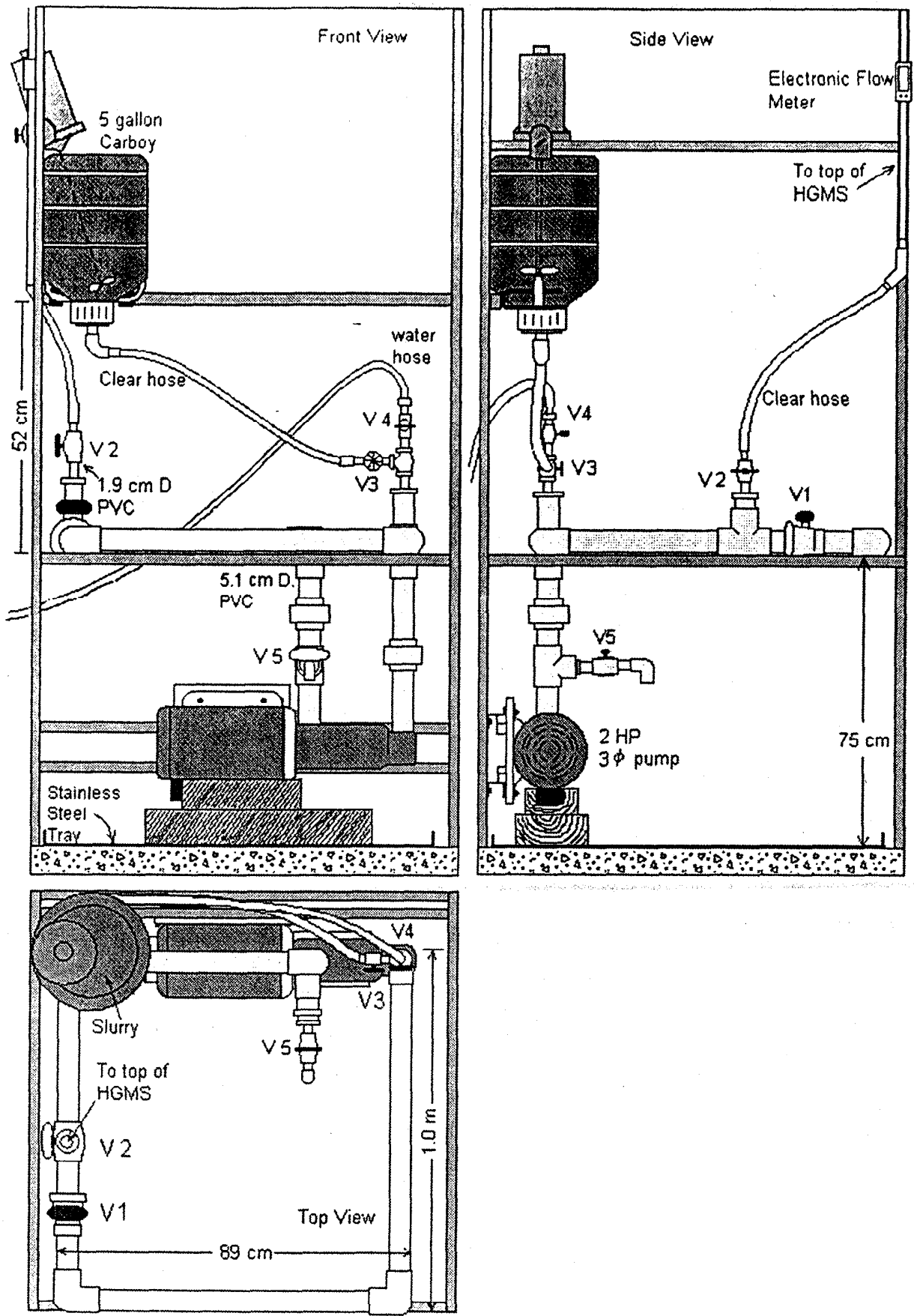

Figure $4 \mathrm{~F}$. Operations diagram for the pumping of slurry waste feeds through the OGMS unit. 


\section{Procedure for Pumping Liquids Through the OGMS Apparatus}

For the procedures below, valve numbers and identifications refer to Figure 4F.

1. Close all valves (V1, V2, V3, V4, V5). Connect water hose to valve V-4 as shown in Figures $4 \mathrm{~F}$.

2. Close off and make sure that the hoses marked as "magnetic," "middlings," and "product", at the outlet of OGMS unit, discharge in containers of at least 5-gallon capacity.

3. Open valves V-4 and V-1. Slowly open valve V-2. If valve V-2 is opened fast, the resulting hydraulic shock will damage the flow meter.

4. Let water flow to the top of the OGMS apparatus. Check for leaks inside the pipe that runs through the cryostat. If there is a leak, raise the splitter assembly piping that comes out at the bottom of the cryostat to compress the O-rings at the phenolic coupling, and tighten the nut at the clamp holding the 2" pipe (see Figure VIII-11).

5. When the entire system is filled with water, close valve V-2.

6. Fill the 5-gallon container with the slurry to be processed and start the stirrer and adjust to desired speed.

7. Make sure valve V-1 is fully open.

8. Start the 2 HP progressive cavity pump.

9. Carefully open valve V-2, and adjust to the desired flow. The electronic meter is activated by pressing the "Display" button. The meter begins showing Calibration A. By pressing button labeled "Display," for more than two seconds, the meter shows Calibration B. Make sure to work in Calibration B. Calibration B was obtained by running water through the meter. This meter can alternatively display flow rate or total flow, by pressing the "Display" button.

10. Open valve V-3 and adjust to the desired flow of slurry.

11. After finishing the experiment, the system can be flushed, and drained through valve $\mathrm{V}-5$. 


\section{Fluid Pressure Calculations for the Slurry Pumping System}

The fluid pressure calculations follow by applying Bernoulli's equation (Eq. 41) for the energy balance between points 1 and 2 in the diagram we have,

$$
Z_{1}+\frac{\bar{v}_{1}^{2}}{2 g_{c}}+\frac{P_{1}}{\rho}+H_{p}=Z_{2}+\frac{\bar{v}_{2}^{2}}{2 g_{c}}+\frac{P_{2}}{\rho}+\Sigma F
$$

where,

$$
\begin{aligned}
& \mathrm{Z}=\text { potential energy term } \\
& \frac{P}{\rho}=\text { pressure energy term } \\
& \mathrm{H}_{\mathrm{p}}=\text { head of the pump at point } 1 \\
& \frac{v^{2}}{2 g_{c}}=\text { kinetic energy term } \\
& \Sigma \mathrm{F}=\text { summation of head losses due to friction } \\
& \rho=\text { density of fluid. }
\end{aligned}
$$

All terms are expressed in heads of fluid. This head is the column of fluid that would generate the same pressure, or if it was allowed to flow, would generate an equivalent amount of kinetic energy. Points 1 and 2 are at the same height so the $Z_{1}$ and $Z_{2}$ cancel out. The mass velocity at points 1 and 2 is the same so they cancel out, too. The resulting expression,

$$
H_{p}=\frac{P_{2}-P_{1}}{\rho}+\Sigma F
$$

shows that the work of the pump, minus friction losses, is going to be manifested as a difference in pressures between points 1 and 2. From the pump performance curve: $\mathrm{Q}=40 \mathrm{gal} / \mathrm{min}$ at $\mathrm{P}_{\mathrm{g}}=23$ psig so,

$$
P_{\text {absolute }}=P_{\text {gage }}+P_{\text {atmosphere }}=23 \frac{\mathrm{lb}}{\mathrm{in}^{2}}+14.7 \frac{\mathrm{lb}}{\mathrm{in}^{2}}=37.7 \frac{\mathrm{lb}}{\mathrm{in}^{2}}=2.65 \frac{\mathrm{kg}}{\mathrm{cm}^{2}}
$$

This pressure is expressed in Eq. 4-4 as absolute pressure in terms of head in meters of water: 


$$
H_{a b s}=\frac{P_{u b s}}{\rho}=\frac{37.7 \frac{l b}{i n^{2}}\left(144 \frac{i n^{2}}{f t^{2}}\right)}{62.3 \frac{l b}{f t^{3}}}=87.1 f t=26.5 \mathrm{~m}
$$

Part of the pump's head is lost fighting the resistance to the flow by the pipe and fittings. This loss of energy results from the momentum transfer from the fluid to the pipe walls. These friction losses are given by the following equation for PVC piping [Corrosion-99]:

$$
H_{f}=0.2083 \frac{(100)^{1.852}}{C} \times \frac{\left(Q^{1.852}\right)}{\left(d^{4.855}\right)}=0.2083 \frac{(100)^{1.852}}{150} \times \frac{\left(40^{1.852}\right)}{\left(2^{4.865}\right)}=3.1 f t=0.94 m
$$

where,

$\mathrm{H}_{\mathrm{f}}=$ head loss for each 100 feet of pipe

$\mathrm{C}=$ coefficient for $\mathrm{PVC}$ pipe $=150$

$\mathrm{d}=$ diameter of pipe in inches

$\mathrm{Q}=$ mass flow in gallons per minute.

The pressure drop in the fully open $5.1 \mathrm{~cm}$ ball valve [Corrosion-1999] is expressed using Eqn. VIII-6,

$\Delta P=\frac{Q^{2} \text { (Specific Gravity) }}{C_{v}^{2}}=\frac{\left(40 \frac{\mathrm{gal}}{\mathrm{min}}\right)^{2}(1.0)}{101^{2}}=0.157 \frac{\mathrm{lb}}{\mathrm{in}^{2}}=0.011 \frac{\mathrm{kg}}{\mathrm{cm}^{2}}$

where $C_{v}=$ fluid flow coefficient for a $5.1 \mathrm{~cm}$ ball valve $=101$. This loss of pressure is better visualized when expressed as a head, in meters of water,

$$
\frac{\Delta P}{\rho}=\frac{0.157 \frac{\mathrm{lb}}{\mathrm{in}^{2}}\left(144 \frac{\mathrm{in}^{2}}{\mathrm{ft}^{2}}\right)}{62.3 \frac{\mathrm{lb}}{\mathrm{ft}^{3}}}=0.36 \mathrm{ft}=0.11 \mathrm{~m}
$$

Therefore, the equivalent length of pipe is summarized below ${ }^{1}$ :

\footnotetext{
${ }^{1}$ High momentum losses for each bend are not well known for slurries. Hence, these values are considered approximate.
} 
Straight pipe

$90^{\circ}$ elbows, $3 \times 1.67 \mathrm{~m}$

Tee, flow through run

Tee, flow through branch

Ball valve, fully open Total
$13.20 \mathrm{ft}$

$16.50 \mathrm{ft}$

$4.30 \mathrm{ft}$

$12.00 \mathrm{ft}$.

$\frac{0.36 \mathrm{ft}}{46.36 \mathrm{ft}}$
$4.02 \mathrm{~m}$

$5.03 \mathrm{~m}$

$1.31 \mathrm{~m}$

$3.66 \mathrm{~m}$

Equation 4-5 gives the head loss due to friction for each 100 feet of pipe (30.48 meters), but our equivalent length of pipe is $14.13 \mathrm{~m}$. So, the head loss due to friction becomes:

$$
H_{\mathrm{f}}=(3.1 \mathrm{ft} / 100 \mathrm{ft}) X(46.36 \mathrm{ft})=1.44 \mathrm{ft}=0.44 \mathrm{~m}
$$

Head and pressure available after subtracting friction losses are

$$
H_{a b s}=\frac{\Delta P}{\rho}+\Sigma F=87.14 f t-1.44 f t=85.71 f t=26.12 m
$$

where $\Delta \mathrm{P}=(85.71 \mathrm{ft})\left(62.3 \mathrm{lb} / \mathrm{ft}^{3}\right)\left(\mathrm{ft}^{2} / 144 \mathrm{in}^{2}\right)=37.08 \mathrm{lb} / \mathrm{in}^{2} 2.65 \mathrm{~m}$ 